

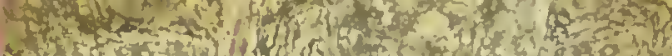

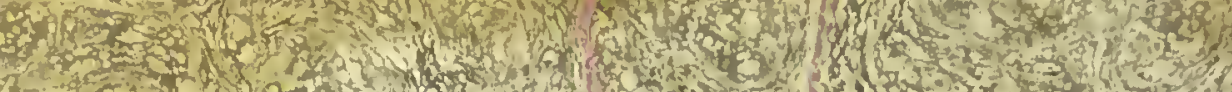

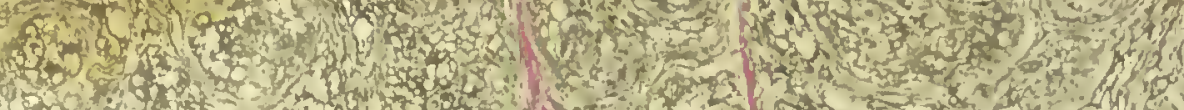

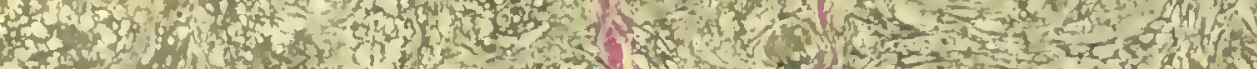

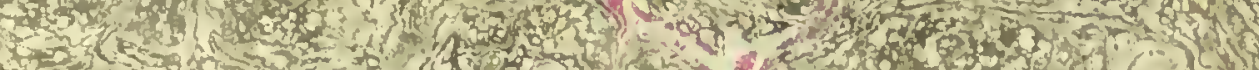

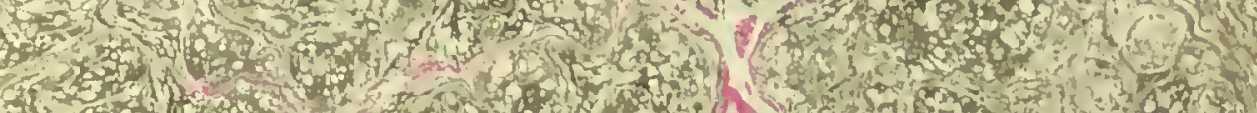

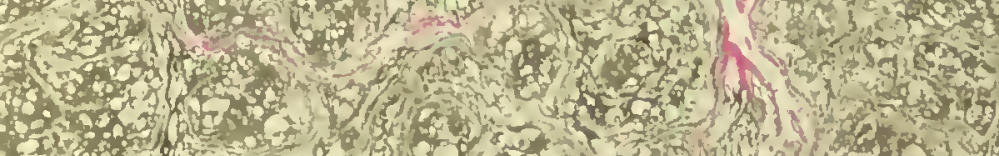

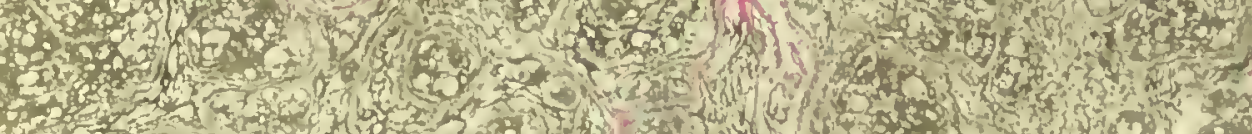

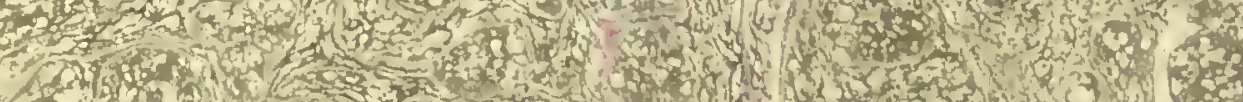

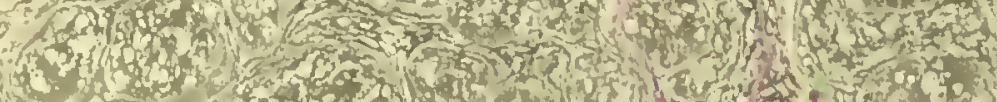

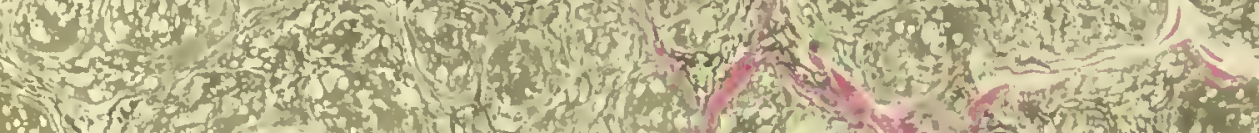

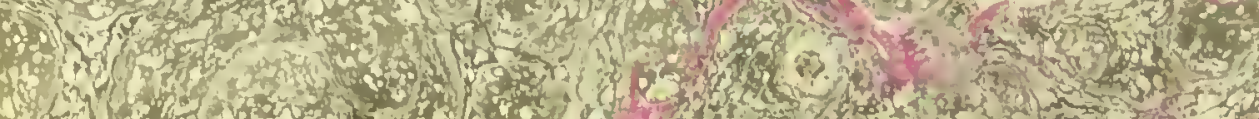

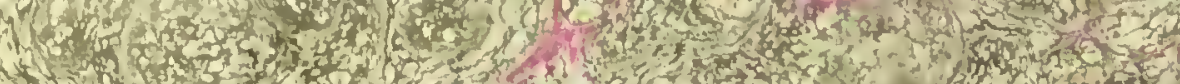

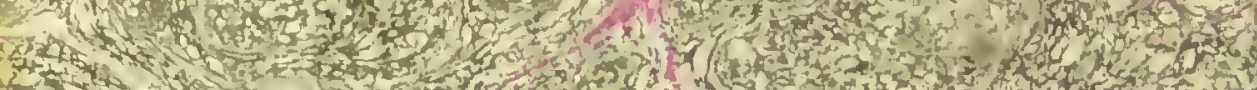

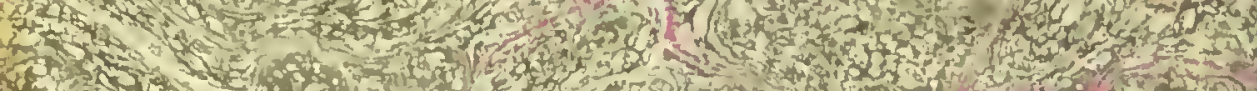
12.

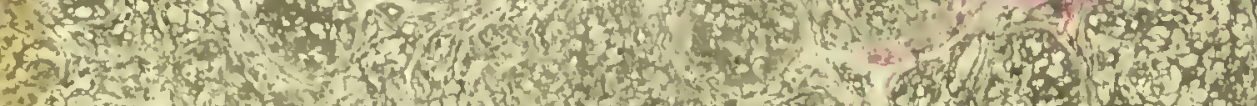

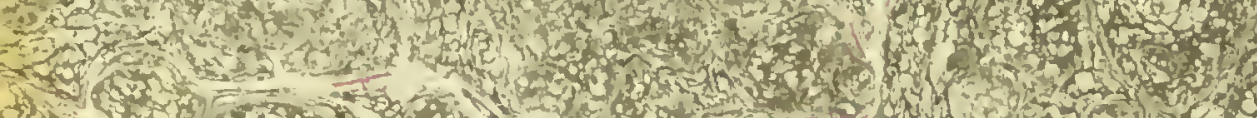

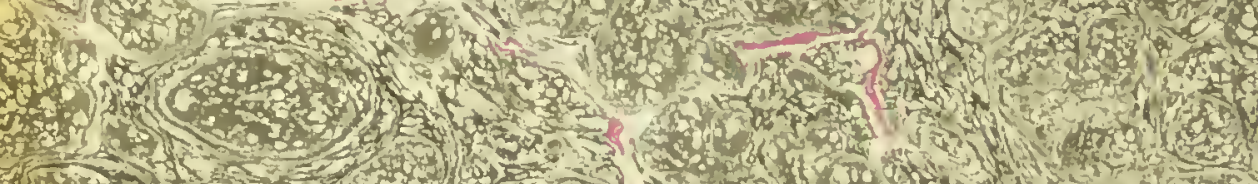

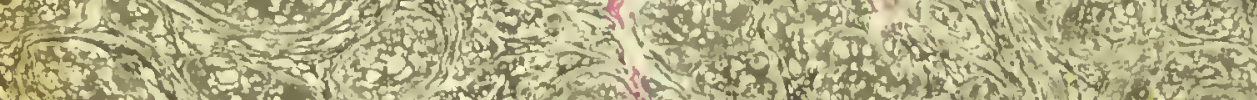

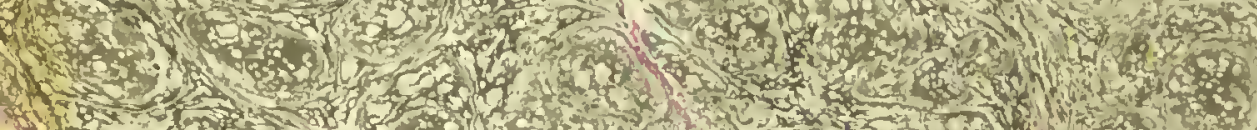

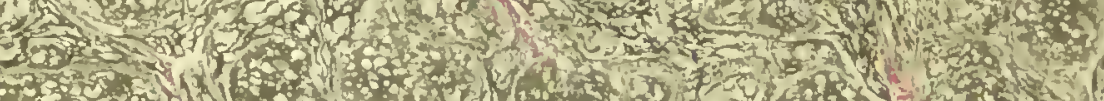

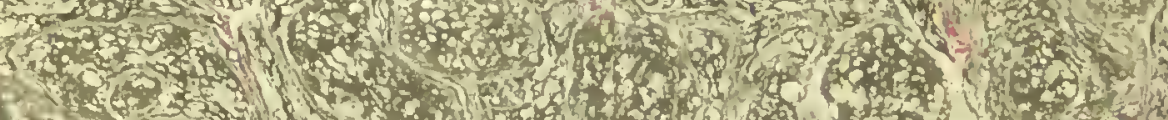

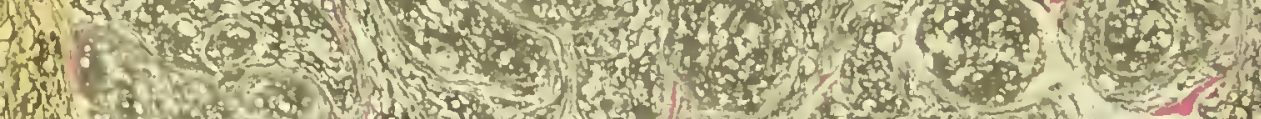

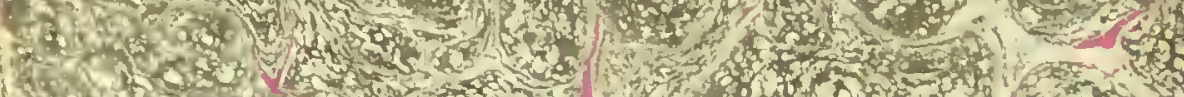

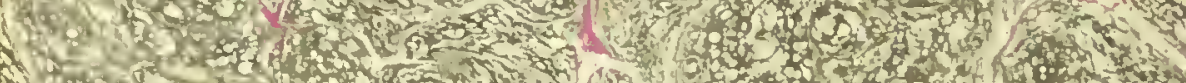

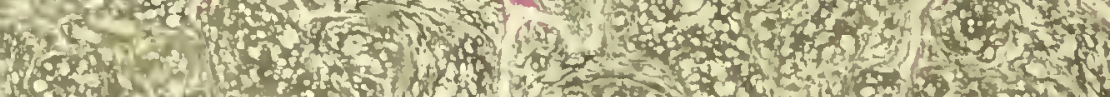

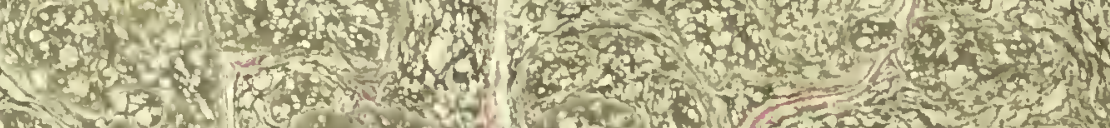

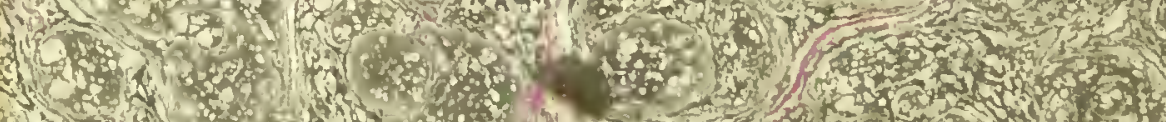

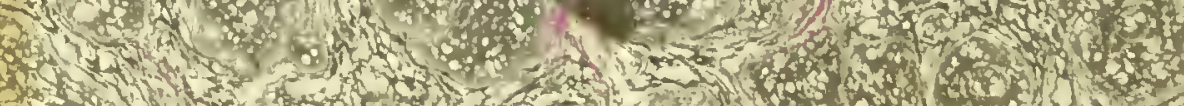

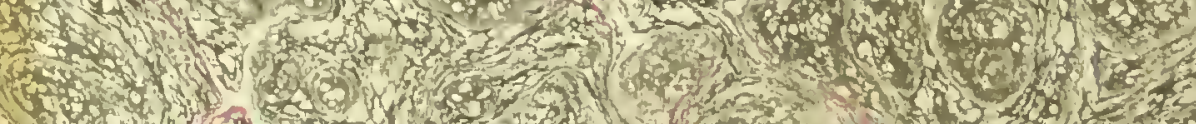

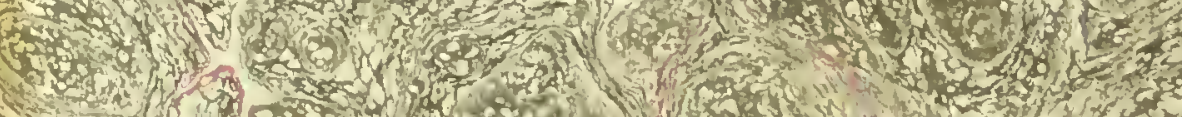

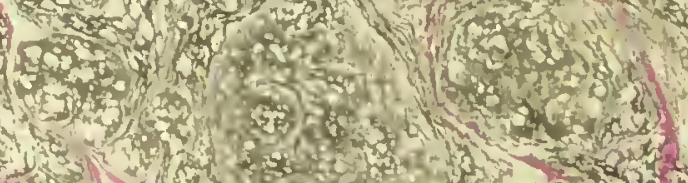

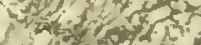

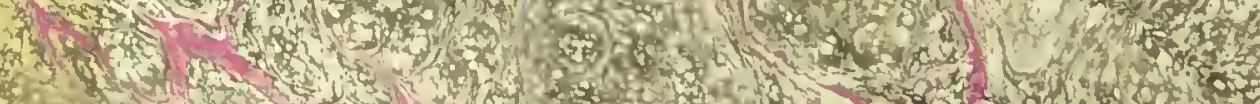

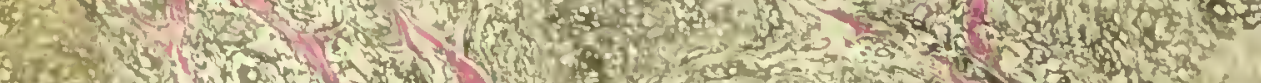

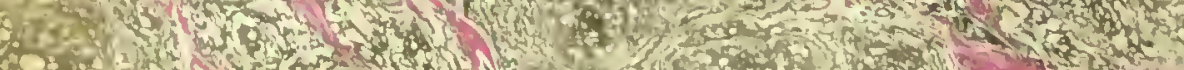




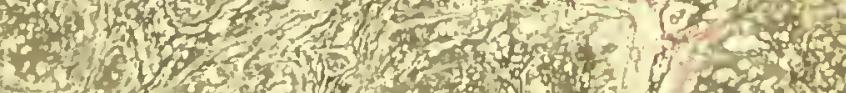

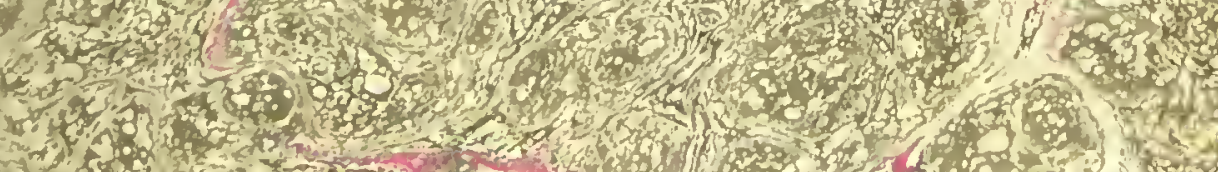

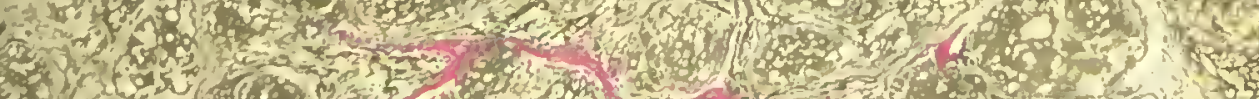

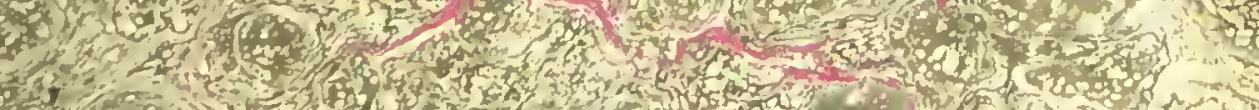

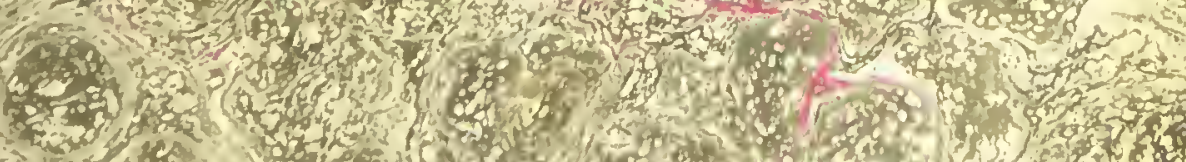

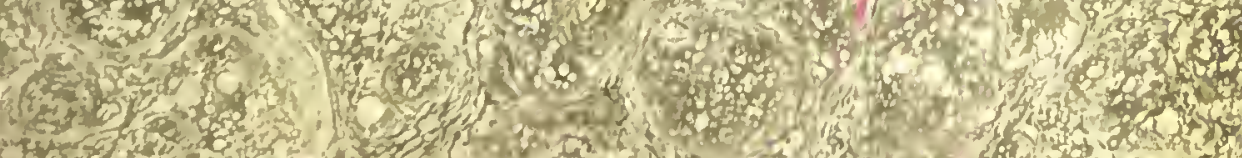

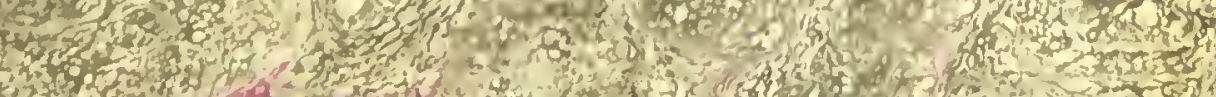

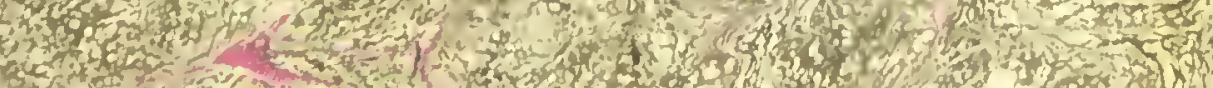

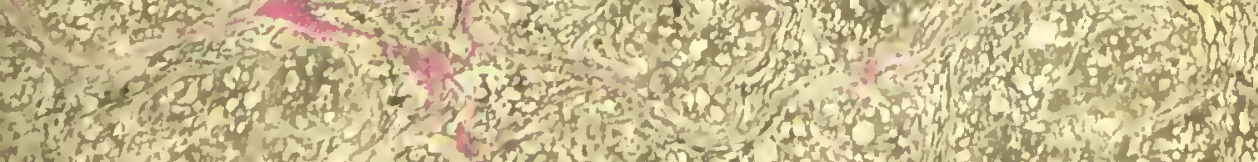
(3)

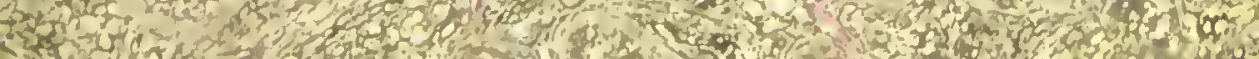


$26 x+1=$ 

Digitized by the Internet Archive in 2016 with funding from Wellcome Library 
É L E M N S D'HISTOIRE NATURELLE: 


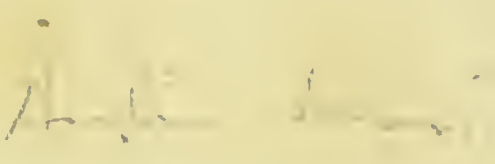

$$
\begin{aligned}
& 27 \text {, } \mathrm{X}+\mathrm{T}
\end{aligned}
$$

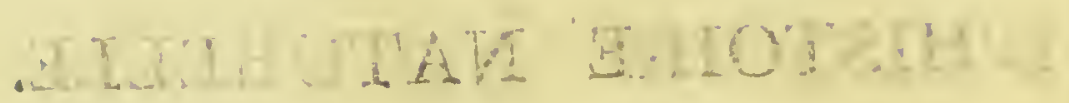




\section{它 L}

\section{D'HISTOIRE NATURELLE.}

$P_{A R}$ A. L. M I L L I N.

* EN ces temps-lá, l'on apprenoit les sciences en langue maternelle, " tellement que, dis les tendres ongles, les eifans commençoient " à entrer en l'école des muses, et pénétroient ès plus beaux " secrets d'icelles, ayant en leur langage les arts et belles dis"ciplines découvertes jusques au front : au lieu que maintenant w le meilleur de notre âge se passe à apprendre des muts; er " quand il faut evtrer en la connoissance des choses, la mémoire " est accablée, et le jugement altéré e'uue infinité d'objets qui, " comme sauces diverses, ont plus souvent renversé son droit "goût : si que presquuc ordinairement l'on voit que nous prenons "plaisir, pour la pluspart, à entasser lettres sur letrres, et qu'a"pres une grande provision de mots étrangers, nous nous trou-. "vons enfans ct démués de la solide coonoissance des choses. "

Plutarque, Hommes Illustres, tom. II. pag. 1191. $\Rightarrow$ Traduction d'Amyot.

\section{A P. A R I S,}

Chez AGASSE, rue des Poitevins, No. 18.

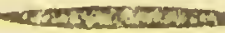

I.'AN III DE LA RÉPUBLIQUE UNE ET INDIVISIBLE. 



\section{P R É F A C E。}

L'histoire naturelle n'est qu'un pur empyrisme, quand sa marche est vague et incertaine; elle devient, avec le secnurs de la méthode, une théorie philosophique. Aucune étude n'est plus propre à donner à l'esprit de la rectitude et de la justesse au raisonnoment. L'habitude de classer, de distribuer systématiquement los êtres, fait naitre colle d'une sorte d'arrangement dans la némeire, et d'un ordre précieux dans les idées.

On a publié en françois de très-bons traités sur quelquics classes de l'histoirc naturelle, mais aucun n'a encore éré mis à la portée des jeunes gens, et on n'a jamais réduit cette science en un cours élémentaire et comorlet. 


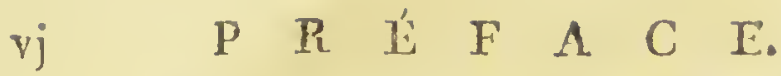

I’ai pensé cuiil falloit, cans cet oum vrage, établir dcs bases constantes, et procéder d'après des principes fixes, quil stifira de dívclopper dans les livres descinés aux hommes din âge plus avaiıcé.

Je ne me suis point livré à des digressions: j’ai principalement cherché linstruction cxacte er solide. Ie me suis sur-tovi aprliqué à ce que mon siyle, clair et précis, cxprimât beancoup de choses en peu de mots, afin de renfermer un grand nombre de faits dans le plus petit espace possible.

Apres avoir défni l'histoire naturelle, et donné une idée de la méthode qui sert à différencicr et à classer les êtres, je commence l'examen de ces êtres eux-mêmes, que je divise cn corps célestes et corps terrestres.

Je ne parle des corps célestes qu'en 


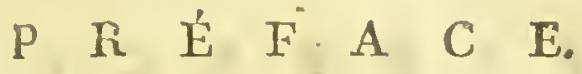

naturaliste. Je laisse les détails plus circonstanciés à l'astronomie.

J'examine ensuite, sous le nom ete corps terrestres, toutes les substancès qui appartiennent à la planèce que nous habitons; mais j'établis entr'elles deux grandes divisions; la première contient les substances inorganiques, celles privées dcs organes nécessaires à la vie; la seconde, les substances organiques, celles qui en sont pourviles.

Tai choisi, pour les differentes classes de ces deux divisions, les méthodes qui miont paru les plus faciles, les plus claires et les plus simples, parmi celles établies par les plus habiles naturalistes, er j'y ai fait les coirections qui mone semblé nécessaires pour les mettre plus à la portée de mes jennes lecteurs.

Les substances inorganiques (les a iv 
viij $P R$ E $F$ A $C$ E.

minéraux) soint rangéés d'après la métl:ode de Daubenton, fondźe siir les caractères extérieurs les plus sensibles et les plus fraprans.

Jai éábli avec le plus de précision et de clarté qu'il m’a ćté possible, les caracrères des classes et des ordres. Cette connoissance suffit au premier et au second degré d'enseignement; celle des genres est réservée all troisicme.

Cepcndant, quelques notions sur les productions les plus usue!les de la nature étoient nécessaires. Je trace iıne description succincte des espices principales, c'est-à-dire, de celles quii servent à des usages utiles, et j'indique la manière de les y employer, ce qui donne aux jeunes gens des idécs générales sur les arts et los métiers. Ainsi, en parlant des substances minérales, je dis un mor de l'art du 


\section{$P \quad R \quad E \quad F \quad A \quad C \quad E . \quad$ ix}

potier, du fondeur, du salpêrricr, du mineur, du métallurgiš̃e. En uraitan des végétalix, je m’arrête un peu à la culture du bié, de la vigne, à l'art de faire le pain, le vin, le sucre, etc. Enfin, en traitant des animaux, $j$ 'insiste davantage suir les plus utiles; j'entre dans quelques détails sur les travaux des abeilles, sur ceux de la chenilie qui file la soie, etc. etc.

Pour facilicer dans chaque ordre la recherche des especes, ic les ai séparées en petites sections, d'après des caractères très-prononcés.

Les substances organiques sont partagées en deux divisions; $\mathrm{x}^{\circ}$. celles gui ne pouvcne pas changer do place à volonté, les végétaux; $2^{\circ}$. colles gri peuvent changer de place à volonté, les animaux. De cotte maniere, l'enfant, après avoin pris une connoissance des corps célcsies guniso mavente 
dins l'espace, étudie la nature du flobe, les minéraux gui forment sa croâre, obscrve les végćáaix qui le vếrisseñ et l'embellisscné ; et enfin, les animaux, qui parcourent sa surface.

Les préliminaires de la division des végítaux ofrent des élémens de botanique convenables à des jeunes gens et aux parens qui se chargcront de les leur faire lire. J'ai évice antant que je lai pu les termes hérissés d"étymologies grecques et latines. Je n'ai cependane pas dû déneturer la science en la privan des mots qui lui aprarticinene et qui composent sa langue porticuliere; je les ai placés dans le discours, de manière quils s'expliquassent autant qu'il étoit possible par leur position. Après avoir ainsi décrit tones les parties des végétaux, j’examine lcurs fonctions, Jeur organisation physique, les principes gue lart 


\section{$\mathrm{P}$ R É F A C E.}

clymique en sait extraire; et enfin, leurs merirs et leurs habitudes particulières.

J'ai adopté, pour la distribution des végétaux, la méthode de Jussieu, cn traduisant ses noms; j'ai seulement regretté qu'il n'ait pas donné à chacune de ses classes nin nom univoque, ce qui aideroit beancoup la mémö̈re; mais je n'ai pas osé porter une main téméraire sur ce beau travail. Avec les classes, j’ai adopté aussi les familles principales, celles que l'on peut saisir avec facilicé, telles que les graminées, les ombellifères, les composées, etc. mais je n'ai pas indiqué les autres, qui ne sont pas aussi aisées à discinguer. Les plantes de ces familles sont placées dans les classes qui leur convicment, sans être soumises à d'autres distributions.

J'ai donné une courte notice des 
xij $\quad$\begin{tabular}{lllllll}
\hline & $R$ & $E$ & $F$ & $A$ & $C$ & $E$
\end{tabular}

plantes indigènes les plus utiles; j’ai indiqué les espèces exotiques, dont l'usage est le plus répandu.

Les substances organiques locomobiles (les animaux) sont distribuées en six classes, d'après la méthode de Linnéus. Chacune est précédée de généralicés sembiables à celles sur la botanique.

Les mammifères sont sérarés en cinq ordres, d'après la forme des pieds. L'enfant trouvera dans les généralités de cette classe des idécs de physiclogie; il y apprendra en peu de mots ce que c'est que la respiration, la circulation, la digestion, etc.

Les oiseaux sont distribués d'après la méthode de Linnéus; avec quelques légers changemens.

Les amphibies sont partagés en deux 
$P \quad R \quad$ É F A C E.

ordres: les tétrapodes, que je nomme ainsi, parce que le nom de quadrupède est plus communément appliqué aux mammiferes, et les serpens.

Je range les poissons selon la position de leurs nageoires, d'après la méthode de Linnéus, rectifiée par Daubenton.

J'ai pris, pour les insectes, les ordres d'Olivier, dans une série différente. Je me suis sur-tout attaché à faire connoître leurs mœurs, si amusantes, si variées, et leurs étonnantes métamorphoses.

Les vers sont classés d'après la méthode de Bruguière. Je dis peu de chose des intestinaux, des mollusques et des zoophytes. Je m'attache plus précisément aux testacés, et je donne, dans les généralités, des élémens de conchyliologic. 
xiv $\quad P \quad R \quad t \quad F \quad A \quad C \quad E$.

Cet ouvrage renfeme ainsi une infinire de choses, et les princires viai-. ment élémentaires de tontes les partics de l'histoire nature!le

J'ai fait usage des nouvelles nomenclatures qui ont érabli la langue des sciences finysirnes sur des bases philosophiques. Comme je parie principalement à l'enfunce, qui n'est encore inbue d'aucuns fućyigés, il est plus facile de lui inculquer dans ta moire les nons dont eiles se composant. Ces noms ne paroîtront pas aux cnians plus étranges que d'autres, pinisure leur esprit cst ézalement neur pour tous.

F'ai donc pensé cu'il éroi romps de les substituer à ceux oni re sone propres qu'à conner des idses fausses. F'ai cependant conservé les noms vulgaires, rarce quils sont nécessuicos à saroir, or je les ai cires comme cynonymes. 


\section{$P$ R E $F$ A C E.}

Lorsque i’ai eu à exprimer áes datcs, des poids, des mesures, des monnoies, les degrés du thermonètre, erc., je me suis servi des divisions décimales, d'après le nouveau systême métrique.

I'ai fait précéder louvrage d'une table des chapitres, et je l'ai terminé par une autre des matières, dans laquelle j’ai fait entrer routes les espèces cirées, leurs synonymes et les termes employés à les décrire. Ainsi, la première table esi une méthode, le corps de louvrage une narration systématique et suivie, et la derniere table, un dictionnaire.

C'est aux parens, aux instituteurs, à diriger les jeunes gens dans la lecture de ces élémens, car il ne faut pas présumer quaucun traité didactique puisse être utile à l'enfance abandonnéc à elle-même. Mais l'auteur d'un ouvrage élémentaire sur les sciences doit présumer avoir atteint lc but qu'il 
$x v j$

\section{P R E F A C E.}

désiroit, si, conduits seulement par son livre, ceux qui élèvent les enfans peuvent leur onseigner les connoissances qui y sont répandues.

Les instituteurs qui auront la faculté de se procurer des figures, hâteront beancoup les progrgès du jeune élève; ceux qui lui feront comparer la nature avec les descriptions, les avanceront encoredavanage.

Ces ćlémens ont été composés, fendancla longue captivité vìjaigémiavec tant dhommes vertueux et instruits, dont jai été à la veille de partager le sort. Je les avois desinés an concours; et plus la persécution contre les sayans. et les hommes de lettres étoit vio'cinte, plus ses cffets étoicnt rapides, plus les victimes ćtoicnt nombreuses, plus je mettois de constance ế de tenacité dans mon travail, plus j'étois impatient 


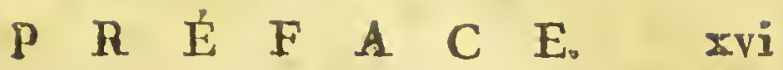

impatient d'en accélérer la fin ; je l'achevai au terme prescrit. J'avois renoncé alors au bonheur de sortir de ma prison, de revoir ceux de mes amis échappés à la proscription qui les avoit presques tous enveloppés, de donner à la vieillesse d'une mère adorée les soins qu'elle avoit pris de mon enfance; mais j'y conservois l'orgueil de rendre, du moins, mes derniers momens utiles. Je pensois que l'importance des ouvrages élémentaires pour l'éducation, engageroit le jury à hâter ses décisions; je me flattois que ses jugemens devanceroient peut-être les arrêts sanglans du tribunal révolutionnaire; je me berçois de l'idée d'être couronné par l'un avant d'être immolé par lautre; et quand ses lentcurs eurent fait évanouir cet espoir, cclui d'obtenir après ma mort un prix qui réveilleroit sur moi quclques regrets, me consoloit encore. 
xriaj P IR L F A C E.

Denuis cetre épogue, les menbres du jury ont presque tous été dispersés sars rendre aucin jugenent; j’ai repris mon ouvrage, pour le porter au grand tribunal de lopinion publique.

Ic ne tcuminerai pojnt ccttc Préface d'un livre que jaai compesé au miliou de vous, sans jetrer quelques fleurs sur voure tombe, sans doner concore quelques pleurs à voirc fin malheureuse, imocentes et généreuses victimes. Roucher, litrératcur distingué ct père de famille si respcctable! André Chénicr, toidont lane avoit tane d’érergic, donte grô̂t éccî si sûr, dont lérudition étoit si brillante et si vaste! Extoi, brave et loyal Eiron, dont lcs bicnfaits soulageoicnês scrècment lindigence de tes compagnons d'infortune, ct chii aimas nieux perir sur l'échaffaud que d'essaycr de t'y soustrairc, en portant le premier, contre le 
$P R$ E A C E. xix monstre qui ty a condult, une acciim sation évidente ct légitime, tant la dénonciation révoltoit ton grand cour ! Aimable Trudaine, ararhéa tes pinceaux, enlevé avec ton frère à la culture des arts; malgré laustère pureté de tes mours, et laimable douceur de ton caractère! Estimable er laborieux Dormesson, Foré au tribural de sang sur ton lir auquel un mal cuisane et incurable t'avcí fixé sans retour, environné de tes livres et de tous les trésors de la lirtórature orientale; qui souffris la mort comme Socrate, après avoir supporte la douleur comme Epictete! Combien jen pourrois nommer d'autres, dont le souvenir ne sortira jamais de ma mémoire; peut-être tronvera-t-on ces détails étrangers à mon sujer: ils le sont en effet; mais ils soulagent mon ame. Les vrais amis des arts, des

$$
\text { b } \mathrm{ij}
$$


Ix

$$
P \text { I E } F \text { A C E }
$$

talens et des vertus partageront mes sentimens, et me les ont déjà pardonnés. 


\section{TABLE MÉTHODIQUE.}

INTRODUCTION.

pages is

\section{CORPS CÉLESTES.}

\section{CORPS TERRESTRES.}

\section{SUBSTANCES INORGANIQUES.}

PIERRES ET TERRES,

Pierres étincelantes sous le briquet, 7 Gemmes,

Pierres et terres non étincellantes sous le briquet, et non effervescentes arec les acides,

Picres et terres effervescentes avec les acides,

Pierres et terres mélangées, 20

$$
\begin{array}{lr}
\text { Terres, } & \text { ibit. } \\
\text { Pierres, } & 21 \\
\text { Réunies par juxt'apposition } & \text { ibid. } \\
\text { Rúunies par un cimertit particulier, } & 22 \\
\multicolumn{2}{r}{\text { b iij }}
\end{array}
$$


$x \times i j$

$$
T A \text { I } 2
$$

SEIS,

Sels simples,

Alkalis,

24

Acides,

ibid.

25

Sels composés,

SUBSTANCES COMBUSTIELES, 34

Combustibles transparens,

35

Soufice,

ibid.

Jitumes,

36

SUBSTANCES MÉTALLIQUES, 38

Jeni mitaux,

40

Miétaux,

43

Métaux imparfaits:

ibid.

Nétaux, parfaits,

48

SUBSTANCES VOLCANIQUES,

50

\section{SUBSTANCES ORGANIQTES.}

TEGTAUY,

ibial.

SANS COTYIADONS,

78

Chanipignons.

ibid. 


$$
M E \text { t II O D I U E. Ixxijj }
$$

Algues ,

Filamenteuses et Gélatincuses, ibicl. Miembraneuses, ilid.

Coriaces. Lichens, $\quad 81$

Hépatiques,

82

Munsses,

ibid.

Fongères,

84

UN SEUL COTXLEDON. ÉTAMITES SOUS

LE PISTIL,

85

Graminces,

ibid.

UN COTYLEDON. Itantines autour DU PISTIL,

90

Palmiers,

ibid.

Jons;

$9^{3}$

UN COTYLEDON. ÉTHMTES SUR LE PISTTI,

DEUA COTYT EDONS. ÉThIMES SUR LE I'ISTII,

23

DEUX COTYTEDONS. ETAMnes AUTOUR DU ISTIL,

99

bir 
DEUX COTYLEDONS. Saxs rétares. Étamines sur le pistil, 101

DEUX COTYLEDONS. UN SEUL PĹTALB. Corolle sur re tistil, 102 Labiées, 111 Borraginées,

DEUX COTYLEDONS. UN SEUL TÉTALE. Conole autour du prste, I 6

DEUX COTYLEDONS. UN SELI PÁTALE. Corolie sur le tistil, 118 Composées, ibicl.

Corymbifères, 123

DEUX COTYLEDONS. UN SEUI TÉTALE. Corolle sur le pistil. Anthizes sérarées,

$$
\text { Rubiacées, }
$$

DeUX COTyledons. Plucieurs pétales. ÉtalinNes sur le ristil, 130 Ombellifères, ibid.

Ombelle, et ombellules sans involucre, ibid. 
M É T H O I I Q U E.

$x x y$

Ombelle nue. Ombellules \& involucre,

131

DeUX COTILedons. Piusieurs títales. Étamings sur le pistir,

133

Crucifères,

$$
\text { I } 45
$$

Malvacées,

Coryophyllées,

DEUX COTYZEDONS. Pont de TÉtales. Étamings autour du pistil, i 51 Rosacées, 154

Légumineuscs, 160

Térébinthacées, 166

DEUX COTYLEDONS. POINT DE miTALIE. ĹtTAMIINESET PISTILS SÉPARÉS, 168 Euphorbes, ibid. Cucurlitacécs, 169 Ortics, IJO 
Amenlacées,

Fleurs hermapinodites,

$17 \cdot 1$

Fleurs diriques,

ibid.

Flcurs monoiques,

176

Conilè̀es,

Quatre incisives

Six incisives,

Deux incisives,

Poine d'incisives,

\section{BISULCES,}

Cornes simples,

Cornes ramcusas, 


$$
\text { M ts II O D I Q U E. xxrij }
$$

Corne sur le nez, . $\quad 228$

Point de cornes, ibid.

\section{CHEIROPTËRES, $\quad 230$}

CATACES,

OISEAUX,

Cire à la base du bec, $\quad 246$

Point de cire au bec, $\quad 2 / 8$

Tête grosse et aplatie. Oreilles aigrettées,

Point d'aigreltes,

250

CORACES,

Circ à la base du bec,

ibid.

Picds promencurs,

252

Ficds grimpeurs,

254

Ficds cheminerirs, 
xxviij $\quad T A B$ A

PASSEREAUX,

ibid.

Bec épais, 256

Bec recourbé à son extrémité, $\quad 260$ Bec échancré ì son extrémité, ibid. Bec simple entier et effilé. $\quad 261$

GALLINACES ,

265

Domestiques,

266

Sauvages,

269

ECHASSIERS,

ANSERES,

Bec denticulé,

Bec sans denticules,

AMPHIBIES,

280

TETRAPODES,

281

Corps cuirassé,

285

Corps verruqueux et court, sans cuirasse, 


$$
\text { MÉ T H O D Q U E. Xxix }
$$

Corps allongé et lisse quadrangulaire,

290

Corps très-allongé, couvert d'écailles, accompagné d'une queue, 291

SERPENS , 293

Exotiques, 294

Indigènes , 295

\section{POISSONS,}

Corps cylindrique, $\quad 305$

Corps plat et arrondi, $\quad 306$

Corps alongé, $\quad 307$

APODES,

310

JUGULAIRES,

Corps comprimé

Corps comprimé. Les deux yeux ì droite,

ibial. 
Corps comprimé. Les deux yeux औ gariche,

Corps comprimé allongé,

ibid.

\section{ABDOMINAUX,}

318

Corps allongé lisse,

ibid.

Corps allongé écailleux ,

ibid.

Corps allongé, tête aplatie,

320

Mâchuires sans dents,

\section{INSECTES,}

COLÉOPTÉRES,

Cinq articles d tous les tarses, 336

Cinq articles anx tarses antéricurs, quatre aux postérieurs, $\quad 340$

Trois articles à tous les tarses; 34. HÉMIFTÉRES,

Étuis de consistance égale,

344

ORTHOPTERES,

HYMENOFTERES,

Bouche sans trompe, 


$$
\text { M T T O DIE E }
$$

xxxj

IVEUROYTERES,

363

LEPIDOPTERES,

Antennes en masse,

Antennes prismatiques,

374

Antennes décroissant de la base ì la pointe,

ibid.

Antennes filiformes. Toupet de la tête avancé, 378

DIPTERES,

APTEPES, 383

FERS,

INFUSOIRES,

388

3̄go

Sans organes extérieurs,

$39 x$

Avec des organes cutéricurs, 392

INTESTINAUX,

ibid.

Corps nu,

3,3

Corps cilić,

395 
xxxii T A E L $\mathrm{E}$, \&c.'.

MOLLUSQUES ,

ÉCHINODERMES,

3,8

TESTACÉS ,

399

Multivalves,

402

Bivalves,

403

Coquille irrégulière,

405

Coquille régulière,

ibid.

Univalves, 407

Uniloculaires, 408

Multiloculaires,

413

Fin de la Table méthodique. 


\section{E L E E N S}

D'HISTOIRE NATURELLE.

\section{INTRODUCTION.}

E'Ur v ERs est la réunion des étres.

Les êtres ont des rapports communs eq réciproques, et chacun d'eux sert à l'entretien du tout.

On appelle nature l'ensemble des lois qui les régissent. L'étude de ces lois appartient à la physique.

La connoissance des êtres, la description de leurs organes, et la détermination des caractères qui les différencient, constituent I'HISTOIRE NATURELI.E.

Cette science agrandit nos idées, elle élève notre ame aux plus sublimes conceptions; elle est sur-tout intéressante ct utile jar son application continuelle aux premiers besoins de la vic. 
La multitude des êtres rendoit l'histoire naturelle incertaine et confuse; il falloit un fil pour se concuire dans cet immense labyrinthe, on imagina les méihodes. Ces distributions, en groupant les êtres qui ont cntre eux cies rapports consians, servent à les reconnoître avec plus de facilité.

On nomme ces difírens groupes classes, ordres, genres et espidces. En passant de la classe à l'ordre, et de l'ordre au genre, on arrive facilement à l'espèce. C'est ainsi que, pour trouver un des défenseurs de la république, il faut savoir l'asinée, la disision, le batribloir et la compagrite où il sert, et on arrive facilement jusqu'à lui. La classe répond à l'arnée, l'orcíre à la division, le bataillon an genre, l'espèce à la compagnic; f'être qu'on cherche est l'inclividu.

Nous partagerons ainsi tous les êtres qui peuvent être reconnus par nos sens. Nous les séparerons d'abord en deux grandes divisions, les corps célestes et les corps teriestres. 


\section{LES CORPS CELESTES.}

Le cres est cet espace incommensurable au milieu duquel des milliers de corps lumineux circulent et paroissent suspendus.

L'étude des mouvemens périodiques de ces astres appartient à l'astronomie.

\section{LES CORPS TERRESTRES.}

LA terre est une masse opaque, ronde et aplatie vers ses pôles. Elle tomrne sur elle-même en vingt-quatre heures (dix heures décimales), ce qui produit pour nons le jour quand nous sommes placés du côté qui regarde le soleil, et la nuit, quand nous passons du côlé opposé. C'est sur la révolution de la terre antour du soleil qu'est établie la division de l'année, des saisons, des mois, des dícades et les heures.

On a fait une foule de conjectures sur la formation de la terre; avouons sur ce point notre foiblesse, et bornons-nous à étudier ses productions, sans chercher à deviner l'impénétrable nystère de son origine.

L'intérieur du globe nous est inconnu: l'homme n'a jamais pu en sonder la vacte A 2 


\section{$4 \quad$ L I E M E S}

profondeur; il a seulement efflenré sa surface, et il y a trouvé d'immenses débris de coquilles, des amas de sels, qui prouvent le séjour des mers et leur retirement successif; des matières vitrifiées par l'action des feux souterrains. Ces fossiles constituent la croûte du globe. Sa superficie est en partie baignée par les eaux, et rendue inégale par des chaines de montagnes plus ou moins hautes, selon que leur formation remonte à des temps plus ou moins reculés; le globe est couvert d'une terre propre à la végétation, il est pénétré par différens fluides.

L'étucle des substances qui se trouvent dans le scin, ou à la surface du globe, est celle qui doit nous occuper; nous ne nous arrêterons cependant qu'à celles qui sont d'une utilité génćrale.

Pour mettre plus d'ordre dans cette recherché, nous partagerons tous les corps terrestres en deux grandes divisions.

ETres sans viz ce sans miouvement.... Substances inorganiques.

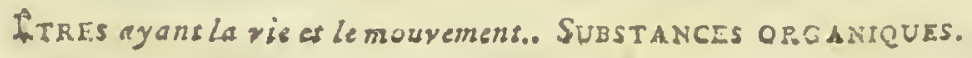




\section{SUBSTANCES INORGANIQUES.}

Les substances inorganiques sont dépourvues des organes nécessaires à la vie et au mouvement. Réunies en masses, elles ne prennent d'accroissement que par l'aggrégation, c'est-à-dire, par le rapprochement de leurs parties similaires, tenues en dissolution dans un fluide. Si ces parties affectent dans leur rapprochement une figure toujours constante et régulière, elles forment des crystaux ; lorsque le rapprochement a été subit, la crystallisation, devenue confuse, ne présente qu'une simple concrétion.

On est convenu de nommer MINÉRAUX les substances inorganiques, quoique toutes ne soient point rassemblées dans ces cavités souterraines qu'on appelle mines : nous adopterons cette dénomination.

On a établi différentes méthodes pour la classification des minéraux; les unes sont fondées sur les caractères extéricurs, principalement sur la figure des crystaux; d'autres ont pour base les principes constituans décomposés par les procédés chymiques; nous suivrons celle fondéc sur les caractères extérieurs, comme la plus facile. 


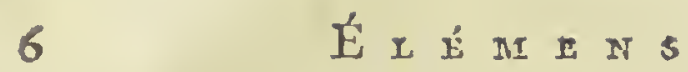

\section{CLASSES DES MINÉRAUX.}

I. Pievres et terres............. Se brisant soiis li marteal.

II. SELS.. ........................... Sulidbles dans l'cau.

111. St bStances INFLAMmablFs. L rulant avic fiamme. IV. M.Érati...................... Fusibles et malliables.

Y. SUbSrances volcanizues... faltéries par les fiux soucertains.

\section{PIERRES ET TERRES.}

Os séparnit autrefoi- les terres des pierres, mais les teries ne sunt yi:e des fraguens de pierres bi i ées, ou les élémens dun les pierres se comprosent.

On croyoit aussi le globe terrestre composé d'un élément pàticulier, appelé Łerre; cependant, cette terre élémentaire ne se trunve nulle part. On connoît quelques terres que l'on nomme vulgairement élémentaires, parce qu'on n'a pas encore pu décomposer les principes quiles constituent; mais l'élément terreux seul, base de toutes les terres, n'existe pas.

Les terres et les pierres sont répandues en grandes masses dans la nature; les unes sont isolezes, d'autres réunies. On peut essayer les pierres d'une manière bien simple, avec 
un briquet et quelques goultes d'ean-iorte, ou acide nitreux.

* Pierres qui étincellent sous le briquet. (1)

1. Le guartz est formé d'une terre primitive qui ne se troure jamais pure, et que l'on nomme terre quartzeuse, terre siliceuse, silice. Cette terre est très-abondante dans la nature; suspendue dans l'eau, ses molécules acquièrent en se rapprochant des formes régulières, et présentent des crystaux opaques ou transparens, ou des masses concrètes de différentes couleurs.

2. Le crystal de nocie est le quartz le plus pur; il crystallise en prisme à six pans terminé par une pyramide à six faces; sa dureté est considérable, et il est susceptible dun beau poli. Sa transparence est quelque-fois troublée par d'autres corps qu'il renferme, ou par des couleurš dues à des substances métailiques. Il se trouve dans les montagnes et dans les rochers. On en fait des bijoux.

(I) L'étincelle est proúnite par la petite portion d'acier qui se détache, se fond et devient ronge.

A \& 
3. Le GRìs est composé de petits grains de différentes figures, plus ou moins liés ensemble, et le plus souvent arrondis. Le grès dur, taillé en morceaux cubiques, sert à flaver les rues; le grè's tendre, à aignuiser les outils; le gres du levant, dont lo grain est trìs fin, à repasser les rasoirs; le grès poreux a les grains assez écartés pour laisser filtrer l'eau, et assez serrés pour retenir los injuretés qu'elle contient.

4. Le sable est un mélange de fragmens de quartz et de silex. Ces fragmens sont arrundis sils ont été fortement roulés par les eaux: tel est le sable des jardins; sỉ ces fragumens sont tiès-fins, ils constituent le sable mouvant et fluide qu'on employe pour nettoyer les vases de métal. Celui qui est mêlé avec de l'argille se nomme sabie des fordeurs, parce qu'ils s'en servent pour façonner leurs moules. Le sable uni avec de la chaux et de la brique pilée donne de la dureté au ciment; fondu avec la soude, il forme le verre et la couverte de la fäience.

5. La chalć́doine est transparente et susceptible d'un beau poli ; elle est blanche et marquée de nuages laiteux; on en fait dos cachets et des bagues. 
6. L'OPAIE réféchit différentes couleurs, selon le sens où on l'expose d la lumière, ce qu'on appelle chatoyer"; sa couleur principale est d'un blanc laiteux.

7. L'agathe a une pâte si fine, qu'on n'en pent distinguer le grain. Elle est d'une grande dureté, et prend un beau poli. On en trouve de nuées, de tachées, de veinées. On appelle ony'x. celle dont les taches forment des zones, des bandes concentriques. Les graveurs en pierres fines tirent souvent un grand parti de ces accidens, pour donner à leurs figures des couleurs différentes. On nomme herborisées, les agathes dont les couleurs présentent des ramifications. Les agathes mozsseuses sont celles qui contiennent, dans leur substance, de petites mousses incrustées. L'agathe sert à faire des petits mortiers et des carrés ponr loroyer des couleurs, des polissoires pour lustrer les toiles, des coupes, des bagues, des bijoux, des tabatières, etc.

8. La connaline est une espèce d'agathe d'un beau rouge; on en fait des bagues et des cachets.

3. Le silex. On désigne sous ce nom diffórentes pierres siliceuses, mais on l'ap- 
plique plus particulicrement à celle que l'on nomme pierre à fusil, parce mielle sert en effet à comrer l'uisicelic qui fait jartir les armes à feu. Le siler a la couleur et la demi-tranipurence de la come; on la trouve abondamment dius la ciaie.

10. Le Jaspe est opaque, très-dur, d'un srain tin, et prend un bean poli; il y en a de verd, de janne, le rouge, de veiné et de nuancé. On aplyelle jaspe sangmin celui qui est verd tacheté de rouge. Le. caillou d'Jispte est un jaspe brun avec des veines noires qui affectent différentes formes; on en fait des petits vases et des bijoux.

11. L'aventurine cst lourde, compacte et rouge, avec des puints brillans de couleur d'or; on la nomme asenturine naturelle, pour la distinguer de l'aventurine artificielle, qui se fait en jettant de la limaille de laiton dans du verre en fusion. Cette préparation sert à faire des taluatières.

12. Le IAPIS LAZULI se nomme aussi picrre d'azur, parce qu'il est d'un bcau bleu parsemé de petites taches d'or produites par des parcelles de mica; on en fait des ormemens et des bijous ; on sait en extraire 
D'HISTOIRE NATURELLI.

sa partic colorante; c'est ce beau bleu si rare aujourd'hui, et connu sous le nom d'outremer.

13. Le schor a une cassure lamelleuse et vitreuse; il est moins dur que les pierres précédentes; il crystallise ordinairement en prisme à six ou neuf pans, avec une pyramide trièdre. Les schorls se divisent en opaques et en transparciss; ceux qui deviennent électricues par la chaleur s'appellent tourmalines.

14. La PIERRE MEULItre, dure, raboteuse et comme cariée, se norrme ainsi, parce giu'on l'employe à faire des meules. Le ciment pénètre facilement dans ses.cavités, ce qui lie les pierres entre elies, et donne une plus grancie force aux constructions; on en fait principalement usage pour les fondemens.

+ Pierres germmes.

15. L g G ENAT est de couleur de lic.de-vin; il crystallise en dodćcaèdre; on en fait des colliers et des bracelets.

(1) On les nomme aussi pierres précicuscs; ce sont des crystaux colorés par des dissolutions métalliques, et qui acquicrent, par lo poli et par la trille, un plue bel sffet. 
16. Le RUBIs approche de la dureté du diamant. On appelle rubis spinelle, celui dont la conleur ronge a l'éclat du feu; et rubis balais, celui qui est d'un ronge plus. pâle.

17. L'HYACINTHL est ordinairement d'un rouge orange.

18. La topaze, d'un jaune orangé.

19. L'améthiste, de couleur violette.

20. Le saphir, de conleur bleue.

21. L'ineraude, de couleur verte.

22. L'aigue alarine, d'un verd d'eau.

* Terres et pierres qui n'étincèllent pas sous le briquet, et ne font pas effervescence avec les acides.

23. L'argille est très-abondante dans la nature; elle hape la langue, ou semble la retenir quand on l'applique dessus; elle se polit sous le doigt, elle attire l'eau avec force, s'arnollit quand elle en est pénétrée, et prend toutes sortes de formes. Elle se retire au feu, et acquiert une grande clureté. Cette terre si utile n'est point pure; sa base est l'alumine, qu'on met au rang des terres élémentaires, et qu'on nomme ainsi, parce 
qu'on la sépare de l'alun : c'est donc l'alumine, mêlée à d'autres terres, qui prend le nom d'argille. Sa propriété et ses usages varient selon ses différentes combinaisons; quand l'alumine est unie avec de la silice, elle constitue la tcrre à la porcelaine; et celle propre à des poteries plus grossières, à la fäience. Pour fabriquer ces diverses poteries, on fait, avec l'argilie détrempée dans de l'eau, une pâte ductile sous le doigt, à laquelle on donne toutes sortes de formes avec la main, dans des moules, ou sur la roue appelée tour à potier. Quand les pièces sont cuites, on les trempe dans une bouillie faite avec des pierres vitrescibles pilées et de la potasse; cette couche, vitrifiée par l'action du feu , forme l'émail ou couverte. La différence des couleurs dépend de la nature des chaux métalliques mêlées avec l'émail. La tuile, le carreau, la brique, les creusets, les tuyaux, font des poteries avec ou sans couvertes.

L'alumine, unie à la silice, et mêlée avec le fer, forme une argille dont la couleur varie, selon la quantité de fer qu'elle contient; on l'appélle terre bolaire ou sigillée, parce que les charlatans qui la vendent et 
lui aliribuent de prétendues propriétés , y appliquent un cachet. On nomme smectire, on terre à foulon, celle qui sert à dégraisser les étuffes.

34. L'andorse est une pierre argilleuse qui peut se tailler par lames; sa couleur est d'un bleu foncé, sa poussière est grise; celle qui prend le moins d'humidité est la meilleure; on en couvre les maisons. On trouve aussi des arduises en tables, qui servent à bâtir et à faire des tableaux pour tracer des figures avec de la craie.

25. Le talc est composé de fenillets trèsminces, plus ou moins flexibles et transpiarens; sa substance est tendre et douce au toucher; on en connoît deux variétés : le talc it grandes feuilles, c'est celui qu'on nomme verre de Moscovie, parce qu'on l'employe dans ce pays pour faire des vitres; il sert aussi dans les vaisseaux à cet usage. Le talc en petites lames ou en paillettes se nomme mica. La pondre d'or, que l'on met sur l'écriture, n'est autre chose que du mica réduit en poussière.

26. L'amiantie est composée de filets plus ou moins longs; on l'appelle vulgairement lin incombustible, parce que ces 
filets peuvent former des mêches, et même servir à faire une toile inattaquable au feu, et qu'il suffit de jeter dans la flamme pour la blanchir.

** Terres et pierres qui font effervescence avec les acides. (1)

27. La terre calcatre se trouve sous des formes très-variées dans la nature; on $y$ reconnoît toujours des fragmens d'animaux, ct même des animaux entiers, principalement des coquilles, dont les analogues vivans n'existent plus dans nos mers. Elle a des usages très-étendus, et sert sur-tout à faire de la chaux; c'est la base des os et de plusieurs concrétions animales.

23. La pierre a chaux est la pierre calcaire la plus pure. L'art du chanfournicr consiste à lui enlever son acide par l'action du feu; celle qui a été cuite au four se

(1) Ces terres sout moins dures, moins solides et plus solubles quc les jrécédentes. Lcs cliymistes mom dernea les nomment aussi substances salino-terreuses, terres salines, terres alkalines, alinlis terremi alles forment le passage des terres aux alkalis. 
nomme chaux vive; si on verse de l'eau dessus, elle fume, se fendille, boursouffle et devient lumineuse dans l'ohscurité. Quand clle a absorbé toute l'eau à laquelle elle peut s'unir, ces phénomènes cessent, et on la nomme chan'x éteinte; elle peut se dissoudre dans l'eau sans s'échaufier. En y joignant du sable et de la brique pilée, le résultat de ce mélange est le mortier qui sert à cimenter les pierres.

29. La craie est blanche, friable, et ordinairement si remplie de débris de coquilles, qu'elle en paroît toute composée; elle forme des bancs considérables, souvent interrompus par des couches de silex, à des distances à-peu-près égales, quelquefois de pierres assez dures pour bâtir. La craie tendre sert pour tracer des lignes et faire des crayons. Le blanc de Troie, qu'on employe dans les arts, est fait avec de la craie. On appelle farine fossile, la craie en poussière; la craie spóngieuse se nomme moelle de pierre.

3o. Les stalactites sont des dépôts laissés dans les fentes des grottes et des cavernes par des eaux qui y filtrent goutte à goutte, et déposent couches par couches 
la terre calcaire qu'elles abandonnent. Les stalactites sont toujours creuses et alongées ; leur réunion ressemble à ces congélations qui se forment le long des toits dans le dégel, et produit le plus bel effet.

31. Les starag vites. Lorsque l'eau ne dépose pas sur la stalactite toute la matière calcaire qu'elle contient, elle tombe au fond de la grotte, et y forme un antre dépót qui s'élève su'ccessivement sous la figure d'une bome : c'est ce qu'on appelle stalagmite.

32. L'albatre. Si les stalagmites et les stalactites viennent à se rencontrer, elles forment des colonnes; ; les intervalles entre ces colonnes se rempiissent avec le temps, et c'est ainsi que se produit l'albâtre, ; cette belle pierre calcaire est ordinairemeni d'un bianc jaunâtre; elle a la transparence du suif, Quand les sucs calcaires tiennent une chanx métallique en dissolution, l'albâtre prend différentes couleurs qui tracent des zônes d'un effet très-agréalble. Cette pierre sert à faire des vases, des figures et des bijoux.

33. Les incrustatiotss. Sonvent les terres calcaires, tenues en dissolution dans l'eau, se déposent 6ur des substances organiques: 
celles-ci se décomposent, et il ne reste plus que l'enveloppe formée par le suc pierreux; c'cst ainsi que s'incrustent les plantes et les fruits abandonnés dans l'aqueduc d'Arcueil.

34. Le marbine diffère des antres pierres calcaires par sa dureté, qui le rend susceptible d'un beau poli. Il est aussi formé par cles débris de coquillages; on disingue ses variétés par le nombre des couleurs. Celui qu'on tire des marbrières de Carare est d'un beau blanc, avec quelques lćgères teintes grises; sa cassure brillante et saline ressemble à celle d'un morceau de sucre : c'est cclui dont on fait los lielles statucs. Le verd antique est très-estimé ; la griote se nomme ainsi, parce que sa couleur rouge approche de celle de la cerise. Le marbre portor est noir et traversé par quelques veines métalliques. On appelle lumachelle le marbre dans lequel on apperçoit de grandes coquilles pétrifiées; la brếchc est formée de fragmens de marbres de différentes couleurs, rémnis par un ciment de mème nature.

L'art est parvenu à colorer le marbre par des dissolutions métalliques; on y grave des figures avec l'eau-forte, comme sur le cuivre, et on l'imite par une espéce de préparation appelée stuck. 
35. La pienre a Batir forme par-tout d'inmenses carrières; elle est composée de débris l'animaux marins, qu'on y distingue facilemrnt; son grain est plus ou moins fin : jamais elle ne prend le poli du marbre.

36. La pIERRE DE IIAIS a un grain plus fin que la pierre à bâtir, et prend un poli mat qui la rend plus propre à la sculpture; on en fait des staines, des chambranles de cheminées, des balustres, des carreaux, etc.

37. Le SPATI cALciIPe est la pierre calcaire crystallisée; il affecte un grand nombre de formes; le plus curieux est le spath d'I slande. Sa figure est celle d'un rhombe ; il est transparent: les ubjets que l'on regarde au travers paroissent doubles. Le greds crystallisé en rhombes de Fontainebleau n'affecte ccte figure que par son mélange avec la terne calcaire.

38. La prenRE DE porc est le produit de la terre calcaire mêlée avec du pétrolé; elle répand une odeur urineuse et fétide.

39. Le SPAtr - fuuor crystallise en cube : on 'e trouve aussi en masse; sa transparence, souvent troublée par de belles teintes de violet, de verd et d'autres couleurs, hui doune une ressemblance apparente avec 
les pierres gemmos; on en fait des vases et des bijoux.

**** Terres E pierres mélangées.

$$
+ \text { Terres. (1) }
$$

40. La marne est une combinaison d'alumine, de silice et de cliaux; elle est calcaire ou argilleuse, selon que la chaux ou l'alumine y sont plus abondantes. Cette terre est ordinairement déposée entre les bancs d'argille et de sable, rarement à la superficie de la terre, et le plus souvent à six, dix, et quelquefois à plus de trente mètres de profondeur; on en distingue plusieurs variétés,

(1) Nous avons déjà vu qu'il n'existe pas de terres absolument pures; que celles que nous nommons élémentaires peuvent être séparćes par l'art de celles aurquelles elles servent de base. Ainsi, toutes paroissent se ranger sous cette division. Cependant, on n'y place que celles dont la combinaison est apparente, sans aroir besoin de recourir à l'analyse chymique. L'ardoise, la pierre de porc, etc. sont aussi des terrez nélangées; mais pour éviter la confusion, nous les nvoris jointes aux substances qui $y$ dominent. 
D'HISTOIRE NATUMETLE.

la marne d'engrais, qui fertilise les terres, par les sels qu'elle contient; la terre à pipe, etc.

41. La terre végétale est le mélange du produit des substances animales ou végétales décomposées, avec les différentes terres où cette décomposition s'opère. Cette terre, qu'on nomme aussi terreall, se trouve à la surface du globe; c'est celle qui sert à la végétation; le meilleur terreau est celui des bois et des prairies.

$$
\rightarrow+\text { Pierres. ( } 1 \text { ) }
$$

+ Pierres rínnics par juxt'appofzion.

42. Le orantT forme des montagnes immenses pour l'étendue et la hauteur, et on ignore encore à quelie profondeur il descend dans la terre; il est toujours composé de

(1) Ces pierres se nomment roches. Les unes son: réunies par un cirnent commun; les autres le sont seulement par juxt'apposition. Les róches forment les hautes montagnes, celles que l'on nomme pritiz:tives, parce qu'on croit qu'elles ont existé les preanières.

B 3 
deux, re trois, de quatre, et même de cinq substances pierreuses très-distinctes les unes des antres, le feld-spath, le mica, le schorl et la stáatite; elles ont toujonis le quartz pour base. On classe le granit d'après le nombre de ces substances, ou la couleur qui $\mathrm{y}$ domine.

Le granit prend un tròs-beau poli ; les édifices qu'on en bitit sont d'une grande solidité ; cependant; le mica qu'il contient étant feuilleté et tenclre, l'ean s'y introduit facilement, le fait enfler, et la pierre s'éclate.

\section{+ + Pierres réunies par un ciment particulier.}

43. Le pOR PhYRe est composé de crystaux informes de feld-spath enveloppés lans une páte siliceuse, ordinairement rouge, ce qui forme une masse rouge parsemée d'ure multitude de petits points blancs et brillans. Le porphyre s'employe pour faire des rases, des colonnes qui sont d'un grand prix; sa dureté et son poli le rendent très-utile pour en faire des mortiers.

44. L'ornzte. La pâte de l'ophyte est d'un verd foncé; cette pierre sert aux nièmes usiges que le porphyre.

45. Le roveusic est formé de caillour 
d'Histaife Naturelle.

ronds et roulés, de différentes couleurs, enchâssés dans une pâte siliceusé; cette pierre prend un beau poli; on en fait des dessus de tabies et des vases.

\section{I. S E L S.}

Les sels ont une saveur plus ou moins âcre; ils peuvent se dissoudre dans une quantité d'eau mille fois plus pesante qu'eux; ils se liquefient au feu, s'y altèrent ou s'y détruisent.

Nous avons déjà vu que plusieurs substances, regardées autrefois comme des pierres, sont de véritables matières salines. On appelle fossiles, les sels qui se rercontrent tout formés dans la nature. L'analyse chymique en a aussi découvert un très-grand nombre.

On les distingue en sels simples, ce sont les alkalis et lo acides; et sels composés, ce sont ceux qui résultent de la combinaison des différens acides avec les allialis. 
* Sels primitifs.

$\rightarrow$ Alhalis.

LES alkatis ont une saveur âcre et urineuse, et ils chaugent en vert quelques couleurs blenes végétales; on en compte trois: ils ne sont jamais natif's et fossiles, et l'art seul peut les extraire.

1. La potasse s'obtient des végétaux en lessivant leurs cendres, évaporant la liqueur, et en faisant crystalliser le résidu. C'est sur-tout du nord de l'Europe.qu'on la tire, parce que ses immerises forêts fournissent le bois nécessaire pour la fábriquer en grand. La Convention, qui ne reut pas que dans la république il y ait un seul bras iractif, et une seule substance inutile, a ordonné de brûler par-tout les bruyères, les herbes sc̀ches et abandonnées, pour en retirer la potasse. Ce sel sert dans la teinture et pour la fabrication du salpêtre. Mêlé avcc le sable, il forme le verre; combiné avec la chaux vive, il brûle et cautérise la peau.

2. La soune ne se distingue de la potasse que par les combinaisons différentes qu'elle 
forme avec les acides; on la retire des cendres lessivées des plantes marines, mais la meilleure est celle qui vient d'Alicante; c'est le produit des cendres d'un arbrisseau nommé kali. On l'employe dans les verreries, dans la tcinture, pour la préparation des savons et dans la pharmacie : c'est la base du sel marin.

3. L'anjuONIAUE. Les denx premiers alkalis sont fixes; celui-ci est toujours fluide, et se réduit facilement en rapeurs. 11 a une odeur pénétrante d'urine et de poisson pourri; les animaux le contiennent abondamment; sa causticité est considérable.

\section{++ Acides.}

LEs sels acides ont une saveur aigre; ils changenten'rouge les couleurs bleues végétales; aucun n'existe pur dans la nature; on les retire de différentes substances minérales, végétales ou animales. Nous avons déjà fait mention d'un des plus importans, de l'acide carbonique, sous le nom d'air fixe. Nous n'entrerons pas dans d'autres détails sur les divers acides: ils appartiennen: à la chrmie; les fáits les plus importans se 
tronveront dans l'histoire des substances qui les prouluisent.

\section{* Sels neutres.}

Ces sels sont formés d'un acide et d'un alkali intimement combinés. Leur nom doit toujours être composé de deux mots, dont 1c premier indique l'acide, et l'autre l'alkali qui lui sert de base; ainsi, muriate de soude indique la combinaison de l'acide muriatique avec la soude : c'est le sel marin.

Il y a un très-grand nombre de sels composés comnus; nous ne devons nous arrêter qu'à ceux qu'on trouve tout formés dans la nature, ou qui sont d'un grand usage dans les arts.

4. L'Ar.c est nommé sulfate d'alumine, parce qu'il est formé d'acide sulfurique et d'alumine. Il a une saveur d'abord doncen̂tre, et ensuite astringente; il rougit le papier bleu, ce qui annonce qu'une portion de son acide est à nu ; cette substance se trouye jarement native, excepté dans le voisinage des volcans. On connoît, dans le commerce, l'alun de roche, ainsi nommé, parce que la plus ancienne manufacture de cetle substance 
D'Histoire Naturelle

étoit à Rocca en Syrie; l'alun de Rome, celui de Naples, et enfin celui de France; qui se fabrique dans nos manufactures, et -sur-tout à Javels, près Paris.

Les procédés de la préparation de l'alun varient, selon les pays; les terres qui le contiennent tout formé n'ont besoin que d'être lessivées. Les substances qui ne renferment que les principes de l'alun exigent des travanx assez compliqués pour les extraice et les combiner. Ce sel est extrêmement utile dans les arts; on s'en sert pour rendre le suif plus ferme, pour faire prendre l'encre anx balles de I'infrimeur, pour clarifier l'ear troulle, pour préparer les cuirs; et enfin, pour aluner les toiles et les papiers avant de les imprimer. I.es substances impregnées "'alun ne peuvent plus brûler avec flamme; c'est un très-bon moyen pour les préserver de lincendic.

5. Je SEL TIARIN, qu'on homme aussi sè? de cuisine, et simplement sel, parce qu'il est d'un usage commun pour la préparation des alimens, est parfaitement neutre. Son acide est très - intimement combiué arec la soude; les chymistes l'appellent muriote de soude, pour indiquer cettc combinaison. 
Le sel est très répandu dans la nature; celui qui se trouve en grande masse et tout formé, comme dans les mines de la Pologne, s'appelle sel gemme, à cause de sa ressemblance avec les crysiaux gemmes.

Le sel s'obtient communément par l'évaporation des eaux de la mer, des lacs et des fontaines, qui les tiennent en dissolution. Sur les bords de la mer, on creuse des fosses: où l'eau se rassemble; l'activité du soleil la fait évaporer, et le sel se rapproche : ces fosses se nomment salins, mamis salans. On fait aussi évaporer l'eau de la mer dans des bassines par l'action du feu, et on obtient un sel plus pur que le premier. L'eau des fontaines salées étant moins riche, on la fait pleuvoir par des robinets sur des fagots élevés par étage sous un hangard sppelé bátiment de graduation; il s'en évapore urré partie; celle qui est la plus chargée de sel se porte dans les chaudières pour y être traitée.

Tout l'art du saunier consiste donc à faire bien crystalliser le sel marin; et à le débarrasser entièrement des corps étrangers qui l'altèrent.

La saveur du sel marin est bien connue; 
elle corrige la fadeur des alimens. Ce sel crystallise en cube, décrépite ou pétille sur le feu, et attire l'humidité de l'air. A petite dose, il accélère la fermentation putride, et c'est ainsi qu'il facilite la digestion. en hâtant la décomposition des alimens; grande dose, au contraire, il préserve les substances organiques de la corruption. Enfin, le sel est utile d̀ la santé des bestiaux, et à la fertilisation des terres.

6. Le SEL a MMONIAC, ou muriate ammoniacal, est composé de l'acide muriatique et de l'ammoniaque. Son nom lui a été donné par les ariciens, parce qu'on le préparoit en Egypte, près du temple de Jupiter Ammon. On le retire de la suie, de la fiente du chameau; on l'apporte en pain, et on le purifie dans nos laboratoires. On l'employe en médecine, dans la teinture et pour souder les métaux; les chaudronniers s'en servent pour frotter le cuivre avant de l'étamer.

7. Le nitre ou salpêtre, appelé par les chymistes nitrate de potasse, est composé d'acide nitrique et de potasse ; mais l'acide nitrique peut encore s'unir a vec beaucoup de terres, telles que la craie, l'alumine, la 
magnésie, et il forme avec elles différentés espèces de nitres à base terrense, qui, loin d'avoir la propriété de crystalliser, comme le vrai salpêtre, attirent f'lumidité de l'air et $s$ y résolvent en liqueur. Ces sels ne peuvent entrer dans la composition de la poudre; il faut donc, pour appliquer le salpêtre à cet nsage, le priver de différens sels à base terreuse qu'il peut contenir. Ce procédé consiste à mêler a vec ces derniers un alkali fixe : l'acide nitrique abandonne aussitôt la terre avec laquelle il étoit uni pour se com: biner avec l'alkali. La terre qui n'étoit soluble dans l'eau qu'avec l'internède de l'acide, se précipite au fond clu vase, et en faisant évaporer l'eau surnageante, on obtient le vrai salpêtre.

Iue nitre existe quelquefois tout formé dans la nature; plusieurs plantes, telles que la pariétaire, le grand soleil, la bourrache, en contiennent quand elles ont cru dans un lieu salpêtré, mais pas cn assez grande quantité pour être utile.

Comme la présence d'un sel quelconque facilite la formation du salpêtre, on en - trouve abondaminent sur les murs de plâtre sabrités de la pluie : c'est celui qu'on appelle 


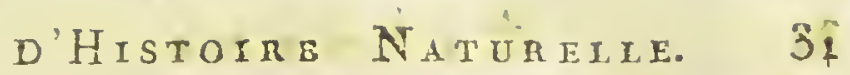
salpétre, ou nitre de houssage. Les vieux platras en contiennent une grande quantite; il se produit aussi dans les caves, dans les écuries, sous les hangards, par le mélange des matières animales ou végétales qui se putréfint.

On fait aussi, pour avoir une grande quantité de salpêtre, des nitrières antifzcielles; ce sont des fosses placées sous des hangards; on y entasse des malières animales et végétales; on y ménagge des courans d'air, et on y entretient l'humidité convenable pour favoriser la putréfaction; quand ces matières se sont chargées d'un nitre assez riche pour être exploitées, on les lessive poúr l'extraire, en y joignant de la potasse, afin que le vrai salpêtre abandonne sa base terreuse et puisse s'y former. L'eau qui a servi à cette lessive est évaporée dans des chindières, et placée dans des vaisseaux, ou le nitre se forme en pain et crystallise; on le fait ensuite dissoudre et crystallise. deux fois pour l'avoir plus púr.

Le nitre purific par trois cuites est celui qu'on employe dans les arts. Sa saveur est fraîche ; il crystallise en prismes ; ses faces sont terminées par des pyramides diedres 


\section{É L}

ou en biseau, et souvent creusées par un canal dans toute leur longueur; mis sur. le feu, il fuse; mais si on y mêle une substance combustible, telle que le charbon, il produit une flamme vive et un bruit violent, ce qu'on appelle détonner; telle est la théorie de la pondre à canon, à laquelle on ajoute du soufre ponr l'allumer. On triture ce mélange pendant dix à douze heures dans des mortiers de bois avec des pilons de la même matière; on y ajoute une petite quantité d'cau; lorsque le mouvernent a évapuré presque tout ce fluide, et que la poudre mise sur une assiète de faïence n'y laisse ancune trace d'humilité, on la porte au grainoir. Grainer la poudre, c'est la faire passer dans des cribles dont les trous sont de différentes grosseurs, jusqu'à celle de la poudre à canon. On tamise ensuite la poudre pour ôter la poussière, et on l'expose dans le séchoir au rayons du solcil du midi, qu'elle reçoit à travers un vitrage. La poudre de chasse se lisse en la faisant tourner dans un tonneau, où elle se polit par le frottement, afin qu'elle ne salisse pas les mains.

On retire du nitre distillé avec une terre argilleuse, une autre substance intéressante 


\section{D'Historne Naterete 33}

dans les arts, et dont l'usage est très-répandü pour dissoudre différens métaux, dorer, graver sur cuivre, sur le marbre, pour les travaux des chapeliers, des peintres, etc.; combiné a vec l'acide muriatique, celui qu'on retire du sel mairin, on en fait l'reide nitro-: muriatique, qui sert à clissoudie l'or.

Le nitre brûlé avec différentes doses de tarire, forme cette matière appelée finx, qu'on employe pour fondre et pour réduire différentes substances métalliques. Le nitre s'administre comme médicament; on le mêloit arec le sel marin dans le temps où celui-ci étoit cher.

8. Le cYrse, nommé aussi sélénite, et par les chimistes, sulfate de chaux, est dû à la combinaison de l'acide sulfurique avec la chanx.

Le gypse crystallise le plus souvent en fer de lance; calciné dans le four du plâatrier, il devient très-friable : c'est le platre fin dont on se sert pour couler des statues blanches et agrćables, mais fragiles; mêlé avec une certaine quantité de craie, comme l'est celui de Montmartre, il forme le plâtre a batir ; il est en masse informe : on le nomme alors picrre à platre; on le cuit 
dans le four du platrier, on le bat, on le réduit en pundre, on le gáche avec de l'cau, il s'échanute un peu, et répand me odeur fétide; il prend corps, et forme l'espèce d'enduit dont le maçou revêt les murs avec sa truelle. Le plâtre ne convient que dans les lieux sees, il se détruit à l'humidité.

9. Le воus est la combinaison de l'acide boracique avec la soude; aussi l'appelle-i-on en chimie, borate de soude. C'e sel, trèsulile dars les arts, nous vient des Indes et de ha Perse, en znasses grasses et verdâtres, qu'on appeile rinckal, ou borax brut. On le purifie en Europe; on l'employe pour sonder l'or et l'argent, et pour faire des émaux.

\section{SUBSTANCES INFLAMMARLES.}

IA combustion ne peut pas aroir lieu sans air vital, puisqu'clle n'est autre chose quéla combinaison du corps qui brûle avec la lase de l'air vial, l'oxygene, qui alors abandonne le calorique. Si la lumière est combinée avec le calorique, il y a dans la combustion flamme et chaleur. Plus lcs 
d'Histotre Naturelit.

corps sont propres à s'unir avec l'oxygène, plus ils sont combustibles. Voici les substances qui ont éminemment cette qualité.

\section{* Combustibles transparens.}

1. Ie diamant est le corps le plus dur. que l'on connoisse, rien ne peut l'entamer; sa belle transparence et la manière dont il réfrange et décomposẹ la lurnière, sont également remarquables; il est composé de lames qu'on peut enlever successivement, ce qui s'appelle cliver; on ne peut le polir qu'avec sa propre poussière, qu'on nomme égrisée; si on l'expose au feu, il y brûle avec flamme, sans laisser aucun résidu; on le trouve dans l'Inde; it en vient aussi du Brésil , mais il est moins estimé.

\section{* Soufres.}

2. Lle soufre est sec, fragile, et d'un jaune citron; il n'a d'odeur que quand il est échauffé ; il devient électrique par le frottement; on le trouve abondamment pur ou combiné à des corps métalliques; il se forme aussi de lui-même dans les matières 
animales putréfićes. Le soufre natif ne seroit cependant pas sulfisant; on l'obtient en grande quantité de la distillation des pyrites. Après l'avoir fondu, on le coule dans des tubes de bois, ou on le volatilise en petits flocons appelés fleurs dé soufie. Brûlé avec du nitre dans des vaisseaux fermés, le soutie produit de l'acide sulfurique, nommé vulgairentent huile de vitriol. I! entre dans la composition de la poudre à canon, il donne une couleur blene à la flamme des f́eux d'artíice, on en fait des mêches et des alumettes, sa vapeur blanchit la soie et tue les insectes; on lui doit les eaux minérales sulfurenses; le soufre, mêlé ì la graisse, guéric les maladies de la peau.

\section{*** Bitumes.}

Idrs bitumes sont des substances combustibles, solides, molles ou fluides, qui contiennent une grande quantité de matière huileuse, et brûlent avec unc flamme rapide.

3. La rovllue est cassante, noire et feuilletée; on la nomme charbon de terre, a cause de ses usages et des lieux où on la 
trouve; on la regarde cependant comme le produit de bois enfouis et altérés par les acides; les mines dont on la tire s'appellent hozillières. Plus le charbon de terre est pesant et compact, plus il s'embrâsé aisément; sa flamme exhale une odeur forte: elle est due à la partie huileuse quï se volatilise. On le purifie en le débarrassant de la portion la plus grossière de ceite huile; ce bitume est très-abondant et très-utile; chacun doit concourir à en répandre l'usage, pour diminuer la consommation du bois.

4. Le JAYET a la cassure vitreuse; sa couleur est noire, sa surface brillante, et susceptible d'un beau poli; on l'ermploye pour faire des bijoux.

5. L'asphatte, que l'on nomme vulgairement bitume de Judée, on poix de, montagne, est noire et solide; il nage sur les eaux; le lac Wallengin fournit celui mni entre dans le commerce; on le môle avec la poix.

6. Le p'́trole est fluide et coule entre les fentes des rochers; on on imbibe des mottes de terre qui servent pour le clauffage; mais sa fumée est épaisse et désagréable; son huile cst utile pour espalmer les vaisseaux,

\section{3}


pour graisser les voitures. Le pétrole peut servir à composer un morticr solide et durable.

7. La tourbe est composée d'me terre ferrugineuse mêlée avec des débris de végétaux et d'animaux; on la irouve dans les lieux maréca geux; après l'en avoir tirée, on la fait sécher et on la délite en pains, auxquels on donne la forme d'une brique; elle est très-utile pour le chauffage.

8. Le succin, ou ambre jaune, est d'un jaune doré et transparent; il contient des insectes dans sa substance; en le frottant, il attire les corps légers; c'est à cette propriété que l'on doit la découverte des phénomènes de l'électricité. Le succin paroît dû ̀̀ une résine végétale; on en fait des bijoux ; on en retire, pour la médecine, une huile essentielle appelée furile de succin ou de karabé.

\section{V. I É T A U X.}

Les métaux sont des corps combustibles, d'une nature particulière. Plus ou moins tenaces; ils peuvent s'étendre sous le marteau ou dans la filière, ce qu'on nomme malléa: 


\section{D'HISTOIRE NATURLIE.}

bilité, ductilité; ils brùlent à l'air libie et se convertissent en oxycles, ou chaux métalliques, en se combinant avec l'oxygène. Les minéralogistes les trouvent vierges, natifs, c'est-à-dire purs, ou bien combinés avec d'autres substances qu'on appelle minéralisateurs; ce sont ces combinaisons qui portent les noms de mines ou minerais.

On nomme aussi mines, le lieu oir les minéraux se rencontrent, et la ligne que ces substances tracent est le filon. Le mineux considère son inclinaison et sa direction, le lit sur lequel il repose, le toit qui le couvre; entin, sa gangue; ce sont les paries étrangères qui l'accompagnent. Son art consiste à ouvric les puits et les graleries ayec intelligence, pour favoriser l'écoulement cles eaur et la circulation de l'air, et ì cxtraire le minerai de la manière la plus éćcnomique.

Le métallurgiste traite le minerai sorti de la mine; il le pile sous le bocart, le lave sur de grandes tables pour emportev ses parties terreuses, le grille, pour volatiliser le soufre et l'arsenic, et le fond en tone mate, qu'il affine ensuite par différens prucédés. Je feu fait vitrifier les subsiances 
$40 \ldots$ É I E $M$ E N S

étrangères, et le métal fondu tombe en culot; le marteau en sépare à grards coups tontes les matières vinitiées. Nous verrons, en traitant des diférens nétaux, les divers procídés appelés liquation, conpelie, aćpart, amalgame, siulination. Les substances métalliques, ainsi purifiées, s'employent à une foule d'usages.

\section{* Demi-nuétaux.}

O nomme ainsi les substances métalliques qui sont peu ductiles; les unes se cassent sous le marteau, les autres ont une demi-ductilité.

1. L'Arsenic a beaucoup de rapport avec les sels ; il est brillant et en lames cassantes d'un gris noirâtre; ii brûle avec une flamme bleve; son oxyde se sublime en tre fumée blanche qui a l'odenr d'ail. Combiné avec le oufre, il constime l'orpiment et le réalgar, qu'on employe pour peindre en jarne ou en rouge. Les préparations arsenicales sont toutes des poisons dangerevix.

2. Le coвalt a un tissu grenu, brillant et d'un gris rosé; son oxyde, fondu arec 
D'HISTOIRE NATURELE.

des matières vitrifrables, donne un très-beau bleu qui entre dans la composition des émaux, et qui sert à colorer la porcelaine et la fäience. Ce demi-métal dissous dans les acides, fait l'encre de sympathie, qui ne laisse aucune trace sur le papier, et paroît d'un beau vert en la chauffant.

3. Le bismutu présente de grandes lames jarmâtres. Dissous dans l'acide nitrique, il fait le blanc de fard, mais il noircit par le contact des vapeurs inflammables. On empioye ce demi-métal pour donner le la dureté à l'étain et à d'autres substances métalliques.

4. L'antmugne crystallise en longues aiguilles; il est blanc, brillant et à grandes facettes; il entre dans l'alliage des caracteres d'imprimeric. I'émétique est une combinaison d'antimoine et de l'acide tartareux.

5. Le LINC est en lames étroites et brillantes, d'un blanc tirant sur le blers; il brûle à l'air avec une flamme blanche. Le minerai de zinc se vitriolise d'air; on le lessive; et on obtient, par l'évaporation et le refroidissement, des masses blanches et grentues qui servent dins la. teinture. Le zinc mêlé au cuirre produit los 
alliages connus sous le nom de tombac ou similor: Sa limaille donné, claus tes feur d'artifice, des étoiles blanches et brillantes; on a propusé de le substituer à l'étain pour revêtir les vases de cuisine.

6. Le MLRCURE est aisé à reconnoître par sa. fhuidité constante, qu'il ne perd ru'à un degré de froid le qurarante-six degrés ; c'est ur solide fondu qui se divise en globules; il est ordinairement minéralisé par le soufre; on l'obtient par la distillation; sa fluidité et sa conleur l'ont fait appeler vif argent, mais il n'a ancun rapport avec l'argent. Ses nsages sont très-multipliés ; minéralisé par le soufre, on l'applelle cinabre; il sert à faic la couleur ronge connne sous le nom de vermillon. Le mercure entre aussi dans plusieurs préparations utiles pour chasser les vers et les insectes, et guérir les manx vénériens; il monte et descend dans un tube de verre, selon que la colonne d'air pèse plus ou inoins'sur lui; c'est sur ce phénomène qu'est fondée la construction du baronètre. Comme la chaleur dilate le mercure, ainsi que tous les antres fluides, on en fait anssi des ihermométres. Sa combinaison avec les mélaux se nomme amalgame. Celui de 
D'HISTOIRE NATURERE.

mercure et de bismuth sert à prendre l'empreinte des cachets; celui de mercure et d'étain, à étamer les glaces. On dore et on argente en frottant les pièces avec un amal:" game de inercure avec l'or et l'argent, on fait évaporcr le demi-métal par l'action du feu, et le métal se fixe. On employe aussi le mercure pour extraire ces métaux de leurs mines, et on les lui fait abandonner par la sublimation.

\section{* Métaux.}

It s se distinguent des demi-métaux, en ce qu'ils sont ductiles et malléables.

\section{+ Mćtanx imparfaits.}

L Es métaux imparfaits sont ceux qui s'oxydent très-facilement, quand on les chaufte avec le contact de l'air.

7. L'ítain est le plus lérger de tous les métaux; il a une odeur assez forte, et il cric quand on le plie. Il est toujours allié a. un peu de plomb; mais quand cette quantitć n'est pas considćrable, elle altère pen sa qualicé. On en fait divers ustenciles de 


\section{EL E RE E N}

mérage, des brocs, des vases, des cuillers, des gobelets; alié au cuivre, il devient la hase de nos statnes; les chaudronniers en revêtent les vases de cuivre, ce qui s'appelle Ies étomer ; le fer blanc a ćlé trempé daus nn bain d'étain : on se sert de l'étain pour souder le fé et le cuivre. Aliié avec le mercure, il étame les glaces. Après avoir été 'légérement calciné, il devient la potée d'étain qui sert à polir les pierres dures et le dirmant. La chanx d'étain rend les conleurs plas vives, elle est très-utile dans la teinture écritale.

8. Le plomb est le moins sonore, le moins ducrile et le plus pesant des nsétaux imparfais ; il est hourd ct cassant. Celui qu'on cxuluite est ordinairement minéralisé par le soufre et en morceaux cubiques appelés galène. Après l'avoir loti, bocardé, grillé et coulé, counme les autres métaux, on le vitrifie pour le séparer le l'argent qu'il contient, et qui reste dans le fourneau appelé coupelle. On fait ensuite repasser le plomb vitrifié à l'état métallique pour le mettre dans le commerce.

Ce viétal sert à beaucoup d'usages, pour convrir los maisons, faire des tuyaux, des 
n'Hrstotre Naturelie. $\quad 45$ balles de fusil, etc. Les vases qu'on en façonne sont dangerenx, parce que les acides les attaquent facilement. En brâlart et calcinant le plomb, on le fait aisément passer à l'état d'oxyde. La chaux de plomb obtenue après la coupellation, se nomme $i t$ tharge; sile f'eu a élé très-vif, on obtientle migium, qui sert à peindre en rouge. La chanx de plonb, mêlée an verre, lui donne de la. transparence, mais elle augmente sa pesanteur. Le plomb bouilli arec du vinaigre produit le blanc de plomb.

Comme ce métal réduit en verre et en scories tous les autres métaux, à l'exception de l'or et de l'argent, il sert à les en séparer, ce qui s'appelle coupeller.

9. Le fer a une couleur livide et grisâtre; il est dur, élastique, et prend un poli brillant; on le trouve, rarement, natif, mais abondamment, oxydé. Sorti de la mine, on le bocarde, on le lave, on le grille. La fusion le sépare de sa gangue, qui se vitrilie; le marleau rapproche ses différentes parties et le met en barres, pour être travaillé dans nos ateliers. On le convertit en acier, en le chauffant dans une boîte de terre rempllie de matières combustibles, ce qui s'appelle cementer. 
Les ochres ou oxydes de fer, nommés terre d'ombre, límatite, sanguine, etc. servent it faire des crayons, des couleurs et des émaux; les matières végétales astringentes, telles que la noix de gralle, l'écorce de chểne, etc. précipitent le f'er en une poudre noire. La gomme arabique suspend dans l'eau les globules de cetre poudre; c'est ainsi que se fabriquent l'encre et la teinture noire. Le fer, décomposé par un alkali et combiné an sang de bouf, fommit à la teinture un précipité d'une autre conlemr, appelée blez de Prusse. L'air et l'eau convertissent le fer en une rouille qui sert à imprimer les toiles. La limaille de fer donne dans les feux d'artifice des étincelles rouges. L'aimant, qui attire le fer, cst lui-même une mine de fer ochracée. Le fer conbiné avec beaucoup de charbon produit, dans la nature, une espèce de métal appelé plombagine, dont' on fait des crayons en l'introdmisant dans des tubes de bois. Cette substance sert aussi à enduire les rouages des machines, à défendre le fer de la ronille; on y roule le plonı de chasse pour l'adoucir ; elle entre dans la composition que l'on met sur les cuirs à rasoirs et dans la couvérte 


\section{d'Histoire Naturite. 47}

de quelques poteries; on la nomme vulgairement mine de plomb.

Le fer se trouve dans les plantes, dans les pierres colorées; c'est à lui qu'est due la partie colorante du sang.

Io. Le curvre est dur, sonore, élastique et assez tenace; sa couleur est rougeâtre, son odeur désagréable. Après l'avoir traité comme les autres inétaux, on le fond avec le plomb qui entraîne l'or et l'argent qui pourroient s'y trouver mêlés; cette opération s'appelle liquation. On le fond ensuite séparément, et on juge de sa pureté à sa couleur ronge plus ou moins éclatante; laminé en plaques, il sert à courrir les maisons, à doubler les navires, ì faire des bassines et des cliaudières; coulé dans des moules, on en fait une foule de vases, d'ustensiles et d'ornemens; uni à l'étain, il devient le bronze de nos canons, l'airain de nos statues; rccouvert d'une couche mince d'étain, on en fait des vases de cuisine; allié à l'or, il lui donne une teinte verdâtre; uni avec le zinc, on obtient le tombac, l'or de Manheim et le laiton; passé à la filière, il donne un fil très-serré qui, aplati et doré, sert a faire des galons. Le marteau peut le 
réduire, comme l'or, en feuilles minces, et on l'applique de nuême. Sa limaille donne me couleur verte dans les feux d'artifice; lair et l'eau le décomposent en un oxyde applelé verd-de-gris; cet oxyde, qui entre dans la peinture verte, est un poison violent. l'oxyde de cuivre en stalactites forme la malachite, substance verte et. susceptible d'un beau poli, dont on fait des bijoux. Les os pétrifiés par une sulsstance unie à cet ox yde ont une couleur bleve; ce sont les turquoises que l'on monte en bagues.

\section{$+\rightarrow$ Métaux parfaits.}

I I.s ne s'oxydent pas facilement en les chauffant avec le contact de l'air.

11. L'ARGENT est très-brillant, très-ductile; il n'a ni odeur ni saveur; on le trouve natif ou combiné avec différens sels; on l'extrait de la mine en l'amalgamant avec le mercure, qu'on sublime ensuite, ou bien on le coupelle, c'est-à-dire qu'on le fond. avec du plomb, qui vitrifie et entraîne avicc lui les corps étrangers. Les acides n'altèrent pas sensiblement l'argenterie unie, parce qu'elle contient peu de cuivre; mais celle qui 
D'Historis NAtuketu.

qui a beaucoup d'ornemens est plus attaquable, parce qu'il entre plus de ctivre dans la souture; son nsage esi dangerenx.

I2. L'or n’a ni saveni ni odeur; sa couleur est jaune; la nature le présente natif oll combiné ; оn l'extrait, comme l'argent, par le muyen du mercure; sa ductilité est si grande, que 4 cenligraves peuvent dorer un fil d'argent de 830 millaires, et 2 gravets d'or penrent convir une aire de 3,5 décimètres. Sa tenacité est si grande, qu'un fil d'or de 2 millimetres de diamètre soutient un poids de 240 graves sans se rompre. On le trouve scus une infinité de formes; on en frappe des monnoies; on en fait des vases et des bijoux.

13. Le I'Latras est plus pesant et plus inaltérable encore que l'or, ce qui le rend utile pour faire des creusets; mais ce métal, qui ne se trouve qu'áu Pérou, est difficile à traitcr, très-rare et très-cher ; il est d'un blanc grisâtre peu brillant. 


\section{SUBSTANCES TOLCANIQUES.}

LES substances volcaniques sent des matières rejcttécs par les vulcans, vastes soutpiraux, au travers desquels les leux souterrains s'ouvrent une issue. Ces masses luh ûlantes prennent souvent une forme crystalline en se refroidissant. Quelques-unes de ces substances sont utiles dans les arts.

1. La impre ponce est nue pierre altérée par le feu, et devenue si légère et si poreuse, qu'elle flotle sur l'ean; elle sert à polir.

2. Les lates sont des fleuves dé matières fondues et vitrifiées, qui coulcnt des volcans; refiroidies, on en peutfaire des bouteilles; plusieurs villes de l'Italie en sont pavées. Comme ces verres sont très-durs, on les polit pour en faire des tabatières, des boutons d'habits, ctc.

3. Le basalte est une lave refroidie et crystallisée, qui offre depuis trois jusqu'à huit faces. Ces pierres sont très clures; on peut en paver les chemins, en faire des édifices, des colonnes et des statues.

4. La pierra de touche, qui sert de reconnốtre la nature des métaux, par la trace qu'ils y laissent, est une espèce de basalte. 
d'Histoire Naterelle.

5. La rouzzolane est la lave en petits fragmens; elle est très-utile pour faire un mortier qui se durcit dans l'eau. Son nom lui vient de la ville de Pouzzole, où elle est abondante, et où elle a été employée très-anciennement à cet ùsage.

\section{SUBSTANCES ORGANIQUES.}

Ox appelle substances organiques les corps doués des organes propres aux différentes fonctions qui constituent et entretiennent la vie, telles que la circulation, la respiration, la nutrition, la génération, l'irritabilité et la scusibilizá.

Ces substances diffèrent par la locomobilité, c'est-à-dire, par la facinité de changer de place à volonté. Cette distinction établit entre elle denx divisions.

SUBSTANCES ORGANIQUES NON LOCOMOBILES

Végétaux.

SUbSTANCES orcaniques locomoriles.................. Animak.

\section{V İ L T A U X.}

LES VÉGŔTAUX se nourrissent, croissent, s'unissent, se fécondent, se reproduisent et mcurent; mais il leur manque, pour 
53 E I L $M$ L N

ressembler aux animaux, le mozsemert volonturire.

La connoissance du nombre, de la strncture, de l'usage, de la sitration, cíc la proportion, et de la différence de leurs organes, l'art de les distingucr ei de les décrire, s'appelle boranizue.

Les principaux organes les régétaux sont Ia racine, la tige, la feuille, la ficur, le frait et la semcnce; il est nécessaire de les bien connoîte, avant de passer à lexancn de leurs fonctions.

La semence confiéc ì la terre y dememe jusqu'à ce que la chalcur nécessaice jour animer le point vital, le coeur de la plante, se fasse sentir, alors elle se gontle, et l'cmbryon se nourril des sucs de la torre, épurés et atténués a travers les lohes qui l'accompagnent, et qu'on romme cotjledons. Des que l'embryon a acguis un peu plus de force, l'épiderme de la semence se rompt, ses lobes s'écartent, la plumzile s'élève, et la radicule descend. La plunir.le sort de terre accompagnée de ses luives, changúes en feuilles séminales, qui périssent aussiıôt.

La radicule plus vigoureuse est cicyonue 


\section{D'IISTOIRE NATURzILE。}

une racine simple, rameuse ou chevelue, qui pompe les sucs nourriciers. Elle pend perperticulairement clans la terre, ou s'éteni latrialement à peu de distance de sa surface. Sa substance est ligrueuse, fibreuse ou churize; sa forme ronde, ovale, noueuse, pyramidale, zubéreuse ou, articulée; ello vit un ail, clewx ans, et quelquefois arz-dela d'an siècle; elle fxe la plante dans-li terre, sous les eaux, et même entre l'écoice d'antros végúlaux, dont elle absorbe les stics.

La plunule léveloppée forme la tige qui part du collet de la racine, et s'élève perpendiclalairement, ou s'éiend dans une direction horizontale; elle est nue ou ornéc de feililles, simple ou ramense; ses rameanx sont opposés, alternes, ou forment sur la ligne des anncaux quion nomme verticilles; sa forme est rumde, triangulaire, tútragone, polygone, selon le noutre de ces angles; sa superficio est lisse, riclés, silionnée, poilue, cozonnemse; clle est défendue par des aigublilons ou par cies épines; an diroction est clroite on inclinc'e; clie s'éleve quelquetois en spirale ì droile . ou à gauche du suleil, et grimpe sur les corps 
voisins à l'aide d'appuis particuliers. Sa substance creuse on soliale est ligncuse ou herbacée. C'est une herbe humble et timide, un arbrisseaz modeste et fragile, ou un arbre dont les racines descendent profondément, et dont la cine semble menacer les cieux; alors on lui donne le nom de tronc. La tige des graminées se nomme chamme. Quelques plantes sont scssiles: elles n'ont point de tige.

Les feuilles sont les organes de la respiration; quelques végétaux n'en ont point, mais la plîpart en sont parés. Les feuilles sont sessiles, ou soutennes par un pétiole zu ou cilé, ou appuyé sur des écailles mer:braneuses appelées stipules. Les différences qu'on observe dans les formes et dans la posilion des feuilles sont innombrables; nous ne nous arrêterons qu'aux plus importantes: elles tiennent à la racine, à la tige, aux raineaux on ì la fleur; elles sont percées par la tige, l'embiassent étroitement, l'€ngaînent ou courent à sa surface; quelquefois elles sont altemes, d'autrefois opposées; rémies par la base, elles forment un anneau ou verticille; souvent elles sont ramassécs et réunies en grand nombre, et se recouvrent 
en toit; leur direction varie comme leur insertion; elles sont droites, horizontales, inclinées, rapprochées de la tige, on forment ayec clles un angle plus ou moins ouvert. Quant ì leur durée, elles tombent tous les ans, ou résistent anx rigueurs de l'hiver, et conservent leur verdure.

Leur structure est sur - tout variee. Les feuilles sont simples quand elles n'offrent ancunes divisions; elles ont alors la forme d'nne alène, d'un fer de lance, de hallebarde ou defliche, d'un ccur, d'un rein, d'un oróe; elles sont triangularires, quadrangulaires ou en lozange; leur bord est eniier, denté, crénelé, scié, accompagnó de cils, ou défendu par des piquans; il est découpé plus ou moins profondément en lobes, qui rorment des angles plus ou moins aigus. Si ces lobes, partagés en cinq, se réunissent on un mềne point, la feuille est palmée, c'est-à-dire qu'elle ressemble ì une main. Ses découpures lui donnent quelquefois l'apnarence d'une lyze on d'une barbe de plume; son extrémiié est aigzue, obtuse, tronquée ou échancrée; sa surface inférieure ou supérienre est brillante, lisse, cotonneuse, lanugincuse, veluc, poilne, húrissce,

D \& 
rabuteuse, ponctuée, ribier, piquanto, t'pireuse, avec ou sans mervines.

Le conleui des feuilles est verte on blanchatre; jeur expansion est plane, convexe, concase, plice, cirpplue, onclulée, creusée engontière; leur substancuest meinbranense, corrace ou chamue, mince ou ćpaisse, pleine ou criuse.

Les feuiles composées sunt formées de plusieurs folioles, lixés sur le même pétiole; elles sont conjugumes, torrós on quaternúes, sulon que ces folioles sont an nombre de deux, de ticois ou de quatre. S'ils scint au nombre cie cinc, ils ont l'apparence des doigts d'une minin, et la feuille est digitée. Si les folioles sont eux-mîmes divisés ou subdivisés, la fonille est composée on surcomposéc. On observe encore la follation, c'est-à-dire la manière dont la ferille est roulée dans le bourgeon, ou ca sortant de cette enveloppe; clle est plicée, rouléce, en boucle, en spirale, etc.

La disposition des fieurs se nomme fioraison; elles sortent, comme les fenilles, de la racine, de la tige ou des branches. La fleur termine la tige; clle est placée à l'insertion des feuilles on des branches; elle 
est sessile, ou portée sur un. péduncule; évée ou inclinée, elle regarcie le soleil ou la terre. On trouve quelquefois plusieurs fleurs sur un seul péduncule; elles y sont réunies en masse, en boliquet, en grappe, en thyrse, en ombelle, en corymbe; elles forment souvent des verticilles autour de la tige ou les branches; clles sont quelquelois enfermées dans une espèce de sac nembraneux, qu'on nomme spathe..

Les fleurs sont nues ou envionnées de bractées, écailles vertes ou colorées, persistantes ou caduques. Dans les ombellifères, ces écailles sont composées de plusieurs fulioles; cette réunion se nomme involucre ou collercite. Les bales des graminces, qui on: tant de rapport avec le calyce extérieur et le spathe qui enveloppe les liliacóes, sont leurs bractées.

Il ne nous reste plus à considérer que les différentes paries de la fleur elle-même.

Le calyce est une continnaibu de' la stibstance de l'ćcorce de la tioje; pres!jue tous les vérgétanx en sont, pourvus. Son emplisi est d'envelopper, de défendre et lie protéger les organes sexuels; il est placé suus lu pistil, dora la striface supéricure lui sert 
quelquefois d'épiderne. Le calyce survit i la corolle, ou tombe avec elle. Il est simple ou caliculi, c’est-à-üre envolopié d'u autre calyce extéricur plus petir; il est conposé d'une feville plus ou mnins décompée, ou de plusieurs iolioles qui aflectont diflérentes dispusitions. Sa figure est celle d'un tube, d'un ontre, d'un sabot ou d'un ensonnoir; il est plus ou moins ouvert et plus ou moins régulier; il prend aussi des noins différens dans quelques familles : c'est la coeffe des mousses, le volva des champignons, l'écaillé des amentacées. Les fleurs composées sont róunies dans un calyce commmzis.

La corolie enfermée dans le calyce est lenvelopne intérieure des organes de la génération; elle esť le plus souvent colorée : elle manque dans quelifues plantes, mais la plûpart en sont pourvues; elle périt ordinairement après la fécondation. Elle est placée au-dessus, au-dessous ou autour du, pistil, et composéc d'un or de plusieurs foétales: c'est airrsi qu'on nomme ses petites fenilles. La corolle monopétale, celle qui n'en a qu'un, prend la forme l'un entonnoir, d'une souconpe, d'unc clocke, l'un 
D'FISTOIPE NATURELII. masque, selon les divisions de ses bords; celle polypétale est régulière, si ses pétales sont disposés dans un ordre régulier, comme en rose, en croix, en étnilé, en molette d'éperon; elle est irrégulière, si elle est formée de plusieurs pièces bizarrement disposées.

Les pétales sont quelquefois accompagnés d'organes particulicrs, que l'on confond sous le nom de nectaipe, parce qu'ils sont ordi-. nairement remplis d'une liqueur sucrée, nectar dont les abeilles composent leur miel. La forme de ces organes est extrêmement variée : c'est un onglet, une glance, une écaille, une fossette, une soie ou un éperon.

Au milien de la corolle sont les organes régénérateurs, pour lesquels tous les antres semblent avoir été formés.

L'étamine est l'organe unâle du végétal; elle consiste principalement dans une anthère sessile, ou supportée par un flet. Eile s'insc̀re dessus, dessous, autour du siyle ou sur les pétales. Le filet est mince, denté, velu, ćcaillenx, gíndulcux. L'anthèrc est ronde, ovale, oblongue, arquée on forme de fer de fléche, de rein, de croissant, ou accora- 
pagnée d'un appendice. C'éśt mu petit sac at une ou plusieurs loges, qui s'onfre sur les côtés, on à son cxirémité, pour laisser échapyer le pollen, poussiere jaune composée de petites vésicules splériques on ovales qui contiement '́esprit sćminal, et se fiétrissent après l'avoir répandu. Le pollen est la matière de la cire des abeilles.

Les éramines sont quelquefois réuniss par les antheres, quelquefuis par les filets, en un ou plusienrs paquots; ces lilets sont aussi d'une longneur disproportionnée, deux ou quatre étant plas grrands que les antres. Le nombre des étamines varie; il est déterniné depuis un jusqu'a douze; mais au-dessus, le nombre cst indéterminé. Les étamines éprouvent un mourenent convulsif quand on les irrite; flies tombent hieniôt aprds la fécondation; queliuesunes sont surabondartes ou avortent.

Lorgane femelle se nomme le pistil, il est placé au centre de la fleur sur le réceptaxcle, ct composé de truis parties, le germe, situé à la laase qui conserve les embryons des semences, et la substance qui sert d lem nutrition; le stylc, colonne ronde et creuse plus ou moins alongée, termince par le 
seygmate, ourerture à plusieurs divisions, qui reçuit le pollen de l'anthère. L'esprit séminal traversant le style, parvient jusqu'su gerne pour féconder la semence. Les plantes ont sourent plusieurs pistils, comme elles ont plusieur's étamines.

Les quatre dernières parics, que nous venons d'observer, le calyce, la corolle, l'étamine et le pistil, constituent la fleur complète; si une seule manque, elle est incomplète. Ainsi, une fleur n'a souvent qu'un calyce sans corolle, on qu'une corole sáns calyce.

La plûpart des fleurs réunissent les deux sexes; elles sont hormaphrocitiss, d’autre sont unisexizelle.j. Le mâle et la femelle sont séparés; s’ils habitent sur le mềne indivilu, on les nomme monciques; elles sont dioiques quand leui babiation 'est distincte.' Zuelques plantes sont polygames et réunissent des fleurs in $\hat{u} l e s$, des fleurs femelles et des fleurs hermaphodites. 'On nounme cryptogames les plantes dans lesquelles les organes sexuels somt tellement cachés, que leir fécondation est, pour tous les yeux, un profond in ystère.

Les étanines et le pistil se changent 
quelruefois en pétales, ce qui donne naissance aux flents donbles. Les fleurs sont prolifires, guand du centre de leur corolle on voit s'élever une autre fleur absolument semblable à elles; ces monstricosités sont produites par la nature du sol, par les engrais ou par quelrun'accident.

Le fruit est composé d'un péricarpe, (espèce d'enveloppe qui prend différens noms;) il renferme la semence, qui est rarcment nue; il est inférienr on supurrienr à la corolle; sa foŕme est osale, sphérique, tronquée, pyramidule, conoide, angulezse, orbiculaire, vésiculense, aîlée, articulée, etc.; sa superficie lisse, sinuense, strite, sillonnée, velue, cotonincuse, hérissée, hispirle, śpineuse, etc.; sa substance chamue, mentraneuse, coriace, osseuse, pulpeuse, succulente; il est sans division, ou bien il s'ouvre à son sommet, à sa base, sur les côtés, et transversalement comme une boîte, ou latéralement au moyen de ualves plus ou moins nombreuses, et souvent élastiques; son intérieur est simple et composé de plusieurs loges séparécs par des cloisons, et appuyćcs sur un axe commun. Le nombre des semences varie; ce 
quí rend le fruit monosperme, disperne, polysperme, selon qu'il en a une, deux ou plusieurs : c'est sur cés différences que sont établies les caractères des fruits. La capszzle est une boîte membraneuse et crustacée ; la silique, une capsule à deux valves, dont les sutures opposées portent les semences. La gousse ressemble à la silique; mais les semences ne sont attachées qu'ì une seule suture. La noix est osseuse; la baie succulente, charnue, pulperse et pleine de semences distinctes; la pomme chamme et solide défend la semence; le broz en veloppe la noix. Le cone est un assemblage de petites semences et d'écailles : l'involucre floral se remplit quelqueforis d'un suc qui le fait gontler et lui donne l'apparence d'm firuit.

La semence, œuf du végétal, qui contient la plante stuture, en abrégé, est nue ou renfermée dans un fruit; elle est alors sessile ou atiachée à un filet ombilical, ou parseinée dans la pulpe; elle diffère aussi dans sa forme ronde, ovale, elliptique, par sa couleur ronge, jaune, blanche, noire; elle est quelquefois converte de deux tuniques propres, dont l'extéri.ure, nembraneuse, curiace, carlilagineuse ou calleuse, est 
garmie d'une cile nu d'une aingrtio. Ia

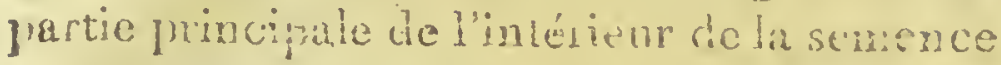
est la plentulé, connoséc de la pluxinle et de la radicule. Cette planula est le point wital, elle est placée, conme le point sraillant de l'uuf l'est dans lo placenta, au milieu des cotyledons qui épmernt Ja nourriture donnée al l'embryon; Ceite nourriture passe par la cicatrice, petile fósse extéricure, qui subsiste an licu où la semence étoit attachée au fruit.

Les cotyledons qui emboittent la plantule Ia nourrissent des sucs qu'ils absorbent, jusqu'à ce qu'elle puisse prendre elle-même sa nourriture. Quelques plantes n'ont joint de cotyledons; d'autres n'en ont qu'un; le plus grand nombre en a deux.

Ia radicule sort quelquefois hors des lobes; d'autres fois elle est repliée entr'enx, et la plantule est dans le périsperme, corps spais, farineux, charnu, corné ou ligricux, qui l'enveloppe totalement ou en partic.

A ces organes principaux des plantes, nous en pouvons ajouter encore quelquesautres moins importans : les, bractécs, qui sonitennent les flemrs; les stipules, sur lesquelles les feuilles s'appuyent; les ćpires, 


\section{D'HISTOR FATERIE.}

les aigzillons, qui en défendent l'approche; les bourgeons, dans lesquels les feuilles ou les flcurs sont roulées; les vrilles, au moyen desquelles quelq'ses végétaux grimpent sur les corps environnans ; les poils, les glandes, qui sont regardés comme les organes propres A la secrétion des sucs, colorés, laiteux, jaunes, sanguins, etc.

Actuellement que nous connoissons les organes des végétaux, il nous sera plus facile de comprendre leurs fonctions.

Les végétaux sont composés de parties très-simples et similaires, appelées fubres et utricules. Ces parties réunies en un tissu utriculaire forment des membranes, des vaisseaux remplis d'un suc nourricier, des sucs propres à la plante, et gonflés d'air. Ces différens tissus produisent la moelle qui occupe le centre, le bois qui l'entoure, et l'écorce qui enveloppe le tout. Enfin, de ces parties sortent les organes destinés à entretenir la vie de la plante, la racine, la tige, les feuilles, et ceux consacrés à la reproduction de l'espèce, la fleur et le fruit; 1 . réunion de tous ces organes constitue lo végétal.

Le centre de la tige et de la racine est E 
occupé par la moelle, substance tout-à-fait utriculaire; elle est recouverte de couches derbois, formées d'un tissu de fibres et de vaisseaux particuliers et parallèles. Sa substance est succulente et humide dans la racine, membraneuse dans les tiges herbacées, seche et raboteuse dans les arbies.

Les sucs préparés dans la terre, dépouillés de leurs parties les plus grossic̀res, sont pompés avidement par les racines. Les vaisseaux de la tige les élèvent. Les jeunes plantes en contiennent plus que les vicilles, parce que les vaisseaux devenant plus solides avec l'âge, leur diamètre diminue. La partie de la séve chariée entre le bois et l'écorce, forme l'aubier et le liber, membranes internes de l'écorce. Le suc sévcux est sans odeur ct sans saveur; il se sépare lui-même en différens sucs miclleux, sommeux, résineux, âcres, qui sortent par les poils, les glandes, etc. C'est ainsi que la circulation et la mutrition s'opèrent dans les végétaux.

On remarque aussi dans les végétaux me fonction semblablè à celle de la respiration; ils absorbent différens principes contenus dans l'atmosphère. Les fluides élastiques 


\section{d'Histota Natuitis.}

sont portés dans tous leurs organes par des trachées. Dans les feuilles échauffées par les rayons du soleil, l'eau dont elles sont pénétrées se décompose, et elles laissent échapper l'air vital. Si l'ombre succède à la lumière, elles ne donnent plus que de l'acide carbonique, gaz délétere et meurtrier.

Ces diverses fonctions suffisent pour entretenir la vie du végétal, les autres on: pour but la reproduction de l'espèce. Cette reproduction s'opère de plusieurs manières: par l'insertion des rejettons dans la terre, par le développement des bourgeons dans lesquels les feuilles et les fleurs sont roulées; par la greffe, en insérant un rameau d'un arbre dans une fente faite sur le tronc d'un autre; par les cayeux des oignons, et principalenient par l'union des sexes.

Le phénomène de la génération des plantes est infiniment curieux; nous en avons déjà pris une idée, en traitant des organes qui lui sont nécessaires; ces mariages singuliers ont été l'objet d'une foule d'observations.

I e calyce est la continuation de l'écorce; la corolle, celle du liber; les étamines environnent le pistil; le filet s'incline et ap- 


$$
\text { Is I, 定 M IE N S }
$$

proche du slygmate; l'antlière qui se rompt y verse le pollen clont elle est remplie; l'esprit séminal, sortant des globules qui composent le pollen, traverse le pistil et descend jusque dans le germe; le fruit gonfle, grossit, mûrit, sc sèche, s'ouvre et laisse tomber les semences.

L'imitabilité des végétaux est prourée par les mouvernens de leurs étanines, et celui des feuilles de quelques espèces, quand on les irrite par un stimulant quelconque; mais ils ne peuvent changer de place is volonté, et c'est ce qui les distingue particulièrement des animaux.

Les végétaux annoncent une sorte de sensibilité, et cherchent la lumière et le soleil.

Lorsque ces fonctions se trouvent interrompues par l'altération d'un des organes dont elles dépendent, le végétal tombe dans un état de maladie; et si toutes cessent, il meurt.

Chaque végétal a une manière d'exister propre, et pour ainsi dire, des mours particulières.

Ils habitent des climats différens; tous affectent un sol particulier; mais ils forment 
quelquefois des émigrations, les Colonies.Les vents emportent leurs semences âlées ou aigrettées; les flots les poussent sur un rivage opposé ; les oiseaux les laissent échapper dans leur vol avec leurs excrémens, les placent dans les lieux convenables à leur développement, et leur. font franchir les bornes que les mers et les montagnes sembloient leur aroir prescrites.

Les amours des plantes ont été le sujet de plusieurs poèmes et de quelques ouvrages ingénieux. Le mâle et la f'emelle, le plus souvent unis, habitent non-seulement la. même plante, mais même ne quittent pas le lit nuptial ; quelquefois séparćs ,"ils ont une habitation absolument distincte. Tous les végétéux ne donnent pas un exemple aussi moral; le mêrne réceptacle réunit quelquefois les épouses légitimes et des épouses illégritimes, qui viennient dérober à I'hymỏn quelques-unes de ses caresses.

Toutes les plantes ne se reproduisent pas chaque année par les semences : plusieurs sulusistcnt deux ans; les arbres vivent un grand nombre d'années; ils perdent, en autornne, leurs feuilles, lcurs fleurs et leurs fruits; mais le ruciinent de ces organcs 
hyberne et demeure, pendant l'hiver, enfermé dans une espèce de bourse appelée bourgeon, où il est à l'abri du froid. La manière dont les feuilles y sont pliées ou roulées, s'appelle foliation. Aux premiers jours du printemps, ces bourses s'ouvrent, Jes feuilles se déroulent et sortent de leur enveloppe.

Les couleurs des végétaux sont extrêmement variées; elles peuvent aussi changer par différentes circonstances.

A des époques fixes et constantes, les plantes germent, les feuilles sortent des bourgeons, se déployent et tombent; les fleurs montrent leurs belles corolles, et produisent des fruits succulens. L'observation de ces époques sert à calculer l'année ruvale, et à rédiger le calendrier de Flore.

L'horloge de Flore est réglée sur l'heure déterminée, à laquelle les plantes s'ourrent ou s'éveillent, et se tournent vers le soleil, qui les échauffe, ou bien celle à laquelle elles se ferment et paroissent s'endormir.

L'art chymique sait décomposer lcs principes des végétaux, et en retirer différens produits. On obtient l'extrait en rapprochant les sucs par la cuisson; les sels essenticls, 
sels que le nitre, la soude, la potasse, et plusieurs sels particuliers, en lessivant les plantes et en faisant crystalliser ces lessives. Le mucilage se trouve dans plusieurs racines fades et douces, dans les jeunes tiges, dans les feuilles nouvelles, autour d'un grand nombre de senences; c'est une substance fade, blanche, visqueuse et collante, quelquefois sèche et cassante. Dans ce dernier ćtat, on l'appelle gomme; tels sont les sucs qui découlent de plusieurs de nos arbres, le prunier, l'abricotier, etc.

Le sucre est un principe végétal trèsabondant. Outre le roseau qu'on cultive dans nos Colonies, le corps sucré se trouve dans beancoup de racines, de tiges, de fleurs et de fruits. Il ne diffère du mucilage que par sa saveur et par la propriété de fermenter et de former de l'alcohol.

L'huile fixe se retire par expression; c'est un suc plus ou moins épais, peu coloré, onctueux, immiscible à l'ean ; qui s'allume quand on le chauffe, jusqu'au point de se volatiliser; toutes les semences des. végćtaux en conticnnent une plus ou moins grande quantité. Si cctte huile est nıêlée avec 
un mucilage, ce dernier la rend susceptible d'être suspendue dans l'eau : telle est la nature des émulsions, des laits d'amande. On appelle huiles siccatives, celles qui se dessèchent à l'air; les autres se nomment huiles grasses.

L'huile essentielle est volatile, âcre et odorante; elle est placée dans la racine, la tige, l'écorce, les feuilles, le calyce des fleurs, les enveloppes des fruits et des semences, et jamais dans l'intérieur de ces dernières parties. On l'extrait par la disiillation et par l'expression; cette huile brûle avec une extrême facilité; c'est pour cela qu'on cnduit d'une huile essentielle les mêches des lampions, pour les allumer. Les parfumeurs donnent le nom d'essences aux huiles rolatiles, et ils les combinent a'vec l'alcohol, les pâtes, les pomades, pour l'usage de la toilette.

L'arome est un principe très-tenu et trèsléger, qui se dégage des végétaux odorans. On l'obrient en les distillant à une chaleur' douce, et on le condense dans l'ear. C'est ce principe qui, en s'exhalant des substances qui en sont chargées, et que pour cette raison on nomme aromatiques, cmbaume et parfume l'air. 
d'Histotre Naturate.

La résine est lo produit de l'huile volatile, épaissie dans les cellules des végétaux; elle est ordinairement seche, cassante, fusible à un certain degré cie chaleur, plus ou moins colorée, depuis le jaune jusqu'au brun, inflammable, insoluble dans l'eau, soluble dans les huiles ct dans l'alcohol. Elle découle de plusieurs végétaux. Quelquefois la résine se combine avec un sel essentiel, et forme les baumzes. La résine unie aur extraits donne ces sucs blancs et jaunes que l'on voit soriir de quelques végétaux en les brisant ; ces sucs épaissis se nomment improprement gommes résines:

L'amidon s'extrait de la farine du froment, mais il existc aussi clans presque tous les végétaux, et sur-tout dans les racines tubéreuses et fraîches; on les' brise par la rape et par le pilon; on les délaye dans l'eau, qui entraîne une poudre très-fine et très-blanche : c'est la fécule ou l'amidon. L'eau bouillante le clissout aisément et en forms une gelée transparentc ou opaque, si l'eau contient plus de fécule qu'elle n'en peut dissoudre. C'est à ceitc union de l'cau et de la fécule, qui cxiste en plus ou mains grande quantité dans nos plantes alimen- 
$74 \quad E$ LE II E N S

taires, qu'est dae la qualité nutritive des végétaux.

Le gluten se sépare de l'amidon par le lavage; il est mou, flexible, ductile, élastique, d'un gris blane, très-tenace, adhérent aux matières sèches et indissolubles dans l'eau. Sa conformité avec la matière animale la fait nommer substance végétoanimale.

La matidre colorante des végétaux est encore un de leurs principes; elle est soluble dans l'eau chaude, se dépose par le refroidissement, et se précipite par les acidès.

Le charbon nécessaire à notre usage s'obtient on brûlant des branches entassées sous des mottes de terre; mais le charbon, tel que nous le considérons ici, existe tout formé dans la nature ; c'est un des principes des végétaux; on ne fait que le séparer des plantes qu'on distille. Le charbon des bois qu'on brûle n'est pas pur : il contient des sels et de la terre. On appelle carbone, la matière charbonneuse pure et séparée de substances étrangères qui l'altèrent dans le charbon commun.

En ajoutant l'cau à ces principes, nous 


\section{I) Hustoirs Naturele. $7^{5}$}

connoîtrons tous ceux comnus dans les végétaux. L'analyse chymique se réduit à les séparer exactement, à les obtenir isolés, à déterminer leur quantité relative, et à en apprécier les modifications.

L'emploi des plantes, dans l'économie générale de la nature, est de parer la terre, qui sans ce tapis émaillé et verdoyant, ne nous offriroit qu'une masse nue et aride, et dé servir à la nourriture de tous les animaux.

Leurs usages particuliers sont extrêmement nombreux; les unes servent pour la nourriture des bestiaux; d'autres sont nos alimens les plus ordinaires, nos remèdes les plus sûrs, ceux dunt la préparation est la plus facile et la moins coûteuse ; elles nous fournissent des instrumens aratoires, des ustenciles domestiques; nous en contruisons des maisons fixées sur la terre, ou des bâtimens qui voguent sur les flots; quelques-unes se filent, d'autres clonnent les coulcurs nécessaires à la teinture.

Urie si grande utilité, l'agrément infini que la botanique procure, ont engagé depuis long-temps des hommes éclairés à se livrer à son étude. Ils ont décrit les p!antes de leur pays, ou entrepris des voyages pé- 
76 É L É M E N S

rilleux pour aller chercher celles des contrées lointaines, afin de faciliter les moyens d'observer les plantes. On les a rassemblé vivantes dans des jardins, ou conservées sèches dians des herbiers.

Les travaux des botanistes ont porté le nombre eles plantes décrites à plus de vingtcing mille; ils ont imaginé différentes méthodes pour les classer; elles sont établies sur la forme des feuilles, sur celle du calyce, du fruit ou de la corolle, sur le nombre et la situation des organes sexuels. Nous avons adopté celle que l'on nomme méthode naturelle, parce qu'clle suit de plus près la marche que la nature paroît avoir adoptée pour la formation des végétaux. 


\section{CLASSES DES VÉGETAUX.}

I. Sans cotyledons.

$$
\text { * Un cotyledon: }
$$

II. Etamines sous le pistil.

III. Etanines autour du pistil.

IV. Etamines sur le pistil.

$$
\begin{gathered}
\text { * Deux cotyledons. } \\
+ \text { Sans pétales. }
\end{gathered}
$$

V. Etamines sur le pistil.

VI. Etamines autour du pistil.

VII. Etamines sous le pistil.

$$
+\rightarrow U_{12} \text { senl pétale. }
$$

VIII. Corolle sous le pistil. IX. Corolle autour du pistil. $\mathrm{X}$. Corolle sur le pistil. Anthères réunies. XI. Corolle sur le pistil. Anthères séparées.

$+\rightarrow+$ Plusieurs pétales:

XII. Etamincs sur le pistil.

XIII. Etamines sous le pistil.

XiV. Etamines autour du pistil.

+-++ Sexcs distincts.

XV. Etamines séparćes du pistil. - 


\section{PLANTES SANS COTYLEDONS.}

LEs plantes de cette classe n'ont point de cotyledons. On les nomme, dans la méthode sexuelle, cryptogames, parce que les organes de la génération ne sont point visibles d̀ l'œil nu, et qu'elles semblent faire un mystère de leurs amours.

\section{* Les champignons.}

LA fructification de ces cryptogames a été pendant long-temps inconnue, et ce n'estque depuis peu qu'on est parvenu à déterminer, à l'aide du inicroscope, leurs organes sexuels, dont la position constitue différens genres.

1. La trufres est noirâtre et ronde, sans racine, granulée, veinée et odorante. Ses semences sont placées entre les mailles réticulées de sa substance charnue. Ce végétal est toujours caché dans le sein de la terre; les insectes et les cochons, qui en sont avides, le font découvrir; c'est un mets délicat, mais mal sain et échauffant.

2. Le mucor est cette substance filamenteuse qu'on observe sur la crô̂te de pâté, 
les confitures, le pain qui ont été gardés quelque temps; on la nomme vulgairement moisissure.

3. LE LYCOPERDE BOVISTE, vulgairement appelé vesse-loup, est globuleux et rempli d'abord d'une chair ferme, qui se convertit en une poussière formée par une infinité de petites semences. Le sommet du lycoperde s'ouvrequand le végétal est mûr, pour laisser échapper cette poussière. Cette poudre arrête les hémorragies.

4. La clayaire corallotde ressemble en effet à un amas de coraux; on la trouve dans les bois; elle se mange.

5. La mortlle comestible est creusée en petites cellules très-profondes, d'où sortent les semences; on la mange fraîche ou séchée.

6. Le bolet 'Amadouvien' est garni de tubes qui renferment les semences; c'est un purgatif violent. Sa substance lavée, macérée, séchée, rapprochée sous le marteau, arrête le sang des blessures; en y ajoutant de la poudre à canon, elle devient l'amadou, dont l'usage est si connu.

7. L'agaric contestible, composé de lames roses, où les semences sont placées, 
est celui qui entre communément dans nos ragoûts, et qu'on fait venir sur couche.

8. Le mousseron est une espèce d'agaric, dont la substance est plus sèche, et qui peut se garder pendant l'hiver.

$$
\text { * Les algues. }
$$

Ces plantes sont filamenteuses ou gélatineuses; quelques-unes sont herbacées.

+ Filamenteuses ou gélatineuses.

9. La tremelte est une substance gélatineuse et cartilagineuse, verte ou orangée, qui disparoît presque dans les temps secs, pour reparoître à l'lumidité.

10. Les conter ves sont ces filets qui nagent sur les eaux et les verdissent.

\section{+ + Membraneuses.}

1i. Les fucus ont leur fructification dans des vésicules; tous se tromvent dans la mer, et servent ì la nourriture des animaux qui l'habitent; on les brûle pour en retirer la soude; on les appelle vulgairement varecs. 


\section{$+\rightarrow+$ Coriaces. Lichens.}

CEs cryptogauzes sont des expansions. végétales qui se présentent sous difiérenies formes, de lèpre, de godet, de membrane, de raneaux, de filfts, etc. Ils habitent par-tout, nôme sur les suistances lés plus lisses et les plus dures; c'est principalement en hiver qu'on les trouve; les a bies en sont alors tapissés. Vivans, ils les défendent contre la rignenr du fruid; morts, ils hâtent leur destruction. Iis sont le fondement de toute végétation, en s'attachant aux rochers. ou aucune auire plante ne pourroit crcîtré, et en y formant une terre qui s'accumule et devient propre à nourrir des forêts. Leurs usagres prarticuliers sont très-nombreux. Plu* sieurs espèces réduites en poudre entrent dans la fabrication d'un pain qui. sontient l'existence des malheureux habitans du nord.

22. LC LICIREN PUIMONAIRE est en grandrs lames; il est utile contre les maladies du ponnon; et sa substance est si coriace, qu'on cn fait des semelles de souliers.

13. L'OBSEILLE. OH confond SOUS Cenom 
plusieurs espèces de lichens qui, macérés avec de l'urine et réduits on une pâte fournissent à la teinture des couleurs jaunes. violettes, bleues, rouges ou noires.

$$
\text { * * Hépatiques. }
$$

Petite plante singulic̀re, herbacéc, terrestre. Voici la plus remarquable.

14. La mancriant. Elle crôit entre les parés humides où elle forme des espèces de parasols et an-dessous des petits godets verlâtues; clle est utile daus los maladies du foie.

$$
\text { **** Mousscs. }
$$

Ces petites plantes sont tonjours vertes, principalement pendant l'hiver; leur tige mince porte une urne coëfée on découverte; celle uric renferme le pistil, le germe et les semences qui s'échappent en une poussière très-tenue. Les mousses tapissent la terre dans le temps oì elle sernit dépovillée, elles rendent solides les marais fangeux dont elles élèvent le fond en le chargeant en terreau, elles empêclient la putréfaction des eaux; les oisenux $\in \mathbb{n}$ garnissent leur 
D'Historre Naturzut: 83 niil, elles servent à conserver les plantes, à envelopper les fruits, pour emballer et calfeutrer; elles ont aussi une foule d'usages particuliers.

15. Le DOLYTRIC commun sert à fáre des tapis, des couvertures; l'écureuil en garnit sa demeure sphérique, plusieurs oiseaux y déposent leur nid.

16. Le I Y COP ODE commun fait de bons tapis pour essuyer Jes pieds.

17. Le I ICODODE en masse donne une poussière jaune, abondante, qui produit une flamme vive sans détonner, sans danger. On s'en sert pour les feux de spectacle. Les apothicaires y roulent leurs pillules.

18. Le SPIIAIGN DES MARAIs converut bientôt les lieux les plus fỉngeux en des prés solides, on en fait des langes qui échaufient les enfans et absorbent leur urine.

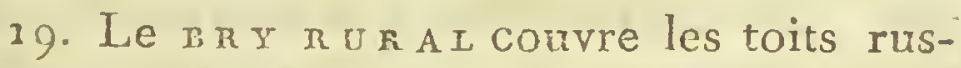
tigues et les défend de la pluie dont il facilite l'écóulement.

20. Le FONTINAI, ANTIPYRÉTIQZUE résiste long-temjs au feu ct préserve de l'incendie les murs et les chambres quil tapisse. 


$$
\begin{aligned}
& \text { EL立MEN } \\
& \text { ***** Fougdres. }
\end{aligned}
$$

Cescryptogames ont les parties de la fructification terminales ou sur les feuilles.

21. La pлевц. Sa fructification forme un épi terminal, ses feuilles sont verticillées, sa tige raboteuse sert à polir le bois et à écurer la vaissclle; on la trouve dans les prés.

22. Les capiluaires. On confond sous ce nom trois à quatre espèces de fougères dont la fructification est à la partie inférieure des feuilles; on en fait un sirop pectoral.

23. La FTERIs Aquiline est l'espèce qu'on appelle particulièrement fougèere; elle formé des tiges très-rameuses. On la trouve dans les bois. Sa racine peut servir à faire du pain; ses tiges se brûlent et font une bonne litière; on peut s'en chaufer, quand elle est sèche; paîtrie dans l'eau et mise en bonle, elle se substitue au savon. Sa cendre alkaline est utile dans l'art de la verrerie. 


\section{PLANTES A UN SEUL COTYLEDON.}

ETAMINES SOUS LE PISTIL.

PAR MI les familles que contient cette classe; nous ne citerons que les graminées.

Les graminées sont extrêmement nombreuses et ne peuvent trop se multiplier. Leur floraison diffère de celle des autres flantes; leur tige mince, creuse et légère, souvent articulće, se nomme chaume. L'épi qui la termine est formé de plusieurs petites fleurs ordinairement à trois étamines et à deux pistils. Leur corolle et leur calyce sont composés de deux battans qu'on nomme balles. Lesfenilles simples, !ongues, étroites; embrassent la tige à leur base; aux fleurs succèdent des semences qu'on appelle grains et dont la forme varie.

On nomme cérécales les graminées qui servent à faire du pain, parce que les poètes les ont regardées comme un présent de Céres. Après que la terre a été retournée et próparée par différens Jabours, on y sème fles céréales, on brise les mottes avec la herse, on les écrase avec le roulcau. Dans les pre- 


\section{6}

miters jomrs de messictor, la belle couleur de leurs épis dorés annonce leur maturité. Les moissonneurs les scient avéc la funcille, les mettent en botic's attachées avec des liens de prille, los amoncèlent en meules; ou les portent dans les granges. On y prépare une aire assez vasie, les bottes dóliées y sont batues, le ficau force le grain d sortir des bâles, le van le sépare de la poussière et des bàles yui y sont inĉlés, le crible le dégage des ordures plurs pesantes, on le porte au grenier, oì on a soin de le garantir de l'humidité et de la piqûre desirisectes.

A mesure que le besoin l'exige, on le livre au méñier qui l'ćcrase sous la menle du moulin. Le bluteau sépare l'épiderno de la farine. Cet épiderme appellé son sert à la nourriture des bestiaux.

Lia farine est le parenchyme, la clsair da grain. Pour faire du pain, le boulan er la détrenupe avec cle l'eau, et la paîtrit a les mains et les pieds; on y ajoute un peu de páte formentée nommée levain. Le pain façonzé eṣt porté au four, où il reçuit le degré de cuisson converable. Le gluicu agron sépare de la faine par le lavage est le pro. 

duit de la plantule, c'est sa partie nutritive. La fécule qui se précipite dans cette opération se nomme amidon, on la blanchit en la faisant séjourner dans un acile; c'est la pondre que l'on met sur les chereux.

Outre ces propriétés les céréales ont encore d'antres usages; leur chaume fait de la litière qui se convertit en fumier; il sert à couvrir les toits rustiques, à tresser des paillassons, des nattes; il prend bien la teinture; on en fait des tabatières en placage et des broderies. La paille brûlée est un cxcellent engrais. Les bâles boûrent des oreillers et des couchettes; les grains ferrrentés, fournissent des liqueurs enivrantes. Leur farine donne de la colle.

1. Le froment est la première et la plis importante des céréales; ses longues tiges portent des épis dont les grains ovales suntémoussésà leur extrémité, convexcs d'un côté et sillonnés de l'autre. La consommatiọn annuclle qu'un homme en peut faire est le produit de deux déciares et de six journécs de travail. Cette graminée rampante qu'on appelle chiendent est une espèce de froment, il ne peut servir qu'à purger les chiens et à faire des tisannes. Les habitans

$$
\text { E } 4
$$


du Nord en préparent cependant du pain, mais avec la fécule de ses racines.

2. Le Sn I G J E se cultive dams les terres sablonneuses et légères. Ses éfis sont barbnıs et plus longs que ceux du froment, ils contiemneut des grains oblongs et presque cylindriques. On cn fait du pain très-bon, sur-tnut quand il est mêlé avec du froment. Le pain d'spice est un mélange de seigle, d'orge et de miel. Quelynes personnes sub. stiment au caffé du seigle rôli el monh. On sème souvent dans une même terre du seiglc et du froment, ce mélange se nomme méteit. On ne sème quelquefivis le scigle que pour lo faucher en verd et faire des prairies artificielles, c'est une excellente pầture pour les bestiaux.

3. L'ongr porte des épis garnis d'une longue barbe; sa farine, en la mêlant à celle du froment, fait un assez bon pain. Son grain est utile pour engraisser la rolaille. Déponillé de sa peau, c’est l'urge mondé, on perlé, si on le prive aussi de ses extrémités. Ce grain est la base dn sncre d'orge et de l'orgeat. Il sert puncipalement à faire de la bicre. Le brasseur, apres l'avoir laissé tremper pour l'amollir, le laisse 


\section{D'HISTOIRE NTATUELI. E. 89}

germer pour développer le corps sucré. On le réduit cnsuite en line farine nommée Inali, on lá délaye dans de l'eau que l'on met fermenter arec du houblon, et on l'enfernıc dans les tonneaux. L'écume qui s'élève pendant la fermentation secondaire qui s'y excite, se nomme levure, et sert à de nouvelles préparations.

Les graminées, qui suivent, n’appartiennent plus aux céréales, on en fait diffcilement du pain sans y ájouter beaucoup de froment; leurs grains ne se mangent qu'en galettes et en bouilies, ils-procurent aux bestiaux et aux oiseaux de basse-cour une excellente nouriture.

4. Le I A $N$ I s contient de petits grains ronds dont les oiseaux sont fort friands.

5. Le MrLit ressemble beaucoup au panis, sa furine est très-nourrissante.

6. Le nis ressemble beaucoup au froment, mais il est plus grand et plus fort; son grain est blanc et transparent, il croît dans les lieux aquatiques et inondés; c'est la nourriture des peuples de l'Orient; nous en faisons aussi un grand usage.

7. Le a äis pousse de fortes liges ct de 
Jongs ép:s, dont les grains jaunes, romges ou violets sont gros comme des pois. Sa rigo contienc in suc dont on peat faire un syrop très-cloux. Cuand elle est sèche, on en tisse des paniers. Les grains verds se mangent de plusicurs manières; scos. ils sout bons pour engraisser la volaille et les cochons; réchits en farine, on en fait des bouillies, des pâtisseries..... etc.

8. L'A forne a un épi lâche quiflotte au gré des vents. C'est principalement pour l'usage des bestianx qu'on la cultive. On pent aussi er faire du pain. Le grain dépouillé de son enveloppe se nomme grmaz. On en prépare des bouillies et des buissons rafraichissantes.

9. L'I $\mathrm{AIE}$ a le grain rougeâtre et plus menu que celui du froment avec lequel on le trouve trop souvent mêlé. Il a une qualité enivsante, on le donne à la volaille.

La graminée, qui va suivre, n’a aucun ripport avec les piécédentes, son produit est lams sa tige et non pas clans son main.

то. La $C I N N E$ a $S U C$ a $E$ a ses hâles veInes ext vieurement et ses fleurs en panicules. Eile crổi maturdlement dans les lides. On la cultive dans les colonies, on rejeste seg 
feuilles; mais les tiges ou cannes, écrasées sous le moulin, donnent un suc appellé vesou. Apzès l'avoir fait bouillir dans des chaudières avec de la cendre et de la chaux, on l'écume et il porte le nom de syrop; on le fait cuire encore avec de la cendre et de l'alun, et on le met dans des tonneaux oi il se prend en masses solides appellées moscovade. On le rafine en le faieant cuire avec du sang de bouf qui le clarific, et en le mettant dans des cônes de terre renversós, dont le sommet est percé et dont la base est remplie d'une argille humectée; l'eau en traversant tous les intervalles emporte les impuretés. On casse ensuite les pains en morceaux qu'on nomms sucre terré, cassonade. Cette matière est traitée de la même manière dans les rafineries d'Europe, et on obtient le beà sucre rafuné, le sucre blanc. La liqueur qui n’a pas pu crystalliser est la mélasse. Les usages du sucre en médecine et dans la préraration des alimens sont suffisamment connus.

Les graminées suivarites se trouvent dans les prés, et mêlóes aux plantes lógumineuses, elies composent le foin dont les 
bestiaux se nourrissent; elles forment ce gazon verdoyant dont la terre est tapissée. Plusieurs ont aussi des usages particuliers.

11. La b R ussì丶 a a des racines longnes et fortes, qu'on employe pour faire ces brosses, anxquelles on donne faussement le nom de brosses de chiendent.

12. Le so UC म $\mathrm{T}$ a ordinairement la tige triangulaire, c'est avec une espèce qui croîr en Egypte que les ancicns faisoient leur papier.

13. Le scyrps, dont la tige est forte et triangulaire, est bon pour couvrir les maisons.

14. L'Éntophone ou chenzelle dont les semences sont entourées de long poils, sert à ouater des habits et des coussins.

\section{PLANTES A UN SEUL COTYLEDON.}

\section{ETAMINES AUTOUR DU PISTIL:}

\section{* Palmiers.}

Ces arbres sont ordinairement élevés, leur tronc est formé d'écailles superposées, ils sont tous exotiques.

1. Le rotANG produit ces petites ba- 


\section{d'Histotre Natureite.}

guettes souples et légères dont on fait des tissus pour les chaises, et qui servent à battre les habits.

2. Le DatTIER porte des fruits délicats dont le noyau est long et silloné.

3. Le cocotirn donne un fruit trèsgros, dont la noix sert à faire des coupes et des vases.

4. L'AR LUE fournit un 'extrait, qui, rendu solide par l'évaporation, s'appelle $c a-$ chou.

$$
\text { * Joncs. }
$$

Cette famille est très-nombreuse, plusieurs des espèces qu'elle renferme ont des épis qui les rapprochent des graminées ; mais leur-fructification est diflérente, puisqu'elles ont six étamines et un pisil, d'autres ont des fleurs à pluvieurs pétales et très épanouies, qui ressemblent beaucoup à celles des liliacées.

5. Le jo s c. Ce genre contient plusieurs espèces qui servent à faire des paniers, des clayon et des onvrages de petite vanerie. Les fleurs des joncs sont réunies en tête ou sortent latíralement de la tige.

6. Le витомi a le calyce coloré, et 


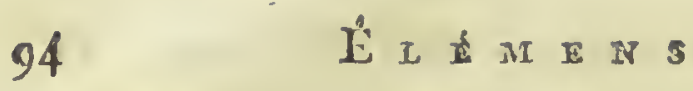

les fleurs en ombelle, c'est l'ornement des jrés humides et des ruisseaux.

7. La Fú́chìñ ressemble beaucoup au butome, mais ses fleurs sont blanches et point en ombelle. Ses feuilles ont la forme d'un fer de flèche, elle habite aussi les ruisseaux.

8. Le corchiqun a beancoup de ressemblance aycc le safran. Les prés sont parsemés en antomne de ses fleurs violettes, c'est un poison pour les hommes et pour les bestianx, excepté pour le cheral; on est cejendant parvenu à en préparer un remède coutre l'hydropisie.

Les plantes suivantes appartiennent à des familles yui ont plus ou moins de rapport avec le lis.

乌. La TUIIP a le ventre plus large que l'ouverture. Sesíeuilles calycinalessont nuancées de lifférentes couleurs, ce qui forme un grand nombre de variétés.

10. Le Lis est plus grand que la tulipe, ses fleurs sont blanches et ont une odevr forte.

11. L'A NANAS porte un fruit jaune, surmonté d'une touffe de feuilles; cette plante, 


\section{Histotre Naturete.}

originaire de l'Inde, ne peut s'élever que dans les serres.

12. L'A I O ̇̇s pousse des f'eriile's charnueset épineuses; on en reire une gomme résine utile en méllecine.

13. L'h yacintue est une fleur printanière dont plusieurs espèces se trouvent dans nos bois. A ses fleurs, ordinairement violettes, succèdent des fruits triangulaires et charnus. L'espèce 'que l'on cultive dans nos jardins et dans nos appartemens, pour sa douce odeur, est l'hya i:the orientale.

14. Liar a los fleurs en omlielle. L'oignon, le poreau, la civette, la ciboule, l'échalotte, sont des espièces de ce genre, toutes servent \& la préparation des alimens. L'ail est un préscrvacif contre la peste, c'est le principal ingrédient du vinnigre des quatre voleurs.

15. L'merimucatiz ressemble beaucoup au lis, mais sa couleur est safranće, elle ne dure gu'un jour.

16. Le NARCISSE est une plante bulbeuse. Le linhe de la corolle est ouvert, l'entrée du calyce est garnie d'un rebord coloré. Celui yui croît dans nos prés est blanc et se numme narcisse des poetes. La jonquille, d'un si bcau jaune et d'une odcur 
si suave, est une espdce de narcisse. La plus belle espèce de narcisse est celle qu'on cultive dans les parteries et qu'on nomme narcisse de Constantinople.

17. La perce-Neice nous offre ses fleurs hlanches, malgré le froid de l'hyver et les neiges qui l'accompagnent.

18. L'in is se fait aisément remarquer par les" six divisions cle sa corolle, dont trois sont droites et trois réfléchies. L'iris germanique est violette, sa racine a une odeur douce. L'iris janne borde les ruisseaux.

19. Le safran ressemble beaucoup au colchique. Ses stygmates contiement une substance jaune, dont on fait un grand usage pour la préparation de différens alimens et qui donne une couleur bonne pour laver les plans. On le cultive en grand pour son utilité, et dans les parterres pour l'agrément.

20. LASPEG porte sur une tige ronde et très-ramease une multitude de petites fenilles verticillées. Ses fleurs en grelot sont remplacées par des baies sphériques. On mange ses jeunes pousses.

21. Le MUGÜt a anssi ses fleurs en grelot, mais blanches et odorantes. Ses feuilles sont larges et ovales, on en fait des bouquets. 
D'HISTORE NATURELE.

quets. On trouve dans les bois une espèce de ce genre appellée grenouillet, dont les jeunes pousses se mangent comme celles de l'asperge.

22. Le F in A ON porte ses fleurs au milieu de ses fenilles qui sont très-piquantes. Ses jeunes pousses se mangent comine lea précédentes. Il devient bientôt liogneux et pliant, on en fait des balais, on couvre les viandes arec ses feuilles pour les défendre de la voracité des animaux.

\section{PLANTES A UN SEUL COTYLEDON.}

\section{ETAMINES SUR LF PISTIL.}

1. LE BANA NIER est couvert de longues feuilles écailleuṣes qui cachent catièrement le tronc. Il porte de gros fruits assez semblables au concombre. On le trouve dans l'Asie, l'Afrique et l'Amérique.

2. Le GINGFIIB est une plante exotique, son fruit est oblong et ccriace, ses loges contiennent des petites semences, sa racine misc en poudre sert a falsifier le puivre.

3. Les on c n s sont de belles plantes printanières, dont la corulle est découpée de tant de manières, que dans une espèce elles 


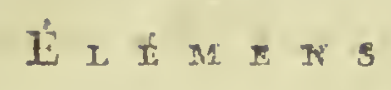

ressemblent à un hommc, dans d'autres d un singe, d un insecte.... elc.

4. La vanilix grinpe sur les arbres, elle produit unc gousse qu'on mểle au cacao, pour l'aromatiser, dans la fabricalion du chocolat. On en fait des parfums. Elle crô̂t dans l'Amérique.

5. La NYMPHA, en épanouissant ses belles fleurs sur les eaux, aplrend aux jardiniers qu'ils peuvent sortir les plantes des orangeries. Elle est extrêmement rafraîchissante, on la nomme par corruption nenzplecer:

6. La ma C drangulaire armée de quatre épines dures. Onla nomme vulgairement chatuigme d'cau, on en fait de la buuilie et même du pain.

\section{PLANTES A DEUX COTYLEDONS.}

SANS FÉTALES. ETAMINES SUR LE PISTIL.

L'ASAR I T a des fleurs noirâtres cachées sous ses fenilles, dont la forme approche 'de celle de l'ureille luntaine; ses semences sont un puissant vonitif. 


\section{TI. PLANTES A DEUX COTYLEDONS.}

SANS PÉTALES.ETAMINES AUTOUR DU PISTIL:

1. Le Dhphś a le calyce coloré à quatre divisions. On distingue dans ce gente la lauréole, dont l'effet est agréable dans les parterres, et le garou, dont l'écorce très-caustique sert à entretenir les cantères.

2. Le raghto se nomme aussi bois dentelle on denteliier, parce que son liber forme un réseau qui ressemble à une gase.

3. Le lavisur, dont on tresse la couronne des guerricrs et celle des poètes, porte des feuilles épaisses etalternes; des bayes ovales succèdent à ses petites fleurs. Ses feuilles sont aromatiques, et se mettent dans les sausses. L'huile qu'on exprime de ses bayes, résont les tumeurs. Ie camphrier et le sassafras, dont on fait usage en médecine, sont des espèces exotiques le ce genre.

4. Le arSCañen produit cette noix qui sert à épicer nos alimens, et qu'on nomne muscade; la meilleure vient des Moluques.

5. Le rolyconim est un genre assez nom-

$$
\text { (5) } 2
$$


breux, ainsi nommé à caruse des condes et des articnlations de ses tiges. On y distingue la persicaire, dont les panicules rouges font un bel effet, la renoude dont la graine fournit une nouriture abondante aux petits oiseaux, et le sarrazin nommé aussi bled noir, de la coulcur de ses grains triangulaires, et à cause de son usage. On en fait du pain, de la bouillie, des galettes, et il est très-utile pour en graisser la volaille.

6. Le nuarx est un autre genre également nombreux. Ses feuilles et ses fleurs sont vertes et paniculécs, elles ont un goût aigre qui se manifeste principalement dans l'oseille. La patience, dont la racine sert en médecine, est une espèce de rumex.

7. La ruvвавва dont la racine purgative est employée en médccine, est l'espèce nommée rinbarbe palmée. Elle est originaire de la Tartarie, on l'a naturalisée depuis peu en Europe.

8. Le kar. est une plante dont quelques espèces sont vivaces, d'autres annuclles; elles ont une grande variété de formes et de couleurs. Les semences du kali ont la figure d'une coquille de limaçon, on les dunne aux bestiaux. Cette plante est précicuse par 
d'Histoire Natuatza. 101 un autre produit, la souclé, quon retire do ses cendres fonducs et à demi vitrifiées.

9. L'ÉPINAH est une plante potagère dont les fleurs sont rassemblées et axillaires. Son jus sert ì verdir différentes préparations d'oflice et de pharmacie.

го. La ветте a les panicules terminales, chaque paquet est formé de trois à quatre fleurs, c'est un aliment rafraichissant. La carle poirée dont on mange les grandes feuilles, Ia betterave dont la racine se prépare de différentes manières, sont des espèces de ce genre.

11. L'aroche a ses fleurs en panicules. Ses feuilles se mangent comme celles de l'épinard.

\section{PLANTES A DEUX COTYLEDONS.}

SA:S RÉTALES. ETAMINES SOUS LE PISTIL.

1. L'amaranthe fait l'ornement des jardins. Ses larges feuilles sont rougeâtres sur leurs bords, et vertes dans leur milieu. La réunion des calyces colurés, forme un superbe panache pouryre on cramoisi.

2. Le plantain est un genre fort nomG 3 
breux, les fleurs forment au sommet de la tige un éri allongé. Sa graine est amuée des petits oisearx.

3. La relte dE Nut a des flems en entonnoir, d'un beau rouge nnancé de blánc. On la cnltive pour l'omement des jardins, et à cause d'unc singularité remarquable; ses flems lenmées le jour ne s'ouvrent qu’à l'entrée de la nuit.

\section{PLANTES A DEUX COTYLEDONS.}

\section{UN SEUL PETALE, COROLLE SOUS LE PISTIL.}

1. L'ANagalts a le calyce í cinq divisions, la corolle en roue, de couleur bleue ou rouge. On l'appelle faussement mouron, on en fait une eali pour le teint.

2. La IRIMEYine doit son nom it sa naissance jrécuce, elle paroît dans les promiers jours dit printemps. Ses calyces longs et enflés renferment me corolle en entunnoir, et formcit des bougucts d'un beau jaine. On mange ses feuilles cuites comme celles de l'épinarl. L'oreille d'ours de nos parterres, est une espècc de primerère, sa corolle est nuancéc. 
d'Iftstome Natenglax. 103

3. I a virnateue. On en trouve plasieurs especes dans les bois, dans les champs et dans les jardins. Sa corolle est ordinairement d'un beau bleu. Ia plus commune est la vérunique officinale, dont les julis bouquets émaillent les gazons. On l'aypeloit autrefois ticé d'Ezrope, parce qu'on substituoit ses feuilles à celles du thé. Elle puritie le sang.

4. Ijionisue est nne belle plante à fleurs purpurines; ses feuilles larges, decoupées et épincuses, ont donné par leur enroulement, liclée d'un des plus beaux ornemens de l'architecture.

5. Le risas porie de helles fleurs en panicules, c'est l'ornement des bosquets; des capsules noircs leur succècent. Les Turcs font ayec ses jennes brancines les beaux tuyau de pines.

6. Le surswis est un grand arbre de futaie, qui nime les lieux frais et humiles; son ćcorce est unie, ses branches sont $\mathrm{cp}$ posées, ei scs fouilles lanyées par paires. Ses fleurs très-passagères lount place à des fruits ầlés, dont l'anaude a un gont amer. Eile se conitit dans lo vinaigre. L'ćcorce du fiesnc est astringente, et supplće la noix

$$
\text { G } 4
$$


de galle; les fenilles nourrissent los bestiaux. Le bois est excellent pour le tour et le charunnage. C'est d'une espèce de fresne que déconle spontanément, ou par incision, ce purgatif doux apjellé manne.

7. L'onrrira a la tige branchue et l'écorce lisse, ses feuilles sont opposées, toujours rortes, ses fleus en panicules axillaires ou terminales. Il leur succède des fruits charnus appelés olives, qui contiennent un noyau long ì deux loges. On conserve ces fruits dans la sammure, on les brise sous le moulin pour en expriner l'fuile, cette substance si utilc pour la prépraration des alimens et pour celle de plusieurs médicamens. Le inarc fait des mottes à brûler; en mêlant lhuile avec de la sonde et de la chaux vive, on en fabrique le savon. Le bois de l'olivier est veiné, il sert aux tabletiers.

8. Le Jasmin est un joli arbrisseau dont on culive deux espèces, l'une à petites fleurs jaunes qui ont la figure d'une coupe, l'eutre a grandes fleurs blanches; on en retire l'huile essentielle en mettant des lits de fleurs de jasmin entre les lits de cuton imbibé d'huile de Ben. Le coton s'imprègne de lem odeur, on exprime l'huile par la 
D'Historre NAturelle. 105 presse, et on verse dessirs de l'alcohol, qui s'empare de la partie aromatique.

9. Je trOENe est d'un joli effet, quand ses fleurs blanches réunies en grappes, comne celle du lilas, sont épanouies. On en forme des haies; on le taille de différentes manières. Ses pelites baies noires et amères plaisent beaucoup aux oiseaux; les enlumineurs en tirent une couleur bleue; les chajeliers en metteni dans leur encre; on s'en sert pour donner au vin une conleur rouge plus foncẹ́e. Le bois s'cmploia pour diférens ouvrages de varnerie. Son charbon est utile pour la fabrication de la poudre ì canor.

10. La vervine offre sur une rige grêle et unie, des petiies fleurs d'un. bleu tendre. On lui atribuoit antrefois des vertus supposées. On en cultive plusieurs belles espèces lans les parlerves.

1. Ia scropmizarne a la tige quadrangrlaire, la corolle globulerse et ciliée, quatre ćtamines dont deux plus longues que les antres. Cette plante est recommandéc dans ios rnaladies de la peau.

12. La JMGITIL croît dans les lieux secs. Sa tige velue et rougcátre porte des grandes 
fleurs pourprées qui oni la forme d'un dez à coudre; elle est d'un bel efiet, et peut orner les parterres. Il y cu a une espèce plus petite ì fleurs jalunes.

13. Le merien se trouve abondamment dans les vicux murs et lims les patevies. Il cst recommoisable it ses petites fouilles nonbrcrses, et ì ses fleurs rouges et blanchâties, ou lèrres, quile font appeler valgairement greule de lomp; on en trouve dans les champs nne espice à flemr jamne, nommén la linaire ( I).

14. Le bouxhor-muare porte des femilles larges a cotonneuses, sur me lige forte, élevée, et cruinéc par un gros épi de flcurs jamnes qui tumbent aisément. On en fait des tisanes dars les max de poitrine.

15. La suseurane ponte re longs épis de fleurs en cloches james et pmparines. Ses feuilles soni cotonneuses; ses fiuis sont operculés, ils s'ouvrent comme nne loîte à saronelte. Szo semences soni noires, elle a unc chleur forte. C'est un poison violent, clle croît le lung les chemins.

(1) Les flenrs, dont la corolle irrégrilièrc inite un mufle à deus lirres, se romment persomécs. 


\section{D'IISTOIRI NATURELF. 107}

16. La NICOTINe a élé apportée en France en I560, par Nicot, dont on lui a donné le nom. Sa tige est hante et forte; ses feuilles sont larges et risqueuses. Ses fleurs en godets sont décorpées en cinq parties. C'est avec les feuilles de cetie plante fomentées et mises en poudre qu'on prépare le tabac.

17. Le straxoniun porte me belle fleur blanche en entonnoir, qui est remplacée par un fruit rond hérissé d'épines très-pointues, et renfermant des semences noires en forme de rein. C'est un poison violent. Quelques scélérats s'cn sont sertis pour ęndormir les citoyens qüils vouloient voler. Ce sommeil est souvent suivi de la mort. Cette plante qui se trouve dans les bois, sè nomme nlgairement la pomme épinerse.

18. La miñascone a de môrue une belle ficur en cioche remplacóe par un fruit rond, 'qui ressemble à une nèfle. Elle se distinģue par sa racine ciont la forme approche quelquefois de celle di corps humain. Liat ajoute souvent à la nature. Cette singulariı́e a fait attribuer à la mandragore, des propriétés aussi fausses que ridicules. C'est un purgalif violont, et un vóritable poison. 
9. La berladnxe, on belle-dame, porte des fruits ronds et noirs, assez semblables à cles grains de raisin; plusicurs enfaus ont été cupuisonnés pour cn avoir mangé. Elle est commune dans les haies.

20. L'AKERENG a des fleurs blanches d'mic seule fièce, qui sortent des aisselles des fenilles. Les frmits sont des baies rouges ct aciles enfermées dans le calyce, cowme dans une ressie.

21. La pomare jo terne est la racine d'une espèce du grnic solunum, dont les ferilles sont laniggineuses et découpées, les fleurs gris de lin et monopétales. Les arithères sont perforées, le fruit est une baie noirc. Oil cultive cetle plante pour sa racine, qui se nangge d'nne infinité de manic̀res, et est ausi snine que savourense. On en fait de la farine et de l'amidon; les bestiaux mangent la feuille et la racine.

22. La muRlute est une espèce du nêma genre. Elle grimpe, ses feuilles sont lancéolées, ses fleurs plus petites. Il ne faut pas manger ses baies noires qui sont un poison. 23. La tonate est le fruit d'une autre espèce de colanum appelé solanum lycopersique, il est rougeâtre et aigrelet, on 
le mange cuit surs la cendre et er salade. On en met dans les sauces pour leur donner une coulenr rouge, on l'appelle vulgairoment porime d'amour.

24. La mílunglas est un fruit semblable au prócélent, et qui appartient au solanum mélongène. Ce fruit est long, sa chair est blanche, on le mange comme la tomate.

25. Le LISERON est une jolie plante rampante, qui porte des fleurs en cloches blanches nuancées de rouge. Il y en a une espèce dont les fleurs sont absolument blanches, et beaucoup plus grosse, qui grimpe dans les haies. L'espèce que l'on cultive dans les jardins, et qui est nuancée de bleu, de blanc et de rouge, se nomme belle de jour. Le jalap qui sert en médecine comme purgatif, est une espèce de liseron. Tous les liserons s'épanouissent le matin et se ferment avant la nuit.

26. La pervenche se cultive dans les parterres, à cause de scs jolies fleurs blenes en soucoupes. La petite pervenche se trouve dans les bois des envilons de Paris; la grasde, dans nos départemens méridionaux. 
27. Lé nínion est ce bel arbuste qui se garde dạns les serres et orne nos jarclins pendant l'été; la forme de ses fenilles, la couleur de ses belles fleurs, lui ont fait donner le nom de laurier rose.

29. L'apocin a ses feuilles couvertes d'un léger duvet; ses fleurs, en cloches, sont découpées, purpurines, et d'une odeur agréable; ses fruits, oblongs et gros comme le poing, contiennent une matière filamenteuse, sous laquelle est unc onate fine et d'un beau blanc, dont on peut bourrer des matelats et fourrer des habits. Mêlée avcc du coton, de la filoselle ou de la soie, on la file pour fabriquer des étoffes; les cliapeliers la feutrent avec le poil de lièvre et de lapin.

29. La cuscute est une plante parasite d'une nature singulière. Elle tire d'abord sa nourriture de la terre, par un filet qui se dessèche bientôt. Elle n'a d'autres feuilles que des fibres rougeâtres accompagnées de tubercules, d'où sortent des filets qui s'insèreas sur tous les végétaux, et dérobent leurs sucs. Ceux des plantes anières, ceux des plantes vénéneuses convicurcrit à la cuscute, comme ceux des plantes sucrćcs. 
Elle porte des petites fleurs en cloches, blanchâtres on rougeàtues. On retiroit autrefois de cette plante une manvaise couleur rouge.

30. La gentiane a la feuille large et la fleur en épi ; elle est vulnéraire et fébrifuge; on la cultive pour l'ornement.

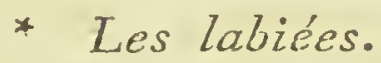

Les labiéés ont beaucoup de rapport avec les personnées; mais le mufle de la lèvre supérieure est moins prononcé. Les semences sont nues, au lieu d'être enfermées dans une capsule.

31. Le romarin est un arbrissean qui croât abondamment et sans culture dans nos départemens mérilionaux. On le cultive dans nos jardins à cause de son odeur; ses fleurs d'un bleu pâle forment des épis verticillés et au sommet des tiges. Ses petites feuilles sont veries en dessus et blanches en dessous; on les brûle à la place de baies de genièvre.

32. La sauge présente, dans les organes de la fructification, quelque chose de singulier. Les étamines sont fourchnes et atta- 
112

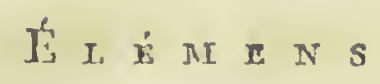

chées à un pédicule particulier. Sa Jève supérienre est grande et courbée; ses feuilles riciées conservont lcur verdure pendant lhiver; on en fail des bordures dans les parterres. On lui a attribué des propriétés universelles pour la guérison des maladies. On la fume pour les maux de tête; son huile essentielle s'employe pour la guérison des xhumatismes; plusicurs personnes en prennent cn infusion. La petite sauge ne diftère de la grande que par sa hauteur; mais on en trouve dans les campagnes une autre espèce, la sauçe des prés, qui se distingue par ses grandes feuilles en cour et par ses épis, qui forment des verticilles peu garnis. Cette plante est d'un heau bleu. Il y en a une variété à fleurs blanches.

33. La SARIETte est un sous-arbrisseau qui forme une toufe d'environ trois décimètres de hauteur. Ses feuilles sont étroites et longues; ses fleurs, en gueule, sortent des aisselles des f'cuilles. On met les feuilles dansles sances pour en relever le goût.

34. L'HYsore ne s’élève guère plus que la sariette; ses fenilles sont plus grandes; scs fleurs, blanclies, bleues ou roses, sont dispersées en épis, mais tournées du mème côté. 


\section{D'Hztotre Naturtits. 113}

côté. On en fait des bordures lans les parterres.

35. La catare, appelée ainsi parce que son odeur plait aux chats et les attire, a des feuilles en cœur et sciées; ses fleurs blanches forment des éfis verticilles.

36. La LaVande a de longs péduncules quadrangulaires, terminés par des épis de petites fleurs bleues. Elle fait des bordures dans nos parterres. Son huile essentielle entre dans difrérens parfums. L'huile d'aspic se tire de l'espèce appelée lavande spic. Son odeur forte chasse les insectes. On en frotte les mêches des lampions pour les allumer plus facilement.

37. La menthi. Toutes les espèces de ce genre croissent dans les lieux humides; elles ont une odeur aromatique. Leur corolle est peu sensiblement labiée; elle a quatre divisions, dont une plus large et échancrée. C'est avec l'huile essentielle de l'espèce appelée menthe poivrée, et un pon d'éther, que l'on fait les pastilles de menthe.

38. La mítorNe a les calyces barbus. Ses fleurs rouges forment un long épi interronpı. Ceite plante est un puissant sternutatoire; on la touve dans les bois. 
39. Le thrir sert à faire des bordures: C'est une petite plante blene dont l'hujle essentielle entre dans plusieurs médicamens et dans les parfums.

40. Le serrouEi parfume les bois et les pays montagneux. Ses petites fleurs purpurines sont disposées en tête sur des tiges raumpantes, et les lapiris cni sont très-friands; ils lui doivent celle saveur qu'on appelie jumet.

41. La milusse porte des grappes verticillées et latérales; ses fleurs sout d'un blanc salc; un la trouve sauvage et on la cullive dans les jardins. En distillant cette plante au bain-nuarie avec de l'alcohol, on obtient son arome. Cette liqueur se nomme eau-de-méZisse; elle est anti-spasmodique.

42. Iue BAsIic a de petites flenrs odorantes, purpurines ou blanches, disposées en tête, accompagnées d'une collerette. On le cullive dans des pois et en bordures; on en aronatise les alimens.

$$
\text { * Borraginées. }
$$

On nomme ainsi les plantes dont la fleur approclie, par sa fonne, de celle de la 


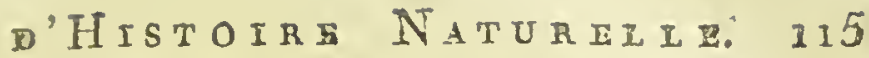

bourache. Elles ont aussi les mêmes propriétés. Elles fournissent une certaine quantité de nitre pur.

43. L'héliotrope a des tiges et des feuilles lanugineuses; l'extrémité de ses épis se roule en spirale. I'héliotrope sauvage n'a pas d'odeur; celui qui a le parfum de la vanille est l'héliotrope péruvien; ón le cultive dans nos jardins. Les feuilles amères et caustiques de l'héliotrope sont propres pour faire disparoître les verrues.

44. La vipírine est extrêmement commune; sa tige est hispide; ses fleurs bleues sont un peu campanulées; les épis se courbent comme la queue d'une vipère.

45. La pulmonaire se trouve dans les bois; ses feuilles vertes et ovales sont marquées de taches blanchâtres; elle porte des fleurs bleues en entonnoir ; son efficacité contre les maladies du poulmon n'est pas certaine; ses feuilles peuvent se marnger commo celles de l'épinard.

46. La consoude porte, sur de fortes tiges, des feuilles épaisses et velues. La fleur est blanche ou purpurine; l'entrée est f'ermée jar des écailles velues; son nom vient de sa proprićté de consolider les parties sćparécs. 


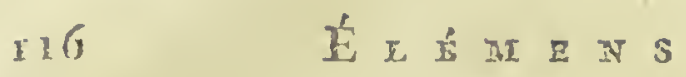

47. La bugiose' a aussi des fleurs blenes en entonnoir, fermé à son entrée par des écailles en furme de voute. Ses lleurs forment des épis latéraux; son usage est le même que celui de la plante suivante.

48. La Bundene a la corolle en roue et fermée par des écailles en forme de rayous. Ses feuilles sont hérissées; clle est laxalive.

49. La crnog losse a des fleurs en entonnoir, d'un bean rouge. Ses fruits liélissés s'attachent ì tous les corps qu'ils rencontrent, et vont ainsi porter ailleurs le germe de la reproduction de l'espèce.

\section{PLANTES A DEUX COTYLEDONS.}

UN SEUL PETAIE. COROLLE AUTOUR DU PISTIL.

I. La bruxine a un calyce à quatre divisions. Les étamines sont attacliées sur le réceptacle, et les anthères sont fendues. $\mathrm{La}$ corolle est petite et colorée. On en compte beaucoup d'espèces. La bruyère vulgaire et la bruycre cendíée sont les plus communes. Ces plantes croissent dans les lieux secs et dans les landes; on en jonche les fossés pour fuire écouler l'eau plus rapi- 


\section{d'IIstoirb Naturgtit: 117}

dement. On les coupe pour en faire de la litière aux chèvies et aux brebis; on les brîly pour en retirer la potasse; c'est la nonmiture de plusieurs animaux des bois; les abcilles prisent dans leur corolle un miel abondant; on en présente des brins an ver à scie pour faire sa coque. La bruyère à balais s'emploie ì l'usage que son nom indique.

2. Le mirntiт́ se nomme aussi raisin de renard, à cause de ses baies d'un bleu foncé, qui succèdent à ses fleurs en grelot. Ces baies ont une acidité agréable; les cabaretiers s'en servent pour foncer le rouge du vin ; elles donnent aus toilcs une couleur bleue, ou plutôt violette.

3. La chmpanue est nommée ainsi à cause de ses fleurs en cloches (1), disposées en

(I) Les plantes qui ont la figure d'uns cloche se nomment campaniformes, dn mot latin campana. Celles qui méritent plus larticulièrement ce nom sont à-peu-près égaloment évasées dans toutes leurs parties. Les campaniformes tubulées ont le corps plus alongé et lo fond plus étroit; les évasées ont le fond beaucoup plus étroit que l'entrée; celles en grelot ont l'entrée plus étroite rque le corps et le fond. 
épis ou en têtes latérales ou terminales. La raiponce qui se mange en salade est une campanule; elle croit dans les champs et dans les biés. A ses fleurs blenes ou purpurines succècle un fruit membraneux.

\section{PLANTES A DEUX COTYIEDONS.}

UN SEUL PÉTALE. COROLLE SUR LE PISTIL.

$$
\text { A N T I I }
$$

* Composées.

Les fleurs composées sont formées de la réunion de plusieurs petites fleurs dans un calyce commun. Ces fleurs s'appcllent fleurons ou demi-fleurons, selon leur forme. Le fleuron est creusé en entonnoir évasé à son onifice. Son bord est découpé en plusieurs parties ovales et recourbées. Le demi-fleuron ne présente qu'un tuyau étroit, évasé par le haut en forme de languette découpée à ses extrémités. Chacune de ces petites fleurs a cinq étanines dont les anthères sont réunies, de manière qu'elles forment une gaîne cnfilée par le pistil, qui s'élève au-dessus. Les 
fleurs qui ne sont composées que de lleurons se nomment flosculeuses; celles qui ne contiennent que des demi-fleurons, semifloscrileuse's. Quand les fleurons et les demiflcurons se trouvent réunis, les fleurons occupent le centre de la fleur qu'on nomme disque, et les demi-fleurons sont à la circonférence qu'on appelle ray'on. La forme de ces fleurs les a fait nommer radiées. Les fleurs réunies dans un calyce commun, mais qui ne sont pas forraées de fleurons et de demi-fleurons, et dont les anthères ne sint pas réunies, n’appartiennent pas aux composées.

I. La Lurtue est ainsi nomméc, ̀̀ cause du suc laiteux qu'elle répand. Ses fleurs sont ordinairement jaunes; les jardiniers blanchissent ses feuilles en les couvrant de terie; ils ont aussi l'art de les faire pommer ou friser. Cette plante se mange cuite de différentes manières et en salade; elle est trèsrafraîchissante.

2. Le pissentit a des feuilles très-découpées et des fleurs jaunes, auxquelles succèdent des fruits surmontés d'une aigrette plumeuse, qui offre un réscau sphérique d'une jolie forme, et qu'un léger soufflo 


\section{0 L L L E M J N S}

anéantit; c'est souvent l'amuscment des enfans. On mange ses feuilles tendres en salade; son suc est apéritif, et c'est à cette propriété que cette plante doit son noms.

3. La sronsoning a le calyce formé d'ćcailles membianeuses qui se recouvent en toit. La couleux de sa racine l'a fait nommer salsifix noir ; on l'accommode cornme colle de salsifix blanc.

4. Le sarsifrx est la racine d'un tragopogon des prés; ce mot signifie barbe de bouc. Son calyce est simple et son aigrette sessile; ses racines sont blanches; du reste, ses fleurs sont jaunes comme celles de la scorsonère, et ces deux plantes ont ensemble beaucoup de rapport.

5. L'artichald a des feuilles roides et découpées, armées de longs piquans. Ses fleurs sont bleues; on en cultive plusienrs variétés. C'est le calyce, et sur-tout le réceptacie, que l'on prépare sous le nom de cul cl'artichaud.

6. Le carnox est une espèce d'artichaud dont les écailles calycinales sont acconpagnées d'épines roides. On nange les côtes des femilles blanchies à l'ombre.

7. L'oñonde a les écailles calycinales 
armées d'aiguillons crochus. Ses feuilles sont ovales, longues et sinućes, ses fleurs blenes. Cette planie s'élève jusqu'à deux mètres; elle borde les chemins. On l'appelle herbe aux anes, parce que ces animamx en sont très-friancis.

8. Lues charpons ont anssi les écailles calycirales épineuses; leur réceptacle est garni de poils. Les aigrettes de leurs semences forment un duvel propre à bourrer les matelats.

9. La cuxconée croît naturellement dans les champs et se culive dans les jardins. Ses fleurs bleues axillaires sont placées sur des tiges sèches; on mange ses feuilles en salade, ainsi qu'une autre espèce de ce genre, nommée endive.

10. La carutre a le calyce garni d'écailles alongées et colorées, qui forment des rayons blancs. Ses fleurs blanches sont disposćes en. corymbe. On mange les jeunes têtes de la carline sans tige.

11. Le cartuarie porte des fleurs d'un jaune foncé sur deș tiges épineuses; on le nomme safran batard, et on le mêle quelquefois an véritable safian. On employe cette fleur pour donner aux suies ces belles 
I蚂

$$
\text { EI E I I }
$$

ruances de cerise, de poncear et de rose; ainsi que pour prćparer le beau rouge des temines. La graine engraisse les perroquets.

I., La cHAUSSE-TRAPPE est extiênement commune dans les chemins; on la nomme aussi charziou étoilé, parce que ses ćcailles calycinales forment des étoiles. Sies flcurs sont purpurines.

13. Ia Jacḱr a le calyce écailleux et découpé. L'extrémité de scs fícurs cst bleue; les champs en sont couverts.

r.f. Le вцеüт a les f́euilles linéaires trc̀sentières. Ses fleurs bleues ont des langmeltes très-alongées et très-irrégulières; on en tresse des guirlandes et des bouquets.

15. La serratule se nomne vulgairement charion hémorroïdal, à cause des pustules qu'on remarque sur ses feuilles, et qui lui ont fait supposer une vertu contre les hémorrhuiles. Elle est très - commune; ses ficurs sont blenes. La sarrète est une espèce de serratule qui fournit aux teinturiers une couleur jaune. 
* Corymbifères.

$\mathrm{ON}_{\mathrm{N}}$ appelle ainsi les plantes dont les rameaus portent des fleurs terminales qui, par leur rémion, forment un plan horizontal.

16. L'Érigeron a les fleurs d'un blane sale, hérissées de poil, ainsi que sa tige. Cette plante fut apportée du Canada, il y a environ cent ans; elle infeste aujourd'hui tnute l'Europe.

17. Le seneçon. La base de son calyce est garni de folioles; et vers le hauc, d'écailles qui paroissent meurtries à leur sommet. Le seneçon ordinaire a les feuilles épaisses et qui embrassent la tige; on le donne aux petits oiseaux. Le seneçon jacobée, qui a les feuilles découpées et qui s'élève à la hauteur de plus d'un mètre, fournit une couleur verte peu durable.

18. Le tussilage a le réceptacle nu, el les écailles du calyce égales. L'espèce dont on fait un sirop pectoral n'est pas corymbifère. La tige ne porte qu'unc fleur jaune qui vient avant les feuilles.

19. Le soucr porte des fleurs d'un jame 
12.

rongeâtre; il croît dans les lieux incultes et dans les vignes.

20. La paqueretTe cst une petite radiée dont le disque est juune et le rajon blanc avec quelques teintes rougeâtres sur le bord des demi-fleurons. Les gazons en sont couverts; on la nomme vulgairement petite marogucritc. Elle n'a jamais plus d'un décimètre de haut.

21. Le chntsanthine, ou grancie margucrite, ressemble, beaucomp a la ylaste précédente; il s'élève is la hauteur d'un mitre.

22. Tua TANArse a les feuilles trois fois ailées et sciées. Ses fleurs sont jauncs. Elte a une odeur très-forte; elle forme des toufies épaisses.

23. Lifraroise a le réceptacle peu velu, des feuilles aillécs, des fleurs noivatres; on la trouve dans les lieux incultes. L'absynthe,dont on sé sert pour donner de l'amertume à la bierre, est une espèce d'armoise, dont les fleurs jaunes sont globuleuses et pendanies.

24. La camonirue a le réceptacle conique; le disque est jaune, les rayons blancs; c'est une plante émolliente. 
D'IISTOINE NATEREED。 125 25. La irltefeurle a les feuilles deux fois aîlées. Ses fleurs formeni des corymbes blancs on rouggeâtres; elle esi très-vulnéraire.

26. L'hémiñthe est cette belle plante appelée vulgairement soleil. Ses tiges sonz hautes de deux̄mètres, ses fleurs terminales d'un beau jaune. La topinarbour, ou poire de terre, est la racine d'une espèce de ce genre, l'hélianthe tubérezx.

\section{PLANTES A DEUX COTYLEDOI'S.}

UN SEUL PETALE. COROLLE SUR LE PISTIL.

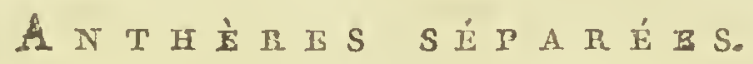

I. La cardiatre, qu'on appelle improprement chardon à bonnetier, n'a aucun. rapport avec le chardon. Ses tiges sont hautes de deur mètres: Ses feuilles, réunies par leur base, forment de petits bassins dans lesquels les oiseaux vont boire et se baigner. Les fleur3, réunies en une tête de la grosseur d'un ouf, sont purpurines ei enfermées dans un calyce dont les dents sont acérées et recourbécs. Ce sont ces dents qui, compri- 


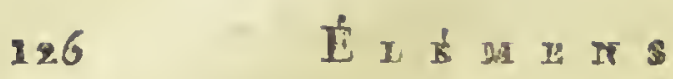

mćcs et retenues cntre des petites planches, forment les cardes des cardeurs de draps. On cultive cette plante pour cet usage. Il y en a une autre espèce appelée verge à bcrger, dont les denits sont droites, et qui nc peut pas avoir la même utilité.

2. La scarieuse a un calyce commun d̀ plusieurs fenilles, et un calyce particulicr pour chacune de ses fleurs, qui sont bleues ct réunies en une tête peu convexe. L'espèce appelée mors du diuble donne aux arts une teinture jame; les autres ornent les champs, ou se cultivent dans les parterres.

3. La valiniane porte de larges touftes de flcurs rouges et blanches, dont la corolle, monopétale et renflée à sa base, renferme trois étamines et un pistil. On la cultive dans les parterres, et elle viont d'elle-mềne dans lés lentes des murs. Ses racines sont vulnéraires. La mache, que l'on mange en salade, est une valérane; clle a la feuille linéaire et la lige branchue.

4. Le curirezculzis a la corolle terminée par des divisions lonǵgues et irrégulières. On le cultive pour sa donce odeur, on en forme des berceaux. 
5. Le GuI est une plante parasite et ligneuse qui se trouve sur presque tous les vieux arbres. Ses fleurs mâles et femelles sont sur des individus différens. Il se forme a l'endroit oì il s'attache aux arbres, un noend assez gros dont on fait des balles de battoir. On faisoit autrefois de la glue avec son écorce.

6. Le sureau porte des fleurs blanches, il est d'un bel effet dans les haies. On le cultive aussi dans les bosquets. Son bois est très-bon pour le tour. Ses jemnes tiges servent à faire des pipeaux rustiques, la moelle à faire des mêches de lampes, et des petites colonnes sur lesquelles on fixe les insectes avec des épingles, dans des cadres. Les fleurs vertes mêlées au vinaigre lui donneni une odeur aromaique, elles se mangent en friture; les baies foncent la couleur du vin. On appelle yeble, une autre espèce de sureau facile 'ì reconnoître ì sa tige herbacée.

7. Le connoumlin a comme le sureau des fleurs blanches en corymbes, mais il n'a que quatre étamines au licu de cinq. Ses fleurs sont remplacées par un fruit $\mathbf{i}$ noyau appelć comouille, qui se mange 
128 E L E $M$ E N

crud, ou confit au vinaigre. Le bois est bon pour le charomnage, et pour le tour.

8. Le mibrre pousse des tiges rampantes et sarmenteuses qui s'attachent aux arbres et aux vieilles murailles. Les branches qui se roncontrent achèrent naturellement ensemble, ce qui peut avoir donné l'iclée de la greffe. Les feuilles sont vertes et coriaces; les flemrs blanches sont remplacées par des baies à cinc semences. Les feuilles de lierre sont vulnéraires. Le bois est caustiqué, on cu fait les boules pour les cantères, et on. applique dessus les feuilles de la plante. II découle du tronc mme résine brunĉtue, l'ure odeur assez agréable, appelée gomnze.de lierre; le bois sert aux tourneurs. Le lienre est le symbole de l'attachement et de l'amilié constante.

\section{Rubiacées.}

Ces plantes ont toutes des rapports avec la garance, nomméc en latin rubia.

9. Le carlielait a la corolle partagécen quatre divisions, les leuilles sont vèilicillées. On distingue le caillelait jarne, et le cailZelaitblanc, dont les fenilles servent égalementínire prendre le lait, et le grateron, ainsi 
D'HIStoIA NATURIR: 199 ainsi nommé des piquans dont ses tiges quadrangulaires sont hérissées.

10. La ganexce a le calyce et la corolle à quatre divisions. Ses fleurs sont jaunes ot remplacées par des baies noirâtres. On la cultive à cause de sa racine qui sert pour la. teinture ronge. Elle procure aussi de la solidité aux autres couleurs, on lemploye pour fixer celles déjà imprimées sur la toile de coton. Cette racine teint en rouge les os des animaux qui s'én nourissent.

I1. Le quinquina produit cette écorce si célèbre par ses propriétés fébrifuges, ct pour arrêter les effets de la gangrène dans les maladies putrides. Il crô̂t en Amérique.

12. Le Caffeyer est un arbrisseau qui porte des baies grosses comme des petites cerises. Elles renferment deux semences convexes d'un côté, plates et creusées en goutière de l'autre. C'est le caffé dont tout le monde connoît l'usagc. 


\section{0 E 1 มี}

\section{PLANTES A DEUX. COTYLEDONS.}

PLUSILUAS PLTTALS. LThMINIS SUR IE DISTIL.

1. Le ginseng, d̀ la racine duguel les Chinois attibuent des propriélés méclicales si miraculeuses, appartient à celte classe.

$$
\text { * Ombelliferes. }
$$

Les onberifines ou flewts en parasol, ont cirrq pélales disposés en rose, mais inéganx. Lemr fiuit est comprosé de deux scinences réunies. Les jéduncules partent d'un contre commun, en s'évasant comine les rayons d'un parasol ou ombelle. Ces péduncules offrent encore un point contral d d'autres petites tiges gui portent les fleurs, et qui forment par leur réurion lesombellules.

+ Ombelles ct ombeliules, sans involucre.

2. Le persiz a des fruits ovales et striés, des flcurs jaunâtres, point d’involucre général, mais un involucre partiel à trois fenilles. Les ficuilles de la tige entront dans plusieurs assaisonnemens. Elles sont le nodèle d'un ornement d'architecture et de bijouterie. 


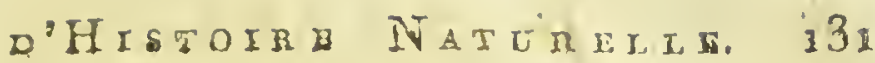

3. Le rimourr a des fieurs jaunes, des fenilles très-découpées, son odeur est forte. On mange ses jeunes pousses, el la tête de ses racines en salade.

4 Le parais sort d'une racine longue, jaunc et charnue, qui se mange dans les potages. Ses fleurs sont jaunes.

++ Cmbelle nue, ombellules à involucre.

5. Le cerfeutle a des fruits blanes, conyexes d'un côté, applatis de l'autre. Ses feuilles entrent dans divers assaisonnemens.

6. Ina coriañde a des fiuits sphériques. Sa graine sert à faire des dragées et des liqueurs. L'odeur de la plante est forte et insupportable.

\section{$+\rightarrow+$ Tnvolucre général et partiel. (I)}

7. Le cume a le fruit oblong, d'un gris brunâtre et cannelé; il a une odeur forte.

( I) Les ombellifères; indépendamment du calyce propre à chaque fieur, ont, à la base des rayous, une enveloppe qu'on nomme involucre; il est général on particl, selon qu'il entoure l'ombelle ou l'omberlule. Il se divise es un nombre plus ou moins considérable de petites feuilles. 
Les Hollandais en mettent dans le fromage, les Allemands en mettent dans la pâte du pain, pour s'exciter ì boirc. Les pigeons aiment beaucoup cette graine, ct pour les attirer on leur présente une pâte fiaitc avec de l'huile d'aspic et du cumin.

8. Le chervi se cultive à cause de sa racine blanche, 'et d'un goût sucré, qui s’assaisonne de difiérentes manières.

9. L'ANGÉltque doit son nom aux étonnantes vertus qu'on lui attribue. Ses feuilles sont égales, sciées; l'impaire est divisće en plusicurs lobes. On confit ses jennes cotes dans du sucre.

Io. La cigue porte sur une tige marquée de taches rougeâtres, des fruits crénelés et globulcux. Le suc de la plante, qui a donné la mort à Socrate, n'est pas celui de la plante que nous appelons ciguë. C'cst notre conium tacheté.

11. La carote a de grandes feuilies vertes, profondément découpées. Le réceptacle de ses fleurs devient un petit fruit velu et rude au toucher. Sa racine longue, charnue, d'un jaune plus ou moins toncé, et d'un goût douceâtre, entre dans l'assaisol- 
D'Histora NAturale. 133 nement de plusieurs mets. On en nourrit les bestiaux.

\section{XII.PLANTES A DEUX COTYLEDONS.'}

PLUSIEURS PETALES. ETAMINES SOUS LE PISTIL.

1. La cléuntite grimpe dans les haies. Ses fenilles sont en cour, ses fleurs à quatre pétales d'un blanc sale. Ses fruits sont enveloppés d'aigrattes plumeuses, qui leur donnent de loin l'apparence d'une araignée. Les branches de cette plante écorcées et dépouillées de leur aubier, peuvent servir a faire des ouvrages de petite vannerie. Les feuilles sont caustiques; et dans les pays où la mendicité n'est pas abolie, quelques lonines paresseux et pervers les appliquent sur leur peau pour y faire venir des ulcires.

2. L'ivinons. Ce genre renferme plusieurs belies espèces qu'on cultive dans le parterres, elles n'unt point de calyce, leurs pétales sont au nombre de cinq, quelquefois plus. La plus belle cst l'anérimone de's jardins. Les espèces les plus remarquables après cllo, sont la sylyic, qui croit dans les bois aux premiers jours dia printemps, ot la pul- 
satille, dont la fleur inclinće et comme suspendue, s'agite an moindre mouvenent. Lillo donne une encie verte.

3. La hinoncula. Ce geme renferme encore plus d'esjèces que le précédent. Son caractèe est d'avoir un onglet à la base de chacmu de ses cing peitales. Presque toutes les espèces ont la fleur jaune, elles émaillent agréablcment les prairies. Quelyues unes l'unt blanche, elícs cruissent dans les eaux.

4. Linetimone. Sun calyce a quatorze femilles, sa flem neuf pétales, sa racine noire est min stemutaloire puissant.

5. L’ancorite est semaryuable par les cind éperons qui accompagnent sa fleur. Elle croît clans les bois. On la cultive pour l'ornenent des jardins.

6. La puruine, nommée vulgairement pied $a^{\prime \prime}$ zlonelte, n'a qu'mu éperon. Ses fleurs blcues, rongreâtres, ou grisîtres, sont en épis. Les feuilies sont très-découpées, elle ome les parterres.

7. L'icontt poric un casque sur sa corolle. Ses f́enilles sont digitées ou palmécs; il y en a piusicurs espèces. In principale est le naijel ; il est venémeux.

8. Le popurages a cinq pélales jaunes. 


\section{D'Historke Naturela. $\quad 335$}

Ses boutons se mangent comme ceux du capriel. Sus feuilles ont la forme d'un rein, elles donnent une encre jaune.

9. La pryoris porte des fleurs extrêmement larges, purpurines et panachées, qui funt un bel effet; mais passent promptonent. Elles sont remplacées par des capsules id trois ou ì cinq cornes, qui renferment les semences. Cette plante a une odenr dísigréable, on ne la cultive que pour l'ornement.

10. Le prvot. L'espèce de ce genre la plus connue, est le pavot somnifère, dont les graules fleurs rouges et panachées, sont remplacées par une' capiule ovale qui renferme des semences noires. Cette capsule ou tête, laisse couler, ou donne par incisiun, un suc blanc qui se sèche en larmes brunes, c'est l'opium, qui, selon la dose qu'on en prend, froduit le sommeil, ou donne la murt; les Orientanx en font beaucoup d'usage. Ses graines fournissent par expression l'huile appelée huile d'olietle.

11. La cuíroorva an une corolle ì quatre pétales, un calyce de deux pièces, et de Inngues siliques. Tontes les parties de la plante foumissent un suc jause qui jouit

$$
14
$$




\section{6

$$
\text { É L }
$$

des mêmes propriétés que le' pastel. Les graines donnent de l'huile, le son qui reste après l'cxpression peut remplacer celui de l'amande. Ses racines font un assez bon tan. La plante plaît aux moutons.

I2. La fuineterne a de petites feuilles rouges et irrégulières disposées en grappes, toutes ses partics sont amères et savonneuses; elle est propre à dépurer le sang.

13. Le cinnier. La principale espèce de ce genre, est le caprier épineux, qui croît dans nos départemens méridionaux. Il a quatre grands pétales et des étamines longues et nombreuses. Les capres sont les boutons récoltés avant l'épanouissement des fleurs, et confits; on en met dans divers assaisonnemens.

14. Le RÉsínA porte sur une tige cannelée des feuilles très-découpées, amères et acides. Ses rameaux soutiennent des fleurs jaunes disposées en épis, elles snnt remplacées par une capsule membraneuse à trois loges. On le trouve dans les lieux incultes. On en cultive une espèce originaire d'Egypte, qui est odorante. L'espèce de réséda la phus utile est la gaucle, qui teint les peaux, les laines et les soies en jaune, en 
d'Histoire Naturelle. 137 f bleu et en verd; les différentes teintes de verd ont toujours été gaudées. Quand les étoffes garancées et empastellées ont reçu la teinture noire, on en adoucit les teintes en les passant au bain $a^{\prime} e$ gazude.

15. Le savonier est uil arbre d'Amérique, dont le brou des fruits se fond dans l'eau, et produit un effet approchant de celui du savon.

16. L'mppocastanum se nomme vulgairement maronier d'inde, parce qu'il est originaire de cette contrée, et que ses fruits ressemblentà ceux du châtaignier. Cet arbre donne un bel ombrage, ses fleurs blanches en grappes jointes à ses larges fenilles digitées, font l'ornement des grands jardins. Ses semences bouillies peuvent se donner aux ccchons et à la volaille, on les brûle pour se chanfier, on en fait des bougies et on en retire de l'amidon. Le bois est blanc ct peu srijet à la vermoulure, il est bon pour la gravure.

17. L'Prabe a pour fruit une capsule comprimée et aîlée. L'espèce la plus utile, celle qu'il seroit important d'acclinater, est l'érable à sucre dont le tronc fournit par incision une liqueur qui, rapprochée et 
crystallisée, devient un sucre abondant et almobuapnt srmblable it colui de la canne. 13. Le Mir.terenters se numme aini, parce quen regardant sos fevilles au soleil, or y remarque une maltiude de poins transparens; ses fleurs jaunes peuvent servir ¿ la teinture; la plante est vulnéraie.

19. Le rus crôit en Cline, on nous apporte ses feuilles que nous prenons en infusion.

20. La vicNe, est nue plante grimpante dont la ige sarmenteuse et tortue est couverte l'sune ćcorce rorguculue et crevassée. Elle s'aitache par ses vrilles à tous les corps qu'elle icncuntre. Ses feuilles sont larges et déconpées; ses fiturs jamâtres, à cinq pétales et ì cinj étanines, nássent de leurs aisselies. Il len succède des baies blanches on phis on muins rornes qui forment des grappes, c'est le raisin.

Cette plante vient de bouture. Le rigneroin taille la vigne et lui donne en diférens temps avec le hojaz, truis labonrs appelés le premier howerie, le second binage, le troisiène sarilage; il piune les échaluts. Il y attache les ceps avec des brins d'osier. Il coupe les bourgeons et les fenilles inutiles. 
D'HISTOIRE NATÚREIE.

Quand le fruit est parrenu à sa maturité, il le vendunge.

Cette opération se fait dans le cours de vendemiaire, on coupe les grappes aver des liseaux, on les place dans des bachaux, hottes enduites de poix et on les porte à la cuve, on les foule avec les pieds, et on y laisse le raisin 'jusqu'à ce que la fermentation spiritzeruse s'y établisse, ce qui nécessite toujours un corps sucré, une fluidité un peu visqueuse, une grande masse et une chaleur de douze degrés et demi.

Toutes ces circonstances sont réunies dans la cuve où le vin a été foulé. Il s'y excite un mouvement rui va toujours croissant. La chaleur s'élève jusqu'à vingt-deux degrés, et le marc surnage à cause du gas acide carbonique qui s'y développe. Alors le vin a été suffisamment cusé; on le porte au jressoir qui en exprime tout le jus. Dans cet état on le nomme molist ou vin doux, à cause de son goût sucré. On l'eriferme dans des tonmecaux non bouchés où il' subjit une seconde fermentation. Le corps sucré, la partic colorante et l'esprit ardent se mêlent, se combinent plus intimonent, at le vin prend plus do corps et de force. 
I 40

$$
\dot{\mathrm{E}} \mathrm{L} \dot{\mathrm{E}} \mathrm{M} \text { E N S }
$$

On le met en bontellles, et il acquiert une plus grande perfection.

On fait le vin blanc en laissant cuver le raisin moins long-temps; lc vin moussenx par l'addition d'un corps sucré yui fait fermenter la liquem dès qúclle éprouve le contact de l'ail. On brule dans les tonneaux des lingesimprégrés de soufie, pour muster le vin, alin qu'il puisse passer la mer; quand il contient mop de Heguse, on rapproche les parties spiritueuses par la cuisson.

Les vins les plus cstimés sont un composé d'une grande quantité d'eau, d'un arome; particulier à charpue vin, d'alcohol, d'un sel essentiel et d'une matière extractive résineuse el colorante, à laquelle les vins doirent leur cuuleur (1).

Lo marc ou résictu de la vendange engraisse la terre et nourit les cochuns. En $\mathrm{y}$ versant de l'eau et la transvasant dans

(1) On fait dur rin de pèches, d'abricots, de prunes, de mùres, de cerises, de pommes, de poires, etc. La bicre, fabriquée arec des semences de graminées, est une espèce de vin, ainsi que la liquenr qui découle \&u palmier, du boulcau, ctc. 


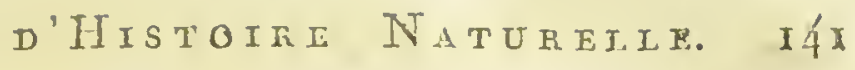
destonnuarx, on fait une liqueur acide rumbuce piquette.

L.e seliment du vin, ou la lie lossivéc et crystallisée, produit le sel de tartré. in Liviant cette lie, on obtient les cendres govivelés, substance alkaline qui sert aux chapuliers pour leur teinture.

Le vin passe à la fermentation acide, c'est ainsi que se fait le vinaigre.

La distillation du vin produit l'espritardent, l'eau-de-vie. Gette liqueur rectifúe, c'est-à-clire, disíllée de nouveau, donne l'esprit de vin, nommé par les chymistes modernes alcoliol. ,

Outre sa propriété fermentescible, le raisin est mis au nombre des meilleurs fruits. Celui qu'on destine à la table crốt sur des treilles ou en espalier. Comme ses rameaux s'étendent beaucoup, on en fait des berceaux impénétrables aux rayons du solcil. On en compte plusieurs variétés. Le muscat, le chasselas, etc.

On scche les raisins au four, et ainsi préparés, on en mêle dans la pâte de plusieurs gâteaux, et dans plusieurs mets. On les prépare encore de différentes manières ; cuit avec du vin et des poires, le raisin fait une 
cspèce de confitures appelée raisinet. Ses prpins foumissent de l'huile par expression. Les feuilles servent à cmballer les fruits, à garantir les viandes délicates de l'âpreté du feu. Elles foumissent anx arts un ornement appelé pampre. La surabondance de le sève se sécrète dans le cours de germinal, en une liqueur visqueuse qu'on appelle plezts de la vigne. Ce nom lui a fait attribuer la propriété de guérir les maux des yeux.

Le raisin cueilli avant sa maturité, se nomme verjus. On en fait des boissons acides.

21. Le grinanion ou bec de grue, est ainsi nommé, parce que ses fruits sont accompagnés d'un très-long bec. Il y en a un grand nombre d'espèces sauvages. On en cultive pour l'ornement.

22. Le tropoézum est originaire du Pérou. Il grimpe assez haut, et on l'employe à couvrir les treillages. Sa corolle de couleur aurore a cinq, pétales, et une espèce de capuchon qui lui a fait donner vul gairement le non de caprcine. Ses boutons se préparent comme ceux di caprier. 23. La ralsamar a des feuilles légére- 
D'HISTOIR N NATUEEL. If 3 ment crénelćes, des fleurs d'un beau ronge panachées, remplacées par un fruit en forme de poire. Il est composé de pièces rassemblées comme les douves d'un tonneau. Quand il est mûr et qu'on y touche, une des pièces se détache, les autres se roulent sur elles-mêmes, et lancent au loin les graines. On nomme aussi pour cette raison cette plante l'impatiente. La fleur fournit une teinture jaune, nous la cultivons pour l'ornement.

24. Le vinettier. Cet arbrisseau porte des fleurs jaunes en grappes. Sa tige est armée d'éfines disposées trois à trois, d'où on l'appelle épinc vinette. Ses étamines éprourent une contraction sensible quard on les touche à leur base. Son fruit est rouge et a une acidité assez agréable. Or en mange crud ou conlit, l'écorce donne une teinture jaune qui sert à colorer le bois.

25. Le Tize U i est un grand arbre dont les feuilles sont rondes, ses fieurs blanches ont des étamines nombreuses. Le fruit est une coque grosse comme un pois. Son bois sert aux charrons, aux tourneurs, aux ébénistes et à la sculpture commune. Ses jeunes 
$144 \quad E$ L $\dot{E}$ II E N S

rejettons servent id faire des ouvrages de vannerie. Ses branches domrent un charbon léger propre a la fabrication de la poudre a canon. L'écorce réduite en James minces sert à faire des cordes à puits. Le liber se file, on en tisse une tuile grossière. Les fleurs se prenncnt en infusion, la semence sert ¿̀ préparer une espèce de chocolat. Les fleurs du tilleul sont très - recherchées des abeilles.

26. Iue ro cou est l'arbre doni la graine macérée et mise en lâte fournit à la teinture une couleur rouge connue sous le nom de roucou. On le cultive dans l'Inde et dans l'Amérique.

27. La Y IOLT т a une corolle à cinq pétales irrégulières et terminées postérieurement en éperon. Sa jolie couleur bleue et son odeur suave la font rechércher pour les bouquets. On en retire par l'eau bouillante une teinture appellée teinture de violette, qui sert à indiquer la présence des alkalis et celle des acides par la couleur verte ou rouge à laquelle elle passe. Cette fleur est rafraîchissante, on en prépare un syrop et des conserves. La violette de trois couleurs se nomme pensée.

28. La nus a les feuilles surcomposées, des 


\section{dorstorre Natureze. 145}

des fleurs jaunes dont la corolle a quatro divisions. Le réceptacle est entouré de dix glandes d'où sort une liqueur mielleuse. Toute la plante a une odeur fortc. Elle sert en médecine.

29. La FRAXINELLE porte de grandes fleurs irrégulières en épis, des étamines chargées de points glanduleux et un seul pistil. La fleur répand le soir at le matin des vapeurs qui s'enflamment à l'approche d'une bougie.

\section{* Crucifères.}

Cenom indique suffisamment que les quatre pétales de ces plantes forment une croix.

3o. Le nAIFOR a une silique articulée et terminée par une corne arrondie. On le cultive poursa racine, qui, mangée crue, excite l'appétit. Le radis est une variété du raifort.

3i. Le siva ris a les siliques velues. Ses semences se mêlent avec du moust à demi épaissi, de la farine et du vinaigre. On broye le tout dans un moulin; ce qui forme cette pâte âcre et piquante qu'on apjelle moutarde. Elle sert à relever le goût des alimens fádes. 32. Le N A VET a les feuilles radicales

$\mathrm{K}$ 
découpées en lyre, celles de la tige sont en cceur. On le cultive pour sa racine qui se mange. Ses semences donnent par expression rne huile bonne à brûler.

33. Le сно у est une espèce du mêne genre, dont les feuilles épaisses, larges et fiisćes se réunissent en une boule; alors il prend le nom de chou pommé. Son usage est suffisamment connu.

34. Ja RAVE' appartient aussi an même genre, sa racine est sphéröide, au lieu d'avoir la forme d'un fuseau comme celle du navet.

35. Le colsa est encore une espèce du même genre. Sa graine donne par expressiox une huile bonne à brûlex, à faire du savoil noir, à préparer les cuirs, d̀ fouler lés étoffes de laine, etc. Le marc esí un excellent engrais.

36. Les GIROFLites se cultivent pour leur douce odeur et pour leurs belles couleurs panachées. Elles devienneni souvent doubles. On extrait leur arome pour différens parfums.

37. Le coculín a croít dans les lieux aquatiques et ombragés. Ses feuilles arrondies lui ont fait donner le nom d'herbe 


\section{d'Historke Naturente. 147}

aux cueilliers. C'estun antiscorbutique puissant.

33. Le c R ESS ON se plât aussi sur le bord des ruisseaux. Ses feritles sont aîlées, ses. fleurs blanches; it est unti-scorbulique; on le mange en salade.

39. La oudidi a les flemés jaunes, les feuilles radicales crónelées, celles de la tige en fer de tlèche. Après les avoir laissé flétu ir et les avoir broyées sous la rone d'un moulin, on les réduit en une pâte qui se durcit et se vend sous le nom de pastel. Il faut laisser tremper long-temps cette substance pour faire ce que les teinturiers appellent la cüve. Ils forment ainsi une couleur très-solicle dont on peut variẹ les nuances. Its l'employent pour la teinture blene et pour guelques autres, mềne celle en noir.

\section{* Nialfacées.}

On nomme ainsi les plantes qui ont des rapports avec la mauve. Leurs éramines sont rérnies par la hase et forment un tube au travers duquel s'élève le pistil, qui devient un fruit à plusienrs capsules.

40. La in u Y E porte sur une tige droite K. 2 
des fenilles à sept lobes aigus. La fleur est d'un bleu violâtre; le calyce est double; l'intérieur a cinq divisions, l'extérieur en a trois, et plus rarement une, deux ou quatre. Sa racine est mucilagineuse.

4.1. La GUIMAUVE a aussi un calyce double. L'extérieur a de six à neuf divisions. Ses fenilles sont simples et cotoneuses. Ses fleurs sont d'un blanc rose. Sa propriété est la même que celle de la mauve. Niais elle est encore plus mucilagineuse et plus pectorale. On en prépare pour le rhune, avec du sucre, cette pâte qui porte son nom.

42. La l A V A Ti in s'appelle aussi mauve encarbre, parce qu'clle approche de la mauve, mais sa tige est crdinairenont ligneuse; il y en a aussi d'herbacées. Le calyce extérieur n'a que truis divisions.

43. Le Goss Y P U m ou cotonier annuel est un sous-arbrisseau dont la capsule renferme des semences enveloppées dans du coton: Il croît dans ilos départemens méridionaux.

44. Le COTONIER est un grand arbre à fleurs jaunes, auxquelles succècle un fruit qui contient des semences noires enveloppées dans du coton. C'est celui dont on 
d'Historite Natereze. I 49 fait des mousselines, des toiles, des bas... etc. Le cotonier croît dans l'Inde et dans l'Amérique.

45. Le FrOMAGER nommé ainsi à cause de la mollesse de son bois, est un autre arbre exotique, qui donne un coton moins fin.

46. Le в А ов А les arbres. Le tronc a sept à neuf mètres de diamètre, il croît au Sénégal.

47. Le GACAOY r est un arbre d'Amérique, dont le fruit contient ces amandes arrondies, qui, broyées et mêlées, ayec du sucre, nous fournissent le chocolat.

\section{* * * Caryophyllées.}

Ces plantes sont celles qui ont du rapport avec l'œuillet nommé en latin cayyophyllus.

43. La mongening a de petites fleurs étoilées de couleur blanche. Ses pétales sortt fendus en deux, ses feuilles sont en cour. C'est le véritable mouron des oiseaux.

49. La I Y CNUIS a le calyce d'nne senle pièce, et cinq pétales un peu échancrés. L'espèce la plus commune est celle dont les 
fleurs sont blanches, et gu'on appelle vulgairement compagnons blancs.

50. L'oevilater s'élève dans les jardins à cause de l'élégrance de son port, de lá beauté de ses muances et de l'odeur qu'il exhale. Ses tiges sont branchnes; son calycc d'une scule pièce renferme cinq pétales frisés, et plus ou moins découpés. Le nombre des pétales augmente par la mćtamorphose des étamines dans les auillets doubles; cette belle plante offre de nombreuses variétés, elle orre les plates-bancies des parterres. On en fait des bonquets, des guirlandes; son arome entre dans les paríums.

51. Le L I s se cultive dans les jardins, à cause de l'agrément de sa fleur, et dans les champs pour son utilité. Sa tige, haute de sept décimètres, est simple et branchne seulement à son sommet. Ses fleurs à cinq pétales sont d'un bean bleu. Un fruit sphérique les remplace; il renferme dix semences dans autant de capsujes. Après avoir sépraré ce fruitavec un peigne nommé drégre, on rouit la tige comme celle du chanvre, on la file pour en tisser de la toile et de la baptiste, ou en faire du fil à condre. La graine du lin est adoucissante, clle donne par expres- 
d'Iistotre Naturtete. 151 siun une luile employéc dans l'imprimerie, dans la peinture et dins les vernis gras. Le son engraisse les bestiaux, la farine est résolutive.

XIV. PIANTES A DEUX COTYLEDONS.

PLUSIEURS ?ETALES. ETAMINES AUTOUR DU PISTIL.

I. LA JOUEARE est une plante grasse, dont la tige porte des fleurs à douze pétales. Elle se plait principalement sur les toits de chaume qu'elle fortifie, eile est rafrainchissarte; ses fenilies se maigent dans le Nord, coinme celles du pourpier.

2. Le Ghoseiller porte sur une tige éplineuse : des fleurs à cinq pétales, qui alternent avec les folioles du calyce. Elles sont remplacées par des baies blanches, dont on se sert comme de grains le verjus, pour la préparation de différens alimens, principalement des marucraux. Ce groseiller crô̂t sarvage ct cuilivé. On élève aussi clans les jarlins une autre espèce non épineuse, qui poite des petites baies rouges ou noires, d'un goût acide etagrćable. On anpelle cassis une espèce de groseiller à fruits noirs, lont on fait une excellenie ligneur.

K. 4 


\section{2

$$
\text { E L E M E N S }
$$

3. Ie pour pix a cinq grands pétales de couleur jaune. Ses teuilles sont épaisses et en forme de coin, elles se mangent en salade; c'est un aliment très-rafraîchissant.

4. La NÉRE sions, une corulle ì cing pétales. Ses teuilles sont éparses ct linéaires, ses fleurs rouges; ses fruits oblougs renferment des semences dont l'aigrctte peut servir à faire de la ouate.

5. Le santat, dont le bois est si odorant, croît dans les Indes.

6. Le nx n ти est un joli arbrisscau dे feuilles alternes, ct à fleurs blanches ou roses. Les artistes font de ses feuilles un ornement dans les sujets amoureux, parce quil étoit consacré à Vénus. Ses fleurs fournissent une eau astringente. Ses haies noirâtres doment un bon gồt à la chair des oiseaux. On en obtient une tcinture arcloisée.

7. Le círoriter est un arbrisscau des Moluques; le calyee et le germe desséchés avant te développement des fleurs, entrent an numbre des épices. On les nomme clous de gérofle à cause de leur forme.

8. Le Granter. Ce joli arbrisseau porte des fleurs d'un beau rouge, dont on 


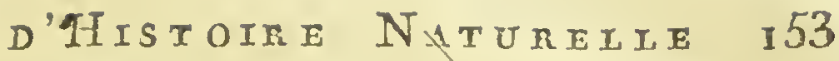

fait des bouquets. Son fruit sphérique et couronné par le limbe du calyce, entre dans la composition de plusieurs boissons acides; il contient un très-grand nombre de semences.

9. Le FUSAIN croit dans les haies; ce joli arbrisseau porte des fleurs sessiles, d'un blanc sale, à quatre divisions. Son bois est employé ì faire des lardoires et des fuseaux, d'où lui est venu son nom; on le sculpte aisément. L'enveloppe de ses baies donne une couleur rouge, elles peuyent servir ellesmêmes 'd teindre les cheveux en blond.

10. Le Houx a un calyce à quatre dents, la corolle en rone est blanche; ses feuilles sont ovales, aiguës et épineuses. Son bois est bon pour des onvrages de charpenterie. Ses jcunes branches tlexibles servent à faire des houssines et des manches de fouet. La seconde écorce de l'arbre putréfiée, pilée, lavée et reposée à l'air, forme ce mucilage épais appellé glzı.

I 1. L'amtenine. Ce beau genre, dont les fleurs ont cinq étamines recouvertes par des écuilles qui ticnnent lieu de pétales, renferme plusieurs espèces agréables et utiles. Ia principale est lo nerprzm, dont les fleurs 
maissent par propuets le long des branches, et auxpuelles il succède des baies qui plaisent aur petits oistanx. Ces baies, arant lemr matuice, donnent une comleur jame ct safrané:; mûres, elles deviennent d'an beau moir. Le sic cxirait, mêlè à l'alur, chrci ci séché dans les ressies, donne aux arts le verit de vessie. Ouand ces bairs ont passé le icrips de leur mat!rié, clies fomrnissent mn rouge propre d teindie les cuirs et à enluminer les cartes à joat. Le syrop de merimun est tiès-pinratif.

i2. Le Jux E I R approche beancoup de laluterne, mais son fruit nummué jujube est allongé. Les habitans des pays nóridionaux le mangent; il fon!nit d̀ la médecine une decocibn pectorale et adoucissante.

\section{* Rozacées.}

Ces piantes ont plusieurs pétales disposés conime cenx le la rose.

13. Le yo iririer a un calyce à cing divisions, cinq pétales arrondis, vingt éta- mines et cinq stiles. Son fruit est divisé incérieurement en loges cartilagineuses, renfermant cliacure deux semences appellées $p e ́-$ 
D'FISTOIRE NATUREIE. I55 pins. Il y a une foule de varićté du pommier, et ses fruits pronncut diférens noms selon leur fornc, leur conleur el leur largeur, tels que le rumbort, le fenouillet, la rainctie, etc. Toutes ces variétés doivent leur origine au pominicr sauvage, arbre dont les fleurs roses sont remplacées par des fruits d'un goût acerbe. Les pommes se mangent crues ou crites, on cin fait un extrait pour le rhume. Celles qui sont plus acides servent à faire un vin appellé ciclre. Après avoir pilé les pornmes daris cles anges de bois, on les porte au pressoir, et on met le cidre dans des tonneaux, oil il subit une seconde fernentation; on y mêle queịuefois du miel pom l'adoncir. On retire de ce vin du vinaigra, de l'eau-de-viè ei de l'alcohol; le marc crgraisse les terres.

14. Le pornizr ne difière du pommier que par la forme de son fruit turlinú, c'esta-dire, qui a la figure d'unc toupie. Ses frnits ou poires prennent diférens noms selon loñ variété. On les nango crues, cuites, on séchées au fomr et applaties. On fait a:ce le suc un vin nonumé poiré, dont on relive las mônes pónduits que du cidre. Is bois do poirier jicud sibien la couleur noin, gún 
ne peut le distinguer de l'ébène que par sun poids. Les luthiers, les tourneurs, les graveurs en bois en font un grand usage.

15. Jue coIG NASSIER porte un fruit en farne de poire, convert d'un duvet fin, on mange les coings cruds, on en fait du vin, des liqueurs, et cet extrait rapproché qu'on romme cotignac.

16. Le Nifler a des feuilles lanugineuses, des fleurs blanches ou ronges, remplacćes par un fiuit charnu, rond et couronné, et très-astringent. Le bois du néflier est très-dur, et s'employe pour les pièces de résistance.

17. L'azérozizer porte un fruit plus petit que la nèfle, on en fait des confitures.

18. L'A U B I IN est extrêmement agréable par la quantitéde ses fleurs d'un beau blanc, qui le font paroître convert de neige. Son fruit a un goût aigrelet. Il plaît aux merles, aux grives et à d'autres oiseaux.

19. Le cor MIEn a un calyce à cinq divisions, et une corolle à cinq pétales, d'un blanc sále. Ses feuilles ailées sont cotoneuses en dessous. Ses fruits ou cormes sont trèsastringens. Les oiseaux et les bêtes fauves les aiment beaucoup; les Suédois en font 
du vin. Le bois de l'arbre est très-dur, d'un gris cendré et susceptible d'un Leau poli; on le recherche pour les pièces qui fatiguent. Sun écorce sert à faire des sceaux. Elle est très-astringente et peut suppléer la noix de galle.

20. Le rosier a le calyce composé de cinq feuilles; les fleurs ont de même cinq pétales, mais elles en acquièrent souvent un plus grand nombre par l'expansion des étamines. La rose est la plus belle des fleurs; on en compte beaucoup d'espèces, toutes agréables par leur forme et leur odeur. Plusieurs ont des propriétés utiles, quelquesunes sont purgatives. La rose de Provins est employée à la guérison des blessures. Le distillateur et le confiseur préparent a vec la rose, des conserves, des liqueurs... etc. Le parfumeur en tire sur-tout le plus grand parti.

La fleur d'une espèce de rosier appellé églantier, se cliange en une baie ovale nomée gratecul. Cette plante porte aussi une sabstance sjongieuse, défendue par des pointes qui resse mblentau fruit de l'hippocastanum. Cette substance, traversée intérieurement par une multitude de filets, se nomme 
bedeguar; c'est une tumeur causée par la piqutre d'un insecte. Voyez cynyps.

21. La pintrentele a des tiges rongeâtres, qui portent des fleurs purpurines en tôte et terminales. Ses fenillesarrondies et dentelées se mangent en salade.

22. Le Fraisin a des fleurs blanches, auxquelles succède un fruit d'une nature particulière; c'est le réceptacle des scunences, qui grossit et se colore en rouge. Les semences s'y font remarcuer sous la forme d'une multitude de petits points noirs. La fraise se mange de diftérentes manic̀res, elle est très-rafiraichissante, on en recommande l'usage aux gouttenx. Le fraisier croît naturcllement clans les bois, ou se cultive dans les jarlins.

23. La noxcra les flours blanches et le fruit assez semblable à celui de la fraise. Il est formé de la réunion d'une infinité de petics baics sur le réceptacle. La tige est ligneuse, verte, anguleuse et armée d'aiguillous recourbés. Le framboisier, quellon culive dans les jardins à canse de son f́ruit, est une espèce de ce genre.

24. Le CEIISIER oftre, après ses fieurs blanches, des baies rouges pédiculées, ran. 


\section{D'Fistotre Natumeit.}

fermant un noyau et une amande. Son fruit se mange crut ou cuit, et de différentes manières. On en fait du ratiliat, un assez " bon vin, et on en obtient par la distilation une eau-de-vic très-forte, appelée kirchwasser. Son bois fait de jolis meubles, et donne une goume sembiable à celle dü prunier.

25. Le PRUNIER a des feuilies dentées, il porte des fruits ronds; qui renferment un noyau rempli d'une ou de deux amandes; il y en a plusieurs variétés qui se mangent de différentes manières. Le tronc est satiné. et propre à faice des meubles. Il laisse couler une gomme qu'on mêle souvent à la gomme arabique, et que les chapeliers employent sous le nom de gomme du pays.

26. L'Авлхсотхв a des firtits un peu velus, arrondis etsillonés d'un côté ; le noyau contient une amande douce ou amère. L'abricot a une saveur agréable; mais conme les fleurs tombent facilement, il trompe souveut l'espoir du cultivateur. On le mange de plusiears manières, et on le contit dans l'eau-de-vie. Le bois de l'abricot est de mêne nature que celui du prunier. Il donne une gomme absolument semblable. 
27. Le rếCHE est originaire de Perse. Son fiuit est velouté, rond, et contient un noyau percé de plusieurs trous. On en connoît une foule de variétés qui se mangent d'une infinité de manières, les noyauxservent à faire un bon ratifiat; leur amande donne par expression une huile amdre.

28. L'A MANDIE porte des fruits ovales un peu applatis, sillonés, verts et veloutés, qui enveloppent un noyau percé de plusieurs trous. L'amande est douce ou amère, selon la variété de l'arbre qui la produit. Ises amandes douces sc mangent de plusieurs manières et fournissent par expression une huile employée dans les potions calmantes. Le son sert à nétoyer la peau, on le nomme plile d'amande sèche. La pâte d'amande liquicie se fait en y joignant une huile aromatisée ; l'amande amère ne se mange pas.

$$
\text { * Léguminerises. }
$$

Ces plantes sont celles qui ont pour fiuit une gousse nommée en latin legumen. Leur fleur à quatre pétales et irrégulière se nomme papilionacée, parce'qu'elle ressemble ì un papillon. Le pétale supérieur se nomme pa- 


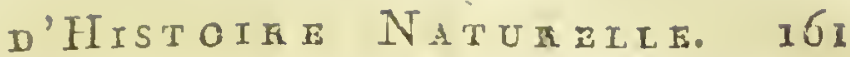

sillon ou ćtendard à cause de sa forme, il couvre toute la fleur et la préserve de la pluie. Les deux pétales latéraux s'appellent - les ailes. Ils sont souvent accompagnés de denx oreillettes à leur origine. Leur oftice est égalemeni de défenulre la fructification; Ia dernière pièce inférieure au pavillon et enfermée entre les ailes est la carène. Elle ressemble à une petite nacelle; elle est ordinairement d'une seule pièce et quelquefois divisée, alors les fleur' ont cinq pétales; les étamines, au nombre de dix, sont renfermées dans la carène et séparées en deux divisions, neuf sont réunies par la base, la dixième est séparée. Le germe en gróssissant devient une gousse, dans laquelle les semences sont attachées à une des valves.

29. La SENSITIV.Il y a un grand nómbre de plantes de ce genre. Leurs feuilles se contractent le soir, et se développent le matin. Quelques espèces ferment leurs feuilles ct les agitent au plus léger contact; ce sont celles qui méritent principalement le nom de sensitive.

3o. Le cassier est un arbre qui porte ces gousses purgatives qu'on appelle casse. Le scrné ext une espèce de ce genre, mais 
162 E $x$, 造 M E IN 3

elle est annuelle; ils croissent dans le levant.

'1. L'A JOAf c cst un sous-arbrisscau dont la tige et las feuilles sont hérissées de piquants, et qui porte des fleurs jammes. Il croît dans les licux incultes. Son hois sert à chauffer le fuur. Ses feuilles peuvent devenir un bon fourage quand on a rompu les épines à coups cle fléau; on en retire de la potasse.

32. L'nenatoxyion se nomme aussi bois a'Inde, bois de Campéche, du pays d'oì il vient; il sert à tcindre en rouge,

33. Le g en Es t. Ce 'gerre contient jusieurs espèces d'arbrisscaux et de sous-arbrisseaux inermes ou déf'enchus par des épines. Ils portent des fleurs jaunes et des gousses plus ou moins enflécs. On donne aussi le nom de genest it d'autres plantes yui on approchent par la forme, mais qui par lcurs caractères botaniques appartiennent à des genres différens, tels que le genest a'es ieinturices, qui est un spartizm, et qui donne une couleur jaune; et le gericst d'Espagne, qu'on culive pour l'ornement à cause de l'odeur de ses belles fleurs jaunes. 
D'Ifstotre Naturate. 163 ।

3. f. Le w u r. Ses gonsses renferinenides scmences orbiculaires yui se mangent comme celles dir pois.

35. LaI B U G R N E porte sur une tige rampante et très-épineusc des fleurá blanches avec des teintes rougeâires. On la nomme arréte-bcuf, parce qu'elle se trouve sonvent au millieu des sillons. La piqûre de ses épines est dangereuse.

36. Le trìte a les fenilles ternées, la fleur un peu ranassée en tềic, le légume à peine plus long que le calyce. Les diverses espèces de trèfle orneni les prairies par leurs fleurs ronges, blanches ou jaunes, et rendent le pîturage plus nourrissant.

37. Le aím L ot a le légume plus long que le calyce, les fleurs jaunes, il ressemble du reste an trèfle.

38. La tric onta e ou fenti-grec a le légume longr, comprimé et pointu.

39. Le r. o t in a le légume oblong. cylindrique et un peu anguleux. Ces durnières plantes se trouvent avec le trèfle.

40. Le ra i i coт a l'étendard réfléchi. Ses fleurs sont d'un blanc sale, ses légrmes pendans renforment des semençes blanches, rouges ou noires, en forme de rein. On l'ap- 


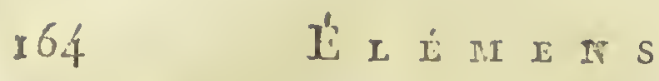

prête de différentes manières. Le légume lui-même se mange quand il est jeune et tendre, on le nomme haricot vert.

41. L'ARUS conticnt dans ses gousses ces petites semences rouges et noires, dont les peuples superstitieux font des chapelets. Ses feuilles sont sucrées et servent en Amérique au même usage que la racine de réglisse.

42. Le ROBINA. L'arbre que l'on connoît dans les jardins sous le nom d'acacia est de ce genre. Sa lige s'élève rapidement à une grande hauteur. Ses feuilles oblongues sont rangées far fraires sur une côte terminéc par une seule feuille, elles s'ourrent le matin et se ferment le soir. Ses fruits applatis conticnnent des petites scmences en forme de rein. Le tronc est bon pour Ies ouvrages du tour. Plusicnis autres espòces de robinia se cultivent pour l'ornement.

43. LC BAGUENAU D IER porte ces gousses gonflées d'air, qui se brisent saus le doigt avec éclat.

44. La RÉGISSE a des'flenrs rouges, sa racine rousse en dehors et jaune en dedans est pectorale. Elle donne aux tisannes, à la bierre...ect. un goht sucré. Son suc réduit 


\section{d'Itstotre Natutede. 165}

en extrait et mêlé avec de la gomne arabique est connu sous le nom de jus de réglisse.

45. Listidgotar produit cette fécule bleue connue sous le nom d'indigo, il croît en Amé:ique.

4̧6. Li G ess a a le calyce turbiné,I'étendart plus grand que les ailes Le légune allongé renforme des semences rondes ou un peu anguleuses. Celles de la gesse vulgaire se mangent. Le macjong est une espèce de gesse, dont la racine tubéreuse se mange comme celle de la pomme de terre. On cultive dans les jartins une espèce de gesse appellće pois de sentcur à cause de l'cdcur suave de ses jolies fleurs.

47. Le r o Is grimpe fucilement au moyen de ses vrilles; le légume allongé contient plusicurs semences rondes attachées par nn inince pédicule. Llles foumissent pendant l'élé une nourriture saine et abondante.

48. La V z S C p pousse des tiges angulenses. Ses feuilles rangcics par pirires sont acconlpagnécs de vrilies. Le légume est oblong; il contient dessemences roncies, noires ou b!anches, dont on nourrit les pigeons.... etc. 49. La r ì e a la lige druite, point de L 3 


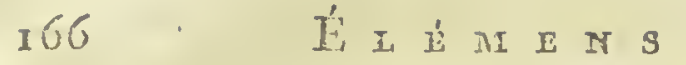

vrilles. Les fluvis sont blanches, les ailes talchetrés do noir. Le légume est énatis et contient de grosses seurencesen forme de rein, qui s'accommollent de plusieurs manières.

50. La r.moxti.e. A sa fleur blanche succède un lósnme court, qui renferme des semences griûtres, plutes et orbiculaires.

51. Le cich s. Sa tige droite purte des légunes rhombö̈daux, qui conticnrent des scmences dont la forme approche de la tête d'un bélicr. On les donne anx chevaux, on les mange lans le miti de l'Enrope.

52. Le 's ax x forr a des feuilles semblables à celles du treffle. Ses fleurs sont rouges, ses légnnues articulés. C'est un excellent fourage.

\section{* * Térébinthacícs.}

Ces piantes ont du rapiont avec le térébinthe.

53. L's a j o u porte des noix semblabies à une semence réniforme. On les mange de plusieurs manières; il n'a aucun rapport avec le bois auquel on donne improprement ce nom; celui-ci est le mahagoni. 54. Le triris In th di csi un arbre dioique. 
n'Histoire Naturele. í́t La femelle portc mu firuit sec et ovale, qui cuticni une nuix monosperme. La pistache est l'ammie du pistachier, espèce de térébintik. On la mange de plusieurs manidres. Lei li Pérens térébintlos foumissent une résine par incision; telles sont. le mastic, la térébonthine de Chio, qui se mâche.

55. Le n o r $\mathrm{x}$. Cet arbre monsiuque devient tics gros; les fleurs femelles sont remplacées p ur des fruits charnus, ils renferment une roix bivalve, celle-ci contient une semence qui se distribue en plusieurs lobes. Les noix encore vertes se nomment cernaz $x$ et se mangent avec du sel et du poirre. L'écorce appeilé brou sert à faire un bon ratafiat. La coquille se brûle, l'amande mise au pressoir donne une huile comestible et dont on lait des vernis gras. Le marc pressé de nowreau donne une seconde huile bonne à brûler. 
XV'. PLANTES A DEUX COTYLEDONS.

POINT DE DLTALES. ETAMINLS ET PISTILS SLPARES.

\section{* Euphorbes.}

Ces playtes ont tontes des rapports avec le tithymale, exphorbia; la plûpart sont vénéneuses.

1. Le TI TIX A A L E a une cor̈olle à quatre ou cinc pétales, insérée sur un calyce ventru, et une capsule à trois coques; on en trouve en France plusieurs espèces qui donnenit un suc laitcux, îcre et canstique. La plus commune est celle nommée réveilmatin à causc de la cuisson que ce suc cause aux yeux.

2. Le buIs a les fleurs monoiques. Ses feuilles sont nombreuses, ovales, creusées et d'une saveur désagréable; on en compie denx variétés. Le buis nain qui encadre les parterres, et le buis arborescent, dont les tabletiers font tant de jolis ouvrages.

3. Le MANIOT produit une racine, dont la fécule nommé cassave sert de nourriture à plusieurs peuples de l'Amérique. Si cette racine étoit mangée crue, sans être 
d'Historre Naterelce. privée par le lavage, la trituration et la cuisson, de son suc laiteux, ce seroit un poison mortel.

4. Le aANCENITR donne un suc laiteux et vénéneux dans lequel les sauvages trempent la pointe de leurs flèches.

\section{* Cucurbitacées.}

Ces plantes ont des fruits ronds ou allongés, semblables à celui de la citrouille, cztcurbita. Ces fruits sont charnus et contiennent les semences au milieu d'une substance fongueuse. On les mange, ou on les vide pour contenir des liqueurs.

5. La pry ONE rampe dans les haies. A ses fleurs blanches monoiques succèdent des baies lisses et globuleuses. Sa racine fournit abondamment de l'amidon.

6. Le corco ar r e a des fruits longe de trois décimètres, gros comme le bras, anguleux ou verruqueux, jaunes ou verts, arrondis par les extrémités. On les mange de plusieurs manières; les fruits encore verds et confits dans le vinaigre, se nomment cornichorss.

7. Le refon a les feuilles plus petites 
que celles du concombre. Les fleurs naissent des aisselles, les firuits som romds ou ovilles, unis, galunnćs on à côte; il y en a une fomle de variétés, la semerece cost tris-ra-, frâichissante, elle plait aux chcvaux.

8 Lepotrox a le fiuit rond, jame et extrêmement gios. Cu le mange de plusieurs manières. Lí semence fournit pal expression une luile banne contre les maladies de la peau.

9. La counGE porte un furt qui ressemble assez ì unc bouteille; cn s'en sert en eflet pour lc nuêmc usage après l'avoir vidéc etséchéc.

\section{$* * *$ Orties.}

Ces plantes sont monniques ou dioiques, rarement hermaplirodites.

10: Le Figuier offre dans sa fructification un pliénomènc particulier. Les fleurs sont renfermées dans le fruit même : poux les féconder, il faut a voir recours ì un moyen singulier appellé caprification. Quelques larves de cynips se nourrissent sur le figuier. Quand l'insecte cst parfait, les culrivateurs portent la figne sauvage sui le fi- 
D'Historat NAturetit.

guier cultivé: l'insccic sort, tout couvert de la poussière des étamines de la pinute. Il pénètre dans la tigure, qui lui est offerte, et porte sur ses pistils le gyerme de la fécondution. Ces fruits grossissent beaticoun, ce sont les seals qui aient des graines. Partout ou la caprification n'a pas lieu, le figuier vient le bouture. La figute est la principale nourriture des habitans de l'Archipel, on la mange crue ou séchéc, le bois du figuier sert aux armuriers, il s'imprègne bien de poudre d'émeril, et devient ainsi propre à polir les instrumens. Il a un suc laiteux et caustique.

I1. L'A R B E A $\mathrm{PAIN}$ est ainsi nommé, parce que son f'ruit d'un goût cxcelient pout suppléer le pain, et croît dans les Indes.

I2. Le MEU $\mathbb{R}$ I $\boldsymbol{R}$ sert à nourrir les vers à soie; c'est principalement le meurierblanc qu'on destinc á cet usage. I! se distingue à ses feuilles lisses et en cour. Ses branches font d'excellens fagots. Les oisenux aiment beaucoup scs fruits. Le memicr roir a aussi les ferilles cn cour, mais rudes au touciver; elles peuvent dans le besoin se substituer aे celles drineurior blanc. Le fruit esi laxatif et rafraichissant, il noircit les mairs et 
laisse sur le linge des taches qui s'effacent difficilement. On s'en sert pour funcer le rouge de différentes liqueurs. Le bois sert aux toimneurs. L'écorce rovic est bonne à faire des cordes, on en falbrique un excellent papicr.

33. L'or tis a des fleurs clioiques disposées cn grappe. Ses feuilles sont armées de piquans très-lins, qui restent dans la blessure et y causent une douleur cuisante. On peut en faire du papier.

14. Le IIOU B LON embrasse étroitement la tige sur laquelle il s'appuie. La femelle porte des petits firuits assez semblables à des cônes de pins, on les net dans la bierre pour l'empêcher de se gâter et lui donner une agrćable amertume. Les jelnes pousses se mangent comme les asperges.

15. Le cir a v v n e porte des fleurs dioiques disposées en grappes sur une tige quadrangulaire. Ses fenilles sont divisées et ont une oleur forte. L'individu fcmelle a des fruits qui contiennent des semences lisses et arrondics, dont la pulpe blanche et huileuse a une odeur forte. Quand le chanvre a été récolté, on lé hat pour en tiver ła graine. On le fait rouir dans l'cau; cette opération 
D'Histotre Naturele. $17^{3}$ dissont la substance grommeuse qui agglutine les fibres. Quand le chanvre a été bien roui, on le lave et on le fait sécher au soleil en évitant la vapeur forte qu'il répand.' On le broye, on rompt l'écorce ou chenevote qui se récuit en poussière. Les filamens longitudinaux forment une filasse, que l'on bat encore pour la séparer des matières qui l'altèrent. La filasse se peigne, pour lui donner plus de douceur. On la tile, on en tisse des toiles grossières, et on en fait.des cordages. La semence de chanvre, appellée chenevi, se donne aux oiseanx de basse-cour. 'On en retire par expression une huile à brûler, on l'employe aussi dans le vernis siccatif.

16. I c p o r y e qui nous vient de la Chine et des Moluques, est la graire de plusieurs arbustes de cette famille.

\section{$* * * *$ Amentacíes.}

On appelle amentacées les plantes dont lesfleurs sont à chaton, améntum, c'est-àdire attachées plusienrs ensemble átutour d'ur filet commun. Ces fleurs sont ordinairement monoiques, plusieurs sont dioiques, quelques-unes hermaphrodites. 
+ Fleurs hermaplitodites.

17. L'oxis est un grand et bel arbre dont la racine est rougoatre et le tronc lroit et rameux. La flemr est en cnturuoir. Il lui succède un fiuit renfermé dans mne enveloppe meubraneuse, et qui coutient mue amande douce au gônt. Les feuilles sont boxdées de dents alternativement plus grandes ou plus pelites. La partie inférieme esi plus large que la supérieure. Les branches de l'orme se compent tous les cing ans pour en faire des fagots. Le tronc est excellent pour le charonage, il se corrompt diflicilement.

\section{+ Tleurs dioiques.}

IS. Le sAULE porte des cliatons cmbriqués, chaquc écaille conticnt une fleur. Le tronc estrabotcux; 'jes branches sont flcxibles et accompagnées de feuilles allongćes, grisâtres d'un côté, vertes de l'autre. Il y en a plusieurs espèces. L'osier plus flexible sert à faire des liens. Je marccar cost cmployé à faire des charpentes, des paniers et d'autres ouvrages de vamueric. Le savile commun sert au vanier. Celui quoon n’a pas étêté 
d'Historrs Naturexis 175 donne des plinclies asscz large.. Son charbon est excellent puar la poulre à canon. Les aigrettes de ses semences peuvent se convirtir en papier. Cet arbre f'ait l'ornement ies prés. Le saille pleurezir dont les Lia iches sont renversées, est extrêmement agriable lans les lieux arrosés, sombres et tran puilles.

19. Lu reUpLa est un arbre très élevé, dunt les fleurs forment des chatons lâches, cylinlilifes et allongós. Cet a:bre cruît promptement. On distingne le ponplierblanc, clont les feuilles sont velues et blunchîtres en dezsons; le peuplier noir, dont les feuiles triangnlaires sont d'un verd plus foncé. Le peuplier d'Italie, si commun en France, et qui s'élève en pyramile, est une variété du peupliernoir. Les feuilies dn peuplier plaisent aux bestiaux, les boutons ont une odeur agréable, ils entrent dans la composition de l'onguent populerım. On en retire aussi une espèce de cire. Le duvet des semences peut servir à faire du, papier. 
I76. EैL

+++ Flcurs monoiques:

20. Le во и L в u. L'espèce la plus connue est le bouleau blanc, ainsi nommé à cause de la couleur de son écorce; ses semences sont anguleuses, ses feuilles orales ct finement dentées. L'écorce extérieurc de cet arbre peut entrer dans le tan, elle donne une couleur ronge. Les Lapons la coupent par grandes plaques pour s'en vêtir; les Canadicns en fabriquent des camots. En Sudde on en couvre les maisons et on en fait ćles bouteilles. Son ćcorce interne a aussi les mêmes usages. Les Kanchatckidales la tranchent par petits filets, et la mangent avec le caviar. Le bouleau donne au printems une liqueur vinerse, analogue à celle qui déconle du palmicr. Le tronc est bon pour faire des manches d'outils, des sabots. Le charbon est excellent pour les forges ct pour les dessinateurs. Les feuilles donnent une couleur jaune; les branches de celui qu'on élève en taillis servent à faire des cerceaux, des ouvrages de vannerie, des liens et des balais. L'aulne est une espèce de bouleau, qui se distingue par ses fruits angulenx. L'écorce est astringente, eille dome une couleur 


\section{d'Histotre Naturite. 177}

leur rouge. Le bois se corrompt difficilement et il est d'un bon usage.

21. Le C F A R M porte des chatons lâches dont les écailles sont uniflores. Son tronc est court, disproportionné et silloné par des nerfs qui partent de sa racine. Sa tête ofire un amas de branches accompagnées de feuilies ovales et crénelées. On l'employe pour fiure ces belles palissades nommées cơurnillos. Les branches servent à faire des fagots, ie tronc à façonner des meubles. Les bestiaux aiment, ses feuilles.

22. Jue in tr r porte un fruit épineux, dur et relevé paŕ quatre côtes; il contient quatre senicnces triangulaires dont la pulpe est blanche; on les nomme faines. Elles ingraissent les cochons, on en retire une huile douce qui a iu rapport avec celle de la noisette. Le buis sert aux charrons, aux ébínistes, auximenuisiers, maio les insectes l'attaquent facilcrient.

23. Le chatignier a l'écorce lisse et tachetée de gris. Le réceptacle des fleurs femelles se change en un fruit épineux qui laisse écllapper doux grosses sernences brunes aplelées châzignes. Les habilans des montagres en font leur principale nomriture. 
On Ies mange crues, rôties, bouillies ou réduites en fécule. "On leur fait prendre un goul sucré en les laissant germer avant de les sécher. On en donne aux bestiaux et à la voLaille. Le bois est solide, presque incorruptible, et très-utile pour la charpente.

24. Le cuk̂ne a le tronc couvert d'une fcorce raboteuse, ses feuilles sont découpées. Les fruits ovales, appelés glands, sont enfermés dans une espièce de capsule. Ils contiennent ure amande d'un guât âpre. Le chêne èst excellent pour la chrmpente des maisons et des vaisseaux. Son écorce et sa sciure servent à tamner les cuirs. Le gland peut se manger dins les teraps de disettc. Il engraisse les cochons et la volaille. L'amande donne de l'huile, ses feuilles fortifient la terre par lés sels qu'elles cuntie nnent. On en tresse la couronne civique, récompense gloriense du vrai patriotisme. Ses feuilles sont souvent blessées par des insectes du genre cynips. Iis $y$ causent ces excroissances nommées pomme de chêne. La noix de galle est occasionnée par la piqûre du cynips noir sur le chêne du levant. Le liege est l'écorce d'une espòce de chêne appelé cluêne liçzier; òn la 
D'HTSOIRE NATURELE.

trempe dans l'eau, on l'expose sur des clmabons enbrîsés. On la redresse en la chargeant de pierres, on la gratte et on la nétinye. Cente écorce légère sert à faire des botichons, et à sumtenir les filets sur l'eau. Le noir a" fispagrie est le charbon du liége brité lano des pots converts.

25. Le coedrier perte un fruit rond enveloplé dans une coëffe membraneuse. tó noisetier est une espèce de ce genre. La noiselte est très-nourrissante; on en retire nne hivile dunce. Le buis fait de bons cerccaux.

26. Le ruatane est droit et élevé, il a pèu de branches basses, nuais sa tête est très-tunffue, ses fenilles sont sinućes. Il se dépouille lui mêrme de son écorce qui est lisse et blanche, et se détache par̃ grandes pluciues. On le cultive pour l'ornement.

$$
\text { ***** Coniferes. }
$$

Les fleurs de ces arbres sont monöiques ou diö̈ques, et le plus souvent en chaton. Le fruit a le côre composé d'écailles ligneuses appliquées les unes sur les autres, s'ourrant par le haut, ct lixées par le bas 
sur un axe qui occupe le centre. La plûpart de ces arbres conservent leur verdure pendant l'hiver.

27. L'IF est diöique. Ses feuilles pointues sont disposées comme les dents d'un peigne. On donne à cet arbre toutes sortes de formes en le taillant.

28. Le gínevrier s'élève à la hauteur dé deux mètres. Ses fleurs divịues sont remplacées par des baies spliériques qu'on nomme geniève, on grains de grenicyre. On les fait entrer dans divers assaisonnemens. On en fait un vin et un ratafiat cordial; on les brûle pour aromatiser l'air. Les ébénistes font avec le hois de julis ouvrages. L'écorce est bonne à faire des cordes; le charbon brûle long-temps. Il découle du tronc une résine recherchée des fourmis. L'encens est le produit du génevrier thurifère, qui croit en Arabie. La sabine dont les feuilles sont opposées et décurrentes sur le rameau, est áussi une espèce de ce genre.

29. Le cyprìs est monö̈que, les fleurs mâles forment des chatons ovales, et fournissent un pollen abondant. Les fleurs feraelles sont remplacées par des fruits zonds 


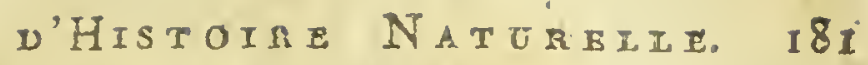
et raboteux, appelés gallizles ou noix de cyprès. On connoît plusieurs espèces de cet arbre, qui toutes font un bel effet dans les bosquets. Le tronc pent devenir très-gros. Le bois est d'un jaune pâle et roxgeâtre, parsemé de veines plus foncées. Il fait de très-beaux ouvrages, et se corrompt difficilement. Les cyprès fournissent par incision une substance qui ressemble à la gomme adragant. Les abeilles la recherchent avec soin pour en composer leur propolis. Les fruits sont astringens, et, regardés comme fébrifuges.

30. Le PIN croit sur les montagnes, il a le tronc druit et rameux; ses cônes appelés improprement pommes depin, sont gros, arrondis et rougeâtres. Ils renferment des amandes blancires, douces, pectorales et. rafraîchissantes, qu'on nomme pighons. Los pins mâles donnent une quantité pro¿igiense de poussière séminale, qui, portée par les vents, a fait croire à des hommes superstitieux, qu'il pleuvoit du sonfre. Les doigts imprégnés de cètte poussière se plongent dans l'eau sans en être baignés; elle s'enflamme aisérment comme, celle du lycopode.

M 3 
L'espèce appelée pin inaritime, est la plus importarte d̀ caluse de sa résine, qui s'obtient par incision; tondue à un feudoux, on la nomue poix de la Cóte d'Or; nêlée avec du noir de linméce, elle donne la poix moire. Elle sert aux cordonniers pous poisser leur fils; on en garnit le col des bonteilles. On la nomme comfosément porx résizc. Cette matière fondne avec din vimnigre devient sèche et brune, et forme ia colophane, dont on se sert pour dégraisser l'archet des instrumens à corles. En brûlnnt Ia résine et en comclensant la funée, on obtient catte suie fine connue sous le nom de zoir de funcu.

31. Le sapró de uistingue par sos écailles femclles, oblongues et en masse, ses côncs regaruent le ciel, pendant que coux du pin regardent ba tere; il sélève à ure très-grande hauteur, ce qui le rend atile poux la, mấture des vaisseaux; on le débite cu planches, et il est bon à brùler.

32. Le núitèz est une espèce de ce genre. Son bois sert pour les construclions maritimes, c'est celui qui donne la térćbenthine.

33. Le ciore a des feuilles articulées, roncles, puintues et en faisceaux; il par- 


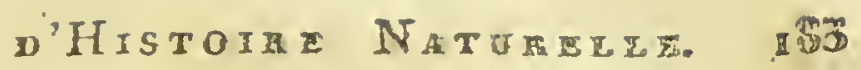
vient à une grande élévation. Le bois est ruugeûtre et odoriférant, on én lait do julis ouvrages de tablettcrie, dos tubes de crayons. On le brûle dans les pays oì il est commun, à cause du parfun rửì répand On pourioit le multiplier en France. 


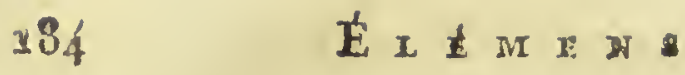

\section{A N I M A U X.}

I ous les êtres organiques qui jouissent de la faculté locomobile, celle de changer de place à rolonté, sont des animaux. On a imaginé différentes méthodes pour les classer. On a établi des caractères nombreux pour les distinguer et les décrire. Voici ceux auxquels il suffit de s'attacher. 


\section{CLASSES DES ANIMAUX.}

I. MAMMIFÈRES. $\left\{\begin{array}{l}\text { Mirmelles. Corps couvert de } \\ \text { poils. }\end{array}\right.$ II. OISEAUX....... Corps aílé, couvert de plumes. III. AMPHIBIES.... Corps sans poils. Ovipares. IV. POISSONS....... $\left\{\begin{array}{l}\text { Corps couvert d'écailles. } \\ \text { Nageoires. }\end{array}\right.$ V. INSECTES....... $\left\{\begin{array}{l}\text { Divisés par segmens.Pourvus } \\ \text { d'antennes. }\end{array}\right.$ VI. VERS............. Ni preds, ui ćcailles.

\section{I. $M A M M I F E R S$.}

Les animaux de, cette classe portent des mammelles, au moyen desquelles ils offrent à leurs petits d'abondantes sources de lait. Ces petits naissent vivans et sans. être enfermés dans une enveloppe. 
Le corps des mammifères est en général couvert de poils. Ils ont quatre pieds, at l'exception de quelques-uns, dont le corps est lisse et qui en sont dépourvus. Leur corps se partage en truis parties; la téte, le tronc et. les soutiens.

La tétc est le séjour des principanx organes des sens; la bouche, le nez, les yerix et les orcilles.

La bouche composée des.lèvres, des dents et de la langue, sert à l'animal pour prendre sa nourriture. Les lèvres retiennent les alimens. La languce les retourne, les dents les déclirent et les broyent pour les réduire en une pâte plus facile à digérer.

Les dents sont implantées dans deux os mobiles, qui forment la machoire supérieure et la mâchoire inféricure. Celles de devant dont l'office est de couper, sont ordinairement taillées en bisean, et se'nomment incisives; celles qui les suivent coniques et crochues, sont destinées à déchirer. On les appelle canines, parce yue c'est dans le chien qu'elles sont sur-tout remarquables. Les dents du fond de la mâchoire, sur lesquelles les alimens se broyent, se nomment molaires, et en gé- 


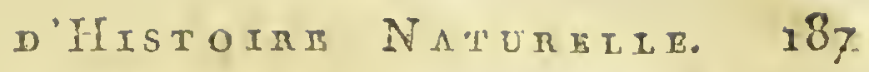
néral elle sont en effet applaties comme une meule. Quand les incisires sortent beancoup de la mâchoire, on les nomme défenses, parce quelanimal les rend souvent fatales à ses ennemis. Le nombre, la forrie et la disposition des dents méritent d'être examinés avec attontion, parce qu'ils serverst à distinguer les mammifères.

Le nęz est un corps charna et percé de trous appelés nainines. Celui de quelques mammifdres est surnonié d'une excroissance qui affccte diférentes formes, ow armé diune corne. Les narines extrêmement cuvertes prennent le nom de nascazı; certaines espèces n'ont à la place du nez que des trous appeiés ouvertures nasales.'

Les oreihes sont des trous; ordinairement accompagnées d'un pavillon qui les défend on les'recouvre, et qu'on nomme: le pavillon de l'oreille, ou l'oreille externc. Ce pavillon manque à quelques espèces, et les sons se transmettent par les. simples trous que l'on nomme auditifs; parce qu'ils servent à entendire.

Les ycux, urganes de la vue sont défendus par les paupieres, nembranes mo biles, nuses ou gavies de poils, nommés 
cils; on $\mathrm{y}$ distingue la pupille, qui est absolument ronde, et l'iris, c'est le cercle qui l'entoure. Les sourcils forment une ligne courbe au-dessus de la paupière supéricure. Presque tous les mammifères ont les yeux très-marqués, quelques - uns voyent mieux la nuit que le jour.

Les autres parties de la tête sont le montou à son extrémité, la face qui s'étend du menton au sommet de latête, les joues placées aux derux côtés de la face, et le sommet qui domine le front. Il est nud, orné d'une crinière droite ou pendante, ou arrsé de coines redontables.

La tête tient au tronc par le col, qui. est plus ou moins gros, et plus ou moins long. On distingue dans le tronc, le dos et le ventre, qui se partage lui-même en trois parties. La poitrine, le ventie proprement dit, et l'anus. Cette dernière est ordinairement cachée par. la queue, instrument mobile et garni de poils, qui sert au mammifère d'abri contre la pluie, de défense contre les ennemis qui l'attaqũent, et de houssoir pour chasser les insectes importuns.

On appelle soutions, les instrumens dess 
d'Histoire Naturelle.' 189 tinés à soutenir les mammifères dans un milieu quelconque, ou sur un corps solide. Ce sont les pieds, les'nageoires, ou les membranes.

Presque tous les mammifères ont quatre pieds, terminés par un ongle d'une seule pièce, ou par un nombre de doigts plus on moins considérable, depuis deux jusqu’à cinq. Ceux qui ont les doigts fendus se numment fissipèdes, ils sont didactyles, tridactyles, tétradactyles, ou pentadactyles, selon qu'iis ont deux, trois, quatre, ou cinq doigts. Quelquéfois ces doigts sont palinés, c'est-ì-dire, réunis par me membrane, ce qui les,aide à nager. Ils sont toujours terminés par des ongles plus ou moins aigus. On nomme ceux-ci rétractyles; quand ils peuvent se repliei sous les doigts.

On appelle onguiculés, les mammifères qui ont plusieurs ongles, ceux qui n'en ont qu'un.sont ongulés; quand cet ongle est d'une seule pièce, sa ressemblance avec une sandale ( 1 ) a fait donner le nom de solipedes aux mammifères qui en sont

(1) Solea. 
pourvus. Si cet ongle est partagé par la moitié, ils reçoivent la dénumination de bisulces ou pied's fourchu.s.

Quelques mammilères ont les doigts antérienrs très-longs, et formant un angie très-ouvert; l'intervalie est rempli par une anple membrane, véritable voile qui leur procure l'avantage de fartager avec ies oiseaux, l'enpire de l'air. La ressemblance de ces pattes menbraneuses avec cies aîles, a mérité aux animaux de ce gonre le nom de chićropicires, c'est-à-dire, à mains ẩćcs.

Plusieurs mammifères n'ont point de pieds. Ces soutiens sont remplacés par des naggeoires, instrumens beaucoup plus ntiles à ces animaux destinés à passer leur vie dans le vaste Océan.

- Le corps et ses différentes partics sont courerts par la pezur. Cette cnveloppe commume est cliez quelques-uns nue et lisse, mais chez ia plipart elle porte des poils çui reçoivent le noun de crins, de piquarzs, de bourre, ou de cuset, selon leur longueur et leur densité. Les différentes couleurs de ces poils confondics ou séparées forment des raies, des bandes, des iaches. Le vontre de l'animal défendn par le corps, de l'ins- 
pression de la Innière, esr toujours d'une coulcur moins foncée.

Ia desciption des parties internes des maumifères applartient à l'anatomie, mais il est nécessaire d'avoir une idée des fonctions de leurs différens organes, puisque le jeu de ces organes et la continuité de ces fonctions produisent, entretiennent et constituent ló vie.

La premiere est la circulation. Ce fluide chand ot ronge appelé sargo, part d'un réestroir commun, le ccur, pour parcourir des vaisseanx nomınés artères, et il y est repolt par d'autres raisseaux, qui ont le nom de veines. Si ce mouvement alternati! s'itrête, c'est la mort, c'est la cessation do l'existence.

Iendart la circulation, quelques liqueurs se séparent du sang, et conduites par des petits vaisseanx, s'amassent dans des réservoirs particuliers. Ces liqueurs qu'on nomme sccrétiors, ont ordinairement une odeur forte, et servent à diférens usages.,

L'atmospluére, qui nous baigne et nous environne, est un composé de différens airs et d'antres substances aussi légères. Aspircé par la bouche, il péndtre le poumon. 
corps spongieux qui en sépare l'air vita; le seul propre à l'entretien de la vie, et la matidre de la chaleur nécessaire pour entretenir la fluidité du sang. L'air qui resto donneroit la mort s'il n'étoit expiré, s'il ne sortoit comme il est cntré. L'actior d'aspirer l'air atmosphérique, d'en. séparer I'air vital et la matière de la chaleur, et d'expirer cet air mortel appelé mofélc, constitue la respiration.

La digcstion consiste a extraire des alinens les sucs nourriciers qu'ils renferment, les dénts les broyent, la salive les humecte et les dissout; réduits en pâte, ils entrent dans un canal qui se continue depuis la bouche jusqu'ì l'anus. Ce canal éprouve arr-clessous de la poitrine un renflement appelé estomac: Les alimens pénétrés et dissuns par de nouveaux sucs y sont encore broyés par le froitement des membrancs qrii le composent. Les sucs nouriciers s'expriment, leur réunion forme le c/ile. Ce fiuile absorbé par.cles petits canaux nommés vaisseaux chilcux, sert à l'entretien de la cliair et du sang. Le canal alimentaire se rétrécit en quittant l'esiomac, il se contourne, se replie en une infunité de 
d'mistotre Natureite. $19^{3}$ sens, et prend le nom d'intestins. Le résidu de ce qui n'a pas éié transformé en Ghile, traverse ces nombreuses sinuosités et s'échappe par l'anus.

La nutiriou est la suite de la digestion. et de la circulation. Chaque organe se nourrit ou se répare au moyen d'un suc particulier qüil sépare du sang, ou d'un autre fluide qui l'arrose; c'est ainsi que 'os os croissent avec l'âge, et se réunissent après avoir été brisés.

Le corps des mammifères est soutenu par les os qui forment sa charpente; à ces is s'attachent les muscles, assemblage de tilamens enveloppés de membranes, et terminés par des cordes plates ou arróndies nommées tendons: dès que ces muscles sont excités par un aiguillon, un stimulant quelconque, ils s'irritent, se contractentet font jouer ainsi toutes les parties dir corps. C'est cette irritabilité qui donne aux animaux la faculté de changer de place, et d'exécuter toute sorte de mouvemens.

Les muscles ne son't pas les scules cordes des animaux, ils en ont encore d'antres appelées nerf's, qui se prolongent dans la cavité de l'épine du dos, et se réunissent par 
paires au cerveau. Ils épronvent du plaisir ou cle la douleur selon la nature des corps qui pincent ces cordes, et c'est ce qui produit la serssibilité.

I.es animanx sont plus ou moins donés d'organes propres à ces différentes fonctions; les mammifères les réunissent tous.

Les mammifères se nourrissent de chair ou de végétaux, selon la conformation de leurs dents, de leur estomac et de lcurs intestius; quelques-uns mangent indistinctement de tout. Mais en général ils n'ont ni les mêmes goûts, ni le même appétit; autrement ils épuiseroient bientôt leurs alimens, ou, réunis dans un même lieu, i]s y porteroient la famine et la peste; mais les uns cherchent les climats chauds, d'autres préfèrent les climats froids. I'un aime les collines exposées au midi, et les roches escarpées, l'autre se plaît dans les bois, l'autre ne peut trouver sa nourriture que dans les plaines. Telle substance délicicuse pour une espèce, est pour un autre, ws poison actif et moriel.

Tous les mammifères peuvent faire entendre des sons, mais aucun, excepté l'homme, ne sauroit prononcer des mots. 
D'Histoing Naturite. ig Leur cri a cependant quelque diférence, et chacun reçoit un nom particulier.

Quelques-uns changent continuellement de séjour, d'autres ont des demeures fixes; ils y vivent seuls ou en,société. On appelle domestiques ccux quel'homme a su dompter, pour les rendre les compagnons de ses travaux; sauvages, ceux qui vivent loin de lui en liberté, et ne sont ni ses serviteurs, ni ses esclaves. Enfin ceux-là sont seulement apprivoisés, qui, sans éviter l'homme et sans le servir, souffrent sa compagnie et son approche.

Dès que l'hiver se fait sentir, grelques mammifères s'ensevelissent sous les neiges, et $y$ passent des mois entiers sans mouvement et sans prendre de nourriture; c'est ce qu'on appelle hyberner. I.a manière dont chacun hyberne est diflérente. En général ils se roulent en boule, quelques-uns s'accrochent les uns aux autres par les pattes. Les mammifères n'hybernent $t_{u}$ pas quand ils sont gardés dans des lieux ou ils éprouvent une chaleur suffisante.

Presque tous les manmifères foulent la surperlicie de la terre. La vaste mer est la demoure de quelques-uns; d'autres passent 


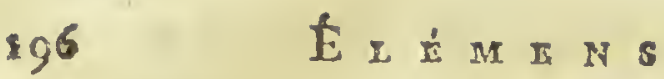

alternativement leur vie sur la terre ct dans les eaux; mais aucun de ceux - ci ne pourroit exister, s'il restoit constamment dans ce dernier fluide : il y trouveroit la mort.

Quelques mammifères peuvent traverser les airs : ils sont en pelit nombre.

On appelle gestation, la durée du temps pendant lequel la femelle porte ses petits dans ses flancs. Elle les allaite jusqu' घ̀ ce qu'ils puissent cheicher eux-mêmes la nourriture qui leur est propre; elle leur apprend a se la procurer. Enfin, elle ne les abandonne que quand ils sont en état de se défendre. Il cst rare que le mále partage aver elle les soins et les peines de cette éducation.

Dans l'économie générale de la nature, les mammifères sont chargés d'entretenir, dans le nombre des animaux, un équilibre constant. Pendant que les uns reproduisent de nouveaux individus, d'autres s'opposent à leur trop grande multiplication, et ils débarrassent la terre des cadavres inutiles.

Leurs usages particuliers sont aussi importans que nombreux; ils nous fournissent lour chair, leur sang, leur lait et leur graisse 


\section{d'Histoint ifaturete. 197}

pour notre nomrriture ; leur toison pour nous habiller et nous convir; leur peau pour différens usages. A vec leurs dents, avec leurs cornes, on fabrique clivers usteriles. Quelques-uns de ces animaux partagent avec nous les danger's des combats, d'autres poursuivent, atteignent et nous apportent les animaux utiles à notre subsistance. Les uns ouvrent le sein de la terre, d'autres traînent ou transportent des fardeaux. Il faut donc connoître leur histoire, pour soigner et multiplier les espèces utiles, et anéantir celles qui peuvent nuire. Sous ces deux rapports, leur étude est aussi nécessaire qu’elle cst curieuse et amusante.

Le nombre des mammifères connu s'élèvo à près de quatre cents. Nous n'examinerons que les plus importans; nous les distribuerons en cing ordres, d'après la forme de leurs picds. 


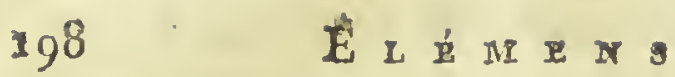

ORDRES DES MAMMIFERES。

* Ongziculés.

I. FISSIPÈDES....... $\left\{\begin{array}{l}\text { Doigts siparis. Plusieurs } \\ \text { ongles distincts. }\end{array}\right.$ * * Ongulés.

II. SOLIPİDES....... $\begin{aligned} & \text { Ongle d'une seule pièce } \\ & \text { et entier. }\end{aligned}$ III. BISULCES......... $\left\{\begin{array}{l}\text { Ongle d'une seule pièce, } \\ \text { fendu. }\end{array}\right.$ *** Alimanes.

IV.CHEIROPTÈRES. $\left\{\begin{array}{l}\text { Doigrts antérieurs, ríunis } \\ \text { par une meñbrane. }\end{array}\right.$ *** Apodes.

V. CÉTACÉS.......... Nageoires au lieu de pieds.

$$
\text { I. F I S I P E D E S. }
$$

Cet ordre, dont le caractère est d'avoir eilui gts séparés et les ongles distincts,

(I) C'cst-à-dire mains aîlées.

(a) C'est-à-dire saus pieds. 
est le plus nombreux de tous. Quelques divisions, fondées sur le nombre des incisiyes, éviteront la confusion.

\section{* Quatre incisives.}

1. L'nomrs. Quelques naturalistes l'ont séparé des animaux; il doit cependant être placé parmi eux, puisqu'il a les mêmes organes destinés aux mêmes fonctions. Ses mammelles pectorales, ses cinq doigts divisés et ses quatre incisives, le rangent infailliblement dans cet ordre.

Son corps est nu et perpendiculaire. Sa hanteur varie depris seize jusqu'à vingt décimètres; il crô̂́ jusqu'à l'âge de vingt ans; à trente, il est dans sa maturité : la vieillesse lui succède; alors, ses os s'endurcissent, son corps se courbe, ses cheveux blanchissent, et il tombe dans la décrépitude, qui le conduit à la mort. La durée de sa vie est de soixante-dix ì quatre-vingts ans; il vit quelquefois au-delid de cent ans.

L'homme se nourrit indistinctement de tout; il existe des pays où, devenu anthropophage, (1) il mange sés semblablés.

(1) Mangeur d'hommes.

$$
\text { N4. }
$$


- Il n'y a qu'une espèce d'homme; mais outre la lifférence qui existe parmi les individus, la nature a encore produit des variétés dont les caractères sont constans; les principales sont l'homme blanc; les Européens ct les peuples d'une grande partie de I'Asie, sont de cetre couleur. Lihomme noir ou le netre: son nez est aplati; ses lèvres sont épaisses; il a les chevenx crépus. Cette variété appartient à une grande partic de J'Afrique. On appelle mélis ou mmlaire, l'individu né d'un blanc et d’une négresse.

Les monstruosités accidentelles ou artilicielles qu'on observe dans l'espèce Inunaine, ne constitnent pas des vajiéiés.

On a parlé souvent d'hommes sauvages, trourés ì des âges difürens dans les hois de I'Enrouve, oil ils s'étoient égarés. Ces prétendus sumvages étoient presque tous des sourds et mueti de uaissance, abandonnés par leur's paiens ou étoient des imposteurs.

Tout paroît lestiné pour lhomine, ou est l'ourrage cle son adresse ét de son génie. Il faut chercher cans los iraités d'anaiomie sa description complète. Les historiens nous transmettent ses actions, les philosophes parlent de ses mours, de ses rertus et de 
D'IISTOIRE NATUREIE. $20 \mathrm{I}$ ses foiblesses. C'eat lans lears livere ouvrages et par sa propre observatiun, gron aplorend à le bien conmoitre.

2. Le singe. Ce nom appartient d̀ un. genre extrêmenent nonbreux. On compte plus de quarante espècées de singes, toutes originaires des autres coninens, à l'exception d'une seule, qu'on trouve en Espagne. Les grancis singes, qui n'ont point de queue, et qui tiennent le plus somvent le corps droit en marchant, ressemblent beaxcoup à l'homme; mais ils n'ont, ni saraison, ni son intclligence, ni son achiesse. Ils ne savent qüimiter sans suite, sans dessein, et ne peuventrendre auciun service. On apporte en iurope les singes qui divertissent par leurs gestes et leur goût pour l'imitation. Les battelenrs leur apprennent difiérens tours, qu'ils n'exécutent cependant que sous les coups de fonet, et par force.

\section{* Six ircásines.}

3. Le critsin. On en comple un grand nombre de vai iécés.

$1^{\circ}$. Le chicn de borger a les oreilles droitcs, l'extrémité de la queue floconnée; 
il n'est pas beau, mais il est bon et utile; c'est le gardien vigilant de nos troupeaux, et le compagnon fidèle du berger.

$2^{\circ}$. Le barbet a les oreilles longues et pendartes, la queme couverte de longs poils; on s'en seri pour la chasse des aninaux aquatiques.

$3^{\circ}$. L'épagneul a les oreilles soyeuses, longnes et pendantes.

$4^{\circ}$. Lic bichor est couvert d'un poil long et soyeux. Cette variété et la précédente sont élevées par los fenmes pomr leur amusement.

$5^{\circ}$. Le dogice a les lèvres larges et pendantes; il garde les maisons avec autant de courage que de vigilance.

$6^{\circ}$. Le danois est porté sur des pattes longues et grêles. Ses oreilles sont courtes, pointues ct pendantes; il se plait avec les chevaux dans les écuries.

$7^{\circ}$. Le chien courant est blanchâtre ; scs oreilles sont pendantes. On l'employe principalement à la chasse du lièvre, du cerf, et des animaux dont la course est rapide.

$8^{\circ}$. Le basset a les jambes courtes; il est utile pour la chasse du renard et cublaireau, qu'il force jusques dans leur terrier. 
d'Historre Naturtert. 203

Ces différentes variétés du chien s'employent, selon leur instinct, à des usages parliculiers. Liun ponrsuit jusque dans sa retraite la proie qu'il doit atteindre; l'autre va la chercher au milieu des eaux; d'autres, l'xil fixé sur elle, la tiennent en arrêt, et lemrêchent do f́ur, jusrju'à ce que le chasseur s'en soit émparé, attaquent en masse et par division les gros animanx; et obéissent attentivement au chef qui les commande. Plusieurs chiens rapportent les effets égarés; d'autres paroissent intrépides au milieu d'un déluge de feu ; quelques-uns exécratent une infinité de tours, à la volonté du jongleur qui les instruit. Dans nos départemens méridionaux, les chiens tonrnent la broche; dans les départemens du nord, on les attache à des petits charriots.

Plusieurs parties du chien s'employent à divers usages; on ine mange sa chair, en Europe, que dans des temps de disette; cepeudant, d'autres peuples s'en nourrissent. La peau sert à faire des gants et des fourrures. Le poil peut se mêler dans la bourre.

Le chien est sujet à plusieurs maladies; la plus dangereuse est la rage, qu'il commu- 
nique aux autres animaux qui s'exposent sa morsure.

4. Le lour a la quene recourbée et l'œil placé obliquement. Le reste de sa conformation le rapproche beacoup du chien; mais ses mours sont bien différentes, et leur haine mutuelle ne permet entr'eux, ni paix, ni tı̀̀ve. Quoique naturellement poltron, le loup affamé s'enhardit, et il attaque les autres animaux, même les hommes; s’il ne trouve pas it se satislaire, il meurt clans des accès de rage. La lonve est sur-tout dangerense quand elle manque de nourriture pour elle et pour ses louvetcaux; elle ose alors pénétrer jusques dans les villages, où elle enlève quelquefois des pelits enfans, ce qui a donné lieu à la fable des loups garous. Le loup a été détruit en Angleterre; il faudroit exterminer par-tont sa race; quelques-unes de ses parties sont cependant utiles dans les arts; on fait des fourrures avec sa peau, et ses dents canines servent à polir la tranche des livres, ou à d'autres usages semblables.

5. Le nENAnD difière des précédens par sa queue longue et toufue, terminée par une tache noire. Sa retraite est un terrier, 
d'Histotre Natureice. 205 d’où la fumće ct la ponrsuite de quelques bassets penvent seuls le faire sortir; la renarde y dépose ses renardeaux. Le renard se met cn uarche la nuit pour exercer ses brigandages. Guidé par le chant du coq, il pénètre dans les basses-cours, où il égorge toutes les volaillés, et les emporte; le jour naissant le force à se retirer après avoir fait plusieurs voyages; le miel, le fromage, le raisir, les vers, les insectes, tout est l'objet de sa gourmandise. Il répand autour de lui une odeur forte; on mange cependant sa chair, sur-tout dans le temps du raisin, qui la rend plus grasse. Sa peau fait de bonnes fourrures. Il est célèbre par son astuce, et les auteurs qui, dans leurs f'ables, ont fait parler les animaux, le prennent toujours pour un de leurs principaux interlocuteurs. On le détruit par la chasse, et en l'attirant dans des piéges, où il trouve l'esclavage ou la mort.

6. Le chuт a la langue hérissée de petites pointes; ses doigts sont armés d'ongles vigoureux et rćtractiles. On en distingue trois variétés.

$i^{\circ}$. Le chat ordinaire. Son poil est court et épais; c'est le plús commun. 
$2^{\circ}$. Le chat d'Angora. Son poil blanc; argenté, et doux comme de la soie, est trèslong, principalement sur le col.

$3^{\circ}$. Le cliat blcu. Son poil est d'un gris blenâtre; on le nomme aussi chat chartrezix.

Le chat voit mieux la nuit que le jour; voleur adroit et rusé, il saisit sa proie avec ses ongles crochus, qu'il retire sous ses doigts à sa volonté; il grimpe avec légèreté, et tombe de très hant sans se blesser; la guerre continuelle qu'il livre aux souris lui fait pardonner ses larcins. Sa chair ne se mange que dans les temps de disette. Sa peau fait des foumures. Son poil se feutre difficilement; mais en le mêlant avec de la laine, on pent le filer et le tisser. En le frottant d̀ rebours dans l'obscurité, sur l'animal vivant, on en ire des étincelles électriques. Ce manumif'ère est l'emblême de Ia trahison ; il égratigue souvent au inoment où on croit qu'il veut caresser. On en a vu élrangler leur maître endormi.

7. Le rron. Le col de ce terrible animal est ombragé par une ample crinière. Sa queuc est teruinée par un floccon de poils; cyst le plus redonable de tous les mammi- 
fères par sa force et son courage; il ne se trouve qu'en Afrique et en Aske.

8. Le ticre a le corps marqué de raies noires.

9. La paxthíre est marquée d'anneaux noirs séparés, avec un point dans le centre.

10. Le LÉOPARD est marqué d'anneaux noirs rapprochés entr'eux.

Ces trois animaux sont également connus par leur force et leur cruauté. Ils appaitiennent, ainsi que le lion, à l'Afrique et à l'Asie; leur peau fait, comme la sienne, de belles fourrures.

11. Le putors doit son nom à l'odeur désagréable que répand une secrétion huileuse rassemblée dans une poche gu'il porte sous l'anus. Son corps, grêle et alongé, passe à travers les trous d'une muraille; c'est ainsi qu'il pénètre dans les basses-cours, dont il égorge les paisibles habitans. Quand l'issue est trop petite pour la retraite, il n'emporte que les têtes des volailles, qu'il aime à sucer. Les chiens mêrnes refusent de manger sa chair. Sa fourrure, quoiqu'assez belle, est dédaignée à cause de l'odeur qu'elle conserve. Les poils de l'extrémité de sa queue servent à fairc des pinceaux. 
12. La fouríe. Elle ressemble beancoup au putois, mais la couleur de son poil est plus foncée. Iille fait les mêrnes ravages dans les ponlaillers. Sun odeur est moins désagréable, sa chair moins mauvaise. Sa peau est une fourrure peu estimća.

13. La marte approche assez de la Covine; mais son poil est plus fin et d'un beau brun. Elle n'habite 'que les pays froicis. On en fait de belles fourrures; la queue sur-tout est recherchée.

I 1. Le furst est encore plus mince et plus alongé que les.inimaux précédeus. Sa couleur est d'un jaune pâle; c'est l'cnnemi le plus déclaré du lapin, qu’il va chercher au fond de son trou; là, il l'atlague, le saisit par le col, lui perce le nez et la tête, et suce son sang, lont il s'enivre quelquefois au point qu’il s'endort sur la place : on ne pent le réveiller et le faire soriir que par la fumée. Il est délicat et dort continuellement. On l'élève pour la chasse.

15. La BELETTE est rousse en dessus, blanche cri dessous, avec une tache plus forcée sur la bouche. Elle est plus petite, mais aussi sanguinaire que le putois.

16. L'henimite ne difièce de la belette que 
d'Histoire Natititit. 209

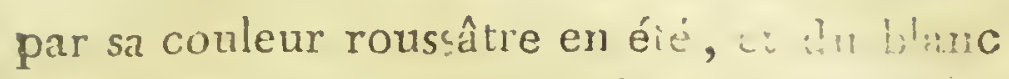
le plus éclatant en hiver; l'extrémilé cie sa quene est noire; on en fait de belles fourrures.

17. La LoUTra est beancoup plus grosse que les animanx précédens, et ses doigts sont réunis par nune membrane; ce n'est pas dans les basses-cours qu'elle exerce ses ravages, mais dans lẹs viviers et les étangs. Quind elle s'y est rassasiée de poisson, elle porte le reste clans sa tannière; on mange sa chair et on emplnye sa fourrure.

18. Liours a environ seize décinèères de hauteur; son museain est alongé, ses inembres sont courts, et son corps difforme est couvert d'un long poịl flocconé. Il cherche les lieux solitaires, où il se nourrit de fruits, de fourmis, de poisson; il aime sur-tout le miel. Paressenx et tranyuille, il ne combat que son aggresseur, mais avec intrépidité. L'ourse sur-tont est dangereuse: si elle croit ses oursons menacés, ellc les défend jusqu'à la mort. Le mâle et la femelle n'habitent point ensamble. Sils ne peuvent trouver un antre ou un arbre creux pour se giter, ils se font, avec des branches, une retraite impénétrable à la neige et à la pluie; c'est 
là que l'ours hyberne vers le milieu de brumaire; il en sort ì la fin de l'hiver, extrêmement maigri.

Quand cet animal est encore jemne, on lui apprend facilement diférens tours, a gesticuler, à suivre, par une danse grossière, la cadence d'un rauque instrument; mais avec l'âge, il n'est plus susceptible d'une semblable élucation. Sa peau est la pius estinée des fourrures communes; on en fait des manchons, des tapis, des housses, etc. Sa chair est chargée d'une graisse dont on relire une hnile qui s'emploie comme celle d'olive, et un saindoux qui remplace celui du porc. Cette graisse est anssi conseillée contre le's rimuatiomes, et on en firt une pommade, qu'on croit faussement bonne pour les cireveux.

On consioit plusieurs variétés de l'ours.

1‥ L'omers moir. C'est le plirs grand et le plus commun; il refuse constamment la chair.

$2^{\circ}$. Liours brun, féroce et camassier.

$3^{\circ}$. L'ours blanc. Il ne se trouve que dans les pays froids.

19. Le blampau ne ressemble à l'ours que par la conformation de ses dents. Son corps 
est alongé, et il est sur-tout reconnoissablo aux bandes noires et blanches dont sa tête est accompagnée. Une converture placée sons sa queue, laisse suinter une liqueur huileuse quill aime à sucer. Il se crense, dans les bois sombres, une demeure tortueuse à plusieurs galeries, et qui n'a pourtant qu'une issue; janais il n'y suuffre d'ordures. Ie renard s'empare souvent, par adresse, de cet asyle propre et commode, et le blaireau s'cn creuse paticmment un autre; c'est-là qu'il hyberne sur un lit de gazon. Sa femelle y dépose ses petits; flle les nourrit du miel des bourdons, de sauterelles, d'œufs d'oiseanx, de petits lapereaux qu'elle leur apporte. Le blaireau ne sort que la nuit; c'est aussi le temps de le chasser; les bassets lo poursuivent jusques dans son terrier. Il a la vie tenace : et combat courageusement jus. qu'à la dernière extrémité. Sa chair n'est pas très-mauvaise. Sa peau sert à faire des fourrures grossières, des colliers pour les chiens, etc.

20. La taure est noire; elle n'a point d'oreilles externes; ses petits yeux sont couverts par le poil, ce qui a fait croire qu'elle étoit aveuglc. La taupe creuse facilement la

$\mathrm{O}_{2}$ 
terre avec ses paltes antérieures, armées d'ongles crochus, et elle lá rejetle avec ses paties postérieures, beaucoup plus larges, qui lui servent de pelle. C'est sur-tout dans les temps humicies qu'elle est plus laborieuse et plus active. Dans les temps secs, elle enire plus avant dans son trou. On reconnoît aisément son lyavail aux pelites mottes qu'elle élève sur la terre. Elle se nourrit d'insectes et de racines, el elle fait de grands ravages dans les jardins. On lui tend des piéges pour la détruire. Son pojl est doux ei serré. Sa peau pourroit fiaire des fourrures.

2I. Le mirrissox. 'Tout son corps cst armé de piquans cutrenêelés cle quelques poils. Cet animal est innocent, se ruple en bonle quand on l'atlaque, et il précenie ì son ennemi un rempart de pointes acérées, qu'il infecte de son urine, pour joindre le dégoût au danger. On le force à ce dérouler, en le présentant au f́eu. Il ne sert à aucun usage.

\section{* * Deru incisives.}

22. LE т.тиль. Cet animal timide, symbole de la trisiesse et de la crinte, a la corys roux ; ses longues oreilles sont tormi- 
D'FISTOTRE NATURELE. 213

nées par une tache noire. Ses jambes postériemres sont beaucoup plus longues que les antérieures. Il habite les plaines, où il se creuse un gîte. Quoiqu'il fuie au moindre 'bruit, et s'échappe par une suite continue de sauts, il s'apprivoise aisément. Sa femelle, appelée hase, est très-féconde. La chasse du lièvre est un des principaux amusemens de la campagne. Sa chair est bonnè mangò'; colle des jeunes levrauts est sur - tout recherchée. Sa peau est une bonme fonrure. Le poil, mêlé avec de la laine, peut se filer et se tisser; seul, il se feutre, et il entre dars la fabrication des chapasux.

23. Le latus est beaucoup plus petit que le lièvie, arec lequel il a cídllerurs me grande ressemblance. Il préfè̀e les bois aux plaines, et il y fait de grands dégats, ce qui oblige à le cétruire, on ì lui abantlomer des tailis entourés de murs ou de fossés pleins d'eau, qu'on appelle garennes. On l'élève aussi dans de grandes fosses, g'un nomne Lapinières, ou lans des tonnenux, e!n le nourrissant de plantes potagdres; mis sa chair devient fale et perd ce fumet dù a: serpolet et aux autres plantes acoinatipues, dunt il se nutrit en libcrió. La lapilte est

O 3 
214

$$
\text { E L }
$$

très-féconde; elle fait en difíérens temps pusieurs laperaux. Sa peau et son poil servent aux mênes usages que le poil et la peau du lièrre. On auroit dú parler de sa prodigieuse fécondité. On élève ane variété du lapin, dont le poil cst entièrement blanc; elle est connue sous le nom de lapin blanc, lexpin d'Angrara.

24. Le castor est bien reconnoissable a sn quene plate et couverie d'écailles, qui lui tient lieu de marteau et de truelle pour batir an milieu des eaux des cabanes et des digrves. Son poil sert â faire les chapeaux les plus fins. Cet animal habite l'Amérique septentrionale. La variécé qui se trouve en Europe, et qui est connue en France sous le nom de bickre, se creuse seulement des terriers; son poil est moins beau que celui des castors cabanés. Ie castor a, près de l'anus, une poühe qui renferme une sécrétion d'une odeur forte, appelée castorezm, dont on fait usage en médecine.

25. Ine caria ressemble assez an lapin, mais il n'a point de queae. Son corps est tacheté de roux ei de noir. Il est originaire des climats chauds; cependant on en élève en France, où on le nomme improprement 


\section{D'HISTOIRE NATURELE.}

cochon d'Inde. Il multiplie beancoup, mais il est heureasement lifficile à élever, puisqu'il n'est bon à aucun usage. Sa chair cst insipicle et sa fourure peu estiuée.

26. L'Éccreuiz. Son corps mince, alon gé, et sur-tont sal longue queue, rendent facilement reconnoissable ce joli petit mamnifère, si agréable par sa gentillesse, et si amusant par la prestesse de ses mouvemens. Le poil de son dos est roux, celui du ventre blanc. Il se plaît dans les grands bois, où il construit pour ses petits, sur des arbres élevés, un nid, dont l'ouverture est fort étroite, et qu'il sait rendre impénétrable à la pluie. On l'ćlève dans des cages tournanies. Sa chair n'est pas mauvaise à manger. Lue poil de sa quene sert à faire des pincearx.

27. Le sorn a la quene plus grosse à son extrémité qu'à son origine; il ressemble, d'ailleurs, beacicoup à l'écurenil, et ses mours sont à-peu-près les mêmes. Ce petî manmitère cause des déz̧âts aux fruits dans les jardins. Il dort presque tout l'hiver, et alors il engraisse. On mange sa chair dans quelques pays, mais on n'en fait point usage en irance.

23. Le m.1T. Cet hôte incommode a le O 44 
corps noîtûte, le poil très-raz, la queue longue et couverte d'écailles, formant des bandes circulaires. Il habite ordinairement les greniers et les caves, d'où il se répand dans les maisons, et ronge, avec ses incisives conicues et vigoureuses, les menbles, le linge, les comestibles, entin, tout ce qu'il rencontre. Il perce les cloisons, les murs, rien ne l'arrête. Malgré les soins qu'on prend ponr les dciruire, les rats se multiplient si facilsment, qu'ils nons forceroient à déserter nos demeures, sans l'éiernclle guerre qu'ils se livrcnt. Ces animaux se mangent entre eux, quand ils éprouvent la disette d'autre nourriture.

29. La souris approche beancoup par sa forme, de celle du rat, mais son corps est d'un gris cendré; elle est aussi beaucoup plus petite; elle a les mêmes habitudes et les mêmes inconvéniens; on parvient à l'apprivoiser. On en élève, par curiosité, une variété fort jolie; elle a le poil blanc et les yeux rouges.

3o. Le RAT D'xau a la quene poilue et moins longue que celle du rat ordinaire; il habite le bord des étangs et des rivières, où il se nourrit de poissons et d'animaux aqua- 
tiqnes. Il nage facilement, plonge sous l'eau, ct rapporte sa proie à terre pour la manger.

31. La marmorts, dont le córps est d'vn brun cendré, a la queue courte et garnie la. longs poils. Elle habite les montagnes, t dort presque tout l'hiver. On mange sa chair, quoiqu'elle ait une odeur forte. La marmotte prise jeune peat s'apprivoiser; les petits montagnards lui apprennent différens tours, et la font voir pour de l'argent.

$$
\text { **** Point d'incisives. }
$$

33. I'éléphaxt. Ce grand mammifère habite les mêmes climats que le rhinocéros.Son nez se termine en un long tube très-flexible, appelé trompe, dont il se sert avec adresse. L'éléphant est docile et intelligent; il rend aux habitans de l'Afrique er de l'Inde d'impoltans services. Ses canines supéricures, très-prolongées, sont vigoureuses et trèsmeurtrières. Leur substance est ce bel ivsire dont on fait rant de jolis ourrages de tour et de tableterie. 


\section{I. $S O L I P$ E D E S.}

Tous les mammifères, dont les pieds sont garnis d'un ongle d'une seule pièce et entier, se nomment solipedes. La substance de la sole est analogue ì celle de la come, ce qui lui a fait improprement donner aussi ce nom. L'urlre des solipèles n'est pas nombreux, sur-tont, en ne considérant que ceux qui peuvent s'offrir à nos regards, ou dont nous pouvons tirer guelque parti. Ces animaux, sont :

1. Ie cheyal. Ce superbe solipède existe cncore sanvagge dans quclipes contrées de l'Asie; mais il est en général si utile, que sa domesticité remonte à la plus haite antiprité. Sir forme est trop connue, pour (ru'il soit nécessaire de la décrice. Ses dents incisives sont carrées et aplaties, ce qui lui donne Ia facilité de broyer l'herbe sèche, le foin et les graines dont il íait sa nourriture. Sa couleur la phis ordinaire est le brun et le noir, nais elle varie beaucoup dans les différensindividus. Sa fumelle s'appelle jument, et le peitit qui naît de leur union, poulain. Les degrés successif́s l'accroissement de dents incisives, indiquent son âge pendant les 
huit premières années de sa vie; passé ce temps, il est hors d'âge; il ne marque plus, mais il rend encore des services importans. Exécuteur docile de tous les mouvemens qui lui sout commandés, l'homme a su le dresser pour la course er pour les combats. Il partage avec le bœuf l'occupation de transporter les denrées et celle du labourage. il vit ordinairement vingt-cinq ans; il dort debout ou . sur un lit de paille, sur la litière. Malgré sa force et sa beauié, il est délicat et facile à blesser; plusieurs insectes le tourmentent, queiqu'il ait soin de les chasser avec sa queue mobile et ondoyante. Ontre les services nom. breux qu'il rend pendant sa vie, il est encore utile après sa mort; sa chair se mange dans des temps de disetie. Le lait de la jrment est la seule boisson de plusieurs peuples de l'Asie; lo cuir sert à faire des harnois; avec le poil de la crinière et de la quene, -qu'on appolle crin, on fabrique cles boutons, les tamis, des loiles, des cordes, des archets d'instument, ot dinélens tissus; enfin, on en bouire des selles, des coussins et des matelats.

2. I'ANe approche beaucoup du cheval par sa forme; mais il est plus pelit, et il n'a 
ni sa force, ni son adresse, ni son courage; ni sa beauté; il est facile à reconnoître à la longueur de ses oreilles. Sa couleur est grise, et son dos est marqué de deux bandes noires qui se croisent. Sa queue n'est garnie de poils quàà son extrémité. Au lieu du henmissement fier du cheval, son cri est un braire désagréable; mais il répare ces cléfauts par d'importantes qualicés. Hatient au trevail, il porte on traine de lomrds fardeaux. Solne et frugal, il trouve par-tont une nouriture facile; les plantes épincuses, pi fuantes ct yulgaires sont ses délices. Il n.: fart cependant pas trop abuser de sa patience; alors il rue, il se vantre, il se défend. Cet animal est ulile pour les transports et pour les charrois. Comme son pied est infiniment sûr, on s'en sert sur-tout dans les scntiers étroits et glissans, sur les bords des précipices. Sa clair est plus dure que celle du cheval; mais celle de l'anon n'est pas mauraise. L'anesse donne un lait léger et facile à digórer. La peau de l'âne seríà faire des cribles, des tanuours, des souliers, des tablettes; c'est celle qu'on cmploye pour la fabrication du inamoquin. Le poil forme une bourie peu estimsic. 
L'union de ces deux solipèdes donne náissance à deux variétés importantes.

$2^{\circ}$. Le mulet, né de l'accouplement de l'âne avec la jument.

$2^{\circ}$. Le bardeau, né de celui du cheval avec l'ânesse.

Ces animaux tiennent toujours plus de leur père que de leur mère. Tous deux sont durs à la fatigue, ont le pied sûr, et portent une lourde charge. Ils sont principalernent utiles dans les pays de montagnes. On appelle en général mulets, tous les individus nés de deux espèces diférentes, dans quelque classe que ce soit.

\section{I I. B I S U L C E S.}

Crт ordre diffère de celui des solipèdes; en ce que les mammifères qu'il renferme ont l'ongle fendu; c'est pour cela qu'on les appelie vilgairement pieds fourchus. Los solipèdes sont consacrés anx transports et aux charrois. Quelques bisulces partagent aussi nos travaux; presque tous servent à notre nourriture. Ils sont plus nombreux que les snlipèdes; la forme de leur corne peut servir ¿ établir encre eux des divisions. 
* Comes simples.

1. Le вовUт a ordinairement le corps d'un ronge de brique; quelquefois il est gris , tacheté de noir. Sa tête est armée de cornes creuses, pointues, et gui forment un croissant. Lété, on le laisse paturer dans les prairies; l'hiver, on le nourrit avcc lu foin dans l'étable. Quoigue sa mâchoire supèricure n'ait pas de dents incisives, il mange vite, mais il mâche imparfaitement; il mmine ensuite, c'cst-à-dire qu'il fait successirement repasser ses alimens dans les quatre estomacs clont la nature l'a pourve. Ouvrier ntile dans la ferme, il trâine des charriots et il tire la charrue. Quand ses forces diminuent, on l'engraisse et on le livre au boucher. Sa chair est délicicuse et succulente; on la mange fraîche, iriprégnée de sel, exposée à la fumće, ou séchće au solcil. Son cuir sert au cordonnier, sa bourre au bourrelier, sa coine au tabletier; sa graisse entre dans la fabrication de la chandelle; son sang est employé pour clarifier le sucre; on retire de ses pieds une huile bonne a brûler; cn prépale, arec les membranes de 


\section{d'Histotre Naturetie. 223}

son estomac, la baudruche employée pour battre l'or, pour la guérison des coupures et pour la construction de petits gíubes aérostaliques. Les rognures de sa peru donnent de la colle-forte.

Sa fimelle, qu'on nomme vache, est moins utile pour les travaux de la campanne; mais le lait qu'elle foumit en abondance la rend préciense; on le prend pur, ou, par la séparation de ses difiérentes partics, on en retire le petit lait, le bezurre et le fromage.

Le petit de la rache se nomme reazu. Sa chair est excellente. Devenu plus vigourcux, on l'appelle tanteau, et il ne prend le nom. de bouf' qu'après avoir été soumis à la castration; alors, il est plus propre au joug ct à tirer la charrue. La vache porte le nom de génisse, jusquà ce qu'clle ait fait un veau.

2. Le BÉLIER est chargé d'une laine blanche et flocconée qui lui couvre jusqu'aux yenx. Ses comes ont des anneaux dont le nombre indiqune son âge. La brebis, sa compagne, est privée de cotte défense; ct l'agneau, fruit de leur union, est le symbole de l'inmocence patiente au milieu des persécutions. 
Dès que le bélier ne peut plus engendrer; on le nomme mouton; et en général, on désigne sous ce nom collectif un troupcau composé de brebis, de moutons et de quelqques béliers. Un seul berger, actif, vigilant et suivi d'un bon chien, suffit pour conchire un troupeau, de cent moutons. II les précècle et les accoutume à le suivre sans s'écarter. C'est dans les terrains secs, daus les plaines sablonneuses et an peu élevées, qu’il les mène brouter le thym et les autres petites plantes aromatiques. Pendant l'automne, dans les lieux où on ne craint pas les loups, on les parque, c'est-d-dire yu'on les laisse la muit au milicu des cliamps; leurs excrémens et leurs steurs engraisscnt la terre. L'hiver, on les nourrit dans l'éuble, d'où on leş fait sortir le matin; on leur donne du sel, qu'ils aiment prodigieusement. Tous les ans, on tond la toison qui les couvrè ; et dès qu'ils vieilissent, on les engraisse pour se nourrix de leur chair; celle de I'agneau est très-délicate; cello du mouton est préférable à celle de la brebis; mais le litit de celle-ci fait d'excellens fromages. Leur laine, après diféérentes prénarations, se file, se iisse, et sert à bourrer des ma-

telats. 
D'HIStOIRE NAEUREIA. 235 celats. La peau s'employe à une infinité d'usages. Les boyaux se filent, et deviennent les cordes de nos instrumens. C'est avec les os de monton, brûlés, qu'on prépare le noir d'os. Outre sa graisse, cet animal a une grande quantité de suif, qui est la base de la chandelle.

3. Le вочс. Son odeur forte l'annonce de loin, et son menton harbu le fait aisément reconnoître. Cét animal, vif et pétulant, a les cornes arquées et sillonées. Sa couleur est noire, mêléc d'un peu de brun; il demande moins de soin que le monton, et coùte peu à nourrir. Sa chair a" une odeur désagréable; celle de la chèvre, șa femelle, est un peu meillenre; et celle du chevreau est très-bonne. Le lait die la chèvre est excellent. La peau de ces 'animaux' s'employe comme celle du mouton; leur poil est plus dur que la laine; on en tisse cependant différentes étoffes, et on en fabriquue du galon et des boutons. La chèvre aime surtout les pays montagneux; elle paroît souvent suspendue sur la cîne des rochers.

4. Le craniors. Ca joli mammifère n'a point de barbe. Son corp̣s roux est marqué sur le dos d'une raie noire. Ses cornes sont 


\section{6}

\section{E I I M I T S}

noires, lisses, rondes, droites ct torminces en hameçons; il se trouve daus les montagnes, ou il cherche les licisx les plus fivids! Ettrayé par le moindre bruit, il n'est harli que pour sauter; mais pour pen gruil ait quelque péril à redouter, il s'clance rapidement de rocher en rocher et it travers les précipices. On mange sa cluair, qui fuurnit presqu'autant de suif jue celle du bélicr. Sus petites cornes funt de julies po:pmes de canne; inais c'est sur-tout pour sa peau, souple et solide, que les cirasscurs biavent les froils !es plus rignureux, et les dangers tonjours renaissans, auxquels sa puursuite les expose.

\section{* Cornes ramezses.}

5. Le cerf. Les cornes des mammifèes bisulces, que nous venons d'examiner, sont creuses, simples, et solidement attachées a leur tête; celles du cerf et des autres animaux qui suivent sont pleines, rameuses, tombent et renaissent tous les ans. L'accroissement du nombre de leurs ramilications indique l'âge du cerfjusq̨u'd dix anns. Cet animal est diune grande légérelé dे la 
course ; cependant les chions l'atteignent; les chasseurs le poursuivent pour sa peau et pour ses cornes, qu'on employe dans les arts sous le nom de bois de cerf; on en fait des manches de coutea ; on en extrait une gelée, et on peut les réduice en colle. La biche, qui est la femelle du cerf, n'a point de cornes; leur faon est long termps marqué de taches blanchâtres, qu'un nomme. sa livé́e. Leur chan n'est pas inauvaise a manger.

6. Le DArN. Il ressemble bcaucoup au cerf par son port, par sa légèreté ct par sa couleur fauve, c'est-à-dire, d'un rouge jaunàtre; mais les ramifications de ses cornes, au lieu d'être rondes, comme celles du cerf, sont plates, et ont d̀-peu-près la figure d'une main. La daine n'a point de cornes; son faon porte la livrée. On chasse le dain pour sa chair et pour sa peau, dont l'usage est aussi agréable qu'étcndu et solide.

7. Le carvenil a les comes rondes; conme celles du cerf, mais plus courtes, grumeleuses et fourchues à leur extrémité; il est plus petit que le dain. Son poil est d'un faure plus foncé. Ces jolis habrans de nos

$\mathrm{P} 2$. 
forêts, qu'i's égay ent par leurs lionds, qu'ils animent par leur vivacié, vivent en famille. Le mâle, sa chevrette et ses chevrotains, forment des petites troupes, que la cruauté seule des classeurs peut séparer. La chair du cherreuil est excellente. Ses cornes et sa peau sont également eurployées dans les arts.

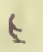

\section{* * Corne sur le ncz.}

S. Li nhinocíros. Cet énorme mammifère n'a d'autre rapport ayec les précédens, que la conformation de ses pieds; c'est le seul qui ait la corne sur le nez, et c'est ce qui lui a mérité son nom, dont la signification est nez cornu. Sa peau, dure et plissée, est impénétrable aux traits, et même aux armes à f'eu. On en connoît deux espèces: le rhinocéros à une corne, qui se. trouve en Asie; le rhinocéros à deux cornes, qui habite l'Afrique.

\section{* * * Sans cornes.}

9. LE PORC se reconnoît aisément an prolongement de son nez mobile, et à ses ca- 
nines, qui sortent de sa mâchoire. On en distingue deux variétés, quỉil faut cónnoitre.

$1^{\circ}$. Le sanglier. C'est le porc libre et sanvage, et par conséquent, supérieur en forle et cn courage. Ses canines inférieures lingues et robustes, s'appellent défenses, et lui servent it percer ses ennemis. Son corps est ordinairement noir; son poil est dur et hérissé; il rit dans les bois, où il choisit les eudroits lés plus solitaires et les plus sombres. Sa chasse n'est pas sans danger; on le recherche pour sa chair, qui est excellente, ct pour son poil, dont on fait des vergettes; sa femelle se nomme laie.

2. Le cochori. L'état de servitude, plutôt que de domesticité auquel il a été réduit, paroît l'avoir énervé. Sa force est extrêmement inféricure à celle du sanglier; son corps est moins ramassé et moins robuste; au licu de défenses, il n'a que des crochets beaucoup plus foibles. Ses goûts sảles et grossiers le rendent très-facile. à nourrir ; il est peu sensible aux coups; il aime à se vautrer dans la fange; ses formes n'ont allcune grace; son grognement est désa gréalle. Cet animal est l'cmblême de lá malpropreté, 
mais il sert d de nombreux usages; sa chär fraîche ou salée se prépare d'une inlinité de. manières; son sang sert à faire du boudin; ses intestins sont garnis d'une excellente graisse appelée saindoux, et son corps est couvert d'une couche épaisse de lard. Avec la peau qui l'enveloppe, on fait des cribles, ei le poil est bon it faire des vergettes, des pinceaux, et les cordonniers s'cn servent pour passer leur til. La femelle, appclée s'uice, est de la même utilité. Quand ses petits marcassins têtent cacore, on les nomme cochons de luit, et ils sont trìs-bons à manger. On appelle verrat le porc domestique destiné à la régénération de l'espèce; il ne prend le nom de cochon que quand il ne peut plus engendrer.

\section{CHEIROPTERES.}

Ces anipiaux, dont le caractère est d'avoir les pattes antérieures en forme d'aîles, unissent la classe des mammifères à celle des oiseaux. Cet ordre est peu nombreux : on n'y compte qu'un gerre.

I. La GaUve-souris. On réunissoit autrcfois ce manmifère arec les oiseaux; mais il 
D'Fistorme Naturticit. 232 n’a nị plunes, ni â̂los véritables; il porte des manelles, pectorales, ot il allaite ses petits. Ln forme de son corps, la coulcur de son p ill, resscmblent un peu à la souris, ce qui lui a fait donner le nom qui le désigne. Lil membrane qui réunit ses doigts s'étend jusques anx pattes postérienres qu'elle enveloppe, à l'exception des luigts; la queue y est aussi engagée. Quand la chauve-souris reut changer de place sans voler, elle se traine sur ses poignets antérieurs et sur ses pattes postérieures; les insectes qu'elle attrape dans son vol font sa nourriture; mais si elle péut entrer dans une cuisine ou dans un office, elle y mange le lard, dont elle est très-friande. Ces animaux ne sortent que la nuit ct se reposent le jour; ils se suspendent les uns aux antres par les paites de derriere; c'est ainsi qu'ils passent l'hiver dáns les cavernos, enveloppés de leur voile c)inine dars un manteau, et sans prendre aucune nouriture. Les mammières suirans sont des espèces de cliauve-somis.

2. L'Or ILlard so norime ainsi, à canse de ses énormes oreilles, longnes une fois comme son corps.

3. Le par a cheyal a sur le nez une mem$\mathrm{P} 4$ 


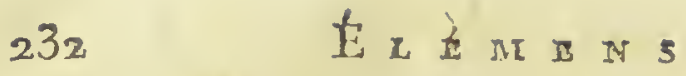

brane, dont la forme Ini a fuit donner le nom qu'il porte.

\section{C E T A E E.}

Sr les mammifères précédens ont pu être confondus avec les oiscaux, ceux-ci offrent avec les poissons une analogie encore plus grande; comme eux, ils vivent dans la mer, et ils no peuvent la quitter; mais les fenelles font leurs petits vivans, et les allaitent. de leurs mamelles.

Le caractère de cet ordre est de n'avoir point de pieds; ils sont remplacés par des nageoires. Les cétacés ont sur la tête des soufflets, au moyen desquels ils rejettent avec force l'eau surabondante qu'ils ont avalée. Les plus importans à connoître, sont :

I. La baleine. Cet énorme mammifère, qu'on prendroit sur les eaux pour une fle flottante, a quelquefois jusqu'à trente mètres de long. Il n'habite point nos plages, et nos marins ront le chercher dans les mers du nord. Malgré sa grosseur, la balcine ne se nourrit que d'insectes très-petits, du genre de l'écrévisse; il est vrai qu'elle les engloutit 


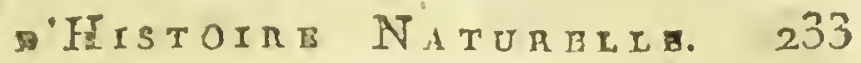
par milliers, à l'aide de ses fanoins, lames longues et d'une substance analogue ì celle de la corme dont sa bouche est accompagnée. Les pêchems lui lancent un énorine harpon, attaché d̀ une longue corle, qu'ils devident et n'attirent ensuite dे eix que quand l'animal, épuisé par la perte de son sang, ne peut plus se débattre; alors on le dépèce à coups de hache, et ses différentes parties sont employées dans les arts. La cliair de la baleine fraîchement tuée n'est pas mauvaise, sur-tout celle voisine de sa quene: Le lard se convertit en huile, qui se mange, se brúle, ou sert dans les manufactures dे la préparation des cuirs, des draps, pour différentes peintures, et pour la fabrication du savon. Ses tendons servent à faire des corcles èt des filets; et avec ses os, on façonne différens ustenciles de pêche et de ménage: Les fanons, conpés par lámes, servent à faire des cannes, des petits bâtons plians pour les corsets, les parapluies, etc.

2. Le cacmatot n'a point de finons, mais sa mâchoire inférieure est pourvue de dents. Les enveloppes de snn cerveau cortiennent cette substance grasse et huilerise einployéc dans les arts, sous le nom de blanc de 


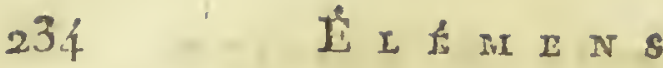

baleine. L'ambre gris se trume dars son csumalc, et parî́t êtie le produil de sa uigestion. Le cachalot n'habite pas nos mers; cependant, il vient quelqucfuis échuuer sur nos côles.

3. Le aransourn a des dents aux denx mâchoires; son corj!s est coniune et sim museau obius. 11 est commun sur nos côies. Sil chair est dure et coriace, mais sa graisse founit beancoup d'huile à brîler. Sa peau est un cuir léger, qui résiste bien aux armes à f'ú

\section{O I S E A U.}

Les orifux nnt le corps convert de plumes, deux pieds senlement, et deux aîles. Leur bec est dépourvu de dents, et leurs jetits naissent enlermés dans un œaf.

Leur tête, attachée ap tronc par un col rond et plus ou moins alongé, contient le bec, composé de deux mandibules de difiérente forme et de diférente proportion, et dont la substance approche de celle de la corne. Sa superficie est nue ou couverte 
n'Iistorme Naturete. 235 d'une pellicule légère et transparente. Sa base est quelquefois gamie d'une membrane colorée, appelée circ.

Le hec renferme la langruc, organe plat ou cylindrique, dont la surfice est lisse ou couverte d'aspérités, et qui est découpée, fendue, taillée en dard, cu poignard, etc. Le bec est percé à sabase par les narines, trous ronds, ou concaves, óu saillans; ces narines sont quelquefois à l'origine du front.

Le front porte souvent une ercroissance charnue, colorée ou découpée, granon nomme crète. On y remarque les yeux, protégés par les sourcils, et contenus dars des paupières mohiles. Les orcilles n'ont artcune apparence extéricure. Le sommet de lá tête est quelqucfois défenclu par un casque membraneux et dur, ou suŕmonté d'une riche aigrette.

Le tronc est coinposé des mêmes parties que cclui des mammifères. La région de l'anus s'appelle crontion. On distingue dans les pattes, la cuisse, ordinairement garnie de plumes: la jasmbe, couverte d'une peau écailleuse, et sourent armée d'un ou de deux éperorss; et les d'oigts, dont le nombre et la distribution varient. Les oiseaux dont 
Ia comrse est rapide ont leux ou trois doigts; cenx dont la marche est plus posée, cn ont quatre, trois en avant, un en alric̀re, ce qui rend leur assiète plus solide; ceux dont l'habitude est de grimper, ont deux doigts en avant et deux en arrière. Tous les luigts sout rémis par une membrane, quand linseau passe habituellement sa vie lans l'eau. Les doigts sont ordiuairennent arués d'ongles crochiss, yui leur servent pour l'attaque et pour la dúfense.

Les ailes soutionnent l'niseau dans l'air, rendent sa course plus léugère, ou lui dument plus de facilicé porr nager.

On distingue dans le plumage de l'oiseau les penmes disposées en quinconce sur la peau; ce sont des tubes creux, terminés par une tige carrée, accompagnés de barbes parailèles; et lesp/umes, filets rameux dont les rayons sont lâches et épars. On trouve toujours deux plumes entre chaque penne.

Les pennes des âles sont fortes et alongées; on les nomme rémiges, parce qu'elles font l'office d'une rame. Celles dé la queue, nornmées rectrices, diuigent l'oiscau dans son vol. Les tectrices sont les pennes qui 


\section{d'Histoine Natumite. 237}

couvrent les rectrices et les rémiges, sur lesquelies elles furmont un double rang.

Les oiseaux se revêtent tous les ans d'un nouvea'i plumage. Cette mue est causée par le dessèchement du tuyau privé des sucs nourriciers, qui se portent à la p'ume nouvelle; celle-ci, en croissant, force l'ancienne à lui céder la place. L'animal est alurs dans un état de maladie; sa voix s'éteint, et ses belles couleurs éprouvent une altération. sensible. Cette riche enveloppe est impénétrable à l'air ; mais l'eau s'y feroit un passage, și l'oiseau ne savoit pas s'en préserver. Il exprime des glandes placées sous son. croupion, en le tiraillant avec son bec, un suc graisseux dont il frotte chacme de ses plumes, en les faisant successivement passer entre ses deux mandibules. Cette opération les lustre, les raffermit, et l'ean ne fait. plus que glisser sur elles. Les oiseaux aquatiques sont les plus abondamment pourvus de cette liqueur. Ceux qui ne vont point $\grave{a}$ l'eau en ont fort peu; mais pour chasser les insectes qui les incommodent, ils élèvent avec leurs aîles des tourbillons de poussière dont ils se saupoudrent, ce qui les fait nommer pulvérateurs. 
La circulation s'opère chez les oiscaux comme chez les inammiferes. On distingne jarmi leurs secrétions le suc huilcux dont ils cndnisent leurs plumes. La respiration ofire rles moyens plus compliqués que celle des autres animanx. Lenr ventre est pourvu d'organes spongieux qui communiquent arec le poumon; ils s'étendent jusques dans les os des aîles, qui sont creux et sans moelle. L'air qu'ils contiennent se raréfie par la chaleur, les rend plus légers, et favorise singulièrement leur vol.

Quelyues ciseaux ont l'estomac membrạneux; il a lui-même peu de force, mais il est rempli d'un suc très actif, qui ramollit les os, et les dissout avec les chairs. I'estomac d'antres oiseaux est composé de rnuscles vigourcux, qui triturent les alimens avec unc tellc force, que les pointes acérées des épingles et cles lanceties y sont émoussées, que les substances les plus dures s'y brisent, et que le verre s'y réduit en poudre.

L'irritabilité des oiscanx égale celle des marnmifères; ils se montrent per sensibles au goût des alimens; les odcurs les afiectent peu. Leur vue est très perçante; ils entendent: moins parfaitement. 


\section{D'Histora Naturete. 239}

On trume des niscaux dans tumes les farliev de la terre; ils vivent en srciété nu soliraires; quelpues-uns nont qu'une compagne, dizntres témuignent des gututs plus volages; cest an mots fhréal que comnencent lèurs anours; dejui, corte éponue juisuen messidur, is sont occujés des soins paternels. Le plus suavent lo lemelle construit senle son nid ; quel fuefois' le mâle l'aide dins ses travanx, et partage avec elle tous les antres détails dé l'education.

Le nial est composé de buchentes, d'herbe sèche, de terre, de mousse, de crins, de poils, cic. Sa forme varie selon linstinct de larchitecte ; quelquefuis il a plusieurs chambres; d'autrofois il ressemble à une bonise suspendue. Q:ılyues niseaux re sé consiruisent pas de niil : ils léposent leurs cuf's sur la terre ou sur des roches arides.

C'est dans le nid que la femelle dépose ses ceufs. La ponte est plus ou'moins nombreuse. La grosseur et la couleur des oufs varie, mais tous sont reconverts d'une croûte appelćc coque, dont la substance est analogue à celle des os. L'ouf est toujours plus 
240 E L É ME N

long que large, et le dianètre de ses extrémités niest pas égal; on a nommé ovalos tous les corps qui approchent de cette forne. On distingue dans l'auf' le germe placé au centre, et qui doit offrir un jour toutes les parties qui constituent l'oiscau. Dès que ce germe est pénétré de l'esprit destiné à l'animer, il vit, et la chaleur égale que la mère lui procure en le couvant, facilite son développement. Le petit se nourrit d'abord du blanc, substance analogue au lait des mammifères; et en croissant, du jaune, qui a plus de consistance el de solidité. Enfin, il rompt sa prison à coups de bec; sa mère l'aicle quelquefois à s'en débarrasser.

L'action de conver les oufs se nomme incubation; sa durée est plus ou moins longue; la femelle couve souvent encore ses petits après leur sortie de l'œuf, pour leur procurer une chaleur égale. Le mâle la remplace quelquefois penrlant qu'elle va chercher sa nourriture; d'autres fois elle reste dans son nid, et il se charge d'apporter tout ce qui est nécessaire aux besoins de sa famille. Il dégorge ce qu'il a pris dans le bec de sa femelle, qui broye de rouveau cet aliment, et le transriet de la même manière 
D'Historng Naturrit. 248 manière à ses pelits. Dès yu'ils sont assez grands et assez forts, ils leur apprennent à marcher, à voler, à nager, à chanter, à poursuive et à évicer leurs ennemis. Devenus plus vigoureux, ils pourvoient euxmêmes d̀ leurs besoins, et vunt chercher les animaux ou les plantes dont ils se nourrissent.

Quelques oiseaux comrent vîle, d'autres ont une marche lente et mesurée. Le rol sur-tout est remarquable. Les os des cuisses et des jambes forment un angle qui ressemble à un ressort et les aide à s'élever. Leur bec pointu fend les airs, et ouvre un passage au corps. Le tronc a lia forme d'un yaisseau, dont. le col est la proue, et la queve le gourernail. Les aîles font l'offico de voile et de rames, et le conduisent dans tous les points de l'espace. Les uns volent rapidement, d'autres s'élèvent excessivement haut, ou planent et se balancent avec majesté. Queliques-uns rasent de près la terre. Leur vue perçante les empêche de se brise: contre des corps durs.

Farmi les mammifères, l'homme seul a le don de la parole, quelques oiseaux peuvent au moins l'imiter et répéter des airs 
$24 x$

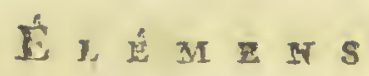

sirivis, et mêne des nots ct des pluases assez lungues. Tous ont un cil parliculiar, et plusicurs un samage agréable et mélodieux ğu'ils se plaisent à faire entendre, sur-tout quand le temps est serein, et dans la saisun des amours. Les femelles ne chantent point, elles n'exprinent que l'appel parlicrilier à leur espèce.

$\therefore$ La plîpart des oiceaux cachent leur lête cous unc âle nendant le somneil, beaucoup se tiemnent sur wn seul pied, el approchent I'aure de leur corps pour l'échauffer. Quelques-uns hybernent et resient cugourdis dans le tronc des vieux arbics, daus les cavernes, et riêre sous la glizce.

- La duréc de la vie varie chrz les oiscaux, clle est en général julus longue dans l'état samrgge qu'en librrté, quand quelqu'événement pariculier n'en abrége jos le terme. Les femclles viłent en génóral plus longremps que les mâtes, é les viseaux de proie plus que tous les autres.

-La différence des saisons oblige qualques oiseaux à chercher, ì des époques fires, un ciel plus chaud, des jours flus longs, une zourriture plus abondanie, et tout ce qui paut ajouter encore aux plaisics de l'amour. 


\section{difitotre Natuneice. 243}

L'agriculteur observe le temps de lenr départ et colui de leur retour. Ils lui indiquent l'époque où il duit entreprendre ef terminer les plus importans travaux. Ces migrations fourzissent aussi sur l'état de l'atmosphère des observations curieuses.

Dans l'ćconomie générale de la nature, les oisenux sont ciargés de déchirer les cadavres et les végétaux corrompus, de peur que leurs parties putrides ne causent des maladies pestilentielles. Ils détruisent les reptiles et les insectes dont la multiplication seroit dangerense. Les oiseaux aquatiques rendent l'eau plus saine en l'agitant. Tous concourent à eniretenir l'équilibre entre. les espèces, à réparer les peites de la nature en disséminant dans leur vol, les ceuís des poissons et les graines des végétaux.

On dresse quelques oiseaux pour la chasse au vol, d'autres portent fidèiement des nessagés; qualques uns devenus gladiatenrs; et armés de pointes d'acier, combattent en présence des spectateurs. La chair dun grand nombre est délicieuse. Il y en a dont les nids sont des alimens ou des remèdes; les ceufs sont excellens à manger. Les niames servent à écrire, à fuire des panaches, 
244 İ $\mathrm{L}$ 它 $M$ EN

à bourrer des couchettes, enfin à une foule d'usages. C'est pour jouir des avantages qu'ils nous procurent, qu'on les prend au piége, au miroir, au lacet, ou avec des fluaux, ou qu'on les élève dans des bassescours ou dans des volières.

Tous les oiseaux peuvent se partager en. six ordres.

\section{ORDRES DES OISEAUX.}

I. ACCIPITPES.... $\left\{\begin{array}{l}\text { Mandibule supéricure, dentée } \\ \text { ct recourbéc sur l'inférieure. }\end{array}\right.$

II. CORACES........ Bec comprimé et convexe. III. PASSEREAUX. Bec conique et acéré.

IV.GALLINACES.: $\left\{\begin{array}{l}\text { Bec convexe. Mandibule su- } \\ \text { périenre voütée. }\end{array}\right.$ V. ÉCHASSIERS..: Bec cylindrique. VI. ANSĖRES........ $\left\{\begin{array}{l}\text { Eec dilaté à son extrémité, et } \\ \text { couvert d'un épiderme. }\end{array}\right.$

I. A C CI PITRES.

CET ordre renforme tous les oiseaux de proie de jour, ou de nuit. L'extrémité de 
D'Historra NATUREte. 3245

la mandibule supérieure de leur bec, forme un crochet aigu qui retombe sur la mandibule inféricure. Leurs narines sont larges; et leurs pie Is robustes sont armés d'ongles vigoureux. Ces serres cruelles leur servent à emporier les animaux vivans, et les lambeaux des cadavres dont ils font leur nourriture. Leur estomac membraneux est rempli d'un suc qui dissont facilement les os, qu'ils ne se donnent pas la peine de séparer de la chair. Ces oiseaux ont une odeur forte et rebutante. Ils font leur nid sur des lieux élevés. La femelle toujours plus grosse que le mâle appelé tiercelet, y dépose quatre oufs. Tous deux prennent un soin égal des petits. On dresse quelquesuns de ces animaux pour la chasse, mais leur chair a un goût clésagréable. Leurs plumes ne sont point employées, et leur unique usage est de débarrasser la terre de cadavres infects et dégoûtans et des animaux inutiles. Cet ordre est le moins nombreux: voici les espèces principales. 
* Cire a la base du bec.

1. Litgle. La base du bec de ce tyran des airs, est accompagnée d'une cire jaune. Son corps brun clair est marqué de raies noirâtres. Il tient parni les ciscaux le mêne sang que le lion parni les inamuilères. It lis surpasse tous $\in \mathbf{n}$ force et en courage. Il construit son aire daus des lieux élevés. Sesaiglons apprennent sous sa conduite à chercher et à saisir les animanx qui doivent faire leur nomritme. Le lievre est sa proie la pius orlinaire. L'aigle aime les lienx froids. On en trouve dans nos montagnes; on peut le drcsser pour la chasse.

3. Le baJBUSARD. Sa cire et ses pattes sont blenes, il se nourrit de poissons qu'il sait prendie dans l'eau, même à quelques pieds de profondeur. Il halite les lieux voisins de la mer et des étangs.

3. Le milan a la cire janne et la queue fourchue. Lâche et férnce, il dévore les charogines, fond sur les oiseaux de bassecour et tos emporte. Mais si un autre accipitre, même inférieur en force, se prépare a lui disputer sa proie, il la lui abandonne 

sans combat. Quand il s'élève à me hauteur médiocre, c’est le présage des temnpêtes; s'il fend la nue, c'est l'annonce d'zn temps serein; s'il crie, c'est un signe de pluie. Sa femeile poud trois ceufs blancs tachetés die jaune.

4. La BUSE. Sa cire est jaune et son corps roux; indolente etstupide, elle demeure des heures entières perchée sur la même branche, principalement dans les buissons. Elie quitte cette embuscalle pour s'élancer sur les lapins et les autres petits mammifores, ainsi que sur les reptiles et les insecies.

5. L'épervikr a les pieds jaunes, sa cire est verte, il a antant d'activité et de courage que les denx éspèces précédentes ont de paresse et de pusillanimité. C'est le plus terrible fléau des garennes, des basses-cours et des colombieis.

6. L'Autour ressemble beaucoup d l'épervier, mais sa cire est noire; il s'en approche aussi par son courage et par ses mours. 7. Le faucon a la cire jaune, le bec d'un gris blcuâtre. Les oiseaux précédcns se dressent pour la chasse du vol, mais le faucon est celui à qui on donne principjalement cetie espèce d'éducation. L'art d'ins- 
truire les accipilres pour la chasse, a pris de lui le nom de fauconnerie. Aussirôt que son maître lui ôte le petit chaperon qui lui couvre la tête et les yeux, il part de dessus son poing, poursuit l'animal yui lui est indiqué, fond sur lui perpendiculairement et sais détour, et s'en rend maîre Il attaque souvent le milan, et le force à lui céder sa proie.

8. L'éziérlllon est plus pelit que les précédens, son dos bleu est manyué de taches brunes. Son vol est rapide, mais peu élevé; il sert pour la chasse des petits oiseaux.

\section{* Point dé cire au bec.}

9. Le lanter gris qu'on appelle communément pie griesche, a le bec noir, plus droit que les précélers, avec nne dent bien marquéc de chaque côté. Liextrémi é de sa langue est déchirée, son dos est griis, ses â̂les sont noires avec nne iache hianche. Ce petit accipitre attarue souvent des animanx plus gros que lui, et ce combat à outran se finit urdinairement que par la chrie, ou la inmt le l'un ou de l'autre adveraire. Il poursuit tous les pelits oi- 
seaux. La femelle fait son nid au sommet des arbres, sur des branches doubles ou triples, où elle trouve un solide appui. Dlle apporte d'abord des insectes ì ses petits, et elle les accoutume ensuite à manger de la chair. On voit voler ensemble des familles composées du père, de la mère et de cinq ou six petits.

10. L'ícorcheur ressemble beaucoup à l'oiseau précédent dont il partage aussi les mours, mais son dos est roux et son bec plombé; il arrive au printemps. Il part avec sa petite famille dans le mois vendemiaire.

$$
\begin{gathered}
* * \text { Tête grosse et applatie. } \\
+ \text { Oreilles aigrettées. }
\end{gathered}
$$

11. Le mirou n'a point de cire, mais il s'éloigne de ceux de la précédente division par sa tête énorme et applatie, ses grands yeur ronds, son bec crochu et ses longues narines, accompagnées de petites plumes en filet qui forment des aigrettes. Son corps est rayé de gris, de roux et de brun. Comme il voit mieux la nuit que le jour, c'est après le coucher du soleil qu'il com- 
250 है

mence sa chasse. Il se nourrit de phalènes, de perits oiseaux et de petits mammiferes, qu'il saisit aisément avec ses ongles robustes. L'éclat du jour le blesse au point qu'il fait milie gestes ridicules. Les petits oiseaux se vengent alors de sa cruauté, et I'insultent sans danger. La fernelle s'empare sonvent d'un nid' étranger, où elle dépose quatre à cinq œufs.

\section{++ Point d'aigrette.}

12. Le cirat-hunte ressemble beaucoup an précédert, nais l'iris de ses yeux est blenâtre. Son plumage est agréublement rayé, il Trabite les arbres creux.

13. L'Brfmate a le dos jaune marqué de points blancs, elle habite les clochers et les toits des églises. Cette demeure et son cri Ingubre, l'ont fait regarder comme nn oiseau funèbre, comme le messager de la mort, et c'est à l'efiroi que cause cette croyance qu'elle doit son nom.

14. La cilovetre. L'iris de ses yeux est jaure. Ses taches ressemblent à de petites flanmes, elle habice le creux des rocher's, ou lans les flanci des montagnes. 
D'IISTOrRe NAtuRelle. 251

\section{I. $C O R A C$ ES.}

Les oiseaux de cet ordre ont le bec convexe et un peu comprimé. Laurs pieds courts et rebustes sont formés ponr marcher avec sûreté. Ils se nourrissent en géréral diinmondices, et sont destinés également d̀ débariasser la terre des substances désorganisées. Leul chair est dure, coriace, désasréabla; peu d'espèces peuvent se manger. Quelques coraces apprennent facilement ì parler, naais leur cri naturel est insupportable.

\section{* Cira à la base du bec.}

1. Le perHoguet a la mandibule supérieure mobile, et garnie d'une cire ì son origine. On confond sous ce now un graul nombre d'espèces difrérentes. Il y a des perroquets gris, verts, etc. Toutes sort amusantes par la facilité de leur apprendre des chansons et des phrases.

2. La penuare ne se distingue des yerroquets que parr sa petilesse. Les perruches apprennent aussi à chanter et à jarter. La plus conumune est la perruche veres de cayense. 
$252 \quad \dot{\mathrm{E}} \cdot \mathbf{L}$ 它

3. Le anas a un cri désagréable et ne parle pas si bien, mais ce talent est remplacé par la beauté diı plumage. Les aras ont une longue queue et une magnifique aigrette. On les nomme aussi cacatoës.

\section{* Ticds promeneurs, 3 doigts anté- rieurs, I postérieur.}

4. Le corbeau a le corps noir et le bec convexe. Il se nourrit de petits animaux vivans, et il se partage avec les mammifères carnassiers la dépouille des cadavres. Voleur et criard, il est importun et incommode. On lui apprend cependant à parler. La durée de sa vie est longue; sa femelle niche sur les arbres élevés ou sur les rochers. Elle pond en floréal cinq à six œufs bleuâtres tachetés de roux, que le mâle couve pendant le jour, et elle pendant la nuit; l'odeur du corbeau est forte et désagréable. Sa chair est rebutante, mais il est très-utile pour débarrasser la terre des charognes infectes. Il faut absolument avoir soin de l'éloigner des terres ensemencées, dont il dévore les grains. Ses pennes servent pour écrire très-fin et pour dessiner. 
D'Histotre Naturelie. 253

5. La Cornjille est d'un noir bleuâtre. Ses mœurs sont absolument les inêmes que celles $\mathrm{du}$ corbeau, mais elle est nuisible encore plus aux semences et aux fruits dans les campagnes.

6. Le gear semble fier de son plumage bleu marqué de raies blanches. On lui apprend facilement à parler. Ses plumes servent à faire de jolis manchons.

7. La ris. Elle parle aussi bien que le geai, et s'apprivoise aisément; sa familiaritẻ devient mème souvent incommode, on la nourrit de chénevis; son plumage est noir marqué de blanc. Elle a du plaisir à déro. ber ce qu'elle trouve.

8. Le zortot a le hec convere, mais conique; la mandibule sipérieure surpasse un peu l'inférieure, son corps est d'un gris sale, les aîles sont noires, il se nourrit de fruits, sa voix est aiguë, sa chair n’est pas mauvaise.

9. La nupe doit son nom a l'aigrette mobile dont sa tête esí ornée. Son bec est long, mince et arqué; elle aime les lieux solitaires, et se nourrit d'insectes et de substances putréfiécs. L’aigrette, ordinai- 


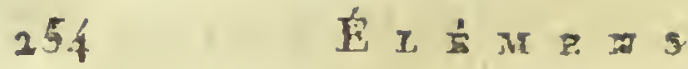

rement conchée, se drcssc quand la huppo est en colère.

$$
\begin{aligned}
& \text { * * Pieds grimpears, } 2 \text { ante- } \\
& \text { rieurs, } 2 \text { postérieurs. }
\end{aligned}
$$

" 30. Le coucou a le corps noir et inarqué de points blancs; sa fernelle inhabile at couver, dépose ses œufs dans le nid des autres oiscaux, principalement dans celui des mésanges; ces mères adoptives en prennent soin. Ie coucou perché sur des arbres élevés, menant une vie oisive et inuile, ne cesse de répéter les sons plaintifs et enmuyeux exprinés par son chant.

11. Ire pic est noir, et le sommct de sa tête est rougge. Il attaque les arbres morts ou malades, il les déchire ct facilite leur prompie conversion en un terreau propre à la végétaion. Il s'attache aussi quelquefois à des arbres sains. Il incrodrit cntre l'écorce son bec conique et pointu, et il en retire avec sa langue dure et en forme de dard, les larves des insectes et les insecies eux-mêmes qui les rongent et les détruisent. Loin de faire la guerre à cet oiseau utile, il faut favoriser sa prepagation dans les forêts. 


\section{D'Iisteiris Natureide. 255}

12. Le $\operatorname{TIC}$ VInD ressemble au précédent par sa fome et par ses mours, mais son corps est d'un beau verd, le sommet de sa tête est également cramoisi; il aime beau. coup les abeilles et les bourdons.

$$
\text { **** Pieds chemineur's, } 2 \text { des }
$$

srois doigts antérieur's réunis, I postéricur.

13. I. e martin-pîcheur est blen en dessrus, et d'un jaune vif en dessous. Il role bien, quoinu’il ait les aîles courtes. Il habite les bords des eaux, et se nourrit dé poissons qu'il avale et qu'il rend presqu'entiers.

\section{PASSEREAUX.}

Les passereaux ont le bec conique et pointu, les pattes minces et le corps délicat, ils se nourrissent de graines et d'insectes; ils construiseni leur nid avec beancoup d'art. La plûpart ont un ramage agréable, et sont un mets très-délicat. En général ce sont les bôtes les plus ainables de nos bois, nous en peuplons nos volières pour jouir de leur chant, et être témoins de, leurs amours, de leurs caresses et de l'eurs débats. Cet ordre est fort nombreux. 
* Trec épais.

1. Le gros azc. Son bec court et robuste lui mśrite bien le nom qu'il porte; son corps est brun avec une tache blanche sur les ailes. Sa f'emelle niche sur l'enfourchement d'un arbre près du tronc. Le gros bee se nourrit du noyan des fuits qüil brise avec facilité. Il est silentieux et paruit avoir le sens de l'onie peu délicat.

2. Le BEc crorsé. Les extrémités de son bec se croisent, ce qui le fait facilement distinguer du précédent. Sa f'emelle niche au commencement de nivose clans les forêts de jins et d'aulnes. Il se nomrit de la pulpe des fruits.

3. Le bouvreut. Ce joli passereau réunit Io double avantage de la beauté et du talent; le sommet le sa tôtc est noir, sa pritrine estcendrée, le veurre estrouse dins le inàle, et bai clans la lemelle. Le boureuil béquete les grairos et les fruits et cause bcaucoup cle dummages aux arbres qu'il ébourgeonne. On l'apprivoise aisément, et on lui apprend avec facilité à sifler des airs et à répéter de petites phrases. 


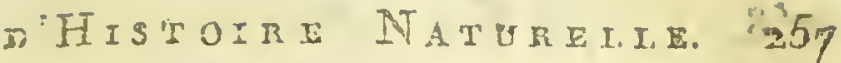

4. Le prnsors. Le pelit bec noir de cet oiscau pince assez lortement pour lui avoir fait donner ce nom. Il a des taches' blanches sur les aîles et sur la quene. Lie mâle a un assez joli ramage, on le rend avengle pour ne lui laisser que le plaisir de chanter, et jouir plus souvent de celui de l'entendre.

5. Le chardonneret. Co petit oiseau impatient et vif a les caprices qui trop souvent accompagnent le talent. Son plumage varié est d'un bel effet, et on ne peut lui rcfuser un rang distingué parmi les musiciens champêtres. On l'élève souvent arec les scrins, mais it se fait m malin plaisir de troubler la pais le leur ménage. Il se nourrit de chénevis et de plantes à duvet. Il se plaît sur-tout à éplucher les aigrettès du charlon, ce qui lui a fait donner le nom qu'il porte. C'est lans les vérgers qu'il construit son nid. Les matéıiaux de ce petit édifice sont des mousses, des lichens, des aigrtettes, des plantes composées. La Cemelle fait deux pontes par an. Malgré son caracière lóger et frivole, on apprivoise Ic chardonneret, et on lui apprend à sifler ou d̀ parler: Sa tềte est d'un beau rouge, il a une plaque jaune sur les âlles. 
6. Le senre est originaire des Canarics; et très-répandu en Europe. On prend plaisir à le faire pondre et couver dans les cages. On Jui apprend à sifler et à chanter. 11 a le corps d'un jaune pâle, et les aîles d'un jaune verdâtre.

7. La LiNotTe doit son nom à son gon̂t pour la graine de lin. Le lessus de sa tête est rouge ainsi que sa gorge.

8. Le moineau a le corps mélangé de gris et de noir, et sur l'âle une raie blanche; parasite aussi vorace qu'incommode, il ne quitte pas nos habitations et préfère même les villes aux campagnes. Il ramasse le grain, le pain; tout lui est bon. En vain cherche t-on à se débarrasser d'un hôte si importun. Si on détruit son nid, il en a bientôt construit un autre; si on brise ses œufs, la femelle en pond aussitôtde nouveaux. Trop effronté pour se piquer des rebuts qu'il éprouve, trop rusé pour se laisser prendre aux piéges qu'on lui tend, il est impossible de s'en défaire. Souvent il fait dans les trous des vieux murs un nid lécouvert, mais s'il le place sur un arbre, il y ajonte une calote pour le défendre de la pluie. Il y a plusieurs pays où la tête de ce petit voleur 
d'Fitstorra Naturaile. 259 est mise à prix; les noineaux se réunissent souvent en troupes nombreuses.

9. L'ORŢorar si renominé parmi les gourmands, a la mandibule supérieure du bec plus large que linférieure. Son corps est roux, et ses piełs sont jaunâtres. Il vit de grains et dévaste quelquefois les champs l'aroine; il chante assez bien, mais c'est pour sa chair délicieuse qu'un le recherche. On l'engraisse dans des chambres où le jour ne pénètre pas, mais qui sont continuellement éclairées par des lumières. L'ortolan trompé par cet éclat ne se livre point au sommeil, et ne cesse de manger le millet qu'on lui fournit avec abondance. Ce n'est bientôt plus qu'une petite pelotte de graisse excellente, mais dont on est facilement rassasié.

10. Le BRUANT se faitaisément remarquer par l'éclat des plumes jaunes qui ornent sa tête. Ce petit oiseau est commun, il est peu farouche, et sa femelle aime tant ses petits qu'elle se laisse prendre à la main sur son nid plutôt que de les quitter. 


\section{E L E II IN}

* * Ecc recourtés ì son cxtrémité.

I I. L'mitrondentex. Cet oiseau est noir ố marqué d’une tache blanchic sur les aîles; il est très commun. Il fait dans nos chemirées ct jusques clans l'intéricur de nos maisons, un nid fortement maçouné avec de la terre mêlée d'herbe et de bourre. Vers la manvátse saison les hirondelles se rénnissent et ront chercher cnsemble des climats plus doux. L'hirondelle rase la terre en volant, guand il doit pleuvoir, pour saisir les petits insectes dont clie nous débarrasse. Ceux qui la détruisent joignent clone l'injustice à la cruauté.

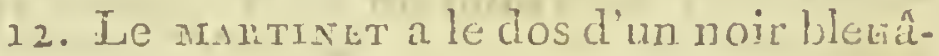
tre et le ventre absolument blanc. Du reste il resscmble parfaitement à l'hirondelle par sa forme ct par ses mours. Il niche aussi dans les maisons, mais il choisit les erdroits solitaires.

* * Bec échancié vers son extrémité.

13. La GrIYr. Son bec cst en forme de coutenu et plat à sa base; l'ouverturc de 
D'Itstotre Naturetig. $26 z$

sa bouche est accompagnée de cils. Sa queue est fourchue, et on remirque une tache binche sur son ocil; la grive se plaít dans les vignes, on la trouve cependant anssi dans les bois; sa chair est cxcellente.

1. Le resti. Son bec jaune, son plumage noir sont les caractères bien reconnoissables. Le merle ne va pas en troupes comme la grive, il est plus facile à apprivoiser; il apprend à sifler et à chanter. On trouve dans les pays froids une variété du merle dont le plumage est blanc.

\section{**** Bec simple entier et effité.}

35. La MÉsAxGe a le bec noir comprimé et garui de poils à sa hase, sa langue, est terminée par des poils. Sa tête et sa qucue sont noires; elle a sur la tête une tache. blanche. Cet oisean esí très-1écond. La ferocile poud huit à douze xut's pour lesquels elle se fat un nid, ou se creuse un trou dins un arbre. Elle se nomrit d'insectes, do grainci, de petis oiscaur dont clle ouvre la tête avec son bec. Elle aine beaucoup la chair, sur tont celle qui a de l'amertume. Sa roiz est monotone et peu agréable. 
16. J.e rossigñor. Cet oiseau dont le corps est petit et le bec allongé, a le gosier d'un juune órangé. L'étendue, la variété et la volubilité de son ramage l'ont rendu justement célèbre. C'est au pintemps qu'il chante le micux. Sa femelle se fait un nid dans les broussailles. Dès que ses petits sor éclos, le mâle suspend ses chants et ne s'occupe plus que de partager avec elle le soin de les noumir. Il les instruit ensuite dans son. art, et ils deviennent bientôt aussi habiles que leur maître. C'est sur-tont la nuit, dans les bois solitaires et sombres, que le rossignol aime à farc entendre ses chants, qui font le charme des ames sensibles et des cocums mélancoliques. On le prend au miroir et au filet; sa chair est bonne ì manger.

17. La rauverwa. Son plumage mêlé dé gris et de roussâire n'a rien de remarquable, mais si elle n'a pas la beauté du rossignol, clle l'égale presúxe par son ramage, et elle y joint une aimable vivacité. Elle niche ordinairement dans les chamıs cie légumes, et elle prend le pius grand soin de ses petits.

38. Le Bouge-gorge. Son nom indique asséz son caractère, il chante bicn et s'apprivoise aisément; querelleur et yaillant, il 
ne peut soufrir un rival sans le combattre; tont lui convient pour sa nourriture.

19. Le roitenet. C'est le plus petit et le plus joli les oiscaux que nous avons en France; sa couleur est brunâtre, une tache aurore quil porte sur le front lui a fait donner son nom, mais il peut abdiquer aisément son titre; cette tache n'a rullement la forme d'une couronne; il se nourrit de très-petits insectes et de graines. Sa vivacité est extrême, et il est clans un mouvement continuel.

20. L'alouette. Ce passereau a le corps roussâtre, les pattes et le bec noirs, la langue fourchue. On l'élève dans des cages à cause de sa facilité à imiter le chant des autres oiseaux, et il s'apprivoise aisément. La femelle cache son nid, et elle a pour ses petits un soin extrême. Le vol de l'alouette est remarquable. Elle s'élève à plusieurs reprises, toujours perpendiculairement à perte de vue, et elle nie cesse jendant ce temps là de chanter. C'est l'alouette que l'on chasse et que l'on vend pour la taljle, sous le nom de mauviette.

21. E'b́rounneau. Son hec est en aldne,

R 4 
264 E L 妾

et ses narines sont grarnies d'un rebord. Son. plumage est d'un brun foncé ponctué de blanc. Les trounes d'élonmeaux forment sonvent sur les marais des espèces de tourbillon. On apurivoise cet oiseati, et il apprend à parler avec facilité.

22. Le 1 I EOH. Les narines de cet oiscaux sont i deni couvertes d'une membranc molle et gonfléc. Le corps est ordinairement cendré. Sa queve blanche est rayée de noir ì son extrémité. On connoît un gुrand nombre de variétés de cettc espèce qui diffèrent beaucoup les unes des antres. En général le pigeon aime la socicté, c'est le symbole de l'amilić constante et de l'amour didèle. La femelle pond deux culfis qu'clle coure pendant le jour, le mâle vient prendre sa place vers le soir pour Ini donner quelque repos. Si le vetomx de l'un d'enx a trop tardé, l'antre allarmé par sa tendresse va le chercher ct le ramène sans plaintes et sans reproches. Quand les pigeonneaux sont éclos, le mâle dégुorge la noumiture quil apporte dans le bec de la colombe, et elle la transmet de mênte à ses petits. On élève les pigeons dans des volières fermẹes appellées colombiers: I eur 
D'íistorng Naturite. 265 chair est excollente et leur fiente fertilise la terre.

23. Le r A min a les pattes couvertes de luvet jusclu'aux doigts. Son bec et l'iris de ses yeux sont jaunîtres, le plumage de sa poitrine est tcint de ce violet chatoyant qu'on nomme gorge de pigeon. Il ressemble beancoup au frigeon, mais c'est un oiseau de passage: Il niche sur les rameaux des grands arbres, où il roucoule plus fortement que l'espèce précédente. Ses mœurs sont du reste absolumeni semblables, mais il est diflicile ì apprivoiser.

24. La tourterelle a les plinmes de la queue blanches à leur extrémité. Son dos. est giv et sa poitrine incarnate. Ses mœurs sont les mêmes que celles du ramier, mais elle est moins sauvage.

\section{V. G A L L I N A C E S.}

Ce nom convient à cet orclee, parce que plusieurs des oiseaux qu'il renferme appartiennent à nos basse-cours, ou ils sont les. compagnons de la poule, gallina. Tous ont le bec conveze ct pointu, et la mandibule surérieure furme une voûte sur linféricure. 
Lenr corps est gres et musclé, leurs doigts sont fendus seulencnt jusqu'au prenier article, ils se nourrisscnt de grains qu'ils avalent avec avidité et sonvent avec des pierres. Leur estonic musculeux est cloné d'une trèsgrande force. Les substances les plus dures, Irs plus tranchintes et les plus aigüës s'y briscutous'y faussent. Ils chassent les mittos, les insectes importuns en se sappoudrant le corps de poussière. Presque tous pondent sur lia terre et sans aucun art des coufs on assez grand nombre. La plûpart des frallinaces sont excellens ì manger; c'est pour s'en nourrir qu'on les chasse, ou qu'on les élève. Leur voix n'a rien d'agréable.

* Gallinaces domestiques.

1. Le paon. C'est le plus bel oiseau de l'Europe, son plumage est d'un vert doré et sa tête est surmontée d'une riche aigrette. Les longues plumes de sa queue qu'il relève ou étale en éventail ont à leur extrémité une belle plaque appellée cil ou miroir. Sa femelle n'a ni cette longue quene ni ces couleurs brillantes. Ses pattes ne sont point armées de l'éperon que la nature a 
n'Historre Naturete. $26_{7}$ donné au mâle. Le paon orgueilleux de sa beauté domine lans les basse-cours. Il vole inal, mais il aine à grimper et se perche, pour dormir, sur un arbre, ou sur un toit. Il est impossible de réunir tonjours les dons extérieurs et lej talens aimables. Le cil du paon est triste et insupportable. La davie de sa rie est assez longue. Il se nourrit le toutes sortes de grains. La cirair des proormeaux est assez bonne. Ses plumes servent d'ornement.

2. Le DINDON est facile à reconnetiro à la crête spongieuse et chamme qui hii couvre la tête, et descend le long le son bec quand on limite. Son plumage est le plus souvent noir. Il se rengorge comme s'il étoit beau, et glousse avec un air l'importance. Le mâle se nomme $\operatorname{cog} a^{\prime \prime}{ }^{\prime}$ de, parce que ce pays lui a donné la raissance. La femelle, ou poule d'Inle, conve en pluviose et en thermilor jusan'à vingl-cinq oenc's à la fois. La chair du dindon est bonne, celle des dindomaux est plus tendre. Ses plumes sont pen estimées.

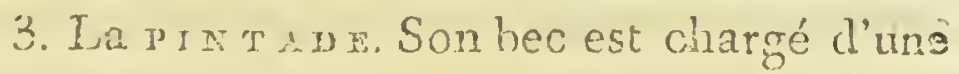
crête qui aproche de celle úu dindon, ot sa tếc osi défendue jar nu casgre dur ét 
callcux. Sa queue abaisséc, ct'scs ailez relevćes forment sur son dos une copéce de bosse. Son corpsg is bleuần e cst poncuéde blanc. On l'élève dans lcs basses-cour's, mais clle préléberoit les champs, et eile est soufont cal querelle arec les poules. Ses wufs et la chair des pintudunx sout bons ì mangor. 4. Le coea lis cròte rouge, double et comprimćo, sa quene cst rulcrée et comprimće; c'est le ninle de la poule qu'on peut regarder comme le trésor des basse cours, et dont it y a tant de valiciés. La plus lëconde cath ponte noive, ses reuf's sont blancs et scivent il une infinite l'usages, on les mange la inili manières. Le jazne mis sous la presse foumit de lihuile, le blanc sert à clarifier les lingicurs. La poule comve ceux qui ont étú fécondés, et le poztiet en sort an bout de vingt-vn joms. Cetto tendre mère continue toujour's il l'échamer, ct ne cesse ses soins que quand il a acyuis tonte sa force. Les mâles qui ne sont pas destiriés ì la reproduction de l'espècese nomment chapons, leur chair est excellente et salutaire. Oir appelle poularites les femeilics qui ne doirent jamais goùer les plaisios de lu maternité. Le coy se fait en général remaryuer an mi. 
d'Historre Naturele $2 \sigma_{9}$ licu de son sérail dont il est le dominateur. Il annonce par son chant le point du jour. C'est l'horlogie des habians des campagnes. 5. Ia f A ISA N. Son no!n vient de ce qu'il habitoit originairement les bords dn Phase, fleuve de la Colchide. Son corps est ronx, et sa tête est blene. On l'élevoit autrefois à grands frais avec des larves de fourmis pour le plaisir et la sensualité des princes dans des lient appelés fuisarduries.

6. Le FAISAN DOR à cause du mólange et de l'éclat de ses riches couleurs. On l'élève dans dés volières par curioșité.

7. Le fatsan a RGenté est blanc. Sa crête et son ventre sont noirs, on l'élève avec les précédent.

\section{* Gallinaces sarudges.}

8. L'OUTARE est un des plus gros.oiseaux de l'zurope. Le mâle a sous la gorge une harbe remarquable. Ce gallinace a le coups brun avec des bandes noires ondulées. On obscrve sous sa largue un sac, quelquefois long 'l'un pied, et qui s'étend jusqu'à la poitine: Il contient jusqu'à sept pintes 
d'eau; ce réservoir est bien prócieux pour cel risean qui cherche principalenent les ylines aricles. Il se réunit en tronpes vers le ten:ps de l'únigration. Son vol est posunt, sa course est rapille. Lioularde est granivire et fait des dégâts dảns les bleds. ¿lle sarrête principalement dans les départemens de la Meurthe, de la Hauie-Marne, é de la Côte-d'Or. Sa chair est excellente.

9. La Cinnepetiere est de moilié plus pelite que l'outarde, mais elie lni ressemble beancoup. Son col noir a un collier blanc. Sa chair est excellente.

10. Le т́ти as. On le nomme vulgairement coq de liriyère. Son curps est varié de différenles couleurs, il a une tache rouge autour des yenx. Il vit solitaire dans les bois de jins ut de bouleanx. Vers le mois nivose on. le voit souvent, perché sur un arbie la quenc étendue, le col incliné, et comme dans une espèce d'extase, appeller sa femelle par ses cris. Sa chair est très-eslimée.

11. Le ragopids. Son plumage d'été esi gris uncié de taches brunes. Celui d'hiver est presque absolument blanc. Cet oiseau parcourt par troupes le sommet des mon- 
d'Histotre Naturale. '37I tagnes. Il se pratique des trous dans la neige et supporte difficilement le vent et la pluie. Il se troure lans les Pyrénées.

12. La GELinotTe est encore un oiseát de montagnes-; les plumes de sa queue sont cendrées, une raie noire les traverse dạns le milieu. Il se nourrit de grains et de fruits comme le lagopède. On le chasse en l'attirant avec des appeaux qui imitent son cri. $\mathrm{Sa}$ chair est recherchée.

13. La PERDIX a une tache ronge audessus de l'cil, les pattes grises. Cet oiscau sédentaire aime les terres à bled et s'écarte peu du canton où il est né. Le mâle et la fernelle se recherchent vers la fin de l'liver, et ces couples ficlèles ne se séparent pas. Un nid grossièrement arrangé dans le pas d'un bœuf ou d'un cheval sert à lia perdrix pour y déposer vers le mois floréal quinze ou vingt ouf́. Elles les couve scule, et le mâle se tient auprès da nid pour l'accompagner yuand elle va chercher sa nourriturc. Dès que les petits sont éclos, il soigne avec elle leur éducation. Les perdraux mangent d'abord des petits insectes, les graines sont leur dernière nourriture.

14. La gantyidis ne diffère de l'es: 
pèce précóclcnte que par la coulcur ronge de ses pattes et de son bec, aussi l'appellet-on perilix ronge. Ses mours sont les mênes, on l'apprivoise plus difficiement.

15. La callz. Cet oiscan de passage a une tache blanche sur l'coil. Ses fréyuenies nigrations le répandent par toute l'Europe. Le, mâle est courageux, on le fait combattre comme les coqs. La chair de ces trois dernières espèces est très-recherchée.

16. L'autrughe ne se trouve quen Afrique et cn Asie: monté sur de longues pattes et aidé d'ailes très-conrtes, ce gros oiscau ne peut voler, mais sa course cst très-iapide. Il fournit an commerce ces belles plumes ondoyantes dunt on orne les cliapeamx, les casques de théatre... etc.

$$
\text { V. 'X CHASSIERS. }
$$

Ce nom convient pariaitement aux oiseaux de cet ordre qui paroisscnt en cf́et montés sur des échasses. Tous ont le bec cylincriqué, les cuisses menues, la queue conrte, la peau fine et la chair savoureuse. La Jongucur de leurs pattes donne à ces oiscaux de rivages la facilité d'entrei dans les lieux farsgeux 


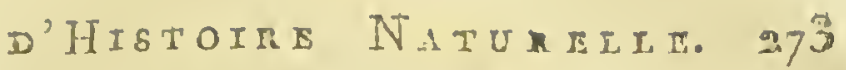

sans moviller leurs corps. Tous nichent sur la tcrtc. On trouve dans cet orclie de très. gros oiseaux.

1. La Grue. Son bec et son col sont d'une énorme longueur, et c'est un des, plus grands oiseaux de passage. Il vole à une très-grande hauteur, et s'arrête rarement en France.

2. La cIGOGre a le bec allongé comme celui de la grue, et d'un 'rouge éclatar: ainsi que ses pattes. Son corps est d'un beau blanc, et ses remiges sont noires. Son vol est soutenu, sa marche mesurée. Elle s'arrête quelquefois dans nos départemens du Haut et Bas-Rhin. Elle se fait un nid assez vaste dans les vieilles tours et dans les clochers. Qu'elle chasse, ou qu'clle pêche, la cigogne nous débarrasse des reptiles et des serpens. Elle nourrit long-temps ses petits qui la soignent à leur tour. Voilà pourquoi les anciens regardoient cet oiseau comme le symbole touchant de la tendresse filiale et maternelle. Nous ne devons pas nous étonner qu'il fùt sacré et quon fît un crime de le tuer.

3. Lc í во tôte est surmontée d'une aigretie noire. Il 
274 İ L E KI E S S

attend souvent pendant des heures entides le poisson lont il veut faire sa proic. Il se nourrit aussi de végétaux, il aime la solitude ct ne recherche la société de ses semblables que dans le temps de la ponte. Les héronaux sont bons à manger. L'aigrette du héron sert à faire des panaches.

4. Le nutor. Son nom est devenu la désignation de la balom lise et de la maladresse. Il est en cfiel aussi mélancoliyue et aussinilolent que lo héron, mais il en diffère par la !orme; sa taille est plus petite. Son dos ronx est marqué de taches transversales. Son cri sescomble au mugissencnt d'un hocul.

5. Le couriss a les pieds blenâtres, les aîles noires, tachetées de blanc. Il habile les bois marécagoux, où il se nourrit d'insecies.

6. La wrecasse a les pattes condrées et les. cuisses couverles. Sa îte est traversée d'une bande noire; elies est, ainsi que les espèces suivantes, un exccllent giljier.

7. La reccasiñe, au lien d'une iache noire, a guatre taches brunâtres sur la tête. On la mange, comme la beccasse, salus la 


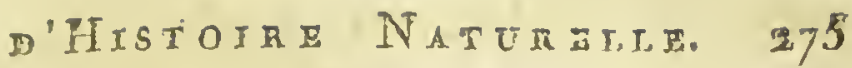

Fuider; ses entrailles broyées sont leur meilIcur assaisonnement.

8. Le vaninau. Ses pieds et sa poitrine sont noirs; sa tête est surmontée d'un panache incliné. Il aime les insectes et les vers, et débarrasse les jardins des limaçons. Sa chair et ses oufs sont très-estimés.

9. Le reupier. Ses pieds n'ont que trois doigts. Son corps noir est marqué de taches d'un verd doré. Sa chair cst cxccllente.

Io Le Ralte. Ses pieds ont quatre doigts; son corps est ferrugineux; il court avec vîtesse dans les champs de blé, où il mange les grains et les insectes; mais il vole mal.

11. La rourgee. Le sommet de sa tête est absolument nu; son front est couleur de feu; son corps est noirâtre; ses doigts ne sont pas palmés, mais chacun d'eux est bordé d'me membrane, ce qui le rapproche de lioudre suivant. La fonlque se nourrit de poissons; on la nomme aussi improprement poule d'cais. 


\section{$276 \quad$ L \\ VI. A N S E R E S.}

CrT ordre a des caractères si marqués, quil est impossible de le confondre avec les autres. Les ansères ont le bre obtus, couvert d'un épiderme, et le plus souvent denticulé à son ouverture. Lenr langne est chnmue, lcurs pieds sont palmés, le plus somvent d'une longueur proportionnée à leur corps; et quelcuefuis si court, qu'ils en ont reçu le nom de manchots. Leur chair est, en général, grasse ct savoureuse ; leur pean, dure et tenace, fait de bonne fourrure. Leurs pennes servent à écitre, lcurs plumes, à bonirer des conchelles. Ils se nounissent d'insectes et de puissons qu'ils altrapent dans l'eau gu'ils laisscnt écouler à travers les petics dents de leur bec, comme dans un crible. Ces oiseaux nichent à tère. Les uns halitient le voisinage des mers, d'autres celui des eanx donces. On en élève quelquesuns dans les basse-cours, pour leur utilité, et d'autres dans les bassins, pour l'ornement. 


\section{- Bec denticulé.}

1. LE CYGNE est d'une blancheur éclatante; et son bec est d'un beau noir; il fait l'orsement de nos bassins et de nos canaux, où il se promène majestueusement en alongeant et retirant son long cul, qui forme différens replis pour saisir les petits poissons, les vers et les insectes aupuatiques. On lui construit, près des eaux, des petite's cabanes. pour l'abriter. La fonelle fait, pour ses œuf́, un nich d'herbes, et elle les couve pendant sir semaines. Le cygne vit longtemps. Les anciens ont beaucoup vanté le chant qu'il fait entendre, disent-ils, au mornent de sa mort. Cependant, le cygne donestique, est muet, et le cri du cygne sauvage n'a rien d'agréable. La chair des jeunes cygnes étoit autrefois fort estince ; on n'en fait guères plus d'usage. Ses plumes s'employent comme celle des autres palmipèdes. La peau de son ventre sert à faire des fourrures et des houppes.

2. L'ore. Ce palmipède est à-peu-près de la grosseur du cygne, mais il a le corps cendré. Quciuquil vive yar-tout, on ne l'élève uti- 
lement que dans le voisinage des étangs et des rivieres; il vit long-temps, ct dort d'un sommcil léger. Le mâle s'appelle jars. La femelle fait truis pontes par an, chacune de dix à donze ceufs. Sa chair est succulente, mais lomde. On peut, par lifúrens moyens, fuire acruérir ì son foie un volume considéiable, et c'est un mets très - délicat. Sa grainse rempiace le bourre. Avec ses os, on fait des appeaux; ses remiges servent pour écrie, et ses plumes, pour garnir des concheties. L'vie sauvage, dont l'oie domestivue n'ést yu'me variété, entreprcnd de longs voyages, pendant lesquels la troupe se fornie en un triangle éifuilatéral.

3. Le canany est beancomp plus petit que l'oie; son corps est cendré. Son col, d'un verd doré, porte un collier blanc. Il a les jamhes courtes, et sa marchè est tròs-génée. Il aime è barboter dans les eaux bourbeuses, pomr y chercher des insectes et des vers, et il porte la voracité au point de s'étrangler. La canne nond quinze à vingt oufs, dont la coque est épaisse, et dont le jaune est rongeâtre et abondant. Ia chair du, canard est excolicntéc celle diu crrizetor, sur-tout, est estimée. Les plumes serrent à faire des 


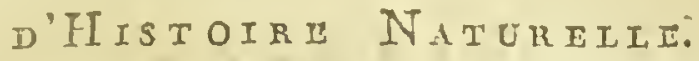

279

conchettes. Le canard sauvage imite l'oie l.ans sa manière de voyager.

4. La sarcelriz a une tache verte sur les ailes, e: une ligne blanche sur les yeux. Sa chair est excellente.

$$
\text { * * iuec sans céenticules. }
$$

5. LE péLICIN. Ses quatre doigts sont pralmés; il est tout blane, et il a sous le lec un énorme sac, ò̀ il fdit une ample provision d'can jonr ses poits, dont le vasio nil est ordinaizenentsin une roche éloignée de la mer. Il va pon eux da pèche; mais il ne se céchire pas la poitrine, ainsi qu'on l'a cru, pour les nourrir de sca sang. Cet oiseilit ne se trouve pas sur nos parages.

6. Le cormonav. Cet ansère, qui aproche du précédent par sa forme, se troure quelquefois en France; il est de li giosseur d'une ois, et son corps est noir. On peut le dresser pour là pêche, comme l'épervier pour la chasse. Les Grocnlandois mangent sa chair; ils se font des vêtemens avec sa peau, et des sac's avec sa poche.

7. Le gritbs. Ce manchot ne peut marcher qu'arec une grande difliculté; mais it 
rase légc̀rement la surface de l'eau, et nage très-bien. Sa tete est lisse; sa paupière inférienre est jaune. On peut manger sa chair et fuire des fourrures arec sa peau.

\section{A M P I I I ES.}

CETTE classe est bien moins nombrense que les quécélentes; les animaux qui la composcut ont le corps nu ou couvert d'écailles; l'envelopje de leurs cufs est menbraneuse et flexible.

Ce n'e.t pas parce qu'ils habitent indiffércmment sur la terre ou dans l'eau, qu'on les nomme amphibies, car il y en a qui ne peurent cxister que de l'une ou de l'autre manière. On les nomme amphibies, parce que leur respiration s'opère dans des intervalles inégaux et non pas alternatifs, comme dans les classes précédentes; la plûpart peuvent rester plus ou moins de temps clans l'air ou dans l'eau, mais ils ne sauroient demeurer continuellement dans ce dernicr unilieu, sans y perdre la vie.

Leur sang n'a pas plus de chale ur que le 
D’Fistotre Naturelle. 281 milieu qu'ils habitent; aussi, leur corps; froid au toucher, cause-t.il une impression lésagréablo, qui, jointe à l'idée que ces animaux sont venincux, à leur odeur forte, à leur forme bizarre, ajoute encore a dó-goût et à la répugnance qu'ils inspirent. - Tout cst cependant admirable dans la nature, et digne de l'attention de celui qui sait l'observer.

On sépare les amphibies en deux ordres faciles à distinguer par la présence ou l'absence des pieds.

\section{ORDRES DES AMPHIBIES.}

I. TÉTRAPODES......... Quatre pieds.

II. SERPENS................ Point de pieds.

\section{TÉTRA PODES.}

Crs amphibies ont quatre pieds. On les appelle aussi quadrupèdes ovipares, pour les distinguer des quadrupedes vivipares, les manmiféres. 
La tête des amplibies tétrapodes est plus on moins alongée; ita n'ont point l'oreille externe; leur ouverture nasale est peu apparente; leurs yeux sont assez gros, relalivement au volume de leur corps, saillans ct conlormés pour voir la nuit. Le corps cst court, le trone plus on moins alongé, et quelquefois terminé par une quene.

Au lien d'étenche leurs pattes en arant, comme les mammilères et les viscaux, ils les plient et les écartent, de mánière qu'ils jraroissent plutôt ramper que de marcher, co qui les a fait nommer rúles, par quelques naturalistes; mais ce nom ne pent convenir qu'aux nnimaux absolument déponrvus de pieds, et on voit même quelques any libics tétrapodes, dont la marche n'est qu'une suite le sauts.

Leurs doigts sont plus ou moins nombrenx, quelquefois palmés, mais le plus souvent entièrement séparés; ils sont, ous arrondis, ou terminés par des ongles crochus.

'T'out leur corps est en zeloppé d'une peau nue, enduite d'une liqueur visqueuse. Cette poau est qunelquefois détendue par unc croute oscense, pri des plaques dures, des écailles 
D'IIstotre NAturelte. 283 pointues ou des tubercules plus or moins saillans.

Le cour de ces animaux est très-petit, ct il I'a qu'un ventricule. Leur sang est rouge, mais froid et peu abendant; quelques-unes de leurs parties se reproduisent après aroir été coupées. Quoique plusieurs ayent des dents, ils ne mâchent point leur nourribure. Leur estomac a la faculté de se distendre, de manière qu'on y trouve quelquefois des animaux d'un irès gros volume. Ils peuveni supporter, pendant flusieurs mois, le défuut total de nourriture. Ils recherchent oudinaiuement les plautes et les insectes; quelques-uns, mais én petit nombre, mangent de la chais.

Lirritabilité des amphibies tétrapodes est extrêmement forte : elle leur survit; et en gúnéral, leur vie est fort tenace; ils ont neu de sensibilité. Ou les tronve engourdis dans des creux, dans l'eau, sous la glace, et ils demenrent long-temps dans un état de scmueil, et même d'une mort apparente. Ils se raniment au printemps; leur peau se desièche, ils la quitient et se montrent parés l'wne rolve nouvelle. Ce dépouillement a lieu fusieurs fois l'année dans certaines es: 
Ièces; celles qui sont armées d'rne croûte osseuse ne se dépcuilient pas.

Ces aninaux ont en général les mocurs donces et paisibles; quelyues - uns se réunissent'en grandes troupes dans les lieux les plus favoratles a leurs icsoins, mais ils n'y font ien en commun; ils n'y vivent pas vóritablement en société.

Ils sont muets, ou ils ne font entendre qu'un cri rauque et désagréable. Le mâle ajpelle sa femelle par ce cri dans les premiers jours ln printemps; elle est ordinairenent très féconde; ses auf's n'ont qu'une enveloppe mollasse; ils sont isolés, ou forment une esı̀èce de chaîne; la femelle les lépose daus les lieux où les pelits pourront trouver leur nourriture aussiôt qu'ils scront aniués; elle choisit ordinairement les trous creusés daus le sable, ou les marais abondans en plantes; clle les y abandonne, et ha chaleur de l'atmosphère f'ait le reste.

La plùpart des amphibies tétrapodes ont une ockeur forte et pénétrante. On les croit en général venimeux, et c'est une des principales causes de l'horreur qu'ils inspirent. Il n'y en a cependant qu'un très-petit nombre à gui on puisse faire ce reprocì̀e, et la plûpart 


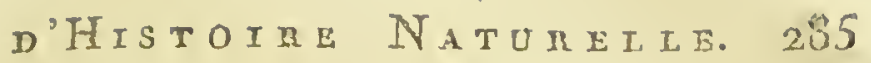
ont des usages prócieux. La chair et les oufs de quelques-uns sont une excellente nomriture; d'autres nou's fournissent leur écaille; tous nous lébarrassent des insectes venimeux ét nuisibles. On peut séparer cet ordre en plusieurs divisions.

* Corps couvert d'une cuirasse ossezse.

i. La Tortue FRANChE. La cuirasse osseuse, dont les tortucs sont armées, sulfit pour les distinguer de tous les autres ampibies.tétrapodes. Cet amphibie se retire en entier sous ce toit impénćtrable; il y brave la serre des oiseaux de proie, et la dent des mamnifères carnassicrs ; mais inhabile à attaquer, il y demenre immobile. Cette cuirasse est composáe de deúx pièces; celle qui couvre le dos est appelée carapace. Elle est convexe, et les vertèbres y sont attachées. La pièce inférieure est réunie aux os de la poitrine; sa forme est aplatie, et elle ne tient à la carapace que par les côtés: on la nomme plastron. Il ne reste ainsi que deux ouvertures, l'une antérieure, qui donne passage à la tête et anx pattes de depant, l'autre postérieure, quil laisse passer la queue 
et les pattes de derric̀re. La carapace est composée de plusieurs ćcussons. On appeile disque, l'ensemble de cenx du milicu, qui sont au nombre de treize; le bord est formé de quatorze. L'arrangement et la disposition de ces ćcussons sert' à distinguer les espèces; le nombre des écailles du plastron varie de clonze à quatorze; dans certaines espèces et dans, d'autres, de vingt à vingt gutatre.

La mâchoire supérieure de la tortue s'emboîte sur l'inféricurc ; ca gueule nicst pas mcublćo de dents, mais d'os fesitonés assez durs pour broyer les sulustances compactes. Ina bouche s'ćcnd jusqu'anz orcillcs, qui ne sont sensibles it l'wil que par les plaques qui les recourrent. Iés narines sont an-dessus de la bouche; les yeux sont gros et saillans; ses membies sont plus ou moins gros; sa quene plus ou moins longue, le tont cst envcloppé d'une peau attachée à la carapace ct au plastron, et qui est garrie d'écailles.

Quand la tortuc veut avancer, elle sort tous scs membres de leur ćtui; elle nage trc̀s-lien, mais sa marche est lenic et pénible. lietournće sur le dos, elle ne peut que se renfermer dans son enveloppe, sans espoir d'échapper au sort gu'on lui desine. Elle 


\section{D'Irstoire Naturet.r. תî7}

se nourrit d'insectes et le plantes marines. Captire, elle s'accommode de tout; nucune n'est carnassière et inallaisante. Flle reste inpunément dans l'air le plus mal sain ; é sa vie esi si tenace, qu'elle dure encore quelque temps après qu'on lui a coupé la tête.

La tortuc franche est la plus giosse cie toutes; on la nomme aussi la gramae tortue; il y en a qui pòsent jusqu'à quatre décibares. Elle pond un grand nombre d'curs. On la liarponne clans la mer, ou on la retourne sur le dos quand clle est prise à terre, et on la dépece à coups de hache. Ses ceufs sont très-hons à manger. Sa chair fraîche est trèsbonne pour rétablir la santé des navigatenrs scoributiques; on la mange anssi salée. Ies anciens Ethiopiens se faisoient des riacelles avec sa carapace; les Indiens s'en Cabriquent des bo ucliers et en' couvrent leurs maisons.

2. Le caret est une tortue de ner comme la précédente; elle en difère, parce qu’elle n'a qu'un ongle aux pattes postérieures, ct la tortue franche en a deux; elle est aussi beaucoup plus petite: on la trouve en Amérique et en Asie. Ce n'est pas pour sa chair, toujours agréuble et quelquefois mal saine, 


\section{E I I II IN $S$}

qu'on la recherche, mais pour sa carapace, 'dont la substance est cette belle érnille dont on fait différens ustenciles et des bijoux. A près l'aroir amollic dans l'can chaude, on la met dans des monles, oì on lui donne, à l'aide d'une forte presse de fer, la forme qu'on desire, el on la polit.

3. La mouranesr habire les ivières. Nos départenens méricionaux en numrissent une grande gnantilé. Elle est beaucoup plus jetitc que la jrécéclente. On l'clère utilement dans les jardins, où elle détruit les limaçons; mais il ne faut pas là laisser pénétrer dans les viviers, oi clle dévoreroit aussi les poissons. C'est celle dont on se sert en médecine pour faire des bouillons anti-scorbutiques.

4. La tonte creceur. Comme clle n'habite ni les flenves, ni les rivières, cette tortue ria pas les picis palmós; elie est de la taille de la précédente. Sn la trouve en Sardaigne dans les bois et sur les hauteurs. On fait grand cas de sa chair et de ses ocul's, et on buit son sang crit.

$$
\text { * Corps }
$$


D'Historis Naturele.

* Corps verruqueux el court. Point de cuirasse.

5. Le cripaud. Le nom seul de cet am. phibie inspire le dégoût, ct fait naître l'idée d'un être aussì hideux que mal faisant. Son corps informe est couvert de petites élérations qui ressemblent à des pustules, et toujours humecté d'une liquenr gluainte. Sâ peau est orchinairement verdầtre. Il esı́ commun dans les lieux sombres, dans le creux des arbres morts, sous les grosses pierres, où il 'fuit l'éclat du jour qui le blesse. Il recherche, en hiver, les caux stagnantes; en été, les marais fangeur; les exdrơits les plus infects ont de l'attrait pour Jui, et il en diminue linsalubrité. C'est sur-tout pendant la nuit qu'il se met en quête; il s'élance avec prestesse sur les petits insectes, dont il veat faire sa proie. Il fixe hardiment les hoinmes gui le regardent, et leur lance une liqueur clairc qui a quelqu'âcreté, maís que l'on croit plus redoutable qu'elle ne l'est en effet. Il répand quelquiefois une odeur de musc. Le crapaud hyberne fort long-temps. La femelle dépose dans les eaux des petits 'T 
œufs disposés sur deux cordons; ils tombent dans la vase. Le petit crapaud ne brise pas son enveloppe dès qu'il est animé, mais elle se distend; et tunt qu'il y est renfermé, il ressemble dे un peit poisson, parce que les pattes de devant ne paroissent point encore; on le nomme tcitard. Dès qu'il est entièrement formé, il rompt ce sac et va en sautant chercher sa nourriture.

** Corps alongé, lisse et quadransulaire.

Ł. La grenourtic. On éprouve d'abord quelque répugnance pour cet amphibie, 丸 cause de sa resscmblance avec le crapaud; cependant il en diffère essentiellement. Son corps n'est pas couvert de verrues; il est alongé, quadrangulaire, relevé en bosse et lisse. La grenouille se nourrit des mêmes alimens que le crapaud, et elle est comme lui la proie des animaux aquatiques. La femelle n'a qu'un grognement sourd. Le croassement rauque et continuel que fait cntendre le mâle, est causé par des vessies placées auprès du col, qu'il vide et rempit d'air à volonté, et que ce gonflement altematif fait 
d'Historre Naturele. 29 résonner comme un tambour. La grenouille, avant d'ètrc parvenue à son entier accroissement, demeure long.temps lins son enveloppe, sous la forme d'un tétard. On mange ses cuisses accommodées de diférentes manières.

\section{* * * Corpstrès-alongé, convert d’écailles, accompagné d'une queze.}

7. Le crocontle. Cet amphibie sicommun en Egypte, est inconnu dans nos contrées. Son corps est garni de petites ćcailles, et. son dos porte une membrane denticulée comme une scie; il est armé de clents redoutables qui secondent bien sa voracité. On ne peut l'attaquer sans danger. Heureusement, quelques animaux détruisent.ses œufs, at l'empêchent ainsi de se tiop multiplier.

8. Ie chameléon. Il a le corps plus ramassé et chagriné, les yeux gros et brillans. Il change de couleur quand on l'irrite, ou par maladie; maisil est faux qu'il prenne celle des objets qu'il voit. C'est pourtant cette supposition qui le fait regarder comme le symbole de l'adulation et de la flatterie. On le trouve en Afrique et en Asie. 
9. Ia SALAMANDRE. Son corps est tacheté de noir et de jaune, sa queue courte et ronde. On la tronve dans les licux sombres et liumides. Quand on la touche, ou quand sa peau commence à se dessécher, elle se couvre sussitôt d'une liqueur laiteuse, qui lui rend la souplesse qui lui est nécessaire. Ce suc n'est point venimenx; il peut défendre quelyues momens la salamandre de l'effet d'un feu méliocre; c'est ce qui a donné lieu à cette fable, que la salamandre pcut vivre dans les flammes.

10. Le zíz.no. Ce joli petit amphibie a la quene longue, pointue et garnie de rangées circulaircs de petites écailles. 11 cherche les lieux sabloneux et arides; il ame sur-tout les vienx murs : il se cache dans leurs fentes pour chasser les insectes, anuquels il fait une guerre utile dans les jardins; il faut donc l'y laisser se multiplier, ce qui n'est pas bien difficile, car il semble chercher la compagnie de l'homme. Loin d'avoir les mouvemens tardif's comme les autres amphibies, il est extrêmement agile; on le mange dans quelque pays. On en trouve un gand nombre de variétés, le gris, de verds, et clont les tcirites sont différentes. 


\section{S IR P E N S.}

CEs amphibies ressemblent beaucoup à un lézard quion anroi privé de ses membres. Leur corps long et cylindrique, s'attache immédiatement à la tête. Ils n'ont point de piels, canctères bien suflisans pour les faire aisćment distinguer.

Leur corps est couvert d'écailles moliles, dont la disposition, la forme et le nombre servent ì différencier les espèces. Chasune de ces écailles se dresse à la volonté de l'animal, et lui procure unn point d’appui sur le terrain qu'il parcoure; c'est ainsi qu'il glisse ou qu'il rampe, action qui se rend en latin par serpere, dont on a fait le mot serpent. C'est en formant le cercle ei en rapprochant leur uruene de lem tête, que ces animaux s'ćlancent comme un ressorísur l'ubjet qu’ils veulent attcindro.

On connoit plug de cent soixante espèces de serpons; mais les plus grosses ei les plus dangoreuses n'habitent gue les pays trèschauds. Ils hybement long-temps, et se dépouillent tons les ans. Ils avalent souvent des animaur si gros, pi:o malgré la dilizta- 


$$
\text { EL III IN }
$$

bilité de leur estumac, ils n'y peurent entrer cntièrement. Le scrpent attend patiemment que la partie arabóc soit digérée, pour englontir le reste. La langne de ces animaux esi fondue; leur cri est un sifflenent; leur couleur est catrêmement variable. Leur vie cat très-tenace; ils peuvent se passer longtemps de nourriture, ct leur quene repousse quand clle a été coupéc.

Quoique tous les serpens passent pour venimeux, il n'y en a peut être pas un tiers de vraiment nuisibles. Le serpent est le symbole de la prudence; s'il mord sa queue, c'est celui de l'éternité.

Nous n'avons pas en France, ni même cn Europe, de très-gros serpens; les plus terribles sont étrangers à notre continent.

\section{* Exotiques.}

1. Lr SBRPET A SONAETtr senomme ainsi, à cause des ćcailles mobiles, csnèces de grelots, qu'il porie an bout de sa queue, ct qui arcrissent de sa dargerense approche. On le trouve en Amórique.

2. Le SERHENT A LURETTE doit son nom ì Ia forme de la marque qu'il porte sur le 


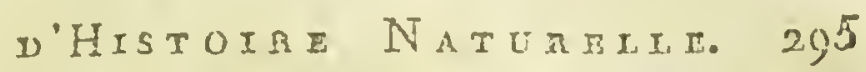
front; il est très-dangereux. On le trouve au Brésil.

$$
\text { * Indigetres. }
$$

3. La ripèng. Ce nom est l'abrégé de vivipare. Il lui a été donné, parce que ses oenfs éclosent dans le ventre de la mèro, et qu'elle semble ainsi faire ses petits vivans. Sa coulenr est d'un gris cendré, avec une suite de taches noires en zigzag.

La vipère pénètre quelquefois jusques dans l'intéxieur des maisons. Elle est foible et innocente en apparence. Elle se nourrit de grenouilles, d'insectes qu'elle saisit avec sa langue gluante. On a imaginé long-temps que c'étoit cette langue qui causoit des blessures si dangerenses, ct on l'a comparéc d un dard cmpoisonné ; mais elle cst fonrchue et ne peut faire aucun mal. Le veniuir de la vipère ne consiste pas non plus dans la bare gluante dont sa bouche est souvent inondée. Il esteconienu dans deux petites vessios placces aux deux côtés le la tête. Outro les dents monstrueuses lont la vipère est pourvue, elle a cncore deux dents aiguës et recourbées. Elle peut diriger cés crochets mobiles ct creax du côté qu'il lui plaî; et T/ 
comme ils communiqucist aux résicules remplies de vonin, ils en injectent une certainc quantité dans la morsure. Ce venin est un suc jaune grii n'agit sur ancune autre parlie; mais nếlć au sang, il cause des efets tros-nuisibles, dont l'inagination augrmente copenilaui beaucoup le danger. Ce snc cst moriel purr les petits animaux, maici rarement pour les autres; il cause sculcune:t une inflammation plus ou moins vive; ct si la mort a quelpuefois suivi cet accident, il faut plutât en accuser la peur, ou quelqu'autrc camse, que la morsure ellemî́nc. L'huile de térélsenthine, appliquće sur la plaie, cu est lc remède; mais le plus sûr est d'agrandir la plaie par des incisions, et de la bruiter avec la pierre infernale. Le venin de la vip̀̀re, pris intéricurement ì grande dose, est aussi un poison violent; il se conscrye long temps après sa mort, et il fiut bien prendre garde de se piquer avec ses crochéis, quoiqu'elle ait perclu la vie. La vipère s'employe en médccine pour différentes maladies, principalemert quand le sang cst appaurri. Sa graisse sert à faire une ponmade cice les femmes employont pour effacer les rides. 
d'Histoire Naturexe. 297 4. La couleuvre. Sa ressemblance apparente avec la vipère inspire une crainte qui empêche de la touchcr. Il est cependant aisé de l'en distinguer par ses belles couleurs. Ses ycux sont entourés d'écailles couleur d'or, et son corps est agréablement nuancé de verd et de jaunc. Non-seulement elle n'est pas nuisible, mais elle s'apprivoise en quelque sorte, et elle joue avec les enfans qui la saisissent. C'est en substituant cet animal innocent à la vipère, que des charlatans font croire au peuple qu'ils bravent son venin et sa morsure.

5. La couleuvre a collier se nomme ainsi, à cause des deux taches blanches qui ceignent son col; elle est aussi commune, aussi peu nuisible et áussi peu farouche que la précédente; on l'emploie en médecine.

6. L'orvet. Ses écailles brillantes sont blanchầres sur les bordis, et rousses dans le milieu. On ne peut le toucher sans le séparer en clifférentes parties. Il est innocent et très-commun. 


\section{POISSON S.}

Les écailles et les nageoires suffisent pour caractériscr les poissons. Lour tête tient immédiatement au corps; la gueule cstdevant, dessus on dessons; les lèvres sont plus ou moins saillantes; les dents, fixes ou mobiles, afectent difiérento forme ct différente position; elles servent cependant plus à l'animal pour retenir sa proie que pour la broyer. La laingue cartilagineuse, et soment imparfaite, n'a d'autre usage que de retourner les alimens.

Les narines sont deux peits trous ovales placés aux deux côtés du museau. Les yeux sont le plus souvent aux deux côtés de la tête, mais ils sont aussi réunis quclquefois d'un même côtó ; leur couleur et leur grandeur varient. Les poissoas n'ont pas de paupières; mais dans quelques espèces, los yeux sont recouverts par une membrane qui est une coninuation de la pear.

On cbserve, ì la partic supérieure de la tête, des espècés de soufllets qui s'ouvrent et se referment successivement. Ces valves, anpolécs ouics, sont composées de pliasieurs 

osplats, garnis d'une espèce de frange; elles servent pour la respiration.

Le tronc est la partic du corps qui commence vers les ouies, et se termine à la queue, organe sulide, formé par les vertèbres.

Le corps est enveloppé d'une peau plus ou moins épaisse ; les écaillesqui y sont attachées ont des formes diférentes; clles se recouvrent cu toit : cuelquefois clles sont cachées sous un épidelme qui leś fait méconnoitre. Certains poissons ont, au lieu d'écailles, des pièces osseuses, dont la réunion. porte le nom de cuirasse; d'autres n'ont que des tubercules plats ou épineux.

Ces animaux n'ont ni pieds, ni aîles, mais la nature les a pourvus d'instrumens bien plus convenables au milieu qu'ils habitent. Cos instrumens, appelés nagrooircs, sont couposés de deux nombranes soutemues pul ies rayons. L'animal peutse diriger ¿ volonie, au moyen le ces rames et de ces ầles mobilis, font on distingue cine! sontes, qui inrennent leur rom de l'endroir où clles sont placics. Airsi, on appelle dorsale, la nagevire du dos; pectorale, celle de la poitrinc; aúulominale, calle du veritre; anale. 
celle de l'anus; ct caudale, celle de la queue.

La respiration s'opère au moyen des ouies. Les poissons reçoivent l'eau par la gucule, et clie surt par ćes organes, qui ne la laisscnt ćchapper qu'après en avoir séparé l'air vital. Le sang des poissons est rougre et froil, comme celui des amphibies, et il circule de la mêne manièce. Qnant à la génération, l'opiniun la ples générale cst, qu'ì une certuinc époque, les femelles léposent leurs oufs dans difiérens lieux; ce temps s'appelle celui du frai; les mîles vienuent ensuite répanule sur les couls une liqueur fournie par deur viscèès appelés laitos. La chaleur du solcil fait éclore ces oufs, et les petits poissoris en sortent après avoir rompu leur enveloppe. Cescuńs sont orlinairement très. petits, nais si nombreux, qu'on en a compté trois cent quarante-deux mille cent quarantequatre dans une carpe de quatre décincitres. Cette prodigieuse fécondité empêche la destruction entière des poissons, quni, dans leurs diférens états er dans leurs ciiférens âges, sont exposés ì une fonle d'uccidens.

I.e pòre ni la mère ne prennent aucun soin des petits, avant ou apres leur naissance; 
d'Histoine Naturelle. 301 ceux-ci pourvoient eux-mêmes ì leur nourriture. Les mus cherchent aे engloutir des mammil"res vivans ou les cadavres des malheureuses victimés de l'inconstance des flots. Ils mangent des plantes, des oiseaux, des reptiles, des insectes, des poissons mêmes. Le vaincu derient la proie da vaincucur; et en général, les plus gros mangent les pilus petits.

Lirritabilité des poissons se manifeste assez par la vivacité des mouvemens qu'ils exécutent. On leur refuse plusicurs sens, parce qu'on n'a pas encore bién cbservé les organes qui les leur transmettent. Icur vue est vive et perçante. L'expérience journalière prouve qu'ils entendent, et l'organe de l'ouie a été dernièrement découvert dans leur crâne. Leurs écailles les rendent moins sensibles au toucher. Le goût est chez eux obtus et presque isul; mais ils reçoivent limpression des odeurs, puisqu'elles les attirent ou les repoussent.

La durće de la viedes poissons est ordinaire. ment fort longue;ils habitent les eaux salćes ou les caux douces, même les eaux thermales. Ils font de longs royages, réunis en troupes immcrises, qu'on appelle bancs, ou remontent isolés de la muer dans les rivières, pour 
y frayer. Outre ces habitudes communes; ils en ont aussi de particulières; les uns semblent servir de conducterrs à de gres poissons, pour se nourrir ensuite des alimiens que cenx-ci dédaignent; d'autres lancent adroitement de l'eau sur les plantes voisines de la mer, pour en précipiter les'insectes et s'en nouriir. Les barbillons de quelques uns leur servent de lilet; d'autres communiquent la commotion électrique ì ceux qui ont l'imprudence de les toucher; quelques uns ont à la mâchoirc une scie ou un glaive redoutable; d’autres sont défendins par cies piquans. Il en est qui peurent indiquer l'état de l'atmosphère, par la partie de l'eau haute, basse, ou moyenne dans laquelle ils s'arrêtent. Les nageoires prolongées de quelques espèces les soutiennent dansl'dir comme dans l'ear.

Les poissons rendent dans les eaux les mêmes services que les autres animaux sur la terre; ils y entretiennent l'équilibre entre les espèces, et en éloignent la corruption. Leurs usages particuliers sont aussi trèsnombreux. Beaucoup se mangent frais, séchés ou sâlés; ils servent même ainsi à la nourriture des béstiaux. La peau de quelques- 


\section{D'Histoxre Natofrelie. 303}

ans est une couverture impénétrable à la pluis. Ceux-ci formissent de l'hule, ceux-ld de la colle; ce sont ces usages qui engagent l'homme à les nourrir dans des ćtangs et dans des viviers, et à entreprendre, pour s'en rendre maitres, des narigations longues et périlleuses. Les différens moyens de prendre le poisson constituent l'art de la pêche.

On connoît environ clouze cents espèces de poissoris, que l'on: distribue en cinq ordres. 


\section{ORDRES DES POISSONS.}

I. CARTILAGINEUX. $\left\{\begin{array}{l}\text { Nageoires s.ins os et } \\ \text { cartilaginenses. }\end{array}\right.$

II. APODES............... Point de nageoires infér.

III.JUGULAIRES....... $\left\{\begin{array}{l}\text { Nageoires inférieures } \\ \text { devant celles de la } \\ \text { poitrine. }\end{array}\right.$

IV.PECTORAUX....... $\left\{\begin{array}{l}\text { Nageoires inférieures } \\ \text { dessous celles de la } \\ \text { poitrine. }\end{array}\right.$

V. ABDOMINAUX.... $\left\{\begin{array}{l}\text { Nageoires inférieures } \\ \text { derrière celles de la } \\ \text { poitrine. }\end{array}\right.$

I. CAR T I L A G I N E U X.

Or appelle ainsi les poissons qui, au lieu d'avoir les membranes des nageoires soutenues par des os épineux, comme ceux des quatre ordres suivans, n'ont que des cartilages. Leur peau est sans écailles; ce sont 


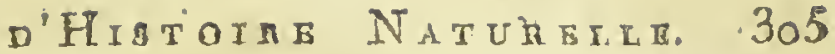

ceux qui se rapprochent les plus des amphibies; ils habitent les mers et les fleuves.

* Corps cylinariques.

1. Li inarproie. Ce nom a été dorné à cè poisson, parce quilil suce les pierres, (I) auxquclles il adhc̀re ensuite par le vide que ṕroduit cette suction; on le trouve dans plusieurs de nos fleuves. Son corps alongé et cylindrique est comme huilemx à sa surface; son rentre est alggenté, ct son dos d'un bleu noirâtre. Sa gueule, arondie à sa circonférence, est garnie d'unc rangée circulaire de clents; et derrière cette rangée, il y a d'autres dents plus petites. Ia lamproie n'a pas d'ouies; thle resjire par sept ouvertures placées de chaque côtć sur une même ligne; et c'est par çes ouvertures qu'elle rejette l'eau qu'ello avoit avalée. Sa vic est tenace; elle se nourrit de vers, d'insectes et d'animaux morts. Sa chair, molle et visqueuse, n'est pas très-bonue; un en rè̀ve le goût arec des aromates.

(1) De lambcre petras. 
* Corps plat et arrondi.

2. La nare. Son corps, plat et large, est bordé jar les nageoires, et terminé par une queire mince et alongée. Sa tête est aplatie; les yeux sont placés au-dessụs, et sa gueule extrêmement fendue en dessous. Elle est entourée de dix ouvertures, qui lui tiennent lieu d'ouies. Ce puisson rorace ne se trouve que dans nos mers.

3. La Rark bouclée se nomme ainsi, parce que son corps est hérissé d'aiguillons recourbés, qui ressemblent assez à l'ardillon d'me boucle. On la pêche abondanment dans l'Océan, et elle est très-commune dans nos march́cs ; il faut la garder ỵuelques jours, pour qu'elle perde le goût de la mer, et que sa chair s'atiendrisse. Les jeunes raies, connues sous le nom de raions ou raitons, sont fort bonnes à manger; mais elles ne peuven supporier le transport. La chair de la raic, débitée par morceaux et desséchée, s’appelle papillons; les Norwégiens font de l'inuile avec son foie.

4. La tonnere a la forme d'un cercle, terminé par une queue. Sou dos est percó 
D'Histoire natureze. 30 p de petits trous, quilaissent éch apper une liqueur propre à entretenir la viscosité de sa peau. Mais ce qui élonne dans cet animal, c'est la facilité qu'il a de donner la commotion électrique à ceux qui le touchent, et d'éloigner ainsi ses ennemis, contre lesquuels il seroit autrement sans défense. Cette commotion se transmet, comme l'électricité , par l'eau, les substances métalliques \&x. ct elle est de même interceptée par le verre, la cire d'Espagne, etc. C'està l'engourdissement qui suit cette commotion, que la torpille doit son nom. (I) L'effet dininue à mesure que l'animal approche davantage du terme de sa vie. I,a torpille dépose ses œufs en automne; sa chair, molle et gluante, ne se mange pas. On en pêche dans la Méditerranée et dans l'Océan, principalement près de Rochefort et de l'île de Ré.

\section{** Corps alongés.}

5. Le pequin. Ce tyran des mers est le plus terrible et le plus redoutable de tous les poissons; il devient quelquefois si gros,

(1) De torpere, engourdir. 
qu'on en a vu du puids d'un et même de plusicurs milliers. Son corps alongé a, près dies yeux, cimp ouvertmes uni rciuplacent les onies. Son énorme grueule, placée à plus detrcis déciuctres derrière l'extrémité de son muscau, esi garnic de plusieurs rangées de dents triangnlaires, en forme de pointes de flc̀che, ot dentelécs ellos - mêrnes sur leur bord. Cette posilion de sa greule le force à se retournor pour saisir sa jroie; mais il ne s'en empare pas avec moins de facilité. Vorace et cruel, affamé sur-tout de chair liumaine et vivante, il s'attache aux vaisscaux, il les sait, même jendant une assez longue route, et si un matelot tombe à la muer, il est aussitôt dévoré. On le pêche avec lics lignes annorcées avec de gros morceaux de viande; mats même hors de l'eau, il faut éviter avec soin sa dangcreuse approche; il ne mori point qu'il n'emporte des memures ou d'énormes lunbeaux. Un comp de sa queve est aussi à crainure que sa morsure. Sa cruanté s'étenu jusques sur sa propre espicé. Sa chair n'est point recherchée; cependant, on mange celle du ventre, sur-tout quand aplès aroir été dépecce et séchée pendant vn an, elle a perdu sa graisse. On fait 


\section{n'Histork NAturtiti. 309}

bonillir le foie pour en retirer l'huile. La peau s'employe à convrir des étuis, des tubes do lunettcs, etc.; ellc est connue dans les arts sous le nom de chagrin. Les dents du reignin se trouvent souvent fossiles; leur figure triangulaire, qu'on croycir être celle de la lringue des serpans, les a fait nommer glossopetres. La stiperstition !eur a fait attribuer, pour la guérison des maladies, plusieurs vertus qui ne sont pas moins imaginaires.

6. Jur rousstт approche du reguin. Sa peau rude et monchetée est mêtne préférée à la sienne. Sa chair a une forte odeur de musc, et n'est mangeable qu'après avoir été long-tcmps macérée. Scn foie est regardé comme un poison, mạis on en tire de l'huile. Ce poisson vorace attaque quelguefois los pecheurs eux-mêmes; on le troure dans la Méditerrannée et quelquefois cans l'Océan.

7. L'esturgen est le plus gros des poìssons que l'on recherche pour la bonté de leur chair. Il cst allongé, et son museau est mince. Sa peau lisse est couverte de plusieurs rangées d'osselets. Il remonte quelquáciois pour frayer dans les rivières, mais il n'est pas conmun dans les nôtres. La 
peau de l'esturgeon fournit de la colle. Ses œufs marinés sont la nourriture de plusieurs peuplés du Nord. Cette préparation s'appelle caviors:

8. L'ichthrocorze ressemble ì l'esturgeon. Son corps allongé n'a qu'une rangée de treize tubercules assez saillans. On mange sa chair fraîche ou saléc. Sa peau fait d'excellens traits. Ses anfs fournissent un caviar trèsestimé, mais c'est sur-tout pour en faire de la colle qu'on le pêche. La matiere qui la fournitest cléposée le long du dos aux cartilages. On la rassemble dans un linge, on la paîuit avec le duigt jusqu'ł ce quelle ait la consistance d'une pâte, et on en forme des pains. La colle de poisson sert a clarifier les liqueurs; la meilleure vient de la Russie. C'est à cette abondance de colle gu'il fournit (uuc ce poisson doit son nom.

\section{A P O D E S.}

Cèt ordre renferme les poissons qui il'ont point de nugeoires inférieures. Comme ces nageoires ont été comparées aux pieds des autres animan, on les nomme apodes, c'està-dire sans pieds; nous n'en citerons qu'une espèce. 


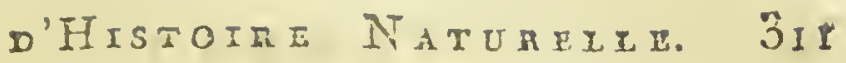

L'A NGUILE. Son. corps allongé et cyIndrique et les replis qu'il forme, l'ont fait comparer à uis serpent. Ses trois nageoire sont réunies. Sa peau est molle et visquense, or la pîche dars les rivières, où elle choisit las endroits troubles. Elle se hazarde quelquefois à chercher sur le rivage des insectes et des limaçons. Elle mange aussi des végétaux. Sa vie est si tenace, que ses tronçons dépouillés et coirpés s'agitent encore. Sa chair cst delicate, mais indigeste. Sa jeau, dure et solide, sert à faire des lanières, des courroies, des fouets...etc.

\section{JUGUIAI $\mathrm{P} E \mathrm{~S}$.}

L.es nàgeoires inféricures de ces poissons précèdent celles de la poitrine, elles avoisinent la région du col, ce qui lear a fait donner le nom de jugulaires.

1. La vir cst appellée ainsi à canse de la tenacité de sa vie. Sa chair est délicate, ce qui engage les pêchears is s'exposer aux. pirjûres danggereuses des aiguillons de ses nageoire3. Ces pigûres causent une doulenr dont l'impression dure fort long-temps. Sa peau esi coriace comano celle de l'anguille, 
atissi l'ćcorche-t-on souvent pour l'accom. moler.

2. La mores. Son corps est allongé,

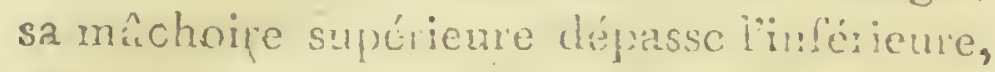
celle-ci est accompagréce d'un harbillon. C'està la pointe de Torre nenve, dans les parages de l'Amérique sepicutionale, que nous allons la pêher. Quoiçue les gros individus mangent les petils, elic y est irès-aliondante. On lui ôte, pour la saler, la langue, les intestins et l'arête. On met altcrmativement des couches de molue et de sel, et on la conserve en his, ou dans des tonncanx." Pour la faice sécher, après l'avoir prénaréc comme porir le sel, et l'en avoir saupoudié, on l'expose au soleil, ou it l'action du vent du Nord. Elle acquiert nno dureté con:isdérable, on la nomme daus cet état merIluche oustuck-fich. La morue ainsi prénate est une manne pour les Norwćgicns; elle leur tien. lieu de pain et de tont antre aliment, et ils cn nomwissent aussi leurs bestianx. La chair de la momre n'est jas la seule partic utile de ce poisson. Les intestins deviennent les appâts pour de nouvelles captures; les œul's font une espèce de caviar appellé resstre; les fuies sont 


\section{D'Histoite Naturelie. 3,3}

nis à part pour en tirer de l'huile. On ne prend guères de grosses morues sur nos côtes, mais on en pêche souvent de petites qui se mangent fraîches, et ne diffèrent de la mo:ne ordinaire que par la grosseur. On les conmoît à Paris sous le nom de cabeliazi. La morue fraîche, salée ou séchée, est un objet de commerce considérable. On prépare de la mêine manière d'autres poissons du même genre, et qui n'en diffèrent que par des nuances légères.

3. Le men in. Sa forme approche assez de celle de la morue, mais il est beaucoup plus petit. Son anus est plus voisin de la tête que de la quene; il arrive par grandes troupes on bancs sur nos côtes où il est très-abondảnt. Sa chair blanche et légère est une excellente nourriture pour le convalescent.

4. La zоть. Ce poisson n'a que dens nageoires sur le dos. Ses deux mâchoires sont égales; sun corps enduit d'une liqueur visquense est narbré de noir et do jaune. Il habite les éiangs est les rivières, où, caché dans les trous et sous les pierres, il guetie les petits poissons à leur passage. Sa chair est d'un excollent goût, la lote est commune dans la Saûne. 


\section{PEC T O R A U X。}

Les nageoires inféricures des poissons de cet ordre sont placées au-dessous de lia poitrine; la plûpart ont le corps comprimé, plusieurs ont les deux yeux situés d'un même côté. Ils ofrent peu d'usages porr lis arts, mais ils scrvent presciue tous a notre nourriture.

* Corps comprimé.

1. Le sarnt-pitrri. On nomme ainsi ce poisson à cause l'une tache ronde qu'il a près des ouies, et qu'on dit lui avoir été donnée pour avoir fourni d Saint Fierre la pièce de monnoie qui lui servit à payer le tribut. Cette tache, sa forme comprimée ế les piquans longs et recourbés qui terminent sa nageoire dorsale le font aisément reconnoître; il est délicat à manger, on le pêche sur nos côtcs.

* Corps comprimé. Les deux y'cux du cóté droit.

2. La ima vor. Ce poisson est beaucoup plus petit que le saint-nierre; on le 
D'Histora Niturexe. 315 péche sur nos côtes, il est cornmun dans nos marchés.

3. La pLIE. Sa forme approche de celle de la limande, mais elle est parsenée de taches orangées. Comme la limande, la plie s'enfonce dans le sable. Au temps du frai elle remonte dans les rivières; on en pêche bearicoup dans la Loire.

4. La soz . Sa nageoire dorsale s'étend depuis sa tête jusqu'à la quene, sa forme est allongée, sa chair est excellente.

\section{* * Corps comprimé. Les deux yeux du côté gauche.}

5. Le тu r. о т. Il est beaueoup plus grand que les précédens, son corps est tacheté de noir et hérissé de petîes épines sans aucun ordie; il est extrếmement vorace; c'est un meis très-recherché.

6. Le CanEL is $\mathrm{T}$. Il est plas petit et moins rare que le tmbot, il a aussi des taches noirâtres, mais sans élévations.

$$
\text { * * * Comps comprimé allongé. }
$$

7. La Don ADr. La ligne dorée que ce poisson porte au-dcssus de l'cill lui a fait 
donner son nom. Ses dents forteg ct robustes broyent facilement les corpullages. Il estahondantr sur nos côtes. Sa chair est de ben goût, ses molaices servent à faire des bagues.

3. La perane. Ce bcau poisson d'un vert doré et marqué de raies noires, se plaît dans les caun vives.

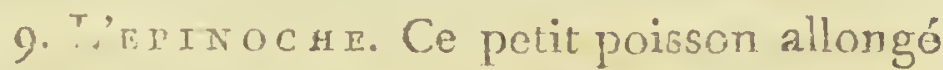
et blanc porte des aiguillons sur le dos; il est très-commun dans les étangs, oì il sert de nomriture aux gros joissons.

Io. Le imaquengau. Le dos de ce poisson est richement coloré de bleu, de blanc et de vert; il est extrêmement vorace. Il arrive sur nos côtes dans les mois floréal ot prairial. Sa chair est excellente; la nuit elle paroit luminense; les Français salent ce puisson comme le hareng.

11. Le т и о . Ce poison a le ventre blanc et le dos cuirreux; il ressemble assez au maquercau, mais il est beancoup plus gros que lui, et son plus cruei ennemi. On observe altenilvement sur nos côtes l'arrivée de ce poisson de passage, et on l'enferme dans une enceinte de filets appellée thonnaire, oì on en rirend unc quantité prodigiense. On le mange frais ou salés à-peu- 


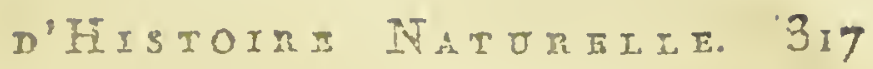
près comme la morue. La chinir du ventre ainsi propurée s'appelle thom marizé, c'est la fihs délicate. Celle du dos moins estimée se momme thonine; l'huile qui se sépare pendant l'opération est vendue aur corroyeurs.

12. Le rouGRT. Ce poisson très-recherché est ainsi nommé, parce que sa chair or* dinairenient d'un jaune olivâtre, devient d'm rouge éclatant quand on a enlevé ses écailles; il est commun dans la Médicerranée.

13. Le p I a p ìn f. En déployant ses deux larges nageoires, le pirajède se soutient au-dessus de l'eau l'espace d'une portée de fusil; il y retombe, dès qu'elles ne sont plus humectées. On. le nomme aussi poisson volant; cet élan prolongé n'est cependant pas un véritable vol, il lui sert de éviter la poursuite des dorades, mais il vient tomber par nombreus essaims sur les bâtimens et il y trouve la mort qu'il fuyait; sa chàir est nourrissante. 


\section{ABDOMINAU}

Ces poissons portent les nageoires inferieures derrière celles de la poirine; on les a nommés abdominaux, parce quelles se trouvent ainsi placées sur le ventre. Cet ordre est le plas nombieux, toutes les especes qu'il renferme sont bonnes d̀ manger.

* Corps allongé lisse.

x. La r o cir. Ses écailles sont à peine sensibles sur son corps cylindrique, sa mấchoire supérieure est accompagnée de trois paires de barbillons. Elle aime les eaux douces, sur-tout celles des montagnes.

* Corps allongé écailleux.

ฉ. Le saumor est un des poissons les plus gros, les plus abondans et les plus utiles. Son corps est épais et allongé; sa tête est petite et conique, sa pean épaisse. Il acquiert promptement une grosseur assez considérable. Il est commun dans l'Océan, rare dans la Méditerranée, il remonte lesfleuves 
s'Histoire Natureze. 319 pour $y$ frayer, et il suit quelquefois jusques à Paris les bâimens chargés de sel. On le mange frais ni salé. On en pêche dans Ia Semoi', rivière du département des $\mathrm{Ar}$ dennes, une variété nommée bécard, parce que sa mâchoire supérieure avançant beaucoup sur l'inférieure, forme une espèce de bec.

3. La TR U T E. Elle ressemble tant au saumon qu'il est difficile de l'en distinguer; sa tête est un peu plus grosse, les taches dont elle est marquée ont le disque noir et le cercle blanchâtre. On la pêche dans plusieurs fleuves de l'Europe.

4. La trutte SaUmonér. Sa chair est rouge comme celle du saumon; son dos est d'une belle couleur verdâtre mêlće de bleu. On la pêche dans le Rhône, où elle vient du lac de Genève.

5. L'ÉPERAA. La forme de ce poisson approche beaucoup de celle diu saumon; mais il est infiniment plus petit et si transparent, qu'on distinguefacilement ses arrêtes et les lobes de son cervau. Il remonte au priniemps par troupes nombreuses dans les rivières. On en prend beaucoup a l'embou- 
chure de la Seine; il répand une odeur forte de violettès, et sa chair en a la saveur.

$$
\text { **** Corps alongé. Tête aplatic. }
$$

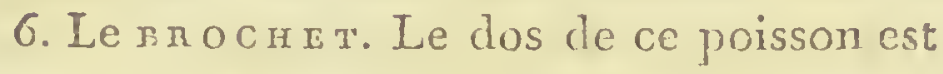
noir. Son ventre est blanc tachoté de noir. Tous les autres poissons, ì moins quils buisscnt lui résister, sont les o!jjets de son insaliable aviciité; il clévore aussi les serpèns, Ins loirs, les oiseaux et les cadavres. La cinrée de sa vie est très-longue; le petit brochet se nomme brocheton, le moyen fruron. Sa cliair et som foyc sont bons à manger, mais ses cufs sont purgatifs.

7. Le harena. Ce poisson est un des plus abondars et des plus ntiles. Sa longueur est ìjen-près dedeur lécimètres; son ventre est blanc et son dos d'un noir blonatre. La mấchoire inférienre dépasse la supérienre, et clle est hérissée, ainsi que la lan tes dents. Lesharengs habitent les profondeurs des mers sepientrionales; mes auprintempset vicnnert sur nos côtes par troupes innonbrables, que l'on nomme bans on flots de harengs. La chair du hareisg mangée fraîche cst sain:e ct agréable. On 
D'Histoirs Naturelie. 321 Ini fait subir, pour la conserver, des préparations qui peuvent se rédıire à deux, celle de le saler et celle de le fumer. Linvention de la salaison est attribuée ì Guillaume Beukeling mort en 1397. Avant de le saler, on le caque, c'est-a-dire, qu'on arrache les ouies, l'estomac er les intestins. On ne laisse que les ouf's et la laite. On lès place dans des tonnes lits par lits avec du sel, et après les avoir bien égouttés, on les arrange dans d'autres barils, où ils sont fortement pressés, ce qui s'appelle les caquer. Ce sont les Dieppois qui ont imaginé la manière de fumer le hareng. Après les avoir salés, on les expose erubrochés par la tête dan's des étuves; ces harengs se nomment saurs ou sorets. Ceux auxquels on ne donne 'qu'un léger apprêt s'appellent craquelins on appétits. On voit par ces détails conbien le hareng est mile. Sa préparation fait vivie une foule de citoyens. Il procure une nourriture facile, abondante et peu coûteuse, et sa pêche contribue à former d'habiles matelots.

8. La Sardite. Ce poisson dont le dos est bleuâtre, et le ventre blanc, resscmble au hareng par sa forme, mais il est beau? 
coup plus petit. Sa pêche se fait de la même manic̀re, et il subit les mếmes préparations.

9. L'a mosi. Elle ressemble an si au hareng, mais clle est plus longue et plus large. Son muscau est f'enclu et ses côtés sont marqués de taches nuires. Flle remonte dans les ficures en foréal et en germinal, et c'est seulement alors quille acquiert celte saveur qui la fait rechcicher.

Io. L'A NCHOIS estlong commela sardine, mais plus gros; sa transparence égale cependant presciue celle de l'éperlan. 11 est coinmun dans la méditerranée; on le sale après en avoir ôté la tête, et il entre dans beaucoup d'assaisonnemens.

\section{**** Machoircs sans denis.}

11: La G A R P. La tête de ce poisson d'eau dọce est courte et accompagnée de quatie barbillons à la mâchoire supérieure, les nageoires ont une teinte violeite et le bord noir. La carpe nage lentement, ellercroit promptement, sa longueur ordinaire est d'un demi-mètro, .elle s'étend quelquéfois jusyu'à deua mètres. La duréc de sa vie esi assez longme. La saveur de sa chair et la cou- 
D'Historne NATUREI. 323 leuri de ses écailles varient selon les lieux qu'elle habitc. Elle se nournit d'herbes, d'insectes, de vers qu'elle tire de la vase en la suçant. Vers les mois floréal ct prairial, elle cherche les plages couvertes d'herbes pour y déposer ses cufs, qui, malgré le dégât qu'en font les grenouilles, les crapauds er les oiseanx aquatiques, procuisent mne nourelle génératicn très-nombreuse. Sa chair s'accommode de plusicur's manières, sa bile donne'une conleur verte. Ses ceuf's font ure, espèce de caviar, et sa résicule aérienne s'emploie à faire de la colle.

12. Le rAR EAU. On le nonme ainsi, parce que ses barbillons sont plus prononcés que ceux de la carpe; . son corps est plus allongé, et sa forme approche un peu de celle du brochet. Sa couleur est olivâtre sur le dos, argentée sur le ventre; il est commun dans nos rivières oì on le pêche avec la carpe. Sa chair est bonne; nais ses culfs sont regardés comme mal sains.

13. Ie goujon: La forme de ce petit poisson-rpproche de celle de la carpe. Il est plus cylindrique; sa gneule ronde est accomprgnée de petits barbillons. Je goujon. 
se réunit en troupes, il aime sur-tout les lacs, d'où il remonte en germiual dans les rivières pour y frayer. Il est bon à manger; sa foiblesse le rend souvent la proie des autres poissons.

14. La TA $\mathrm{x}$ in s. La teinte noirâtre de ce poisson le distingue des précédens. Il se plaît dans les étangs et dans les lacs, surtout dans les eaux vaseuses; il passe aussi quelquefois dans les rivières; il mange les pelits poissons; sa vie est tenace, et il dépose ses œúf's sur les joncs dans le courant de floréal; sa chair est blanche et molle.

15. Le cypran dorí. On le connoît vulgairement sous le nom de poisson doré de la Chine, parce que c'est son pays originaire. Il offre en effet sur son dos des reflets éclatans de pourpre, d'or et d'argent. On ne l'élève que pour l'ornement dans des petits bassins, ou dans des vases de crystal, il faut avoir grand soin de ne point le laisser à sec, et de ne point le toucher.

16. L'ABLA. Ce poisson est tout blanc, excepté sur le dos, où sa couleur est bleuàtre. Sa chair est peu estimée, on ne le prend que pour faire des appâts, et sur-tout à cause de ses écaiiles argrentées qui tombent 
D'Histotre NAtURELE. 325 facilement. En les broyant dans l'eau, il s'eis détache une substance argentée qu'on nomme essence d'Orient. On enduit avec cette substance l'intérieur de petits globes de verre que l'on remplit ensuite de cire. Ce sont les parles fausses dont on fait des colliers, des bracelets et d'autres parures.

17. La b Resm. La figure de ce poisson est celle diun lozange dont les angles sont arrondis; son dos est couvert d'écailles d'un jaune doré, ou argenté. Ce poisson d'eau douce est peu estimé; on en prend dans la Seine.

\section{INSECTES.}

Le corps des insectes est partagé en plusieurs sections articnlées, c'est al cette particularité qu'ils doivent leur nom. (I) Ils ont en gónéral six pattes, ct ils subiosent différentes métamorphoses. Beaucoup de ces

(1) De secare, couper; insectim, divisé, partagé. 
animaux échappent à l'ocil par leur pelitesse, mais ils n'en sont yas moins alnirables par lenr organisation.

On Jistingne dans les insectes la tête, le corcelc't ie corps, les pattes et les ailes.

Lá téte renferme la bouche, les yeux et les antennes. Les différentes parties de la bouclie sont des instrumens dont le mécanisme est extrêmement compliqué. On y remarque la lève inférieure, et la lève supéricure; les mandibules qui avancent plus ou noins, se nouvent latéralement et servent ì saisir et à déchirer les alinens. Les julpes, espeece de petits barbillons a:ticules, dont l'emploi cst de toncher les alimers, tiennent licu de l'odorat et en sont peut Âic les organes. Ontre ces diférentes iartics communes aux insectes, quelquesmus ont les gatétes, pièces larges qui cachent toutes les autres; l'auires une langue en spinale, me troinpe ou un susuir, pour cntimer les fleurs, onvir lour nectaire et se nourrir des sucs qu'il renfeme.

Les ycux sunt ordinarement au nombre de deux, quelunefois de quatre. Quelques insccies en ont huit; les uns offrent mu "éseaz, d'aucres soni taillés à faceites; ils sont 


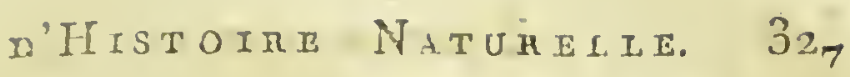

queląuefois portés sur une tigge plus ou moins longuc.

Les arternes sont des pièces mobiles plus ou moins longues. Elles sont ordinairement an nombre de doux, quelynefois de quatie et insérées au-dessus, on au-dessous de l'ail, ou sur l'oil mêne; leur forme est extrêmement variée; elles se terminent en masse, en croissant, en crochet, en peigrie, en prisme, en globile... etc.

On appelle corcelet la partie qui se trouve entre la tête et le corps; elle est arrondie, carrée, orbiculaire, Innulée etc. Su partic inférieure sert d'attache aux deux premières paties. Le corcelet est quelquefois terminé par un écusson triangulaire.

Le comps vient après le corcelet, sa parie antérieure sert d'attache aux quatre autres pattes, et elle est percée latéralement de stigmates, potits trous an moyen desquels lanimal respire. Isabdomen qui termine le corps est d'ure consistance moins ferme. Il est accoinpagné par dies filets, on armé d'un aignillon flus ou moins redoutable.

I:insecte cont sur h terre avec ses pattes, ou se bailance dans l'air au moyen de ses ai'es. Ses paites sont aussi composées de 
plusieurs pièces articulées. Elles sont ordinairement au nombre de six, mais les insectes privés d'ailes en ont quelquefois d'avantage.

On y distingue la hanche qui unit la patte au corps. 'T a cuisse ordinatrement renflée est munie de muscles assez forts. La jambe cylindrique et quelquefois accompagnée de poils ou de pi puans. Le tarse composé d'articles, dont le nombre sert à la classification des insecles. Le dernier est muni de denx ou de quatre crochets minces, ou de pelottes qui servent à l'animal pour se soutenir sur les corps lisses et polis.

Les ailes sout attachćés à la partie postérieure et latérale du corcelet, elles sont au nombre de quatre ou de deux. Les ailes supérieures de ceux qui en ont quatre sont souvent plus ou moins membraneuses, et mềne si coriaces, qu'elles ne peuvent servir que d'étuis, ce qui les a fait nomıner élytres (1). Les ailes sont elles mêmes veinées, réticulées, ou couvertes d'une poussière écailleuse. Elles sont formées de deux membranes très-

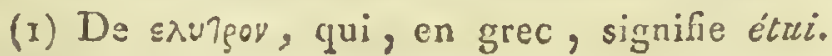


fines, traversées par les vaisseaux imperceptibles qui les nomrissent.

Les aîles des insectes qui n'en ont que deux sont accompagnées de petits ailerons placés à leur origine, ou de balanciers, filets très-minces, terminés par des petits globules. Quelques espèces sont à la fois pourvues d'ailerons et de balanciers.

Telles sont les parties principales des insectes. Toutes ont une grande variété de formes et de couleurs.

Les insectes, n'ont, au lieu de sang, qu'mne liqueur froide et blanchâtre. Iis respirent par des ouvertures latérales nommées stigmates; ces ouvertures aboutissent à cies trachées qui font circuler l'air dans tout leur corps. Leurs secrétions ont souvent une ocleur forte, quelquefi,is agréable et aromatique. Quelques-unes sont de violens caustiques; plusieurs de ces animaux s'infectent à volonté d'une liquenr gluante et huilense qui rebute leurs ennennis, d'autres se cachent dans une bave, ou dans une páte cxcrémentilielle.

On n'a proint encore trouvé l'organe de l'ouie, ni celui de l'odorat chez les insectes. Il est cependani ceriain qu'ils entendent, 
puisfu'ils fiugent le bruit; quelqués odenrs Ies attircnt, d'autres les repoussent. Le clooir qu'ils font do leur nourriture, indique anssi le sens du goût.

Les partics de la génćration sont ordinairement cachées dans i'ouverture de l'anus, mais les araigicés mâles les ont il lorigine des pulpes; les aruingécs fémelles à la base du venure; les derevisses à l'inscrion de la guene, ct les libcllule's femelles sous la poituine. Ces organes se recomnoissent aisémcnt. Ils sont en haueçon dans le mâle, en tube dans la fornclle. La différence des sexes s'indinne anssi par d'autres signes; la femclie est orinairement plus grosse que le nâle. Elic a souvent à lanus un aiguillon, un conticlás ou une tarrière, pour préparcr la place ò clle doit déposer ses œufs, mais les antennes du mâle ont une organisation plus parfaite. Ses cornes, ses mandibules sont plus fortes et plus sens:bles; il est sowrent aîlé, tandis que sa femelle est sans aî̀es.

Ia fécondité des insectes est prodigieuse. Le soin avec lequel ils céposent leuss wuis dans les lieur les plas propres à nourrir les petits qui en doivent ćlore, est actmi- 
D'HISTOIE NATURELE, 331 rable. Les mus les conficnt aux caux, d'autres à la terre, ceur-ci les placent sur les fézilles, d'autres dans l'intérieur des graines et les scmences, quelques-uns sous la peau les autres animaux morts ou vivans; ils les déposent nuls, les enduisent d'un vernis, les enveluppent de poils, les entourent de soie, ou les logeint dans des alvéoles. Quelques-uns sont cachés sous le cadarre de la mère qui les a pondus, et qui sert de nourriture aux petits dès qu'ils éclosent, d'autres ont leur habitation dans une excroissance produlic sur quelque partie des plantes par l'extravasion des sucs, suite d'une piqû̀e que ia-mère y a faite.

Ces ocul's, plus ou moins nombrenx, se développent dans diférens temps, mais le peit qui en sort n'est jamais entièrement formé. Il lui faut avant de devenir insecte parfait, passer par diférens états qu'on nomme ses métamorphoses.

En quit ant l'ceuf, ce n'est encore qu'une Trye, espèce de masque sous lequel l'insecte cs: caché. Cas larves ont un nombre plus ou moins grand de paties, et ressemblent assey à de petits vers. Elles seules sont susceptibles ce croitue, et elles changent 
plusieurs fois de peau; elles sont très-voraces: parvenucs à leur dernier accroissement, elles subissent nie métamorphose, et passcnt à l'état de nymphé. Mais avant ce changement, clles se préparent une demeure paisible dans une coque de soie, entre les fenilles roulées ou dans des trous profondément crensés. La nymphe a rarement lia faculté de changer de place. Elle demeure inmobile et sans prendre de nomrriture jusqu'à la dernière transfornation, alors elle rompt toutes ses enveloppes, et l'insccte paríait pourvu d'aîles, de pattes, et des organes générateurs, va remplir le vou de la nature en peuplant la terre de nouveaux indivicus. C'est donc avec raison que les tormes divcrses sons lesquelles il a paru, ont été regardées comme des déguisemens couposés d'enveloppes difićrentes qu'il lui a fallu rompre pour se mon-trer avec tous les attributs qui le caractérisent; les insectes sans aîles ne subissent pas ces métamorphoses.

Il n'y a point de substance organique, mortc ouvivante, quinenourrisse quelqu'insecte. Ils vivent seuls, on réunis en frrand noinbre. Quelques-uns forment des yérita- 
d'Histotre Natumeiti. 333

bles sociétés, et exécutent en commun des travaux singulie:s.

Telles sont leurs mœurs générales; mais leurs mceurs particulières, qui ont toutes pour objet le soin de chercher leur nomriture; et de se reproduire, exigent une étude approfondie de chacun d'eux. C'est pour examiner leur forme quion en fait des collections, c'est pour étudier leurs mours qu'on les élève vivans, dans des boîtes vitrées ou couvertes d'un marli. On les prend dans l'air ou dans l'eau avec des filets d'un cannevas léger, et on les fixe avec des épingles dans des boîtes dont le fond 'est garni de liége. Cette petíe chassc est anusante et fournit mille sujets d'étude et d'observation.

Les usages des insectes, dans l'économie de la nature, sont extrêmement étendus. Ils entretiennent l'équilibre entre les êtres et débarrasserit la terre et les eaux des substances corrompues et putrides; ils servent à la subsistance d'une multitude d'animaux. Quant à leurs nsages particulicrs, les uns servent à notre nourriture, d'autres entrent dans la composition de diférens médicamens, quelques-uns nous fournissent 
une substánce vile pour nous vêtir, et des coulcurs pour la taindre.

Le nombre des insccies combrns s'élè e it plus de quinze mille; nous ne nous arrêtcrons qu'arx plus intêressans que nous.diviserons en luit orclies, l'après le nombre, la forme e! la disnosition de leurs ẩles. 


\section{ORDRES DES INSECTES.}

I. COLÉcptères.... Etuis durs et coriaces.'

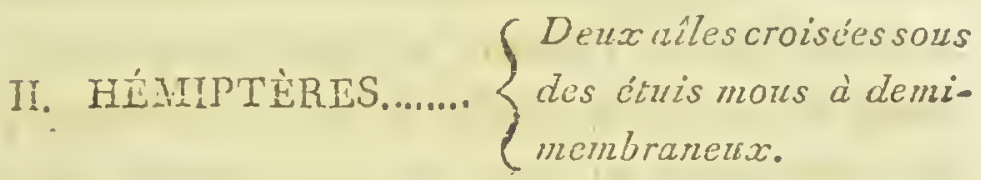
III. ORTHOPTĖRES... $\left\{\begin{array}{l}\text { Deux aíles pliées lon- } \\ \text { gitudinalement sous des } \\ \text { étuis presque membra- } \\ \text { neu.x. }\end{array}\right.$ IV. HYNÉNOPTERES. $\left\{\begin{array}{l}\text { Deux ấlescroisées sous } \\ \text { des cítuis mons à demi- } \\ \text { membrancux. }\end{array}\right.$ V. IEUROPTĖRES... $\left\{\begin{array}{l}\text { Quatro aî̀es nues, mem- } \\ \text { brancuses, réticulées. }\end{array}\right.$ VI. LAPIDCPTìRES.... $\left\{\begin{array}{l}\text { Quatre aúles membra- } \\ \text { neuscs, convertes d'une } \\ \text { poussière ćcailleuse. }\end{array}\right.$ VII. DIPTLRES............ Deux aîles. VII. APTÉRES................ Point d'aíles.

\section{COLEOPTERES.}

Ce nom, qui signifie aîles à éhuis, est appliqué à tous les insectes, dont les âlles supéricures sont dures et coriaces, $\therefore$ 
ct ne servent qu’à défendre les aîles inféri-mes. Chacun de ces ćtuis s'appelle élytre. Les insectes de cet ordre on: deux grands 'nY it réseanx, mais point d'yeux lisses. Leur larve longue et mulle à six pattes écail. tenses et point d'antennes. Quelqnes coléoptères n'ont point d'â̂les sous leurs élytres, et alurs celles ci sont réunies en une scule pir̀ce. Les coléoptères âlés écartènt leurs clytres et déployent leurs aîles pour prendre lenr vol. Cut ordre est extrêmement nombrex. On pent y établir quelques divisions, d'après le nombre des articles du tarse.

\section{* Cinq articles à tous les tarses.}

1. Le lucane-cerf. Les mandibules longnes et profondément dentées de cet insecte, l'ont fait nommer cerf volant, parleur ressemblance avec le bois du cerf. Su larve se loge dans ïintérieur les vieux arbres. Elle les ronge et les réduit on une espèce de tan; c'estlà qu'il subit ses différentes métamorphoses.

2. Le scarabie nasicorne. Ce gros insecte brun a sur la tête une corne recourbée, qui lui a méritć son nom; sa larve est extrếmement grosse. On la trouve dans les couches des jardins ei des putagers. 


\section{o'Historre Naxureice. 337}

3. Le rifulains. La tête de ce coléoptère est taillée en lozange, ses étuis sont noirs ct sillonés. La femelle cherche les matières les plus sales, elle en fait des boules en les roulant, et elle y dépose ses cufs. Les barres qui en ćclosent y trourent leur nourriture, et y subissent leurs difírenenies métamorphoses.

4. Le hanneton. Ses antennes sont en peignes, ses élytres sont brunes, son corps noir est marqué de taches triangulaires. Cet-insecte si commun ronge les feuilles et les fleurs. La femelle fécondée creuse en terre un trou de denx décimètres, et elle y dépose ses oufs. Peu de temps après les larves sortent, elles passent en terre trois années, et y changent plusieurs fois de peau. Elles creusent plus profondément en terre pendant l'hiver, et ne prennent point de nourriture. Au printemps elles remontent à la surface, c'est alurs qu'elles rongent les racines des fleurs et des légrmes; les jardiniers les connoissent sous le nom de vers blancs. Dans l'automne de la quatrième année, ces larves descendent à un mètre de profondeur, là elles se changent en chrysalides; l'insecte parfait sort au $\mathrm{Y}$ 
commencement du printemps. Ces insecies seroient le plus terrible fléau des jardins, si les enfans et les oiseaux n'en détruisoient pas un grand nombre.

5. L'íneracoins. Ce coléoptère d'un verd d'émerande en dessus, ct d'un verd cuivreux en lessous, se trouve principaloment sur le rosier. Sa larve allayue les racines des arbres et des plantes.

6. Le DERMESTE. Ses antennes sont comjuosces de lames enlilées, son corps est noir et allongé; ses élytres sont centrées a leur origine. La queue de sa larve est garnie d'un pincon; cette larve s'attache à la viande; clle aime en général à ronger les parties d'animaux; ciest le fléau des collecticns d'histoire naturelle. L'insecte parfait se trouve souvent dans les maisons et sur les fleurs.

7. Le dermeste pretetren. Son corps noil est marqué de deux points blancs; sa larve, qui est très-velue, se trourc clains les pelleteries qu'elle dévore.

3. La varlete. Ce petî insecicest oblong et prescauc cylindrique, sa coulen cst brinâtrc, ses antennes ont une masse pcu vi- 
sible; quand on le touche, il retirc les pattes, reste immobile et semble faire le mort; c'est sa larve qui perce le hois de nos meubles d'une infinité de trous, clle cst hlanche, molle, et ses fortes mâchoires le réduisent en poussière. Cette larve file quelques soies au fond de sa galerie, elle s'y change en nymphe, et y demeure à l'abri de tout danger jusyùì sa dernic̀re métamorphose.

9. Le campre. Ia tête de ce coléoptère est entièrement cachée sous le corcelęt. Le mâle est aîlé et porte des ćlytres brunes. La f'emelle n'a point d'aîles, les trois derniers anncaux de son ventre sont jaunes, ils contiennent cette matic̀re phosphorique qui les feroit prendre la nuit pour des charbons ardens; cet éclat attire lc mâle. Il a fait donner à cat insecte le nom de ver-luisant. On le trouve sur l'herbe tendre, dans les mois messidor ct thermidor.

10. L'Étatiráchts De souris. Cet insecte, qui a la forme ellypti jue et dont les élytres sont grises, a une singularité remarquable; c'est un ressort qui s'altache ì la poitrine, cis'insère sur le ventre, au moyen duruel il s'élance ét retombe sur ses pattes, 
quand on lc place sur le dos; tous les ćlaters ont la même propriété.

- 11. Le carabe dorí. Ce superbe coléoptère est très-commun dansnos jaruins; ses élytres d'un verd doré ont de larges sillons. Son corps laisse échapper une liqueur roussâtre, âpre etcaustique. Sa larve, après avoir creusé un trou en terre, tient sa tête au niveau du trou; clle guette paticmment les petits insecles qu'elle saisit et dévore à lenr passage.

12. Le touniqut. Ce petit insecte lisse et ovale esi nommié ainsi, à cause des cercles qu'il décrit dans l'eau par ses tomnoyemens; il a yuatre yeux tıćs-apparens.

* 5 articles aux paltes antóricures, 4 aux postérieures.

13. La cantuaride. Le corps de cet insecte est allongé et d'un beau verd doré. Ses antennes sont noires, on le trouve sur le fresne dans le courant de messidor. C'est un caustique violent; misen poudre et mêlé avec de la pommade, il brûle les parties de la peau sur lesquelles on l'applique, y produit une cloche qu'on enlève, et la sup- 


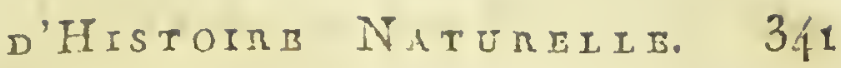
puraiion s'établit; c'est ainsi qu'on l'employe pour les emplâtres vessicatoires.

14. Le tenebrion meunirr. Son corps est allongé, ses élytres brunes et lisses sont marquées dèneuf sillons. On l'appelle meznier, parce que sa larve aime la farine. On la trotive quelquefois, ainsi que l'insecte parfait, dans le pain avec lequel elle a été paîirie.

*** 4 articlés à tous les tarses.

15. Le cerambix-géant. On a aussi donné le non de grand capricorne à ce coléoptère, à cause de sa grande taille et de la longueur de ses antennes.

16. Le ceramib Ýx-nugqué. Il est semblable au précédent, mais d'ui tiers plus petit. Ses élytres sont d'un vercl cioré; on le trouve sur lo saule, il répand une odeur de rose qu'on a trouvé le moyen l'extraire et de fixer.

17. Le charion. Cecoléoptère diunc forme allongée, a la tête et le corcelet blcuâtre, les élytres rouges aves une tache également bleuatre. Sa larve s'introluit dans les cellalcs des aboilles, oi elle cause de grands Y 
dégâts; elle en sort après sa dernière métamorphose, et yole sur les sommités des. fleurs.

18. Le ciraratson dub blé. Ce pelit insecte brum a ie corcelet presque aussi long que scs élytres, et la têtc terminée par une trompe mince et longue. Il dépose ses œufs dans les grains de bled. La larve qui éclot dévore lia substance farineuse, et ne laisse que l'enveloppe. Linsecte parfait la perce pour en sortir; il faut cn garantir arec grand soir les tas de bied.

\section{* ** Trois articles à tous les tarses.}

19. La coccinelin is sept points. C'est cee insecte brun et hémispliérique qu'on appelle. vulgairement bête à dieu. Il y cn a d'autres espècos à-peu-près semblables qui ne se distinguent que par le nombre et la couleur de leurs points.

20. La fanficura. Les élytres de ce coléoptc̀re ne couvrent qu'une partie des â̂les, mais ils sont coriaces, comme ceux des précédens. Son anus est armé de deux pinces arquées qui forment une espèce de 
n'itstome Natureite. 343 tenailie ou de forceps; mais cetie arme, qui n'est pas unême recloutable pour les pelits inscctes, ne samoit être dangerense pour lhomme. Il est fanx que la forticule puisse pénétrer par lem secours dans le conduit anditif; c'est pourtant ceite supposition yui l'a fait nommer vulgaircment et très-impropremont perce-oreille.

\section{H L M P T E R E}

Les étuis de ces insectes re sont point coriaces, ce sont presque des aîles propres au vol comme. celles qu'elles recouvrent; c'est pour cela qu'on les nomme hemipteres. Leur bouche est terminée par une trompe reconbée sous la poitrinc, qu'ils savent introdure dans le corps des animax et dans le tissu des plantes, pour en tirer les sues dont ils se mourrissent; la larve ne diffère de linsecte parfilit, que par l'absence des ailes. Quclques espèces demeurent toujours dans l'état de nymphe, et n'en acquièrent jamais. On peui partager cos in. sectes en deux divisions. 


\section{EL मै}

* Etuis de consistance égale.

1. La cigale a des antennes très-courtes, et une trompe. Son corps est noir, scs anreaux sont bordés de jamne, ses étuis et ses â̂les sont transparens et réticulés. Son prétendu chant est un bruit aigu causé par le firttement du corcelet.

2. Le puczion est le plus commun, le plus muhiplić des insectes; c'est aussi peut-être le plus singulicr. Son corps lourd et massif cst terminé par une petite tête arméc l'une tromple recoubée; son abdomen est accoiruagné de cornes. Quelques puccrons ont des aîles, d'autres n'en ont pas. Ils sont vivipares tout l'été, et pondent des culs en automne. A l'époque de la f'écondation, les petits vivans sortent du ventre de la mère, ct elle en fait quelquefois quinze d̀ ringt dans un même joùr, sans paruître plus grosse qu'auparavant. Si on prend me de ces mères et qu'on la presse doucenient, on fait sortir de son ventre un plus grand nombre de pucerons, toujours plus petits, qui filent comme des grains de chapelet; mais ce qui est encore plus singulier, c'est 
n'Histotre Naturetib. 345 qu'un seul accouplement féconde les femelles pour plusicurs générations; on cn a observé ordinairement cinq, ct on en a compté jusqu’à neuf consécutives. Tous les pucerous aîlés ou non aîlés, changent souvent de peau. Plusieurs de ces insectes sont couverts d'une poudre blanche on d'un duvet plus ou moins cotoneux. Ils laissent suinter des deux cornes de leur anus, une liqueur miellée qui attire les fourmis. Ces insectes infestent les plantes; les feuilles et les tiges deviennent malades et se contournent. Le meilleur moyen de détruire les pucerons, est de nuettre sur les plantes quelques-uns des insectes qui en sont avides. Il y a plusieurs espèces de pucerons, qui diffèrent par la coulear, et s'aitachent à des plantes particalières. Celui du pistachier dome une belle coulcur rouge.

3. Le cheraits a une trompe allongée, qui sort du corcelet entre la première et la seconde paire de pattess. L'extrémité du ventre est garni d'un filet. Le mâle a quatre aîles, mais la fermelle n'en a point; quand elle est jeune, on la prendroit pour un pe. tit cloporte blanc qui auroit six pattes. Au boutde quelque temps, elle se fixe sur une 


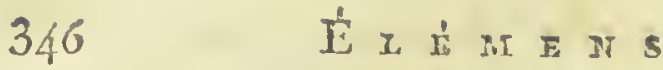

partie de la plante où elle vit; elle y demeure parfaitement immobile, et elle change de peau; bientót son corps se gonfle, sa peau se sèchc. Elle crô̂t beaucoup ct meurt ensuite. Le ventre se flétrit, et il no reste plus qu'une espèce de coque solide, sous laquelle les œuns sont renfermés. Ises petits étant éclos restent encore quelque temps sous celte enveloppe, et le cadavre de leur mère lcur sert de nourriture. Ils en sortent ensuite pour produire, do la même manière, de nouvelles générations.

Il y a plusiems espèces de chiermès. Le princiulal est lo chermes du chêtue veri, qu'on appelle fraine d"écurlate, parce qu'il sert à teindre en rouge. Il étoit sur - tous cmployé, avantqu'on se servit de la cochenille que l'on trouve en Amérique sur l'opuntia. On recucille aboulanment en $\mathrm{Po}-$ logne une autre espèce dechounès, qui se rciicontre aussi sur nos plantes, et qui sert à teindre en rouge; il resscrible it un grain brunâtre. 


\section{O R TH OP T E E S.}

Ces insecies ont aussi les étnis mous; mais leurs aîles sont pliées longitudinalement. Lear bouche n'a pas de trompe, elle est munie de fortes mâchoires; la larve ne diffère de l'insecte parfait, que par l'absence des â̂les. Quelques insectes de cet ordre derneurent toujours dans l'état de nymphes, qui cependant s'accouplent et se reproduisent.

1. La biatte commune est très-connue dans les cuisines et dans los boulangeries. Elle est large, applatis, lisse et brune. Cct insecte hideux court fort vîle, mais vole très-mal, parce qu'il n'a que des moignons d'aîles. La larve ne diffère de l'insecte parfait que par le défaut d'â̂les et d'étuis. Elle se nourrit ćgalement de chair, de cuir, et sur-tout de farine, dont elle est très-rorace; clle ronge aussi la racine des plantes.

2. Le GRILLON. Ses étuis sont veirés; il a près de l'anus deux petits filets pointus, et la ferrelle porte à l'extrémite de son corps une pointe dure, qui lui sert à percer la terre et à y déposer ses ouís. Cet insectc se 
- trouve dans les champs, mais il se plait principalement cntre les briques des cheminées et des fours, et il produit par le frottement continucl de son corcelet, un bruit incommode qui lui a fait donner le nom de cri cri.

3. La courtiring. Cette autre espèce de grillon est facile à reconnoîtré il ses pátles armées de fortes scies, quilui servent ì couper. les racines des plantes, et de fouir la tcrre comme une tampe, ce qui l'a fait aussi nommer tanpe grillon; c'est le plus terrible ennemi des melonières.

4. La siuterelili est d'un beâl vert, scs âles sont très-longues; elle saute aisénıent à l'aide de ses pattes postéricures, fortes et beaucoup plus longues que les antéricures. Les femclies ciéposent leurs oul's en terre, au moyen du saibre et di coutelas dont elles sont armécs. Ces insectes manyoun les herbes et sont très-voraces; un champ sur lequel tombe une nuée de sauterelles est bientôt dévasté.

5. Le cringet diffère de la sauterelle en ce que ses antennes sont très-curtes, et ses étuis sont brunâtres et marbrés; ses nîles sónt bleues cu ronges marqućes de noir; 
D'Histoirs Natereidi. 3. 9 il est très-aisondant sur les prés où on le voit suter par centaines.

\section{II I M E N P T E R S.}

Les insectes de cet ordre ont quatre â̂les membrancuses d'inégale grandeur, les deux inférieures sont constamment plus courtes et plus petites; les unes et les autres sont chargées de nervures longindinales bien marquées, et l'autres transversales moins sensibles. L'insecte, en faisantusage de ses aîles, les unit si fortement, qu'elles semblent n'en faire qu'une. Isa plîpart de ces insectes ont une trompe, d'autres ont un aiguillon fort et pointu, caché sous le ventre; outre le mâle et la femelle, on trouve dans cet ordre des individus qui ne jouissent d'aucun sexe, et qui souvent n'ont pas d'aîles; ceux-là semblent uniquement destinés au soin des petits. La larve est en général un ver mol, blanchâtre et sans pattes.

* Bouche sans trompe.

1. La gourarr. On a beaucoup parlé de la sage préroyance de cet insecte, qui. 
amasse, cit.on, pendani l'été des magasins pour se nourir l'hiver. Il est malheurew que tont ce qui a élé racenté à ce siijet, ne soit fondé que sur des rapports incxacts et des observations fusses.

La fourmi a les mâchoires vignmreuses, et la tête triangulaire. On remarque une petite écaille à la jonction du corcelet avec le corps. Cet insecte se réunit en troupes et vit cn société composćc de mâlcs, de femolles et de mulets. Les mâles sunt plus pelits que les femelles, ils sont éçalement â̂lés; les ouvrières tiennent le milicu pour la grosscur entre les mâles et les femelles, elles ont les mâchoires plus grandes et n'ont point d'ầles. Lẹs mâles volent autour de lhabitation générale, mais ils n'en approchent guc̀re. On ne trouve que des femclles et des ouvrières dans ces souterrains appelés fourmiliéres.

Ces trous sont oudinairement crcusés au pied d'un arbre, ou d'un mur dans un terrein ferme et scc. Lientióc de l'habitation est un peu ceintrée en voûte, et soutenue par cics racincs de plante, pour empêcher les caux d'y pénétrer. Il $y$ a quelurefois deux d trois issues pour une scile demeure; 


\section{D'Historse Naturelie. 351}

elles conduisent à une cavité souterraine, enfoncée souvent de trois dácinc̀tres, irrégulière en dedans, et sans aucune séparation ni galerio. Cutte fouille doit coûter beaucoup de peine aux fourmis qui ne peuvent détacher, couper et emporter qu'une trèspetite quantité de terre ì la fois; mais le nombre des ouvrières supplée à leur force et à leur grandeur. Elles se partagent en denx bandes; l'une est composée des fourmis qui emportent la terre au dehors, l'autre de celles qui rentrent pour travailler; de cette manière elles ne s'embarrassent pas, et le travail n'est jamais interrompu. Quand la fourmilière est creusée, les onvrières s'y retirent le soir, et ce n'est qu'après une journée laborieuse qu'elles pensent d̀ manger. Jusques là clles sont uniquemont occupées de leurs travaux, et pas une re porte de nourriture à l'habitation; mais leur ouvrage fini, elles vont chercher leur subsistance. Fruits, racines, pain, insectes morts, charognes, tout leur est bon, clles déchirent ces substances et ne laissent que les parties dures avec tant d'exactitude, que pour avoir des oiseaux et des feuilles bien disséquées, il les faut placer sur une 


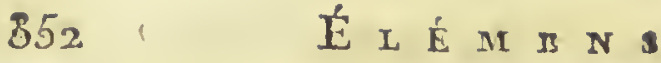

fourmilière. Si quelqu'une périt dans la marche, les autres portent son corps hors du chenin. La nourriture transpostée à l'habitation J'est point mise en réserve, elle est dévorée sur le champ, on partagéc aux petits. Les auf's sont blancs et presque imperceptibles; il en sort des petites larves blanches, qu'on nomme improprement neus de fourmis; les ouvrières ont l'attention de les apporter, vers le milieu dn jour, à l'entrée de leur soutcrrain, et de les rapporter, à l'cntrée de la nuit, clans la fourmilière. La larve se change en nymphe. Les ouvrières ont pour elle le nême soin, mais sans avoir besoin de leur donner de nourriture. La in ymphe devient une foumi parfaite, aîlée ou sans aîles, selon le sexe. Les fourmis demeurent engourdies et entassées les mes sur les autres dans leur souterrain pendant l'hiver, il est donc faux qu'elles fasscnt des provisions pour cette saison.

Les émanatums des fourmis sont âcres et corrosives, elles font naître des pustules. Le papier exposé au-dessus d'une fourni-. lière y rougit; on retire de la distillation des fourmis, un acide appelé acide formigue. 


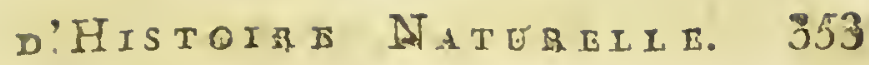

Les fourmis fournissent ì la médecine nne liqueur astringente et tonicue. Les larves s'employent pour la nouriture des faisans. On compte dans les enviróns de Paris, six espèces de fourmis qui se distinguent par leur conleur.

2. Le cyrres. Ses antennes sont coudées. Il est armé sous le ventre d'un aiguillon terminé comme une tarrière, et garni de pointes sur les côtés, comme le fer d'une flèche. La larve de cet insecie ressenble à un ver blanc, sa tête est brune et écailleuse. La femelle se cache sous des excroissances qu'elle produit avec son aiguillon ì la partie supérieure ou inférieure des fenilles, et elle pond un œut qui, coulant le long de la rainure de la tarrière, reste dans la place qui lui est destinée 'par le moyen d'une espèce de glu qui l'enduit. Les sucs de la feuilie s'épanclient par les vaisseaux qui se sont ouverts en cet endroit, ei yoforment une excroissance ou tubérofité dans laquelle l'œuf est renfermé, et qui acquiert successivement du volume et de la consistance. Quand cctte galle est un peu grosse, I'cuf éclot, la larve se nourrit de ce qui est à sa portée, et aggrandit ainsi sa de- 
moure à mesure qu'elle grossit. Le plus souvent elle subit sa métamorphose dans la gollle elle-mêrne, et ne la perce que quand elle est derenuc insecte parfait. Quelques cynips ne se font point de galle, et se tiennent seulement cachés sous les feuilles.

La pluppart des cynips ont des coulcurs b:illantes, quelques-uns ont une couleur plus olscure. On distingue à canse de lenr singularité et de leurs usriges :

Le cynips du bélegmar. C'est celui qui produit celie excroissance filamenteuse et pelotonée que l'on remnaryue sur le rosicr. Il a le corcclet vert, l'abutomen doré et accompagné de soies aussi longues que son corps.

Le cymips du chêne. Flusieurs cynips produisent des galles sur les fenilles et d'autres. parties du chêne. Celui dont il est ici question, fournit la noix de galle dont on se sert pour précipiter le fer en noix, et l'appliquer ainsi à la fabrication de lencre, et pour la préparation de difiérentes teintures.

Le cynips psènes est celui qui donne lieu au phénomène de la caprification. Voyez figue.

วิ. La cutrn a le corps lisse, les antennes. 
n'Ifistotre Naterite. 355.

brisées; elle n'a point de trompe, mais l'anus est arné d'un aignillon. On! connoit nu grand nombre i'espèces do grû́pes, dont les plus vemarijuables sont la ğuêpe frêlon, la plus grosse de tontes, et la gruêp pe commizne, dont le corcelet porte trois rangées. de points jaunâtres.

Les guêpes se construisent dans de vieux murs, on de vieux arbres, des gâteaux. composés de plusieurs cellules hexagonez et contiguës. Ces gâteanx ne sont pas de cire conme ceux des abcilles, lenr substance ressemble à un papier brovillard brun et très-fort; elle est formée de brins de bois et de fibres pourris, imbibés d'urie liqueur gommeuse, qui sọt de leur bouche, et' qui. donne à cette matière quelque consistance. Les guêpes y déposent leurs cufs, les larves en sortent bientôt, et elles les nourrissent d'un miel moins doux que cclui des abeilles. Après avoir changé de peau plusieurs fuis, chaque larve se transtorme en nymphe; les guêpes ferment alors les alvóoles avec unc calótte; l'insecte parfait, dévcloppé, brise ce dôme, sort, et se met aussitôt à travailler avec les autres.

Les guêpes viveni en société de douze,

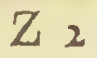


de vingt, et quclyuelois plus, rais jamais ausi nombreríses que celles des abeilles. Quelques-unes sont solitaires, et déprsant leurs oufs dans une boule de terie pâ̂trie, qui n'a qu'une ouverture par laquelle clles nourrisent la larve; elles la ferment cnsuite, quand celle-ci se change en nymphe, et vont firire un autre nid pour y déposer t\}n antre ouf.

4. L'Aв̈Lt.i.s a des nntennes brioées, dont: le premier ammean est très. Inng ; les aîles inférieures plus courtes que les surérienres; la bouche armée de mâchoires et d'une trompe membranerise anchéc en dessons; wn aiguillon simple et en prointe; le ventre attaché au corcelet par un pédicuie cumrt.

Les abuilles livrées à elles-inĉues se rassembleroient dans des troncs d'aybes crenz, ou darıs l'autres cavités commules, offertes par la naturc. Celui qui veut les élever pour profiter da fruit de leur industrie, leur jrésente me ruche, habitation conigue d'osier, de paille de seigle, ou construite er bois, et dont les panneaux sont vitrés. On y attire, en la frottant de miel, l'essain qui sort d'une autre ruche.

Les abeilles se réunissent alors par mil- 
R'HISTOITE NATERET.

liers, mais le nonvel éthlissrnom ne pent rénssir que lorscuc la conlonie est composéo de lons los indivi ins nécéssáres à sa mulriplicalion et iो ses travaux. Ces individus sont:

Liabillemale, qu'on nomme ansis vulgaicment farr bourdon. llle est moins Inugue que la femelle, nais plus grosse que les abeilles ouvrières; son corcelet est plus velu et son ventre plus lisse. Une rucie de tren'e mille abeilles ne contient guères plus de denx à trois conts mâles. Les abeilles onvrières ne leur peruettent de vivre sans travailler, que pour repeupler la rnche. Dess que la ponte. est faite, ces mêtnes cuvrières qui les avoient nourris avec soin jusqu'au printemps, massacrent ces fainéans qui, faute d'armes, ne peuvent se défendre.

L'abeilie fencllo est nnique daus la ruche dont elie est le chef. Elle surpasse aussi toutes les autres par sa taille; ses antenues sunt composées de quinze pièces, et son ventrc de scpt inmeaux. Il est exirêmencrit allor:gé et armé d'un aiguillon plus vigoureux, dont clle fait cependant peu d'usage, car elle surt rasement de la rucha oi tout parcî́t edjpressé ì la servir, à tui 
préparer, et à lui préscnier sa nourriture. Iille peut par sa seule présence suspendre Jés travaux, on les rendre plus actifs. Celle femelle est clouće d'unc fócondité jurocigicuse. Llle répond aux caresses de ses lifférens favoris, et prr des porites multiplices depuis germinal jrosu'en prairial, clie entretient senle la population de la ruche, ¿ui s'accroî ainsi au point qu'il en sort tous les ans le nombrenxessains, qui vont, sous la conduite d'un autre chef, fonder de nourelles colonics. Cette femelle vole avec pcine, il suffii de s'en emprarer ci de la meitre dans une ruche, pour y faire cntrer les abcilics qui la suivent.

Les aboilles ouvrieres sont les individus de la ruche les plus pelits. On les reconnoît fucilcmeis aux brosses cui s'observent d la paülie intéricure de lours cuisses de derrierc; elles sont armées d'un aiguillon. Ces abcilles sont celles qui méritent plus particulièremeni le non de mouches ì mich, puisque c'est sur clles seules que tombent tous les soins et tows les travaux de la ruche. On les nomme aussi mulets, parce qu'elles ne peuvent ni féconder, ni pondrc. Tous leurs travaux tendent ì conserver les petits que 
n'Histotre Naturextr. 359 la fenclle leur a Jornés. Ils consistent à comstruire les cellules oil cetto forncllo doit déposer ses auf́s, et à les remplir d'une nourriture conrenable à la larve gui doit éclore.

Pendant que les mâles et la femelle wo s'occupeni qu'au soin cie la régéuération, les onvières ront chercher fort loin leurs matériax, ce gुui les force souvent ì de longs voyages. Elies recueillent d'abord sur les plantes résineuses et gommeuses, dans les jeunes bourgeons du saule, du periplier, etc., une espèce de gluten connu sous le nom de propolis; cette matière est odorante et ferme. Elles en enduiscnt l'intériear de la ruche, et s'en servent pour boucher avec soin toutes les fentes. Après ce premier travail, elles commencent d construire leurs rayons.

les abeilles vont chorcher dans les fours Ia matière de la cire. Eiles se roulent sur les ćtamines, se couvront de leur poussière, se frotient avcc leurs pattes, la rassemblent cu boulcs dans les brosses ou palettes triangnlaires de lcurs pattes postérieures, et les apportent d̀ la ruche. D'autres abeilles regoirent cette substance, l'avalent, l'élabo- 
rent dans leur estomac, et la défonrgent par la bouche. A l'aide de leurs pattes et de leurs mandibules, elles forment aveccette bouillie des alvcóles hexagones pressés l'un contre l'autre.

Quand les alvéoles sont construits, il faut les cmplir de miel. C'est dans le nectaire des Heurs que les abeilles le pompent avec leur trompe; elles l'élaborent et le dégorgent dans les cellules; une pellicule de cire les reconvre. Les abeilles consomment dn miel lhiver pour leur propre nourriture, quand elles n'en trouvent plus dans les champs.

Les cellules sont destinées à différens usages. Les unes sont vides, les autres contiennent la cire brute, qui, dans les momens d'une récolte abondante, a été miso en dêpôt et recouverte d'un péu de rniel. La plûpart sont occupées par les eufs, d'autres, couvertes de calottes plus élevées, renferment les chrysalides. La réunion de ces alvéoles compose les gâteaux ou ravons.

Dans les instans de repos, les abeilles se suspendent l'une a l'autre par les pattes, se tiennent accrochées et forment des grouppes. Lt; essains nouvellement sortis se suspen- 
d'Histothe Naturite. $36 x^{\circ}$ dent de mêne ì une branche d'arbre, pour attendre le choix que f'ait leur chef', d'un asile converiable.

Les produits que l'on retire de l'éclucation des abeilles sont considérables. La cire et le miel sont les principaux; la propolis cst seulement employée en médecine pour la guérison des abcès.

Le miel a une couleur jaunâtre, et me consistance syrupeuse, une saveur sucrée et aromatique. Pour l'obtenir, on pose les rayons sur des claies d'osicr, on les égoute, on les porte ensuite sous la presse; mais le miel qui en sort est toujours inféricur au premier, parce qu'il est moins pur, et qu'il s'y trouve des insectes écrasćs. Cctte substance cst pectorale : dissoute dans l'eau, et mêlće au vinaigre, on en fait une boisson rafraîchissante nommóc oaymel, le niel est lexcipient de plusicurs méticamens dont it prend le nom. Tols sont le niél rosat, le michmercuriel, cic. On mangc le miel surle pain. Combiné avec la farine d'orge et celle de seigle, il faii le pain d'érice; on le substime an sucic, et on en retice un sel absolament semblable. Il passe à la fermentation 
spirifieuse, et dars cet état on le nomme Jiydromel.

Quand les rayons ont été égontés, pressés et laves, on les fornd ei un prsse la cire à travers un linge four la déimasser de tous les corins ćtrangers. On la fait tomber dans l'ean, clle sumage en lames winces que l'on seche sur des toilus ì la rosce qui la bianchit. Cette opération de la fonte et Ju blanchincnt do la cire se répite truis fois, ei cile a acquis alors toute la blancheur durielle esisuscptible; on la numme cire vicige.

La cire chanféc à un feu doux, forme un fluile huilens et traisparent; clle relevient solide nai le refruidissement. horsgru'on la chaute avec le cuntact de l'air, clle s'allume ct se rolatiise; c'est l'erfet de Ia mêche dans la bongie. La cire vierge, outre cet nage, sert dans la primerie et dans lin phamacic pour la préparation des poinmades, des cnguens, des empiâres et des cérats. La circ jaine sert à cirer les appartemens ct à faire des bougies grussières. On colore la blanche en la mêlant arec de lhuile, et en la broyant arec des couleurs. La poir grasso la conserve dans un 
état de mollesse qui la rend utile pour l'appiication des scellés. La cire mêlée au sucre candi forme une pâte propre à prendre l'empreinte des pierres gravées. On modèle des statues cn cire, on en enduit des étofies de toile et de soie pour les resdre impénétrables ì la pluie; mais il faut y ajouter de l'huile, afin que cet cnduit ne soit pas cassant.

Outre l'abeille qui donne le miel, on en voit beancoup d'autres cspèces extrêmement singulièrcs; l'aucille perce-bois, rcmarquable par sa conlcur violette, et qui pond ses œufs dans les profondes galeries qu'elle creuse it travers le hois; l'abcilie maggonne, qui se construit des collules avec un mortier ćpais gấché comme du plàtre \&ic.

\section{N $\mathrm{VROPTHRE}$.}

Les ciranire â̂les de ces insectos sont nues, transparentes, et n'ont que quelques nervures qui les souticnnont. Cicst d ces nervures quils ánivent leur nom. La forme de leur corps est extrêmement variéc. Lcs antenges sunt très-ccurtes ct presqu'imperceptiibles. Lcui bouche cst armée de fortes 
mîchnires écaillenses; les larves varient fuancoup. On remarque en géréral dans le's "ynuphes tontes les paries de linsecte parfitit.

1. La miberiula. C’est le nom gue les naturatines donnent ì ces beanx insectes qu'on a!preile vulgaicenent demesisellen. Lenr tère est accompangée l'antennes trèsconries, mais leur bumche est armée de fortes roachuires. La larve les libellulos ent aquatipue, on y remaripue prespue tounes les parties del'insecte parfuit; mais ln tête est converte d'un masque mobile qu'clle sonlève, prour saisir les autres insectes dont elle se nomrit. La nymple difinie pén de la larve, l'insecte parfidit ac.juiert un corps plus allungé, plusétroit, quatre â̂les transparentes et réticulées. Lo mâle se distingne par les filets qui accompaznent l'extróniité de sa queuc. Les organes sexueis sont attachés près du corcelet au prenier anneau du ventre. La f'emelle dépose des œutfs oblongs sur les plantes aquatiupues. Quelyues libellules ont les âles relevées, dautres les ont étcndues. Le corps estrond ou applati; on en compte beaucoup l'espèces. La plus jolie est la Lozzise, dont le corps d'un verd 
d'Histoire Natumejés. 365 cuivicus se halarice surden ailes vitreuses, tesminés far anc lache d'un noir fomcé.

2. Le fucruinin. Le nom a été cinnué d cer insecte, jaice quil fait une chasse cominielle anx fommis, et qu'il est prou elles ausi tenihle que le lion pour les autıes animanx. Su larve rấi des auf's quo linsec'e parfuit a dépusés dans un sable tin el sec en quelyu'endruit abrité de la pluie. Sa conieur est gi ise, et sun corps est cuavert de petits tubercules de conleur ovale. Sun extrémité pustérienre se termine en pointe. Au-devant de la tête sont des pirices dentelées, aigı ës et creusées, quilui servent à saisir et à sncer. Comme il marche en reculant, il hii seroit difficile cle joindre son eunemi; mais il creuse, on turnant, un trou conique, et rejette le salile avec ses antennes; il se tayit an fond de ce trou. Si un insecte arrive sur les hords, le fonrmillion s'en apperçoit par les grains de sable. qui roulent, alors il l'accuble de celui qu'il Lui lance avec ses antennes, le saisit avec ses pirces; l'entraine et le suce. Quand la larve a accuuis toute sa croissance, elle se fait une coque de sable tapissés intérieuremon: d'une suie blanche ot fase; elle s'y 
change en une nymple gui offe toutes les parties de l'insecte parfiti.

Le fourmillion parvenu à cet éiat, est très-allongé; ses grandes aîles sont chargées de nervures et le taches.

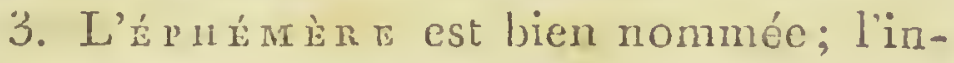
secte parfait ne vit en clfet qu'un seul jour. C'est dans l'eau que sa larve se troure; clle est oblongue, sa tête est grosse, et son corcelet est cumposé de trois anneaux, son ventre de dix. Il a de chaque côté des appendices qui ressemblent il des narreoires, et la quene est terminée par un jolipanache. Cette larve dont la couleur est jaune, on d'un bleu tirant sur le verd, croît !entement; elle vit trois annécs dans cet état et habito les trous qu'elle s'est creusé près de l'earu, pour y éviter la poursuite de ses ennemis. Aú bout de trois annécs clle quitte sa premic̀re enveloppe; devenue nymphe ailée, elle voltige et s'athache au premier endroit qu'elle rencontre. Elle n'est qu'un instant sous cette forme quielle quite encore, et paroît entièrement mćtamorphosée. Alors ses pattes sont plus longues, les filets de sa qienc sont augmentés. Sa tête est grosse, ses anicnacs it peine risibles; les ailes su- 
D'Ristoire Naturexta. 367 póricures sunt très grandes, et les ailes inrérieures jeu sensibles. Dذs que cette métamirphose est faite, ces felits animan no. duivent songer qu'̀े hâter les momens destinés à la reproduction de l'espèce. La lemelle dépose aussi-tôt ses oufs sur la surface des rivières; c'est dans le comrant de l'été, dans les mois messidor et thermidor, que ces animanx subissent leur dernière nétamorphose. Il en vient souvent une si grande quantilé à la fuis que l'air en est obscrirci, inais on en est bientôt célivré ; les eaux sont. couvertes de leur corps cui servent de pâture anx poissons, aussi les pêcheurs les nonimontils la manne aes poissons. Dans quelques pays les cultivateurs en remplissent des sacs pour en engraisser la terre. On connoit plusieurs: espèces de ce genre qui se distinguent par leur couleur et le nombre de leurs filets.

\section{L E I D O P T E E S.}

Les insectes de cet ordre ont quatre ailes courertes de petites écailles colorées, ce qui leur a mérité le nom de lépidoptères. Ces é aalles se recourrent comme les tuiles d'un toit. Ellcs sont si fines qu'elles s'at- 
tuchent aux doigts comme une poussière farincuse. Ce sont ces écrilles qui forment ces belles couleurs dont leurs ailessont émaillées; si on les culève, l'aile reste sans coulcur, ce n'est filus qu'une membrane composée de deux lames fines et trumsparentes, tuaversées par les musclesquila font mouvoir, dont on distingue les attaches, et par les raisseaux qui les nourrissent.

Le corps de ces insectes varic selon la famille à laquelle ils appartiennent, mais toms subissent des métamorphoses curieuses.

Leurs Jaryes sont connues sous le nom de chenilles, clles sont allongées et composées d'une tête et d'un corps qui a louze anneaux distincts en comptant le derrier. La tête porte deux calottes sphériques, ce sont ses yeux; elle est arinée de mâchoires dures et riguës, insirumens des ravages de l'insecte sur les fleurs et dans les potagers. Au-dessous de la tête est la filière, petit trou par lequel passe en effet le fil que l'insecie sait former. Les anneaur sont pourvus le stigmates par lesquels l'insecte respire; ces plarties sont à-peu-près les mêmes dans tontes les chenilles; mais le normbre des paties rarie, cependant jamais la chenille 
I)'Histora NAturetiz. 369 n'eri a moins de huit ni plus de seize. Les six premières sont tonjon's écailleuses, elles contiennent les six pattes que loit avoir l'insccte paifait. L:-, antres, apnellées pattes membibzuzses, sont couronnées par des cro. chets dnrs, qui atremissent l'aninal sur les branches. Ces pattes sont celles dont le nombre varie. Elles avancent ordinairement $\mathbf{e n}$ formant des ondulations; mais leschenilles a douze pattes, après avoir appuyé leurs six paittes écailleuses, tirent à elles le reste du corps en formant un anneau; comme en s'allongeantet se déployant ainsi, elles semblent mesurer la terre; on les a nommées chenilles géomètres ou arpenteuses.

L'enveloppe de la chenille est nue ou couverte de poils fins, serrés, ou disposés par paquets. Ces poils, en s'insérant clans la peau, y causent une démangeaison cuisante.

Les stigmates aboutissent chacun à un. vaisseau aérien. Tous ces vaisseaur vont se réunir à deux longues trachées qui reçoivent et rendent continuellement l'air. Un long canal alimentaire, qui s'érend de la bouche à l'anus, tient lieu à la chenille d'osophage, d'estomac, ct d'intestins. A côté de ce canal est un yaisseau artériel qui remplace le cocur,

A. a 
et aux deux côtés sont deux autres vaisseaux qui ront abontir à la tilière. Ils cuntiennent une liqueur transplarente, qui devient sulide à l'air. C'est cette soie dunt l'insecte forme sa coqne. Le resie lu corps est une matière graishense, qui facilite les mélamorphoses de l'animal.

L'insecte parfait dépose ses œuís sur les substances propres à noumir la petice larve aussi-tôt qu'elle sera éclose. Celle ci croît promptement et change plusicurs fuis de peau. Lille se ti:c de son enveloppe comme d'un fourean, et paroît avec l'autre peau qui étoit cachée sons la prenière. On compte quelquefois jusqu'à huit de ces changemens successifs.

Parrenue à son dernier accroissement, la chenille passe à l'état de nymphe; mais avant de subir cette transformation, elle exécute un grand travail, elle s'enfonce dans la terre, ou roule des feuilles, ou tile une deneure ovale d'une soie plus ou moins fine, qu'on appelle coque.

Ia nymple des lépidontères se nomme chrysalidé, à cause de ses couleurs dorées; fève à cause de sálorme; c'est l'insecte parfait resserré, replié qui sort ensuite, et 


\section{D'ilistora}

se développe. Le lépidoptère reste plus ou moins long-temps dans cet éłat. Enfin l'insecte rompt la peau sèche et dure qui l'enreloppe, et perce la coque où il étoit enfermé. Il est d'abord mol et humide, ses ailes paroissent mouillées et chiffonnées, il demeure immolile. Toutes ses parties exposées à l'air se sèchent et s'affermissent. Il rend par l'anus une liqueur sanguinolente qui le gonfloit. Cette liqueur semée sur les murs, sur les toits, sur les chemins, a sonvent donné lieu à la croyance superstitieuse des pluies de sang.

Le lépidoptère prend son essor. Quelques espèces ne vivent sous cette forme que le temps nécessaire pour s'accoupler. Les œufs sont ordinairement ronds, allongés ou applatis et enveloppés d'une écaille dure. Ils sont jettés en un tas, disposés en ordre, ou forment des anneaux autour des branches.

Le nombre des lépidoptères s'élève à près de trois mille; on les sépare en plusieurs genres, d'après la forme cie lears antennes et la figure des parties de la bouche. 


\section{* Antennes en masse.}

1. Les pariluts. On a réuni sous ce même genre tous les lépidoptères dont los anternes sont en masse, c'est-à-dire terminées par un globulc.

La larve ciu papillon est une chenille a seize pattes. Plusieur's sont hérissées d'épines branchucs posées sur les anncaux, d'antres sont très-velucs, d'autres absolument nues. La chrysalile est nue, atiachée par la partie postérieurc à quelque corps abrité de la pluic. Sa couleur d'or est due à un snc épais, qui, vu à travers la peau, prend l'apparence d'un vernis. Cependant la chrysalide d'es papillons n'est pas tonjours jaune, il y en a de vertes, de lurunes, de noires etc. Illcs sont chargées d'un nomlure de pointes qui varie.

Les papillons ont toujours le corps allongé, six pattes et quatre grandes ailes. De leur tête sort une trompe roulée en spirale, avec laquelle ils poupent le nectar des. fleurs. Le nombre des espèces s'élève ì plus de mille. Pour les reconnoître, on les clisiribue en plusieurs familles, d'après les angiges for- 


\section{d'Fistorte Naturelex. 373}

més par leurs ailes, le nombre et la position des taches et les yeux qu'on y obstrve, le nombre des pointes de la chrysalide etc. Il est impossible d'entrer daus tous ces détails.

Les papillons les plus remarquables parmi nous sont le paon clu jour, qui poite des yeux peints sur ses ailes. La tortice, dont les coulcurs imitent celles de l'écaille. Le' nacré, qui a en effet des taches argentées semblables à la nacre; le damier, marqué comme un échiquier; l'argus brun, et l'argus bleu, dont les ailes sont parseriées en̈ dessous de petits yeux. Le'papillon clu chou, qui les a blanches et marquées de deux puints noirs. On le voit souvent voler dans les rues des grandes vilies, ou il a été apporté avec les herbes potagères. Le grazé, dont les ailes jaunátres sont réliculées; le dezil, marqué de teintes noires. On nomme portequeze les espèces, dont les ailes postérieures sont terminées par une quene. On y distingue le machaom, dont les ailes sont hordées d'yeux magnifiques, et le flambé, dont les taches ressemblent on cict à des flammes. 


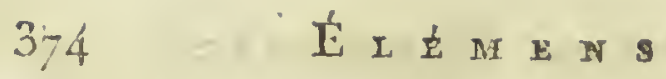

* Antennes prismatiques.

2. Les S I I $\mathrm{x}$ r $\mathrm{x}$ se distinguent facilement aux antennes anguleuses et prismatiques, amincies à leur extrénité. Leur chenille se file une coque, dans laquelle la chrysalide est renfermićc; elle y passe souvent tout l'hyver et en sort au printemps. Les sphynx ne sont pas aussi nombreux que les papillons. On remarque l'atropos, ainsi nommée à cause de la tête de mort figurée sur son corcelet. Le sphynx vitrez $x$, dont les ailes sont transparentes.

* * Antennes décroissant de la base à la pointe.

3. Les т beaucoup pour la f'crme, la grandeur et le nombre des pattes. Les unes sont unies, d'autres très-velues, beaucoup ressemblent à de petits morceaux de bois sec, ce qui les fait échapper à la voracité des oiseaux. A près avoir changé plusieurs fois de peau, elles se filent une coque et elles se métainorphosent en chrysalide. La soie en est 
n'Histoire Natuterie. 375 plus ou moins frue, plus ou moins abondante; 'quelyues-unes en filent très-peu. Elles funt alors leui co fue dans la terre, ei joignent seu!ernen: avec quelques fils les brins de buis at les morceanx de feulles sèches dont ello it composée. Les chrysalides des phalènes sont pour la plüpart ovales, allongées et point angileuses comme celles des papi!lons; elles restent long.temps dans la corre, et plusieurs ne deviennent insectes parlaits quel'année suivante.

Les phalènes sont plus lonrdes que les papillons, plusieurs ne volent que la nuit, et viennent dans les appartemens voltiger autour les lumières. Les unes ont les antcnnes cn filets, d'autres en forme de peigne. L'absence ou la présence de la trompe forme encore des divisions dans ces denx fumilles. L.e grand paon cit la plus grande de nos phalènes. Ses ailes veloutées sont ornées de guatre yenx. La tortue et l'écaille brine ont des cunleurs vives et brillantes. Ia feuille. mo:te mérile ce noin par sa couleur ct par la situntion de ses ailes, dont deux sont étendıes et deux relevées. D'autres se font aussi remarye: par le port de leurs ailes relevées, droites ou inclinées. (3irlyues-unes

$$
\text { A a } 4
$$


ont des trices et des caractères dont ellos prennent le nom, telles une le lambda, l'omégra. le prsi; mais la pulus précieuse de toutes les phalènes est colle qui nous donne la soie.

Cotte phaline porte, ainsi gue bcaucoup d'autres, le nom de l'arbre qui la nourit: on l'appelle phaline du miricr. Ses outs ronds et grisâtres ćclosent à me clialeur de donzo dégrés et demi; lespetites larves ressemblent à des vers, et c'est de lì que lenr cat venu le nom de rers ì soic. On les nomrit avec destenilles de mùier tendres, et, à lenr défant, de ld lailnc. Ces petits animaux filcnt presqu'en naissant. Il faut pour les élever beaucoup de propreté et de soin. Au bout de trois décades le ver di suie est d'un assez beau blang On y distingne aisćment les quatre carossans yri lui sont particuliers, ct l'érine qu'il porte sur. son denier anneau. I) dévore alors cle grandes feuilles de mîrier en un seul jour. Cette strabondance de nomriture se tourne en soie, cil monte pour filcr sur les pelites branches de bruyère gu'on lui présenta.

La soic est un mucilage végétal combiné avec me luvilc animale paticulière, qui lus 


\section{d'Histora Naturetis. 377}

donne sa souplesse, sa ductilité et son élasticité. Elle se dessèche et prend de la consistance aussi-tût quiclle éprouve le contact de l'air. Les premiers fils du ver à soie ne sont quine bourre très-grossière. L'animal s'établit sur le premier réseau, et par le mouvement régulier de sa-tête, il construit sa coyne qu'il achève en sept à huit jours; cilc est d'un senl fil, qui a quelquefois jusqu'ì trcis cents mètres de iongueur, ế si délié, que l'organsin des taffetas et des gazes les plus fines est au moins composé de quatre à cinq brins, et ordinairement de sept ou huit. Ia soie des demiers fils est toujours trop fine et trop gommée pour être détachóc. Quand on ne veut pas conserver l'animal pour la régćnération de l'espèce, on le fait périr dans l'eau bouillante. La matière de lá coque est employéc à différens usages; la bourre ne peut se dévider, on la carle, on la file, clle se nomme $f_{l-}$ loseile. Los cocons, après avoir donné toute la scie quils peuvent fommir, devicment la matière de ficurs artificiclles. La soio aéviléc frend diftérens noms, selon les préparations qu'clle a subic. On l'appelle soic crue, cuite, organsin....ctc. Le mucilage 
végéto-animal yui la produit donne uns acide particulier, l'acille bomby que.

Quand on veut conserver l'animal, on regarde le cocon; la phalène yui en sort est connuissable à ses antennes en peigne, ct à ses ailes rabattues. Les feinelles sont presque toujours immobiles; İs mâles, plus petits, agitent beauconp l'urs ailes, mais volent tirs peu. Les uns et les autres menrent quelgues jours apres la ponte.

On s’est bearcoup occuiné de l'ari de soigner les vers à suie, et on est parvenu d̀ faire avec le prodiat le la mòne graine trois éducations, font la seconde éuili née de la prenière, et la truisicme de la seconde.

*** Antennes filifornics. Toupet de la tête avancé.

4. Les mitgres ressemblent beancoup aux phalènes; on les en distingue cependant avec facilité, par le petit tomper avancé qu'elles ont sur le devant de la tête. Leurs chenilles, ordinairement lisses et à huit pattes, ne sont point à nu comme les précédentes; elles habitent un fourreau qia'elles se composent 


\section{n'Historre Naturetr. 379}

de différentes matières, et qu'elles tran'sportent avec elles; quelques - unes vivent entre les deux pellicules d'une feuille : d'autres dans l'intérienr les fruits. Ces petits lépidoptères ont les â̂les rayées d'or et d'argent, et érnaillées des couleurs les plus vives. Les aigrettes ct les franges, dont quelques - uns sont parés, augmentent encore leur beauté. Ils dévastent les tapis, les vêtemens de laines, les fourrures, les plantes, etc.

\section{DIP TE RES.}

Ces insectes n'ont que deux ailes au lieu de quatre, mais elles sunt accompagnées de petits filets terminés par un glubule qu'on appelle balancier: Ils sont quelquefois couverts par une espèce d'aileron qu'on nomme cuillcron. Les insecies parfuils volent dans l'air; mais la larve vit sur la terre, dans les eaus et dans quel ques pariies des animaux morts ou vivans.

1. Liofstre di boeut. La larve de ce diptère resscmb!c à un ver court, mol et sans pattes. Sa freun est comme ciragrinée et de couleur ardoisće; elie vient des coufs que 


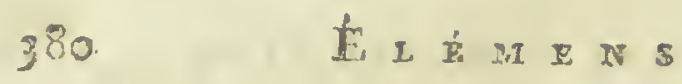

Yinsecte parlait a déposés sous le crir du bout. Elle y produit en grossissant un ulcère, d'où il suinte une sirrie dont elle se nourit. Quelques bouf's sont couverts les élévations cáusécs par ces ulcères, et n'en paroissent jas très-incunmodés. La larve paryciue à sa grosscur sort de celte tuneur, se laisse tomber à terie et s'enfonce sous quelque pierre pour se nétamorphoser. Son enveloppe se durcit, et forme une coque ovale, espècc de chrysalide. L'oestre parfait ressemble ì une grosse mouche. Son corcelet est jamne avec un cercle noir.

2. L'orstre de chrvat est très-velu et d'un jumne fiâle; la larve est brunâtre, clle vit dans le fondoment des chevan, et elle y auhere par les crochcts dont clle est armće. Elle se laisse tomber à terre pour subir ses métanorphoses.

3. Liontra Du MOUTON est cendré ct ponclue de noir. Sa lárve habite les sinus frontaux du nez des moatuns; elle se métanorphose comme les précédenics.

4. Le taon ressemble à mie grossc mouche, ses antennes sont divisées on quntre parties, sa bouche estarmée rl'une trompe, ses yeux sont saillans, ses âles grosics ét panachócs. 


\section{D'Historfe Natuterea 38}

On en cumpte plusieurs espèces qui sucent le sang des boul's et des chevaux, et les incommodent bearcoup pendant l'ćté.

Les arouches sont les insectes les plus communs. Leslarves sontmolles, blanchâtres et sans pattes. Les unes vivent sur les arbres et y dévorent les fucerons; d'autres, dans les animaux-morts et dans les matières pourries, quelques-unes dansl'eau. Leursnymphes sont renfermées dans des cáques formées par la peau de l'insecte même qui se durcit, et la mouche en sort pour s'accoupler. Elle est reconnoissable à ses antennes formées par une palette avec une soie latérale. Sa bouche est armée d'une trompe. Les espèces les plus vulgaires de ce genre nombreux sont la monche bleze, dont la larve infeste les viandes pendant l'été. In moncthe verie, qui vole antour des matières excrémentitielles pour y déposer ses œufs. La mozche domestique, dont nos maisons sont remplies pendant l'été.

(j. Le s тo I OXE est d'une couleur cendréc et ressemble tellement à la monche, qu'on le courond toujours avec elle. Sa tête e it arméc l'unc trompe dure, noire et pointue, avec laquelle il picue los lommes et 


\section{Ex E $\mathrm{E}$ EN}

les animarx pendant l'automne, ce qui fait croire que les mouches piquent plus en automne qu'en été.

7. I e cousin. Les antennes du mâle sont en peigne, celles de la femelle en panache. Sa bouche est un tuyau mince $c t$ allongé Sa larve composée de neuf'anneaux se trouve dans les eaux dormantes et tranquilles. Après avoir changé de peau plusieurs fois, elle devient une nymphe dont la partie postéricure est heaucoup plus grosse que la tête. L insecte parı́nit en sort au bout de huit ì dix jours, et se retire dans les bois humides, dans les prés, auprès des licux où il doit déposer ses œufs. Il enfonce profondément sa trompe dans la peau de lanimal qu'il veut piquer, jusqu'à ce qu'il soit parvenu à un vaisseau sanguin. Ces insectes volcnt le soir par troupes nombreuses. La femelle pond ses œuf's sur l'eau, et leur réunion forme une espèce de petit bateau pointu par les deux bouts. Le cousin commun est cendré; son ventre csícomposé de huit anncaux roussâlres. 


\section{y'Hestotra Naturbie. 383}

\section{A P T i R E S.}

Ces inseces sont ainsi nommés, parce qu'ils noni print d'âles. Lia puce sente parni eux subit les mélannyphases; les difiérentes parics de leurs corps s'accroissent par la nutrition, comme celles des animaxx des autres ordres : quel fues-uns ont un nombre prodigieux de pattes.

1. Le pou'a six pattes, des anternes filiformes, et le ventre allongé. Sir figure varie selon les difércntes espèces, et ón erm compte plus le cent qui habitent sur l'homme et sur tous lesanimaux. Quelqnes uns servent de domicile à plusieurs'; l'homıne même cst attaqué par deux espèces, le por ct le morpion. Ces insectes sont ovipares, lenrs œufs se nomment lentes. A près en étre sortis, ils changent souvent de pearx; trus ont à la partie antérieure de la tête une trompe creuse, avec laquelle ils sucent le sang.

2. La r U C E a six pattes piopres à santer, et le ventre arrondi. Sun corps est revêtu d'écailles dures et fermes, et sa bonche arnée d'une trompe aigıё. Elle se métamorphose comme les insectes des autres ordies, 
elle pond des aul's qui s'altachent à la hase du poil des animaux et des couvertmes; il en sort des pelites larves longues qui vivent cachées sous ces poils, elles forment ensuite des petites coques d'un blanc.sale et pulvérulentes, ou la chrysalide devient insecie parfait. Ia force de la puce est prodigieuse relativement à sa grosseur.

3. La Treu a huit pattes, une trompe plus courte que les anternes. Les espèces de ce genre échapjent à la vue par leur petitesse, les animaux vivans en sont dévorćs, et on en tronve dairs plusieurs substances en putrélaction. La tique du fromage s'appelle ciron.

4. L'ARATREE. Ses yeux sont an nombre de huit rangés en rond, en quarré, en demi-cercle, en trapèze, en parallélipipède, enfin de plusieurs autres manières, selon les espèces. La bouche est armée de fortes inâchoires avec lesquelles l'ardignée saisit et tue sa proie. Les antennes sont composées de plusicurs pièces articulées; les palpes dú ruâle sont teminés par un bouton, qui renferme les organes de. la génération.

Les mammelons placés à l'extrérnité du ventre sont autant de filières, par lesquelies sort 


\section{D'Fistoder Natureite. 385}

sort cette liqueur qui devient solide comme In soie avec le contact de l'air, et dont le tissu de leur toile est composé. Cette toile a des contours différens selon les espèces. Tantôt elle est tendue perpendiculairement et formée de fils rangés circulairement autour d'un centre commun, où l'insecte se tient en embuscade. Les araignées domestiques placent leur toile horizontalement dans les encoignures des murs et des feriêtres. Les araignées de caves tapissent d'une toile le trou qui leur sert de retraite, et ne filent que quelques soies au dehors. Les araignées d'eau attachent sur les plantes aquatiques de légers fils. Quelques araignées vagabona'es et sauteuses courent après leur proie sans lui tendre des filets. C'est toujours au centre de la toile que chacurie d'elles se tient. İaraignée, avertie par le plus léger mouvement, accourt; si l'insecte est petit, elle l'emporte dans son trou; s'il est gros, elle le garotte avec quelques fils, l'emporte avec elle, ou le dévore sur la place, et travaille aussi-tôt après à réparer le dégât. Elles se font souvent une guerre cruelle, s'emparent réciproquement de leur toile et se dévorent mutuellement. La f́emelle dépose 
dans son nid des ocuf's ronds renfermés dans une coque de soie. Ils éclosent promptement, et les petits se mettent ì filer aussi-tôt après leur naissance. Le nombre des araignées décrites jusqu'à ce jour s'élève à plus de cent cirnquante espèces.

5. Le scorriona les pattes antérieures armées de pinces, et le ventre terminé par une queue longue et noueuse, dont le der nier anneau renferme un aiguillon venimeux. On le trouve dans nos départemens inéridionaux.

6. Le crabz. Cet insecte a dix pattes dont les deux premic̀res sont armées de fortes pinces. Tout son corps est couvert d'une croûte calcaire, qui âfait donner aux insectes qui ont des rapports arec lui le nom de critustacés.

La forme des crustacés est cxtrêmement variéc. Les uns sont larges comme le crabe commun, d'autres alongés comme le homart qu'on pêche dans nos mers, et l'ćcrevisse qui est vulgaire dans. nos ruisseaux.

Cette derrière espèce a la tête grosse, denx longues antennes, le corcelct d'une seule pièce, la queue longue ct garnie en dessous de ficullets frangés. Les dix pattes 
font attachées au corcelet, celles 'de devarit' sont en forme de pinces. Lá mâlc a les parties de la génération vers'íorigine de celles de derrière. La femelle a une grande quanzité d'oufs qu'elle porte snus la quẻue. Cet insecte est très-vorace. Ses membres coupés ou cassés se régénèrent; il change au printemps d'enveloppe et d'estomac. On appelle frussement ycux d'écrevisse des concrétions pierrenses qui se trouvenl dams cet estomac, et qui paroissent être la matière destinée à la reproduction clu test. I a chair des écrevisses est nourrissante et de bon gout. L'animal rougit au fer. On le prend en le saisissant clans ses trous, ou en l'embarrassant dans des ragots.

7. Le croporte a quatorze pattes et des antennes coudées. Son corps est formé de dix anneaux couverts de lames dures. 11 change de peau plusieurs fois; on distingue l'armadille qui se ronle en boule quand on veut le saisir, et le cloporte commiln que tout le monde connoît.

8. La scoloreñre est appellée insecte d mille pieds, à cause du nombre le ses pattes. Elle a le corps applati, on la trouve sous Los picres, clle court vîte et en serpentant. 
On distingue les espèces par le nombre des pattes; unc en a vingt-huit, l'autre trente, l'autre soixante, l'autre cent quarante-quatre, etc.

9. L'IU L e ressemble beaucoup à la scolopendre, mais son corps est cylindrique. Les espèces se distinguentaussi par le nombre des pattes; on en compte deux cent dans l'iule terrestre, ot deux cent quarante dans l'iule sablonier.

\section{I. V E R S.}

LES VERS n'ont point de tête bien conformée, tous manquent de pieds, ils aiment en général l'humidité. Quelques-uns ont des appendices mobiles et rétractiles nommés tentacules; presque tous régénèrent leurs parties amputées. Ils sont mols, nuds ou couverts d'un test calcaire. Leur cœur est formé d'une suite de ncuds qui se contractent les uns après les autres, leurs vaisseaux sont très-petits, leur sang est froid. et sans couleur. Ils sont souvent enveloppés 
d'Historme Natuxzix. 389 d'un inucilage visqueux, la manière dont ils respirent est inconnue, leur estomac est très-irrégulier, ce n'est souvent qu'un vaisseau continué dans leur longueur, ils sont très-peu sensibles. Toutes ces propriétés les ont fait distribuer en six ordres. 


\section{ORDRES DES VERS.}

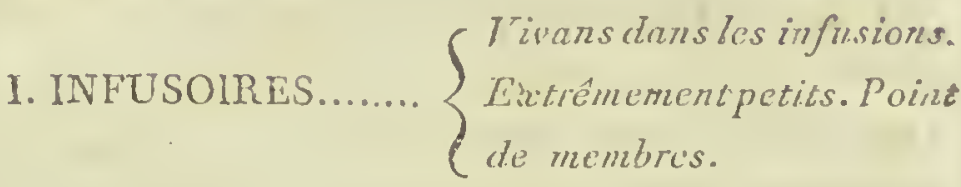
II. INTESTINAUX... $\left\{\begin{array}{l}\text { Tivans dans le corps des } \\ \text { animaux. Point de meri- } \\ \text { bres. }\end{array}\right.$ III. MOLLUSQUUS.... Ponrites de incmbres. IV. ECHINODERMÉS. Converts d'unc peau coriace. V. TESTACÉS..女a..... $\left\{\begin{array}{l}\text { Enfermés dans une co- } \\ \text { quille c.Ilcaire. }\end{array}\right.$ VI. ZOOPHITES....... $\left\{\begin{array}{l}\text { Formans des expansions } \\ \text { semblables à des flenrs. }\end{array}\right.$

\section{I N F U O I R E S.}

CES VERS scnt mous, transparens, infiniment pelits ct presque toujours impcrceptibles à la vue simple. Ils se muliplicnt par les oufs et par une division, qui s'opère 


\section{d'Historine Naturelte. 3gi}

naturellement sur leur longneur ou leur lar. geur; ils sont presque tous aquatiques. On les nomme infusoires, parce qu'on les trouve dans des infusions, tellos que les eaux croupies, le vinaigre, le jus des viandes, le lait.. ctc. Les uns ont des organes extérieurs, d'autres en sont privés. Nous ne pouvons pas entrer dans de longs détails sur des êtres si difliciles à observer, il suffira d'indiguer les plus singuliers.

* Sans organes extérieurs.

I. L $\mathrm{x}$ r O TÉ E ne se roit quavec l'instrument apıelé microscope, dont la propriété est de grossir les petits objets. Il paroît composé de molécules homogyènes, qui forment un corps elliptique avec un long col'terminé par un noul, mais sa forme varie sous l'ceil même de l'observateur. Il hubite dans l'eau long-temps conservéc.

2. Le vorvox est arrondi, on le trouve dans l'eau oì nil a mis des plantes il infuser, il esi blanchâtre ou o:angé. Il reriferme un globule, qui sort quand il a rompu la prenière enveloppe, ct contientlui-mêne d'autres globulcs qui paroissent succossive- 
ment de la même manière; de sorte que cet aniunal porte en lui-mêne son fils', ses petitsfils et leurs nombreux descendans. Ontrouve dans d'autres infusions d'autres espèces du même genre.

3. Te viBnion a le corps filiforme. Les petits vers en forme d'anguille qu'on observe dans la colle de farine, dans plusieurs sédimens végétaux et dans le vinaigre, sont de ce genre.

* Luec des organes extériezers.

4. La von Ticelle a l'extrémité supérieure garnie de cils. Les animaux de ce genre sont connus vulgairement sous le nom de polypes dieau douce. Ils s'attachent aux plantes. Plusieurs bras disposés en ombelles sortent d'une même tige, et deviennent euxmêmes la base de nouvelles ombelles. Si on les coupe, ils se reproduisent.

\section{I. I N T EST I NA U X.}

CEs virs sont simples, nuds et sans aucuns membres; leur corps est long, articulé et composé d'un bout 'autrę de segmens 
n'Historte Naturele. 3,3 annulaires. On les nomme intestinaux, parce qu'ils habitent ordinairement les intestins des animaux; ils vivent principalement dans les eaux, quelques-uns dans la terre. Les uns ont le corps arrondi et filiforme, d'autres sont plats comme une bandelette. Ils sont dépourvus d'yeux, presque tous réunissent les deux sexes. Leur étude est très-intéressante, à cause du dérangement qu'ils occasionnent dans l'économie animale.

On distribue les espèces de chaque genre, selon l'ordre auquel apparticnt l'animal dans lequel on les trouve.

\section{* Corps nu.}

1. LE DRACONEAU est un ver extrênement lisse, long et filiforme, égal dans toute sa longueur, qui se trouve en Asie et en Afrique. Il pénètre dans les pieds des hommes qui marchent sans chaussure, et $\mathrm{y}$ cause une douleur vive.

2. Les ascapidis. Ces vers ont le corps cylindrique, articulé. Les extrémités sont inégales. Ils sont très-communs, et tourmentent tous les animaux. Celui gu'on trouve le plus communément clans les intestins de 
304 ELE M E N

Thomme est l'ascaride vermiculaire. II canse vers le soir des chatouillcmens incornmodes, et multiplic avec une grande promptitude. Quel ques espèces d'ascarides ne se rencontrent que dans les intestins cies pois. sons.

3. La sangSu a le corps cylindrirue, tronqué et dilatable à chaque extrémité. Elle suce le sang des animaux, en s'appliquant anx parties les plus délicates qu'clle entame arec sa trompe, et avec le triple dard dont sa bouclie cst armér. Elle se gorge de sang jusqu' à l'assoupissement. Flle marche en s'appuyant sur sa queue, avec larjuelle clle peut aussi se suspendre. Ellc habite les ruisseaux. Conscrvée dans un bocal, elle se montre sensible aux variations de l'atroosphère, c'est un baromètre vivant. On peut la garder ainsi des années eniières sans lui donner aucune nourriture.

4. LA TAE N A est blanc, et composé d'anneaux applatis. Sa tête est accompagnée de quatre suçoirs; c'est celui qu'on nomme vulgaircment ver solitaire, é cui cause dans l'estonac de l'homme de si horribles ravages. On en compte un grand nombre d'espèces qui affectent des formes très-diffé- 
D 'Historats Naturetz. 395 rentes, et qui attaquent les animaux de tous les ordres. On les nomme taenia, parce qu'ils ont l'apparence d'un ruban. Le tænia de fhomme a quelquefois jusqu'à six mètres de longueur.

\section{* Corps cilié.}

5. LE I o M r R I se nomme vulgairement ver de terre. Son corps rouge est cylindrique et composé de plus de cent anneaux garnis de cils, et tous semblables à l'exception d'un renflement qu'ils éprouvent vers le trentième; sa bonche est p'acée sous le prenier. L'extrémité postérieure est terminée par une membrane échancrée. Il rampe en allongeant et en contŕactant son corps. Il vit plusicurs années, on le trouve dans le bois pourri et dans la terre humide. Il ronge les cotyledons des plantes. Plusieurs anisaux en font leur nourriture. Si on le coupe par morceanx, chacun d'eux remue encore long-temps. Les pêcheurs en font un appas pour les poissons. 


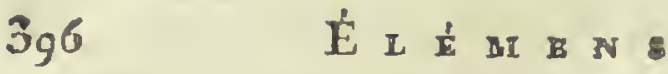

\section{M O L L US Q U E S.}

C ES VERS sont nuds comme les intestinaux, mais ils sont articulés et ont des soutiens et des tentacules. Quelques-uns vivent sur la terre, la pluppart nagent dans la vaste mer. Plusieurs domnent la nuit une lumière phosphorique qui éclaire sa surface. Nous ne citerons que ceux qu'il est facile d'observer.

1. La I I corps allongé a sur le dos un écusson char$\mathrm{nu}$, et au-dessous mn disque allongé et plane. Un trou latéral clonne passage aux excrémens et aux organes de la génération. Elle a deux tentacules rétractiles terminés par des globules que quelques naturalistes ont regardé comme des yeux. Ces animaux vivent plusieurs années, ils déposent sur la terre des petits œufs mous et blanchâtres : nous en connoissons plusieurs espèces. La limace brune, dont la peau silionée et pleine de rugosités est bordée d'une sorte d'e membrane qui se termine en pointe. La limace marbrée qui vit prircipalement dans les caves; on la suit aux traces luisantes de sa mucosité. 


\section{d'Historke Naturite. 397}

La limace cendrée est beaucoup plus petite que les autres. On la trouve fréquemment sur la salade. Ces vers sont en général très-voraces, ils aiment l'humidité et sortent, sur-tout la nuit, pour dévaster les jardins et les vergers. Plusieurs oiseaux et principalement les coraces et les ansères en font leur proie. Leurs tentacules coupés se reproduisent.

2. La SEICHe est'couverte d'une peau molle, son corps est enfermé dans un fourreau charnú, et accompagné de deux tentacules et de huit bras, intérieurement parsemés de verrues. Son bec allongé est d'une substance cornée. Son dos est défendu par une écaille assez solide d'une seule pièce, qu'on nomme os de seiche. Cet animal se mange de plusieurs manières. L'os de seiche est léger, uni, blanc, ovale et grand comme la main. Les orfèvres en font des moules de cuiller, de bagues... etc. On en suspend dans les cages des petits passereaux pour aiguiser leur bec, et les oiseleurs le connoissent sous le nom de biscuit de mer. La seiche répand souvent une humeur noire, qui trouble l'eau et la clérobe à ses ennemis, ou empêche sa proie de lui échapper. Cette liqueur peut 


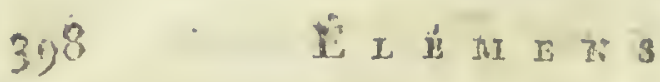

servir à faire le l'encre, on croit que c'est la base de l'encre dé la Chiné. La seiche mange les animanx plus peits, elle est elle-mêne la victime de ceux plus gros qu'elle. Les baleines en dć vorent une grande quanticé, et l'ambre gris qu'on retire de l'estomac du cachalot est rempli de becs - de sciche, ce qui le fait regarder comme le produit de cette nourriture mal digérée.

\section{IV. $\mathrm{CHINO}$ D E R M ES.}

CIS Vrins ont le corps couvert d'une peau coriace et dure, et d'une croûte osseuse, très-poreuse, parsemée à l'intérieur de tentacules et d'épines articulécs.

1. L'asterie. Ce var plus connu sous le nom d'éloile de mer, mérite son nom par sa ligure étoilće. Le nombre de ses pointes et lcurs dispositions préscntent une grande multiplicité de formes. L'espèce la plus commune est celle à cinq rayons. Toutes ont dans leur centre une ouverture à plusicurs valves, qu'on nomme la bouche. De chaque rayon sortent sur plusieurs rangs une mulsitude de suçoirs que l'animal allonge, ou retire à volonté. Quand un de ces rayons est amprté, il se répare. 
d'ilistorte Naturtile. 399

2. L'Échrnús nommé vulgairement oursin de mer, à cause des piquans dont il est hérissé, est applati ou sphérique, toujours couvert d'une croûte osseuse; il est composé d'une multitude de piòces réunies par des sutures légères et couvertes d'une mulitude de pointes, qui tombent souvent avant la mort de l'animal, dont les a pophyses laissent voir sur le test des trous sans nombre. Ces piquans de différentes formes et de différentes grosseurs servent de pied à l'animal qu'ils font tourner sur lui-même. L'aaus est placé dessus, dessous, ou latéralement selon les espèces. On les classe d'après leur forme sphérique, oroide ou applatie. Les oursins se mangent, ils ont le gout des écrevisses. On trouve souvent des oursins pétrifiés, ces fossiles se nomment échinites.

\section{TES TAC I S.}

LES T⿱R TACÁs sont couverts d'une enveloppe osseuse appellée coquille. Les vers qui habitent ces coquilles sont mous, ils tiennent par un ou plusieurs inuscles à cette enveloppe, qui les garantit de toute espèca 


\section{E L E M E N}

de choc, et dans laquelle ils se renferment au moindre danger.

La substance de la coquille est analogue à celle des os des animaux; elle est forméede denx substances de nature différente, l'une membraneuse, l'autre crétacće, unies par juxt'apposition.

Ces vers sont en général vivipares. Dès la naissance du petit animal la coquille est déja formée ct proportionnée à son volume, elle prend avec lui de l'accroissement.

Les testacés sont marins, fluviatiles ou terrestres, et ne peuvent changer de milieu sans danger. Quelques - uns se nourrissent des sucs de la terre, d'autres rongent les bois, d'autres les fruits. C'est au printemps que le mâle et la femelle se recherchent, et il y en a qui demeurent accouplés plus d'une décade; d'autres ne se trouvent que fossiles, leurs analogues vivans n'existent plus; ce sont des monumens précieux qui attestent le séjour des mers sur la terre et la hante antiquité du globe, aussi leur étude est-elle également utile et intéressante. Ces vers servent de nourriture à beaucoup d'animaux, nous en mangeons nous-mêmes plusieurs cruds ou apprêtés; on peut en tirer 


\section{D'Historre Natureict. for}

tirer des matières colorantes, ils nous fournissent la nacre et les perles dont on fait tant de riches ornemens. On peut les convertir en chaux. Les bans immenses de marbre, de pierre à bâtir et de craie que nous exploitons, sont formés, comme nous l'avons vu, par des amas énormes de coquilles entassées,

Les coquilles fournissent à la médecine des remèdes absorbans. Quelques-unes sont si transparentes qu'après les avoir amincies et réduites en lames, clles tiennent lieu de nos vitres. On façonne-avec d'autres des boëtes, des lampes et toutes sortes de vases. Les Egyptiens se servent de coquilles pour polir. Les Tarentins font des tissus délicats avec les soies de la pinne marine. On figure des fleurs et des animaux en assemblant des petites coquilles de différentes couleurs; quelques espèces sont si poignantes qu'elles servent de stilet; enfin il y en a une qui est en Guinée la monnoie courante.

Les coquilles sont formées d'une, de deux ou de plusieurs valves; cette disposition seryira à les diviser. 
402

$$
\text { t } x \text { E } \text { AI E N S }
$$

\section{* Coquilles multivalves.}

O $\mathrm{N}$ appelle ainsi celles qui sont composées de plus de deux pièces, elles sont souvent si bien réunies qu'elles paroissent n'en faire qu'une seule. Elles sont égales, ou inégales. La coquille est quelquefois fixée par une de ces pièces à des corps solides, elle est d'autrefois libre ou soutenue sur un peduncule tendineux. La base des multivalves est cetie partie sur laquelie elles sont supportées pendant que l'animal est vivant. Les valves sont attachées par un ligament écailleux, lisse, ou hérissé. Le ver est mou, charnu et terminé en avant par unc ou deux ouvertures en forme de trompe. Ces coquilles sont moins nombreuses que celies des autres divisions. Les principales sont:

1. L'osca brion composć de plusieurs valves transverses tuilées, convexes en dessus, concaves en dessous ct réunies sur leur bord par un ligament. Cetre coquille est ovale, elie ressemble assez par sa forme an cloporte, aussi l'appelle-t - on vulgairement cloporte de mer. Ce ver s'attache aux plantes et a quelques cétacés, ce quil'a fait aussi nommer pou de baleine. 
D'Histotre, NAturesto 403

2. Le taret a une coquille tubulée, cylindrique, ouverte aux deux houts. L'orilice ijıtérieur est pourva de deux valves: ce ver ronge les digues, les vaisseaux et les pieux enfoncés dans la mer; il y trace des sillons profonds en prolongeant toujours le tube qui l'enveloppe. On le connoît vulgairement sous le nom de ver des digues.

3. La phorade est composée de deux grandes valves bâillantes et d'une ou plusieurs petites valves placées en dehors sur le ligament. Ce ver ronge les rochers calcaires, ou il se creuse une demeure.

\section{* Bivalves.}

CEs coquilles sont composées de deux pièces, on les"nomme aussi conques. Le ver est à-pen-près conformé comme celui des multivalves. Les valves sont égales ou inégales, ćpineuses, sinueuses, rayées, striées..etc. En tenant la coquille sur le sommet et ayant en avant le ligament cardinal, et la lunule en arrière, on appelle valve droite ou valve ganche, celle qui répond à l'un de ces deux côtćs. Juenr partie la plus enflée forme une élévation qu'on

C $\mathrm{C}_{2}$ 


\section{EL I I I I 5}

appelle ventre; la chamière est la partie la plus épaisse de la circonférence des ralves; elle est comprimée, échancrée, lacérale, oblongue, terminale, tronquée et toujours accompagnée de dents de proportinns différentes, qui servent à fixer les valves les unes contre les autres. Ces dents sont des excroissances solides ordinailement pointnes. Elles sont alternes, antérieures, bilicles, comprimées, longitudinales; elles sont reçres dans des fusscttes opposées. Les valves portent souvent des cicatrices cansées par l'impression des muscles. Qnelques valves ont des oreilles égales on inégales. En général les coquilles bivalves sont adlićrentes à quelque corps solide, ou libres; bâillantes ou exactement fermées, barbues, comprimées, cylindriques, linéaires, équilatérales, pectinćes, auriculécs, radiées, rhombiidales, accompagnées d'un bec en forme de caur... etc. Celles dont le contour, l'épaisseur et la forme varient sur tons les individus d'une même espèce sont irrégztlières; celles qui se ressemblent scus ces trois rapports sont régulières. 
n’Hitora Naturede. 405

\section{+ Coquilie irréguliire.}

1. L'I U iтre a une charnière sans dents, une goutlière sillonée, où cst logé le ligament; ses valves sont compósées de plasieurs écailles informes, sa surface est raboteuse, l'animal se mange crud ou cuit : celle qu'on nomme l'hûtre comestible est la plus commune, on en pêche une énorme quantité. On construit sur le bord de la mer des pares pour les engraisser.

\section{++ Coquille régulidre.}

2. La it y a la charnière composée d'une dent non-articulée. La plus commure est la mye des peinties, ainsi nommée, parce que sa coquille épaisse et solide sert à mettre des coule ur's.

3. La PINAE a la coquille oblongue et bâillante à ses extrćmitćs supćricures. La charnière n'a point de dents. Les valves sont sculement attacliócs par m ligament; les coquilles de ce genre sont garnies d'une soie qui se tisse et se travaille comme celle de la phalène du milier. Le ver est excellent à manger.

$$
\text { C c } 3
$$


4. La soun ressemble beaucoup à la yinne, mais cile est entièrement fermée. Sa chaniòre cst quelquefois garnie d'une ou de deux dents. L'espèce la plus cominune est lat moule comestibie, dont le ver s'apprête dé plusiems marières. I a monte maygrilifüre, qui se tromve dans l'ucéan Indien, cst plate et orbiculaire. Ses valves cizclées servent à faire des boëtes et différens ouviages; c'est la nacre a'e perle. La substance qui la produit se secrète souvent en un globule isolé, qu'on appelle perte. Une coquille cn contient quelquefois plusicurs; clles different de prix, selon leur grosseur et leur qualité; les phas belles sont les perles i'Orient.

5. La terine a une forme orbiculaire, elle est marcuée d'un pli sur le côté antérieur. Sa charnière est composée de trois dents; il y en a me qu'on appelle telline die ruisseath, parce qu'elle y est commune.

6. Le soinx'a les valves très-longues, hâillantes à leur. extrémité supérieure. On le nomme aussi manche de contcau.

7. Le BUCA R D est ainsi appcllé, parce que sa forme approche de celle d'un cocur. 
d'Histota Naturerce. 407 On l'apprelle anssi cour de bouf. On en cu.npte beancoup d'espèces.

8. Le perg ñ a des oreilles. Sa surface est orlinairement marquée de stries profoules, ce qui lui donne quelque ressemblunce avec un peigne; ce genre est nombiens; on en tronve beaucoup de fragmens dans les pierres coquillières.

\section{*** Utrivalves.}

LEs coquilles univalves sont composées d'une seule pièce. La partie supérieure est furmée par la spire, qui se compose des différens tuurs de la coquille autour de son are qu'on appelle columelie, et qu'on ne pent bien appercevoir qu'en sciant la coquille. La base entière ou échancrée est oplosée à la spire.

Les tour's de la spire sont creusés en goutic̀re, ou relevés en carènc. Ils oftrent des dents, destuivercules, des points, des épines, des découpures, des stries, des bandes, des treillis; ils vont de droite à gauche, et rarement de gauche à droite.

La spire, qui présente leur rémnion, est C c 4 
convere, creuse, obtuse, èlevée, tronquée; pyramidale, pointue ou. couronnée.

I.e dos est la partie bombée, opposée d̀ l'onverture de la coquille; le ventre est le dernier tour de la spire. Quelquefois l'axe autour duquel la spire tourne, forme une cavité centrale qu'on nomme ombilic, et qui ressemble en effet it un nombril.

L'ouverture qu'on appelle vulgairement la bonche, est lit partic par laquelle l'animal sort et rentre dans son intérieur; elle présente des différences qui servent à caractériser la coquille; clle est anguleuse, applaiie, linéaire, longitudinale, orbiculaire, ronde, arrondie, rénversée, bâillante... etc.

Toutes ces diférences dans ses parties donnent il la coquille univalve la forme d'un disque, d'un ovale, d'une sphère, d'mne olive, d'un fuseau, d'un sabot... etc.

\section{+ Coquille uniloculaire.}

$\mathrm{O}_{\mathrm{N}}$ appelle ainsi celles qui n'ont qu'une cavité non-interrompue.

1. La satere est la plus simple de 
- 'Fistoire naturitiz. 409 toutes les coquilles; elle ressemble à ưne petite écuelle ovale, son sommet est pointu et quelquefois percé. L'animal s'attache aux rochers les plus lisses, et il faut assez d'efforts pour l'en sćparer. Elle fournit aux habitans les côtes une nourriiure abondante: l'ancyle qui se trouve sur les joncs est une patelle fluviatile.

2. Le CôNE doit son nom à sa forme; son onyerture est longitudinale, étroite, sans dents. On appelle couronnés ceux dont la spire forme une couronne, d'autres l'ont tronquée, d'autres convexe. On en connoît plus de cent-cinquante espèces. Le plus commun est le cône tiģre, ainsi nommé à cause des taches dont il esi parsemé.

3. La porcelarive a aussi l'ouverture longitudinale. Ses lèvres sontsouvent dentées; son dos est bombé. Il y a dans les cabinets un giand nombre de belles espèces de ce genre; la plus utile est le carcris qui est ovale, blanos et parsemé d'élévations en furme de loosse. On va le pêcher aux îles Maldives, et il sert de monnoie cu Guinée, ce qui l'a f'ait appeler vulgairement monnoie de Guinée. Lues pelites espèces de porcelaines servent à fajze des colliers, des bra- 
celets et d'autres ornemens. Les grosses espèces servent à fairc des tabatic̀res.

4. L'oxive a la coquille presque cylindrique, échancrée à la base, la culusuelle marquée de stries ubliques.

5. La rolute est touméc cn spirale comme le cône, mais l'onverture est plus large. La columelle est dentée ou plissée.

6. Le в C CCI a est oblong, ventru, son ouverture est lerminée à sa base par mne ćchancruse ublique, sans canal sensible ni rebord extérieur. On compte dans ce genre plusieurs belles espèces. La plus commune dans les cabiicts est la harpe, dont la forme approche cin efet de celle de l'instrument de ce nom. Le ver du bucciu teinturier fournit une lípueur rouge analogne d̀ la pourpre des anciens.

7. La pourris est épineuse ou tuberculće Son ouvcrume est terminée par un canal très-court, et par une petite écharlcrure oblique; la couleur pourpre des anci ns cst due au ver d'une coquille de ce genre.

8. Le casque a la coquille bombée, l’ouverture dentée, terminée à la base par une 
d'Histoire Naturelis. 4 ti échancrure, dont les bords sont repliés vers le dos.

9. Le Fus a u est terminé à la base par un canal droit.

10. La v Is est turriculóe; son ouverture est terminée à la base par un canal trèscourt, large $\in t$ échancré.

11. La toup e est conigie, son ouverture est presque quadrangulaire. Ia columelle est percée obliquement.

12. Le sABот ressemble beaucoup à la toupie, mais il a la bouche arrondie. Ces deux genres renferment beaucoup d'espèces; le sabot vivipare est commun dans la Seine.

I3. Le buline est globuleux, ovale, ou turriculé; són ouverture est entière, point échancrée à la base, et toujours plus longue que large. Plusieurs espèces de ce genre te!les que le bulime des murais, le bulime stagnal, le bulime racitis, se trouvent dans les eaux douces; quelques-anires, telles que le buline des mousses, dans la terre humide; d'autres se rencontrent sous l'écorce des arbres qui croissent dans les lieux arrosés; ils sont d'une extrême petitesse, tels sont le bulime grain d'orge, et le bulime morlsseron... etc. 


\section{2

14́. L'HÉLICE a ses spires tournées en volute plus ou moins allongće. L'ouverture est plus large que longue et en croissant. Plusienrs cspèccs sont terrestres, et se rencontrent dans nos environs. Les plus communes sont l'hélice jartinicire connuc valgairement sous le nom de linass, limaçar, colinaçon, cscargot et l'hélice vignerone, qui est beancoup plus grosse. Ces deux espèces font beaucuup de dégats dans nos jardins, dan's les vignes et dans les vergers. L'animal se renferme l'hyver sous une opercule furméc par une conche éjaisse de sa mucosilé dessćchée. Ce ver se mange, on cn fait des bouillons pour les marx de poitrine. On trouve encore dans los jardins une jolie espree, plus pelite et plus plate, jame ct rayée de brun, qu'on appelle la livée.

15. Le I I $\mathrm{N}$ ORBE se distingue de l'hélice par sa forme discuilic des deux cốtés. Ses spires sont roulécs sur un plan horizontal. Le planorbe corné est fort commun dans les ruisscaurs et les élangs. On le nomme vulgairement cornet de Saint-IIubert; le ver donne une couleur rouge; on trumve sous l'écorce des sanles d'autres planorbes 


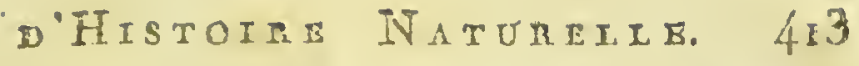
extrêmement petits. Toutes les espèces de ce genre sont fluviatiles.

16. La NÉRTE a une onverture demironcle, terminée par une columelle dentée. Les petiles coquilles rayées, dont le sable des rivières est parseıné, sont des nérites.

17. L'haliotide est très-applatie et percée de six à sept trous placés sur une ligne parallèle. Elle est nacrée en dedans, ridée en. dessus. Sa forme la fait nommer vulgairement oreille de mer.

\section{++ Coquille multiloculaire.}

CE sont celles dont la cavité est interrompue par des.cloisons ou des étranglemens qui forment autant de loges distinctes.

1. L'amonite. On appelle aussi les coquilles de ce genre cornes d'Anmon, à cause de la ressemblance que leur donnent les plis de leur spire avec la corne du bélier. On n'en connoît point encore d'espèce vivante; celles qu'on trouve dans les cabinets sont toutes pétrifiées ou miñéralisées, c'est-à-dire que leur substance, en se décomposant, a été remplacéc par des sucs pierreux ou minéraux. 
4If EI ́x M I N S

2. Le NAUTIX est ainsi nommé parce qu'il ressemble à me nacelle; les saurages en font des vases a boire.

\section{Z O O P.H T T E S.}

C ES Virs ont l'extrémité supérieure perforée et garnie circulairement d'un rang de tentacules simples ou composés. Ils sont contenus dans des cellules calcaires, cornées, coriaces, oufibreuses, qui constituent par leur rénnion des masses informes, ou des tiges branchues ordinairement fixces par leur base et composées d'une ou de deux substances différentes. Ces animaux en étendant leurs tentacules ressemblent à des fleurs. Cette propriété et leurs tiges les avoient autrefois fait classer parmi les végétaux. On sait aujourd'hui que ce sont de véritables animaux. On les classe d'après la figure de leur demeure, qu'on nomme en général polypier. On distingue dans cet ordre.

1. Le tu bipon e composé de tubes perpendiculaires terminés au-dessus par un rebord applati et radié. 
D'HIStotre NAtrete. 415

2. Le MI DRÉpor E composé de cavités gamies également de lames radiées.

3. Le MÉ ANDRTE dont la superficie offre des sillons sinutux, larses et profonds. Leurs parois sont ganies de lanes obliques, parallèles et alternes.

4. Le IILLEORE. Sa superficie est parsemée de pores très-nombreux disposés sur plusieurs rángs.

5. La C ORALIINE est composée de fibres tubulées, divisées en plusieurs articulations calcaires. Il y a une espèce nommée vulgairement coralline de Corse, qui, réduite en poudre, est un spécifique contre les vers dont les enfans sont tourmentés.

6. La corGon a une tige cornée, branchue, formée de couches concentriques, couverte à l'extérieure d'une enveloppe poreuse, vasculeuse ou friable, et parsemée de cellules dont chacune contient un polype. C'est à ce genre qu'appartient le corail qu'on pêche en grande abondance dans la Méditerranée, et dont on fait des colliers et des bijoux. Réduit en poudre, on s'en sert pour nétoyer les dents.

7. L'E R O G E a une tige fibreuse, flexible, très-poreuse, simple, tabulée ou ratuiliée. 


$$
416 \text { I I I } 1 \text { × }
$$

Sa superficic est couverte d'une glaire peu sensible et parsemće d'ouvertures qui absorbent l'eau. On en trouve une espèce dans les rivières, une autredans les lacs c' les étangs, mais la plûpart habitent les mers d'où on les tire. Tout le monde connoît l'usage de l'éponge ordinaire.

\section{F I N.}




\section{T A B $\mathrm{E} E$}

A L P H A B E T I Q U E

Des Genres, des Espèces, des Synonymes et des Termes.

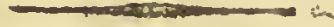

A

A Abdomina!. 299 Agaric. Abdominaux. 30,-3x8 Agathe. Abeille. 356

Able. femelle. -

Abricot. Abricotier. Abrus. Acacia. Acajou. Acanthe. Accipitres. Acides. boracique. carbonique. -formique.

357 maçonne. mále. ouvrière. perce-bois. nitrelix. nitro-muriarique 33 Acier. Aconit. Adragant.

363

357

$35^{8}$

363 324 159 ibid. I6/4 ibid. 160 103 Ailes.

244 Ailorons.

25 Aimant.

34 Air fxe.

25 atmosphérique. 352 infamnable.

33

bid. 46 i 34 I8 I

Aggrégation. nuéc. tacise.e. Agreau. Asigle. Aiguc-narine. Aire. Airain. Ajonc. herborisée. ilvid mousseuse, ibid. veinée. ibid. uny. ibid.

9 ibid. ibid.

192 ibid. ibid. 246 47 162 153 


\section{8}

Albâtre.

Alcohol.

Algues.

Alk "lis.

Alkekenge.

Aloës.

Alose.

Alouette.

Alumine.

Alun de France. de Naples. de roche. de Rome.

Aluner.

Alvéoles.

Amadou.

Amalgame.

Amandier.

Amaranthe.

Ambre giis. juune

Amentum. Améchiste.

Amianthe.

Amidon.

Ammoniaque.

Ammonite.

Amphibies.

Anagallis.

Anale.

Analyre.

Ananas.

Ancyle.

Anchois.

Ancolie.

Ane.

Anesse.

Anemone.
$T A$ B $L$

$\begin{array}{rlr}\text { I7 } & \text { Angélique. } & \text { ibid. } \\ 7 \text { I-141 } & \text { Angora. } & 206 \\ 80 & \text { Anguille. } & 315 \\ 24 & \text { Anmimux, } & 184 \\ 108 & \text { Annés. } & 3 \\ 95 & \text { Anon. } & 220 \\ 322 & \text { Ansères. } & 276 \\ 263 & \text { Antennes. } & 327 \\ 12-25 & \text { Anthère sessile. } & 59\end{array}$

27 réunies. II

ibid. composées. ibid.

26 Antimoine. 41

27 Anthropophage. $\quad 19^{6}$

ibid. Anus. 183

3 Apo Apocyn. $\quad 110$

79 Apodes. $\quad 304-310$

4C-42 Appel. 242

I60 Appétits $32 \mathrm{I}$

ro1 Apprivoisés. I95

234-398 Apteres. $3 \%$

$3^{8}$ Araignée. $\quad 384$

173 Aras. 252

ibid. Arbreà pain. I71

12 Ardoise. $\quad 44$

14 Arćque. 93

73.87 Argent. 49

25 Argile. $22-13$

413 Argus. 372

280 Armadille. $\quad 387$

102 Armoise. I24

299 Aromatiques. $\quad 76$

72 Arome. 72

94 Arpenteuses. $\quad 369$

469 Arète-bœuf. 16;

322 Arroche. IOI

134 Arsenic. 40

219 Artères. 191

220 Articliaud. I20

I3) Asaret. $9 \$$

desjardins. ibid. Ascarides. $\quad 393$ 
A. I $A$ B 1 E I Q U E. 419

Ascaride vermiculaire. $39+$ Auditif. $\quad 187$

Asperge.

Asphalte.

Astérie.

96 Autour.

247

37 Autruche. 272

Astres.

Astronomie.

398 fivoine.

90

10

Atmosphère.

Atropos.

Aubepin.

Aubier.

$\begin{aligned} 3 & \text { Aventurine. } \\ \text { ibid. } & \text { naturelle. } \\ 192 & \text { artificielle. } \\ 374 & \text { Axonge. } \\ 156 & \text { Azerollier. } \\ 66 & \text { Azote. }\end{aligned}$

B

Bacinav.

I35 Bauciruche.

Baguenaudier.

I64 Baumes.

63 Bec.

Baie.

137 Bec croisé.

73

Bain de gaude.

Balariciers.

Balbusard.

Baleine.

Bâles.

Balsamine.

Bananier.

Baudes.

Banes.

Baobab.

Barbe-de-bouc.

329-379 Bec-de-grue.

234

256

142

319

246 Becard.

232 Bécasse.

85 Bécassine.

274

ibid.

I 42 Bédeguar. $\quad 258$

97 Belerte. , 208

I90 Bélier.

301-320 Belladone.

I49 Belle-dame.

223

108

ibid.

120 Belle-de-jour., 109

323 Belle-de-nuit. $\quad 102$

Barbeau.

Barbet.

Barbillon.

Bardeau,

Baromètre.

Bartavelle.

Basalte.

196 Benjoin.

323 Bête-à-Dieu.

99

342

221 Bétoine. 113

42 Bette. IOI

ibid.

50 Biche. 227

Base.

Basilic.

Biction.

202

214

138

Basset.

202 Binage.

Bátiment de graduation. 28 Biscuit de mer.

397.

$\mathrm{D} \mathrm{d}_{2}$ 


\section{TA B I E}

Bismuth.

Bisulces.

41 Bourbeuse.

228

Bitumes.

Bitume de Judée.

190-221 Bourdon.

Bivalves.

Blaireau.

Blanc de baleine.

36 Bourgeors.

37 Bourre.

403 Botivenil.

160

197 Bracićes.

2,6

234 Braire. de chanupigrion. 78 Brasier. de fard.

de plomb. de Troie.

Blatte. 41 Brebis.

45 Brêche.

16 Brême.

Bleu de Prusse.

Bleuet.

347 Biques.

46 Bryone.

Blé noir.

Bluteaù.

Bocard.

Bocardés.

122 Brochet.

100 Brucheton.

$\varepsilon 6$ Bronze.

64

220

.88

$2=3$

18

325

13

169

$3=0$

39 Brosses.

44 Brossière.

Bocuf.

222 I3rou.

Bois de campêche.

Bois de cerf.

Bois d'Inde.

$16 ́ 2$ Bruant.

2:7 Bruyère.

Bolet a madouvier.

Boles.

Bombyque.

Borate de soude.

Borax.

Borraginées.

Botanique.

Boue.

Bouche.

Bouillon-blanc.

Bouleau.

Bourache.

blanc.

79

378

34

ibid.

114 Buglose.

vulgaire.

Bry rumal cendrée. ibid.

Bucarde.

Buccin.

Bugrane.

52 Buis.

225

186-258

106

176

ibirl.

110
Bulime.

nain.

arborescent.

Buse.

Butome.

Butor.
83

406

410

163

116

I 68

ibid.

ibid.

4 II

247

93

274 


\section{C}

$\mathrm{C}$

Cucdoye:

Cacatoës.

Cachaiot.

Cachou.

Caffeyer.

Caille.

C.iillelait.

\section{blanc.}

jzure.

Callou d'izypte.

C.lendrier de Flore.

Cailiculé.

Calrigue.

Calyce.

Can omille.

Ca mpanule.

C.mp.niformes..

$$
\text { évasées. }
$$
en grelot. tub.lées.

Camphrier.

Canard.

Canines.

Canne.

Carnè̀ sucre.

Canne:on.

Cannepesiè.

Cantilaride.

C.pillaires.

Capres.

Caprier.

ipireux.

Caprification.

Capusule.

Capucine,
313 Caque.

I 19 Carabé doré.

252 Carapace.

233 Carbone.

93 Cardiaire.

r29 Circle poirée.

272 Cardon.

I28 Carelet.

ibid. Carêne.

ibid. Caret.

yo Carline.

70 Carote.

58 Carpe.

34 Carthame.

57 Cartilagineux:

124 Caryophyllées.

I1 7 Casque.

ibid. Cassare.

ibid. Casse.

ibid. Cassier.

ibid. Cassonade.

125

IOI

120

3is

$16 \mathrm{I}$

287

121

132

322

$12 \mathrm{I}$

304

149

$235-410$

168

161

ibid.

91

9 Castor. 214

273 Castoréum. ibid.

185 Cataire. I 13

278 Caudiác. 300

90 Civia. $21 \frac{1}{4}$

2,9 Cauris. 409

260 Caviar. $\quad 176-310-312$

340 Cnywa. 67

84 Cèdre. I8:

136 Caliule. 368

ibid. Cementer. 4.5

ibid. Cendres gravelées. 14 ह

170 Ceps. 138

63 Cérambyx-géant. 341

If Cérambyx-musqué. ibic.

$$
\text { D. } d 3
$$


422

Cerf.

Cerf-volant.

Cérisier.

Céréales.

Cerfeùille.

Cernaux.

Cétacés.

Chagrin.

Chalcćdoine.

Chalcur.

Chaméléon.

Chamois.

Champignons.

Charivie.

Chapons.

Charanson.

Charbon. de terre.

Chardons. à tonnetier. étoilé. hémorroïdal.

Chardonnerot.

Charme.

Charmille.

Charnière.

Chasselas.

Chat.

$$
\begin{aligned}
& \text { d'Angora. } \\
& \text { bleu. } \\
& \text { char treux. } \\
& \text { ordinaire. }
\end{aligned}
$$

Chat-huant.

Châtaignes.

Châtaigne d'eau.

Châtaignier.

Chaton.

Chatoyer.

Chaume.

Chausse-trappe.
T A B I I

226 Chauve-souris:

336 Chaux vive.

158

85

131

167

232

309

8

34

$2 \% \mathrm{r}$

225

78

172

268

352

74

36

12 I

125

122

ibid.

257

177

ibid.

404

$34 \mathrm{I}$

205

206

ibid.

ibid.

205

250

177

98

177

173

$54^{-8} 5$

Chiendent.

éteinte.

métalliques.

230

16

ibid.

39

Cheiroptères. 191-230

Chélidoine.

Chêne.

Chêne liégier.

135

178

Chenevi.

Chenevote.

ibid.

Chenilles.

Chenuelle.

173

ibid.

Chernics. $368-369$

92

Chermés de chêne vert. 346

Chervi.

Cheval.

132

218

Chève.

Chevreau.

225

Chevrefeuille.

ibid.

Chevrette.

126

Chevreuil.

228

Chevrotains.

2:7

228

Chicorée.

I 2 I

Chien.

301

$\begin{array}{lr}\text { barbet. } & 202 \\ \text { basset. } & \text { ibid. }\end{array}$ de berger. $\quad 20$

bichon.

202

courant. ibid. danois. ibid. dogue. ibid. épagneul. ibid.

Chile.

Chocolat.

Chou.

Chou pommé.

Chouette.

87

152

149

146

ibid.

250

Ch ysalide.

370

124 


\section{A I P H A B E T I Q U E. 423}

Ciboule.

Cicatrice.

Ciche.

Cidre.

Ciel.

Cigale.

Cigogne.

Cigne.

Ci!s.

Cinzbre.

Circulation.

95 Collerette.

I3 I

160 Colophane.

264

155 Colss.

$18 \mathbf{3}$

3 Columelle.

146

344 Combustibles transparens.

Cire.

Ciron.

Cirrouille.

273

132 Compagnons blancs. $\begin{array}{r}350 \\ 150\end{array}$

188 Composée. $\quad 56$

Civette.

Clairon.

Classes.

42 Concombre.

I9 I Concrétion.

169

Clavaire coralloide.

235-359 Cône.

384 Cône tigre.

169 Conferves.

95 Conifères.

241 Conium tacbeté. $\quad 132$

2 Conjuguées. $\quad 56$

Clématite.

Cliver.

Cloporte.

commun.

de mer.

Clou de gérofle.

Cobalt.

Coccinelle.

Cochléaria.

79

133

35

Conques.

403

Corsoude.

Coq.

387 Coq de Bruyère.

ibid. Coq d'Inde.

$4 \mathrm{O}^{2}$ Coque.

I 52 Coquille.

40 Coquille multiloculaire.

342 4I3

Cochon.

Cochon-d'Inde.

140 Coquilles multivalves. 4 2

Cochoin-de-lait.

Cocons.

Cocotier.

Coefie.

Cour.

Cœur de kæuf.

Coignassier.

Col.

Colchique.

Coléoptères.

Colimaçon.

229-230 Coquille uniloculaires. 408

215 Coraces. 251

230 Corail. 415

377 Coralline. ibid.

93 de Corse. ibid.

53 Corbeau. 252

121 Corceler. 327

$4 C 7$ Coriandre.

15,5 Cormier. 156

188 Cormoran. 279

94 Cornes d'Ammon. $\quad 413$

335 Cornaline. 9

412 Corneille. 253

D d 4 
Conset de St. Hubert. 412 Cri-cri.

Cornichon. $\quad 169$ Crins.

Corinulle. 127 Cinquet.

Corsuiller. ibid. Crochets.

Corolle. $\quad 58$ Crocodille.

Curps célicsies. $\quad 2-3$ Croupion. 235

Curps ceriestres. ibid. Cruciferes. 145

Coryoubiteres. 123 Ciristacés. 386

Cotignac.

Cutcomer.

C. :nniar annucl.

I 56 Crysial de roche.

C iyiedons.

Co.cou.

Coudricr.

148

Coulenvre. ¿̀ collicr.

248

Ciystalisation.

Crystaux.

$52-6+$ Cryptcgames. $\quad 81-84$

254 Cucurbitacées. $\quad 160$

179 Cuilleron.

c)7 Cuisse.

ibid. Cuivre.

379

Coupe!le.

Coupeller.

Courge.

Courlis.

Courtillière.

Cousin. $4=-44$

Cul d'articlaud.

45 Culot.

170 Cumin.

274 Cuscute.

120

348 3 is ibicl.

Crabe.

commun. commun.

Craie.

Curc.

Cynips.

$17^{0-1} 7^{8-353}$

386

ibid.

du Bédeguar. du chêne. noir. 16

$28 \mathrm{y}$

321

147

$+3$

235

psines.

Cynuglose.

- Cyprès.

Cyprin doré
Crapaud.

Craquelins.

Cresson.

Creuset.

Crète.

D

T)

Daine.

Damier.

Danois.
227 Daphné. ibici. Dattier.

373 Décacles.

202 Défenses. 
A I P A S t T X Q U I. $\$ 25$

\begin{tabular}{|c|c|c|c|}
\hline $\begin{array}{l}\text { Delphine. } \\
\text { Demi-leuron. } \\
\text { Demi-métaux. } \\
\text { Demoiselies. } \\
\text { Dentellier. } \\
\text { Dents. } \\
\text { Départ. } \\
\text { Dermeste. } \\
\text { Dermeste pelletier. } \\
\text { Dátotner. } \\
\text { Deuil. } \\
\text { Diamant. } \\
\text { Didactiles. } \\
\text { Digestion. } \\
\text { Digitale. } \\
\text { Digitée. }\end{array}$ & $\begin{array}{r}134 \\
118 \\
40 \\
364 \\
99 \\
186-49.4 \\
40 \\
338 \\
\text { ibid. } \\
32 \\
373 \\
35 \\
189 \\
192 \\
105 \\
56\end{array}$ & $\begin{array}{l}\text { Dindon. } \\
\text { Dindonaux. } \\
\text { Dioiques. } \\
\text { Dipteres. } \\
\text { Disperme. } \\
\text { Disque. } \\
\text { Distllation. } \\
\text { Dogure. } \\
\text { Do:grs. } \\
\text { Doride. } \\
\text { Dorsale. } \\
\text { Domestique. } \\
\text { Dragoneau. } \\
\text { Drège. } \\
\text { Ductiltét. } \\
\text { Duvet. }\end{array}$ & $\begin{array}{r}267 \\
\text { ibid. } \\
6 \pi \\
379 \\
63 \\
619-285 \\
71 \\
202 \\
235 \\
315 \\
299 \\
195\end{array}$ \\
\hline
\end{tabular}

\section{$\mathrm{E}$}

Esu acidulée.

Eau de mílisse.

Eau minérale.

Eau-de-vie.

Ecaille.

Ecaille florale.

Echalotte.

Echassiers.

Echinites.

Echinodermes.

Jichinus.

Eclaire.

Ecorse de chêne.

Ecorciseur.

Ecrevisse.

Ecursitil.

Ecitsson.

Efiraie.

Egrissée.

25 Eglantier.

Eluter gris desour.

25 Electricité.

i 1 Elément. 6

58-298 Eléphant. 217

58 Elytres. $\quad 328-336$

95 Email. 8

272 Embryon. 52

399 Emeraude. 12

390-398 Emeraudine. $\quad 338$

399 Enerillon. 248

I35 Enrécique. $4 \mathrm{I}$

46. Empasietlées. 137

2.1.) Emulsion. 72

300 Encens. xüa

215 Encre de la Cline. 398

286 Endive. 128

250 Epagncul. 200

35 Eperian.

319 
426

Eperons:

Epervier.

Ephémère.

Epiderme.

Epinard.

Epine.

Epine vinette.

Epinoche.

Eponge.

Erable.

Erigeron.

Eriophore.

Es:aigor.

Especes.

Esprit ardent.

Esprit s.mis.al.

Esprit-de-vin.
Espailer.

TA B I E

235 Essain.

247 Essence d'Orient.

366 Estomac.

86 Esturgeon.

Iol Etamer.

64 Etamine.

143 Etain.

316 Etendard.

415 Fither.

137 Etoile de mer.

123 Etourneau.

(92) Etres. I

412 Erressans vie et sans.mou-

If I vement. 4

2 Erres ayant la vie et le

I4I mourement. ibid.

60 Euphorbes. 168

141 Expiré. 192

F

F

Faines.

Fanons.

Faisan.

argenté.

doré.

Faisanderie.

Faon.

Farine fossile.

Faucon.

Fiauconnerie.

Fauvette.

Faux-bourdon.

Fécule

Feld-spath.

Fenotil.

Fenu-grec.
I 88 Fer.

177 Fer à çheval.

233 Fermentation. I

269 Fenille.

ibid. Feuille morte.

ibid. Féve.

ibid. Fibres.

227 Fignier.

I6 Filamenteuses.

247 Filet.

262 Filon.

357 Filoselle.

73 Fissipèdes.

22 Fléchière.

I3 I Flambé.

163 Fioraison.
248 Filière.
375

165

65

I 70

80

5.7

368

39

377

$189-198$

$9+$

$3-2$

56 
A I P II A B E T I Q U E. $\quad 427$

Fleur.

52 Fourmillon.

365

Fleurs de soufre.

Fleuron.

130 Fragon.

97

36 Frai. 300

Flosculeuses.

II8 Fraisiers.

Flots de harengs.

$x$ I9 Framboisier:

Filux.

Foliation.

Folioles.

320 Fraxinelle.

158

ibid.

Fonctions.

33 Frelon.

145

104

$\begin{array}{rlr}\text { 56-70 } & \text { Fresne. } & 103 \\ 56 & \text { Fromager. } & 149\end{array}$

68-191 Froment.

Fontinal antixyrétique. 83 Front.

Forficule.

$34^{2}$ Fructification.

Fossette.

Fossile.

Fougères.

Fouine.

Foulque.

Fourmi.

Fourmillières.

59-414 Fruit.

23 Fucus.

84 Furet.

208 Finet.

275 Fumeterre.

349 Fusain.

$35^{\circ}$.Fuseau.

\section{G}

Galeules.

I8 I Gélatineux:

So

44 Gélinotte.

39 Gemme.

Gileries.

Galères.

Galle.

Gailinaces.

Gangue.

Garancées.

Garence.

Garenres.

Garou.

Gasé.

Gâteaux.

Gaude.

Gaudées.

Geai.
326 Génération.

353 Genest.

265-266 d'Espagne:

39

137

$\times 29$

213

99

372

360

136

137

253
Genevrier. thurifere.

Genièvre.

Genisse.

Genouillet.

Genres.

Gentiane.

Géomètres:

Géraniuın.
59

80

208

II 4

136

153

$42 I$
271

12

69

I 62

ibid.

ibid.

180

ibid. ibid.

223

97

2

II I

$3^{5} 9$

$\mathrm{x} 42$ 
428

Germe:

Geioflicr.

Gestanon.

Gingembre.

Ginseng.

Gircfiécs.

Gland.

Glandes.

Glossupètres.

Glu.

Gluten.

Gonme. dc lière. du jinys. réfures.

Gorge de pigeon.

Gurgone.

Gossypium.

Goujon.

Gousse.

Graine d'ćcarlate.

Grainoir.

Grains.

Graminées.

Grand paon.

Grande marguerite.

Granit.

Grappe.

Gratecul.

Grateron.

\section{IA B I}

60-240 Grès:

152 Grefie.

I; 6 Gren.tdier:

97 urendi. II

13 Greno:ille. 25,0

I 46 Grès. 8

178 dur. ibid.

65 du Levant. ib.d.

309 pures.

I 33 tendre. ibid.

$7+86$ cryatallisé. ibid.

y I Crille. 39

I23 Grillé. . 44

159 Grillon. 347

73 Grillon taupe. 348

265 Griote. I8

415 Grive. 260

I 48 Grognement. 229

323 Grosciller. I5 I

63-160 Gros bec. $\quad 256$

$3-16$ Gruau. 90

32 Grue. 273

85 Guicle. $\quad 147$

ibid. Grêpe. 354

375 frêlon. 355

124 commune. ibid.

21 Gueule de loup. Ic6

57 Gui. 127

157 Guimanve. 148

128 Gypse. 33

$\mathrm{H}$

Hatiotier.

Hanche.

Hanneton.

Hareng.

Haricot.
413 Haricot vert. 164

328 Harpe. 410

337 Hase. 213

320 Hellebore. I 34

163 Héliuthe. 225. 


\section{A I P A A B E T I Q U I. 429}

Hélice.

$$
412
$$

jardinière.

rigneronne.

ibid.

ibid. Horloge de Flore.

200

Héliotrope.

I1s Honilon.

ibid.

Honerie.

Ios Houille.

Hellebore.

Hématite.

Hémato:alon.

Fiémerocille.

Hómiptères.

Hunisenent.

Hépetiques.

Herbe aux ánes.

46 Hotillières.

262 Houssine.

95 Houx.

343 Huile d'amande. 160

220

82

à coron.

121

248

anx cueilliers.

He:bier.

176

Hérisson.

76

Hermaphrodite.

212

Hermine.

бII

Héron.

208

Héronaux.

Herse.

Heures.

Hêtre.

Hibou.

Hippocastanum.

Hirondelle.

Histoire tiaturelle.

Homar.

Homme.

273

274

85

H.ûtre.

d'aspic. II3

fi:e.

71

essentielle. $\quad 7^{2}$ grisse. ibid: de lin. $\quad 150$

de noix. - I67

d'oliette. 135

siccative. $\quad 72$

de succin ou de k.trabé.

de vieriol.

38

3 Iiuppe.

177 . Hyacinthe.

249 orientale. 95

137 Hyberner. 70-195

260 Hydromel. 302

I Hymenoptères: $\quad 34.9$

386 Hysope. IIZ

599

\section{I}

Ichtyolle.

If.

Impatiente.

Iucisives.

Incrus:ations:

$\begin{array}{llr}310 & \text { Incubation: } & 240 \\ 180 & \text { Indigo. } & 165 \\ 143 & \text { Indigotier. } & 165 \\ 286 & \text { Indivitu. } & \\ 17 & \text { Infusoires. } & 390\end{array}$


430

Insectes.

Intestinaux.

Incestins.

Involucre.

Iris.

Ir.s.

gerinanique.
TA B L E

$\begin{array}{rlr}325 & \text { Iris jaunc. } & \text { ibid. } \\ 390-392 & \text { Irrégulières. } & 404 \\ 193 & \text { Irritabilité. } & 68-193 \\ 57 & \text { Inle. } & 388 \\ 188 & \text { tcrestre. } & \text { ibid. } \\ 96 & \text { sablonier. } & \text { ibid. } \\ \text { ibid. } & \text { Ivraie. } & 90\end{array}$

J f.ĆE.

Jacobée.

Jalip.

Jars.

Jardinière.

Jambe.

Jaspe.

Jasmin. sanguin.

Jaune de l'œuf. Jayet.

\section{J}

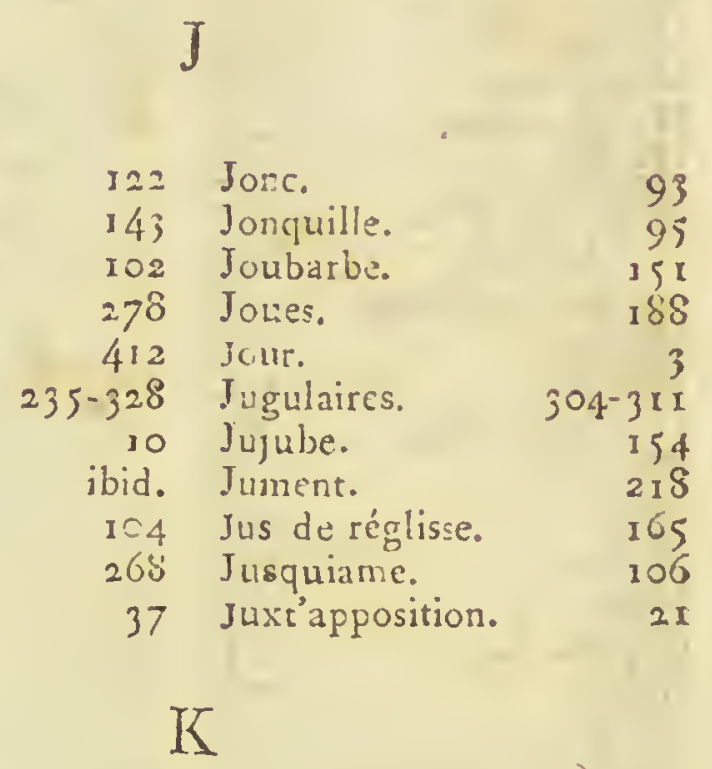

95-100 Kirchwasser:

159

L
Iabrés.

Lagopède.

Lagetto.

Laie.

Laine.

Lait d'amando.
II Laip:

270 Laitue.

99 Laiton.

229 Lambda.

223 Lamproie.

72 Lampyre.
300

I 19

47
376

376

305

339 
$A$ I I I A. B E I I Q U E. $43 x$

Eançon.

Langtie.

L.:?IEr.

Lapereau.

Lapin.

blanc.

d'Angora.

Lapinière.

L.pis lizuli.

Larve.

Lituréole.

Liarier.

Laurier-rose.

Lavande.

Lavande spic.

Lavaterre.

Lave.

Laye.

Légume.

Légumineuse.

Lentes.

Lentille.

Léop..rd.

Lépidoptèrss.

Levain.

Levraut.

Lèvres.

Levure.

Lézard.

Libsilule.

Liber.

Lichen pulmonaire.

320

I $36-235$

2., 8 Limeçon.

396

$2 i 4$ Limande.

213 Limas.

ii.i.l. Lin.

ibid. Lin incombustible.

$2{ }_{3}$ Linaire.

Io Linotte.

331 Lion.

99 Liquation.

ibid. Lis.

I IO Iiseaux.

II 3 Liseron.

ibid. Lit de la mine.

397

412

314

4.12

150

14

106

258

$2 c 6$

148 Litharge.

50 Livrée.

229 Loche.

160 Locomobilité.

$40-47$

94
138

109

39

44

412

318

160 Loir.

383 Lombric.

166 Loriot.

207 Lote.

367 Lotir.

86 Lotier.

213 Loup.

386 Loup garoux. ibid.

89 Loutre. 209

292 Louve. 204

364 Louvetau. ibid.

66 Lucane-cerf. $\quad 336$

8 I Lumachelle. $\quad 18$

141 Lupin. $\quad 163$

${ }_{7} 8$ Lychnis. 149

Liége.

Jierre.

Lièvre.

Lilas.

Limace.

brune:

228 Lycoperde boviste. 79

212 Lycopode commun. 83 203 en masse. ibid. 396 Lyre. 


\section{M}

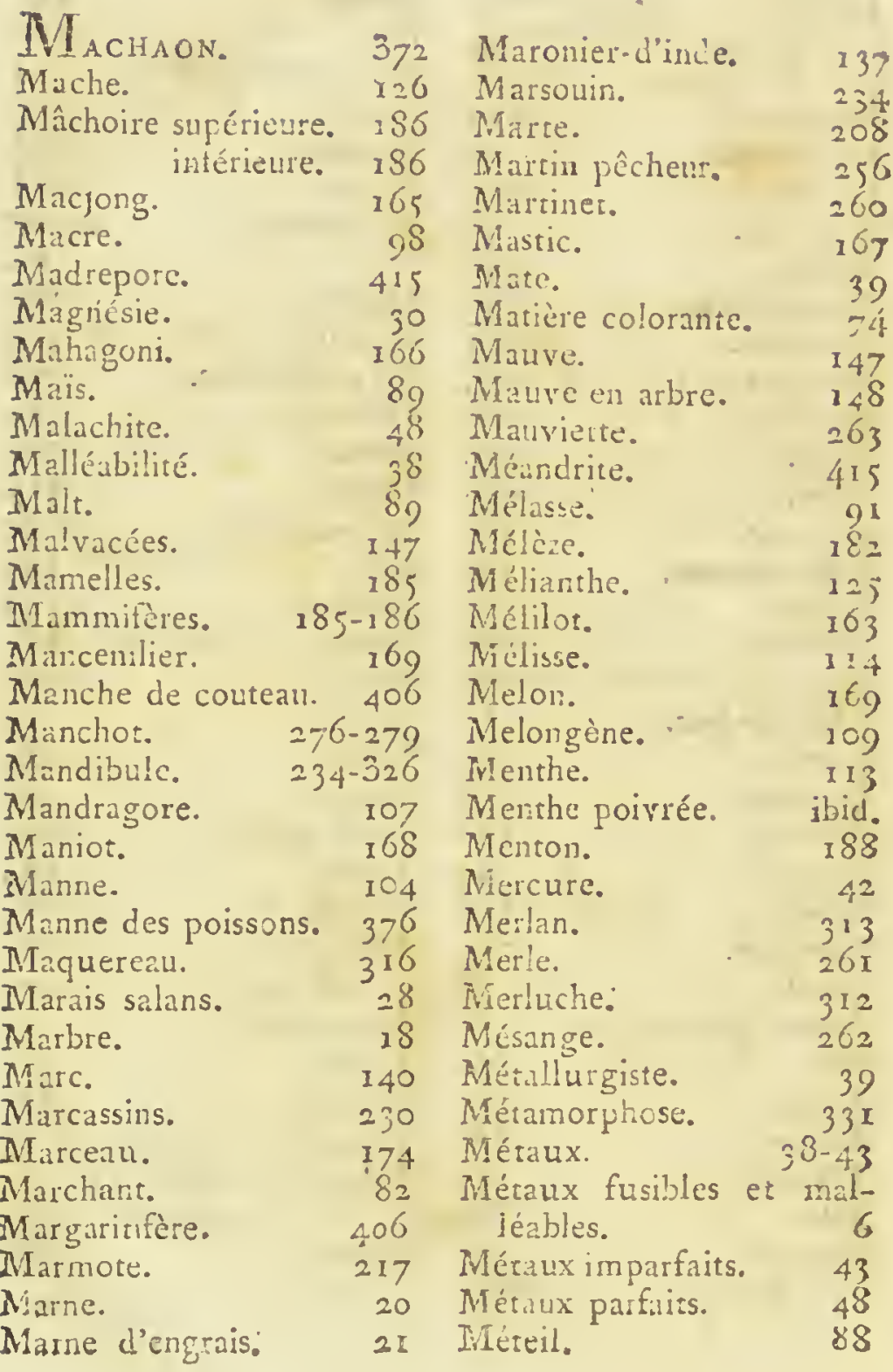



A I P II A B É T I Q U E.
433

Néthodes.

Métis.

2 Morgeline.

200 Morille comestible.

149

Meurier.

bl.nc.

I71 Morpion.

ibid. Mors du diable.

ibid. Mortier.

79

noir.

Míica.

Miel.

Miel rosat.

Miel mercuriel.

14-22 Morue.

360 Moscovade.

$36 \mathrm{r}$ Mouche.

ibid. bleue.

Migrations.

Milas.

243

Miviler.

Millefeuille.

Millepertuis.

Millepore.

Minès.

Mines oll minerais.

Mire de plomb.

Minéraux.

Minéralisateur.

Mirium.

Miroir.

Moelie.

Miloelle de pierre.

Mofète.

Moineau.

Moisissure.

Mois.

Moisson.

Molaires.

Mollusques.

$\begin{array}{lrrr}\text { Mondé. } & 89 & \text { Muscadier. } & 99 \\ \text { Monnoie de Guinée. } & 409 & \text { Muscles. } & 193\end{array}$

246

89

125

138

415

5 Mouron des oiseaux.

383

126

I6

312

39 Moust.

47 Mousses.

verte.

domestique.

Moule. à miel.

$7 \mathrm{r}$

381

ibid.

ibid.

ibid.

358

5 Mousseron. $8 \odot$

30 Moutarde. $\quad 145$

45 Mouton. 2.24

266 Mourement volontaire. 52

65-66 Mucilaga.

I6 Mucor.

192 Muflier. $\quad 106$

258 Muguet. $\quad 96$

79 Mulátre. 200

3 Mulet. 221-358

86 Mulicivalyes. 403

I86 Muriate de soude. 26-27

Monoiques.

Monopétale.

Monosperme.

Míonstruosité.

Montagne.

Morelle.

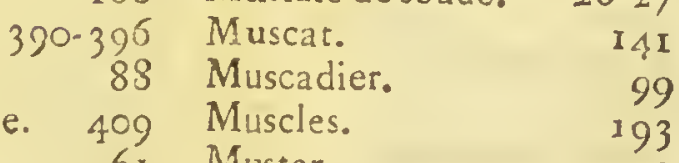

140

58 Mye. 405

63 Mye des peintres. ibid.

62 Myrthe. $\quad 152$

4 Myrthil. I17 
Nacre de perle.

Nacré.

Nageoires.

Napel.

Narcisse.

des poères. de Constantinople. $9^{6}$

Narines.

Nisea .

Nature.

Nautile.

Navet.

Nectaire.

Neflier.

Nègre.

Nénuphar.

Nerfs.

Nérion.

Nérite.

Nerprun:

$$
\begin{aligned}
406 & \text { Névroptères. } \\
37^{2} & \text { Nez. } \\
\text { 298-299 } & \text { Niz cornu. } \\
\text { I } 34 & \text { Nicotiune. } \\
95 & \text { Nid. }
\end{aligned}
$$

ibid. Nitrate de potasse. 29

Nitre ou salpêtre. ibid. 187 Nitrières artificielles. 3 r ibid. Noir de fumée. $\quad 182$

I Noir d'Espagne. $\quad 179$

414 Noisette.

$1+5$ Noisctier.

59-360 Noix.

156 Noix de cyprès. ibid. ibid.

200 Noix de galle.

98 Noyer.

193 Nuit.

110 Nutrition.

413 Nymphe.

153 Nymphéa.

\section{O}

Ochres.

Qiil.

Oestre du bœuf.

46 Oignons:

266 Oiseaux.

95

379 Olive.

Oestre du cheval.

380 Olivier.

234

410

Oestre du mouton.

Ombelles:

Eufs.

ibid.

239

Ombellifères.

(E)ufs de fourmis.

352 Ombellules.

Euillet.

Oie,

s 50 Ombilic.

104

131

ibid.

ibid.

377 Oméga. 
A I P II A B E T I Q U E. 43 5

Ongles.

Ony'x.

Onguiculés.

Onoperue.

Opale.

Opercule.

Ophyte.

Opium.

Countia.

Ordres.

Or.

Or de Manheim.

Orchis.

Oreiliard.

Oreille.

Oreille de mer.

Oreille d'ours.

Oreillettes.

Organsin.

Orge.

Orgeat.

Orme.
236 Orpiment.

9 Orseille.

189 Ortie.

120 Orthoptères.

9 Ortolan.

412 Orvet.

22 Os.

I35 Oscabrion.

345 Os de seiche.

2 Osier.

49 Ours.

47 Ours blanc.

97 brun.

23 I noir.

$187-235$ Oursin de mer.

$4 I 3$ Oursons.

IO2 Outarde.

101 Outremer.

397 Ouvertures nasales.

88 Oxydes.

ibid. Oxygène.

Ift Oxyme!.
80 $170-172$

347

259

297

I 93

402

397

174

209

210

ibid.

ibid.

399

209

269

II

187

39

34 $36 r$

P

$P_{\text {AIN. }}$

Pain d'épice.

Palmé.

Palmiers.

Palpes.

Pampre.

Parais.

Panthice.

Panis.

Paon.

Papillon.

argus bleu. argus brun.

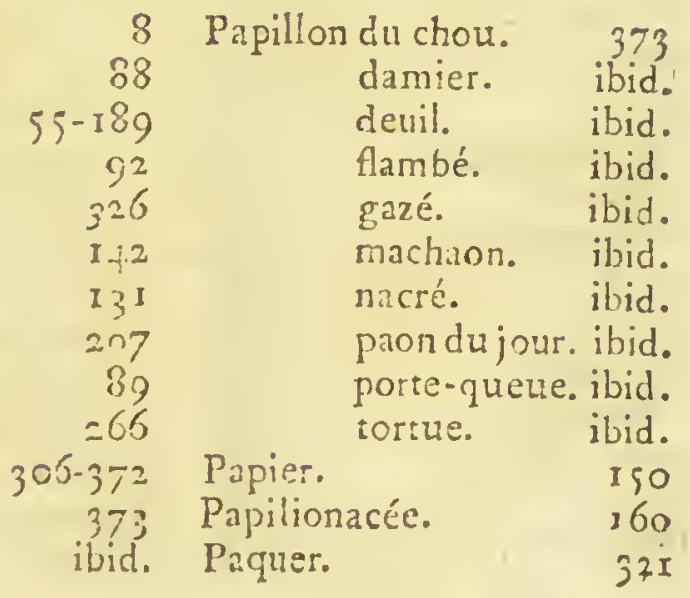

E e 2 - 
436

Paquerette.

Parc.

Parenchyme.

Parquer.

P.isereaux.

Pasticl.

Pâte d'amande.

Patclle.

Patience.

Pattes membraneuses. 369

Paupières.

Pavillon.

Pavillon de l'oreille. 187

Pavot.

Pean.

I'êcher.

Pectorale.

Pectoralix.

Péduncule.

Peigne.

Pélican.

Pennes.

Pensée.

Pentadactyles.

Pepin.

Perce-neige.

Perce-oreille.

Perche.

Perdreau.

Peidrix.

Perdrix rouge.

Péricarpe.

Périsperme.

Perlé.

Perles.

Perroquet.

Perruche.

Persicaire.

Persil.

Personnće.
T A I B B

124 Pervenche: IC9

405 Péra!e. 59

86 Pétiole. 56

224 Périole rit ou âlé. 54

255 Perite margucrite. I 4

147 Petite sauge. 112

I bo l'ćtrole. 37

408 Pétrificaion. 417

I0o Peuplier. $\quad 175$

309 noir. ibid.

blanc. ibid.

d'ftalie. ibid.

Phalènes. $\quad 373-376$

I 35 Phalènes écailles. 375

I9o Phalène du murier. 376-405

160 Physique.

209 Pic.

304-314 Pic verd. 255

57 Pie. 253

407 Pie griesclie. 248

279 Pied d'alouette. $\quad 134$

236 Pieds furchus. Igo-22x

I 44 Pieds chemineurs. - 235

18, Pierre. 21

I) 4 d'azur. IO

96 à bârir. I9

323 à chaux. 15

316 qui étincelle sous le

271 briquet. 7

ibid. à fusil. Io

272 gemme. II

62 de liais. In

64 sneulicre. II

88 à plâtre. 33

406 ponce. 50

251 de porc. 19

$25 \mathrm{I}$ de touche. 50

100 Pigeon. 204

I30 Pigeonneaux. 264

II Pignons. I8I 


\section{A I P II A B E T I Q U}

Pilulaire.

Pinprenclle.

Pin.

Pin maritine.

Pinne.

Pissor.

Pintadeาu.

Pintade.

Piquars.

Pizuetie.

Pirapede.

Pistache.

Pistuchier.

Pissenlit.

Pistil.

Pivine.

Placenta.

Planorbe.

corré.
337 Poils.

I 5 S Point saillant.

181 Point vital.

Iis Poires.

405 Poire deterre.

257 Poiré.

259 Pois.

$=67$ Pois de senteur.

I QO Poirier.

It I Poissons.

317 Poisson volant.

ió7 Puisson doré.

ibid. Poivre.

IIg Poin noire.

60 résine.

135 de ivontagne.

64 Pollen.

412 Polybe d'ean douce.

iuid. Polygames.

I 1 Polygonum.

Plantain.

Plantes à un setil cotyledon.

8

Plantes sans corylcdon:s. 73

Polvpétale.

Polyuier.

Polyjerme.

Plintulc.

Plistion.

Piataite.

Platins.

Plitre fin.

$$
\text { ล̀ bâtir. }
$$

Plâtrie:-

Pleurs de la rigne.

Plia.

tons?.

plomlagine.

Piuic de sang.

Fivie de sonte.

Plแn:aुs.

Plusies.

Plunule.

Piuvier.
64 Polytric commun.

385 Pomme.

179 Fomme d'amonr.

49 Pommeric chêne.

3 Pommé épineuse.

ibid. Pommescle pin.

3: Pemme dectre.

$14 \mathrm{r}$ Pommicr.

315. Populage.

4.4 Fopuleum.

46 Poncal.

3yt Pore.

Iô! "orcelaine.

2:6 Perphyre.

ibid. Poitor.

52-53 Porce-quene.

275 Pctasse.
65

$5=-64$

155

$12 ;$

155

$x$ 615

ibid.

155

258

317

315

173

182

ibid.

67

352

$6 \mathrm{I}$

99

5)

A. 4

63

83

$63+155$

$\therefore \mathrm{Cg}$

173

107

$18 \mathrm{I}$

108

354

I3 4

17 ;

95

223

$4($ (i)

22

18

373

24 
438

Potće d'ćtuin.

Poterie.

Potiron.

Poll.

Pou de balcine.

Poudding.

Poudre à canon.

Poudre d'or.

Poulain.

Poulardes.

Ponle.

Poule d'eau.

Poumon.

Pourpier.

Pourure.

Porrzolane.

Preslc.
T A B $\mathrm{I}$ В

44 Pressir.

132

13 Primevère:

102

62

3 Prupolis. $181-359-361$

402 Protée.

22 Psi.

29 Ptéris aquiline.

14. Prunier.

218 Puce.

268 Pticeron.

ibid. Puits.

39 ?

396

84

I 59

383

344

275 Pulmoraire.

191 Pulsatille.

152 Pulvérateurs.

4 Io Pupille.

51 Putois.

84 Punséfaction.

II 5

133

237

I 68

208

21

\section{Q}

Guadrupines ovipares. Guartz.

$\begin{array}{rr}281 \text { Quaternées. } & 56 \\ \text { Quadiugdes vivipares. Queue. } & 188\end{array}$

ibid. Quinguina.

$R_{\text {Acis }}$

Radićes.

Rachicule.

Radis.

Rais.

Raie bouclée.

Raifort.

Kaions.
53 Raisin.

I19 Raisin de renard. II7

52-64 Raisinet.

145 Raiponce.

190-3G6 Raitons.

306 Rălle.

145 Rambour.

306 Ramier.
138

142

118

$3 \div 6$

275

I 55

205 


\section{$A$ I T H A B E T I Q U E. 439}

Rat.

215 Rhubarbe. 100

Rat d'eau.

Rave.

Réalgar.

Réceptacle.

Recritié.

Rectrices.

Réglisse.

Rigulières.

Rejertons.

Rérniges.

Renard.

Renarde.

Renardeaux.

Rerouée.

Renoncule.

Peptiles.

Reouin.

Réséd.

Résidu.

Résine.

Rıssure.

Respiration.

Rétracty!es.

Réveil-matin.

Rhinccéros.

216 Rhubarbe palmée. ibid. ${ }_{14} 6$ Ris.

40 Robinia. 164

60 Roche. $2 x$

I4I Rocou. 144

236 Roiteiet. 263

I64 Romarin. III

404 Ronce. 158

67 Rosacées. 154

236 Rose de Provins. $\quad 157$

204 Rosier. ibid.

205 Rossignol. 262

ibid. Rotang. 93

100 Rouge gorge. 262

I34 Rouget. $\quad 317$

282 Roussette. 309

307 Rubiacées. 128

I36 Rue. I44

140 Rubis. I2

73 balais. ibid.

312 sinelle. ibid.

192 Ruche. 356

189 Rumex. IOO

168 Rumination. 192

228

3

Sabing.

Sable des jardins. mouvint. des fondeurs.

Sabot.

S.itran.

Safran bâtard.

Sainfoin.

Suint-Pierre. tio Saisons.

8 Silanandre. $\quad 292$

ibid. Silbanque, $\quad 39$

ibic. Sulins. 28

$41 \mathrm{i}$ Salpêre, ou nitre de hous-

96 silge. 32

121 S.tisifix. $\$ 23$

166 Sang. 190

314 Surglier. $\quad 228$

E e 4 
Sangsue:

Santal.

Sanguine.

Saphir.

Sapin.

Sarcelle.

Sirclage.

Sirdine.

Sariettc.

Sarrazin.

Sassafras.

Sauge.

Sauge des prés.

Sauie.

Saule pleureur.

Saumon.

Saunier.

Silurs.

Saute:elle.

Sauvage:

Savon.

Scabieuse.

Scarabé.

Silurl.

opaquıs.

transparens. tourmaline.

Scolcpendre.

Scorp:on.

Scorsonère.

Scrophulaire.

Scyrpe.

Secrétions.

Seiche.

Seigls.

Sel.

ammoniac.

essentiel. de cuisine.

Sel composé.
394

152

46

12

182

279

138

321

112

100

59

I 1 I

112

174

171

$3: 5$

2 'a

3: I

348

195

137

I 26

3,6

I1 -22

ibid.

inid.

ibid.

387

386

120

I05

92

$19^{1}$

397

88

$23-\div 7$

29

$7^{\circ}$

27

23 gemme:

marin.

neutre.

primitif.

simple.

Sélénite.

Semence.

Semi-flosculeuse.

$26-27$

8

25

2.1

23

3:

52

Sunecon.

jacobée.

ordinaire.

Senné.

Sensibilité.

Sensicive.

Serin.

Serpent.

à sonnette.

à luncite.

Serpolet.

Serratule.

Sessle.

Séve.

Silex.

Silice.

Silique.

Similor.

179

123

ibid.

ibid.

$16 x$

10.4

$x 01$

258

293

20.4

ibis!

$11+$

122

5.7

2-10: 6

7
63

42

Sinapis.

Sing:.

1.45

202

Smcctite, ou terre à foulon.

Soie.

1 /

Soic cruc.

376

$3: 7$

ibid.

ibid.

Solantum.

organsin.

108 lyconersique. ibud. nélongène.

$1<$ ?

Sole.

$218-315$

Solci!. 
A I I II A ถ⿱丶万仒 T I C U E. 44x

Solen.

Solipède.

Sommet.

Son.

Screts.

Souchet.

Souci.

Soucle.

Soufres.

Sourcils.

Souric.

Souriens.

Spathe.

Spth calcaire. fluor.

4.6 Stomoxe.

189-218 Siranonium.

I? Silick.

IC7

86 Stygmate.

321 Siyle.

18

92 Sublimation. 40

I23 Substances inflammables. 24.101

57 Subsiances volcaniques.

19

ibicl. Sucre.

$6-34$

Substances inorganiques. 4 Subsances organiques. 4- 5 I Substance végéto-animale.

83 Succin.

Sphaigne des marais.

Sphynx.

374 Suçoir.

Sphyri vitreux.

Spire.

Stalactites.

Stalagmites.

Siértite.

Stipules,

Stock fich.

Sulfute d'alumine.

$0-50$

407 Sulfite de chaux.

16 Sulfurye.

72

17 Surcomposéc. 56

22 Sureau. $\quad 127$

$54-64$ Sylvie. 133

312 Syrop. 91

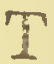

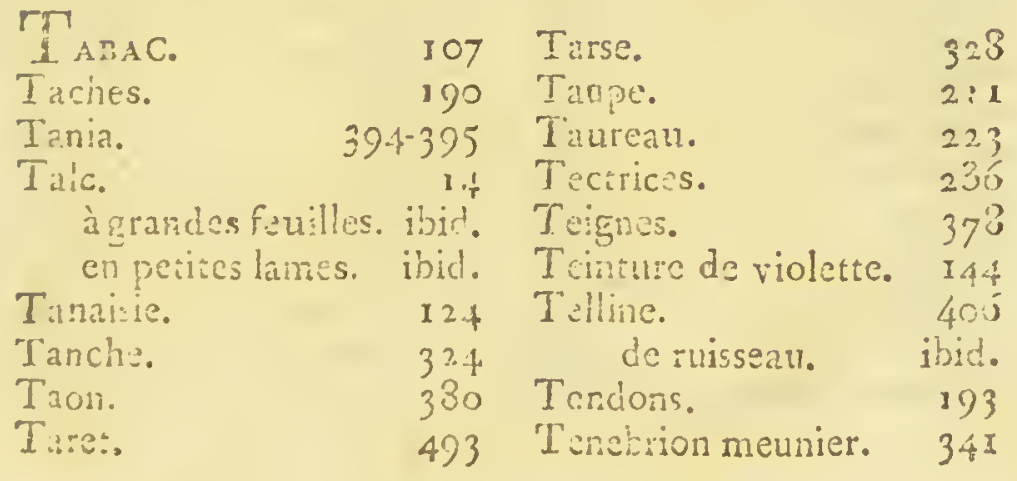




\begin{tabular}{|c|c|c|c|}
\hline \multicolumn{4}{|l|}{ Tentacules. } \\
\hline $\begin{array}{l}\text { Terre. } \\
\text { Terre bolaire ous }\end{array}$ & $2-6-20$ & Toit de la mine. & 39 \\
\hline $\begin{array}{l}\text { Terre bolaire ous } \\
\text { Terre calcaire. }\end{array}$ & & Tomate. & xos \\
\hline $\begin{array}{l}\text { Terre calcaire. } \\
\text { Terre d'ombre. }\end{array}$ & 15 & Tombac. & $42-47$ \\
\hline & 46 & Topaze. & $I_{2}$ \\
\hline Terre à porcelain & $\begin{array}{l}2 ! \\
13\end{array}$ & $\begin{array}{l}\text { Topinanbour. } \\
\text { Torpille. }\end{array}$ & $\begin{array}{l}125 \\
30.6\end{array}$ \\
\hline Terres et pierre & s mélan- & Tortue franche. & $287-287$ \\
\hline $\begin{array}{l}\text { gées. } \\
\text { erre quartzeuse. }\end{array}$ & 20 & Tortue grecque. & 288 \\
\hline $\begin{array}{l}\text { Terre quartzeuse. } \\
\text { Terre siliceuse. }\end{array}$ & ibid. & Toupié. & $\begin{array}{r}411 \\
28\end{array}$ \\
\hline $\begin{array}{l}\text { Terre siliceuse. } \\
\text { Terre végétale. }\end{array}$ & $\begin{array}{l}\text { ibid. } \\
2 \mathrm{I}\end{array}$ & $\begin{array}{l}\text { Tourbe. } \\
\text { Tourmaline. }\end{array}$ & $\begin{array}{r}38 \\
11-22\end{array}$ \\
\hline Terreau. & ibid. & Tuurrerelle. & 265 \\
\hline érébenthine. & $18=$ & Tourniquet. & 340 \\
\hline Térébenthine de & Chio. 167 & Trachée. & 65 \\
\hline Térébinthacées. & 156 & Tiéfle. & $1 ? 3$ \\
\hline Térébinthe. & ibid. & Treilles. & 141 \\
\hline Ternées. & 56 & Tromelle. & \\
\hline $\begin{array}{l}\text { Testacés. } \\
\text { Tétard. }\end{array}$ & $\begin{array}{r}390-399 \\
200\end{array}$ & Tridactyle. & $\begin{array}{l}189 \\
163\end{array}$ \\
\hline $\begin{array}{l}\text { Tétard. } \\
\text { Tête. }\end{array}$ & $\begin{array}{l}290 \\
386\end{array}$ & $\begin{array}{l}\text { Trig nelle. } \\
\text { Troemne. }\end{array}$ & 105 \\
\hline Téiradactyle. & 189 & Trompe. & 326 \\
\hline podes. & 281. & Tronc. & 54 \\
\hline Tétras. & 270 & Trofceolum. & 342 \\
\hline $\mathrm{T}$ & $3^{3}$ & Trou auditif. & 187 \\
\hline Thé d'Europe. & 103 & Trufte. & 78 \\
\hline Thon: & 316 & Truie. & 230 \\
\hline ine. & 3.7 & Truite. & 319 \\
\hline mariné. & ibid. & Truite saumonée. & ibit. \\
\hline Tho & 316 & Tubérolité. & 353 \\
\hline Thy & 114 & Tubipore. & 414 \\
\hline & 57 & $\begin{array}{l}\text { Tubulé. } \\
\text { Trilié. }\end{array}$ & ibid. \\
\hline elct. & $24 i$ & $\begin{array}{l}\text { Trilé. } \\
\text { Tulipe. }\end{array}$ & $\begin{array}{r}10.64 \\
94\end{array}$ \\
\hline $\begin{array}{l}\text { Tige. } \\
\text { Tigre. }\end{array}$ & $\begin{array}{r}52 \\
207\end{array}$ & $\begin{array}{l}\text { Tulipe. } \\
\text { Turbiné. }\end{array}$ & 94 \\
\hline Tiileul. & $\begin{array}{l}207 \\
1+3\end{array}$ & $\begin{array}{l}\text { Turbine. } \\
\text { Turbat. }\end{array}$ & \\
\hline $\begin{array}{l}\text { Allleul. } \\
\text { Tinckal. }\end{array}$ & $\begin{array}{r}173 \\
34\end{array}$ & $\begin{array}{l}1 \text { 1urbot. } \\
\text { Turyucises. }\end{array}$ & 48 \\
\hline & & Tusiluge. & 123 \\
\hline & & & \\
\hline
\end{tabular}


U UIVALVES.

Univers.
407 Unisexuel.

1 Uricules.
61

65

V

T A CHE.

Vaisseaux chileux.

Valériane.

Vanille.

Vanneau.

Valves.

Varecs.

Yeau.

Végétaux.

Vézéto-animal.

Veines.

Vendanges.

Ventre.

Verd anique.

Verge à berger.

Vers.

Vers blancs.

Ver des cigues.

$V$ er luisant.

Ver à soie.

Ver so!itaire.

Var di terre.

Verrade Iloscovie.

Verrat.

Yerjus.

Vermillon.

Véronique.

$\begin{aligned} 223 & \text { Vesou. } \\ 192 & \text { Verticile. } \\ 126 & \text { Verveine. } \\ 93 & \text { Vesce. } \\ 275 & \text { Vesse-loup. } \\ 62 & \text { Vibrion. } \\ 80 & \text { Vierge. } \\ 223 & \text { Vif argent. } \\ 51 & \text { Vigne. } \\ 74 & \text { Vinblanc. } \\ 191 & \text { Vindoux. } \\ 13 & \text { Vin mousseux. } \\ 404 & \text { Vinaigre. } \\ 18 & \text { Vineticr. } \\ 126 & \text { Violette. } \\ 389 & \text { Vipere. } \\ 337 & \text { Viperine. } \\ 403 & \text { Vis. } \\ 339 & \text { Vive. } \\ 378 & \text { Vivipare. } \\ 394 & \text { Voix. } \\ 396 & \text { Voluts. } \\ 14 & \text { Volva. } \\ 230 & \text { Volvox. } \\ 142 & \text { Vorticelle. } \\ 42 & \text { Vrilles. } \\ 103 & \text { Vrillette. } \\ & \end{aligned}$

91

54

105

165

79

392

$39-364$

42

133

140

139

140

141

143

144

295

115

4 II

3II

295

$24 \mathrm{I}$

410

58

391

392

65

338 


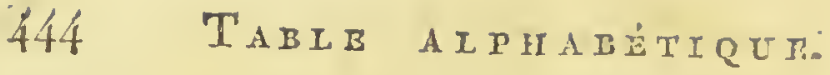

$$
\text { Y }
$$

$\prod_{\text {Yeux. }}$

$$
\underset{187-235}{127} \text { Yeux d'écrevisse. } \quad 3^{8} 7
$$

$$
7
$$

ZINE.

$$
\text { FIN DE LA TAEL。 }
$$







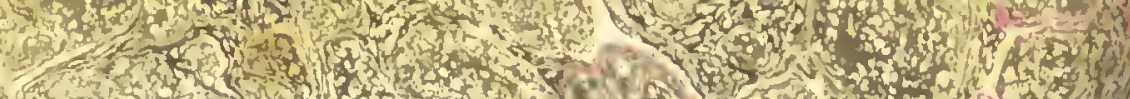

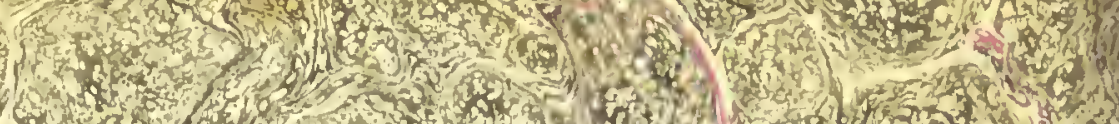
1.

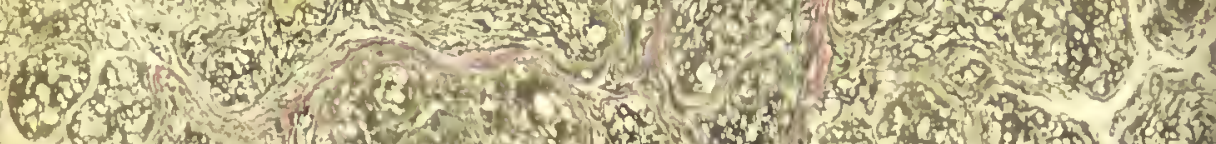

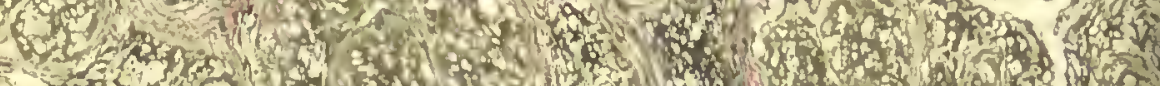
trat W.

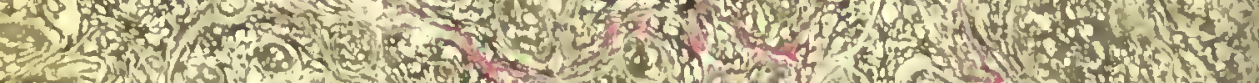
B.

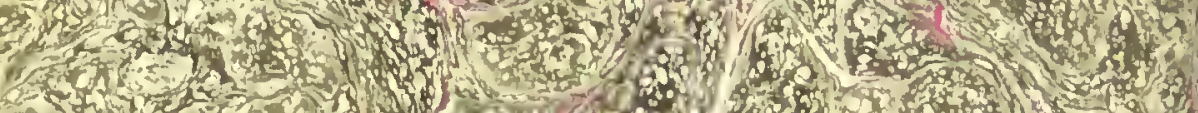
15. 25. (2)

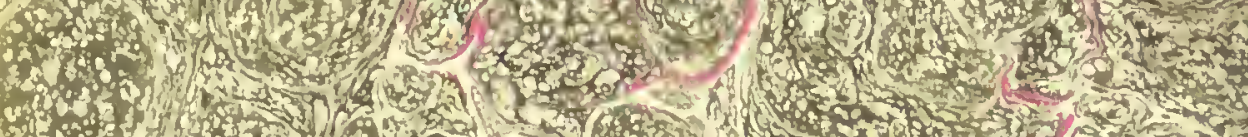
(2)

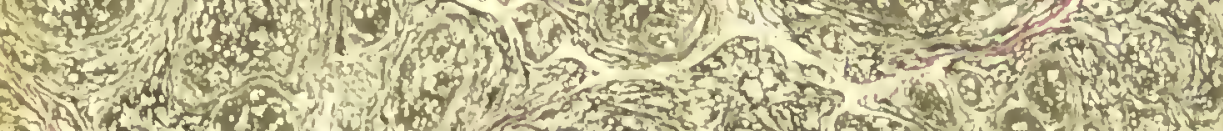

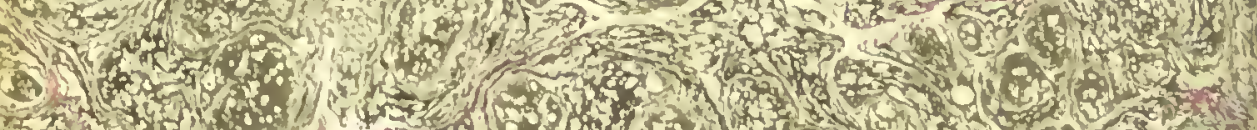
2.

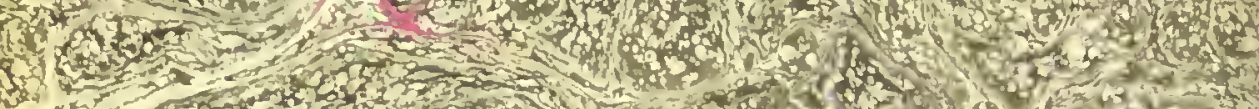
7.7.7. 



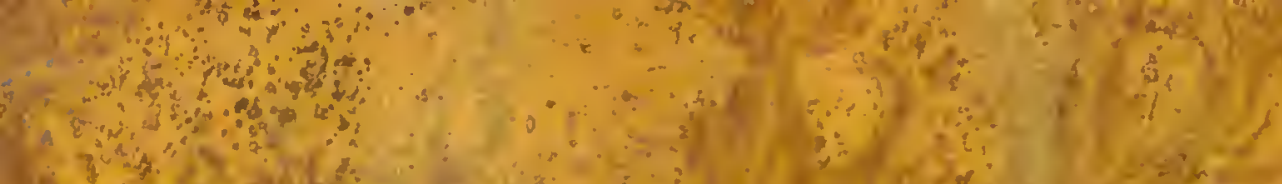

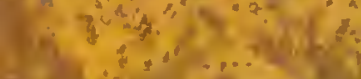

fritas

$2 \times 2+5 x^{2}$

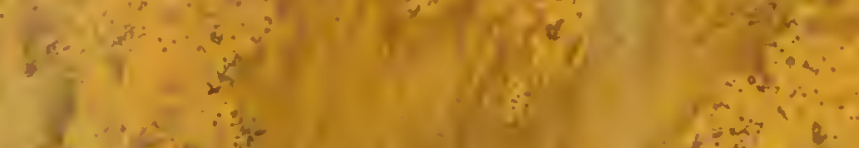

$+-\sin _{2}$

ton.

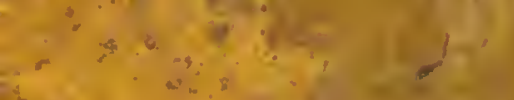

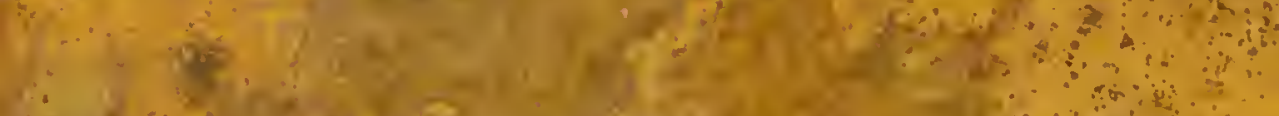

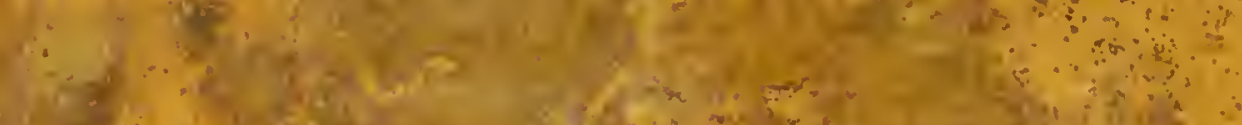

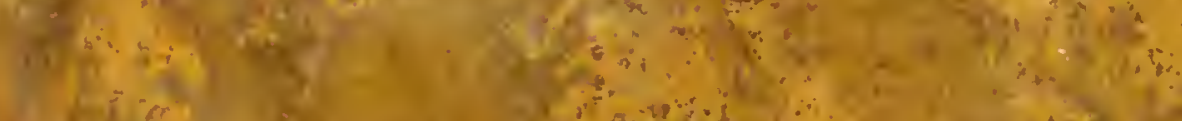

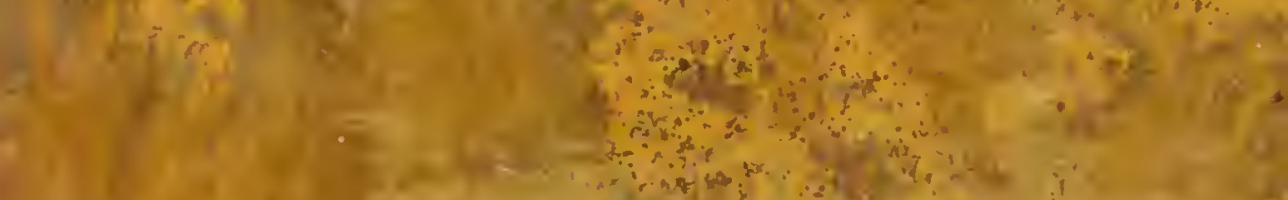

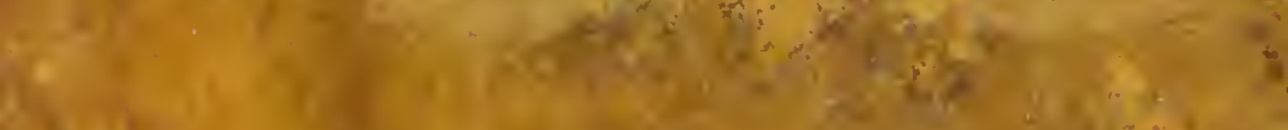

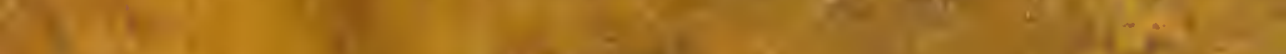
$x^{2}-\sqrt{2}+4$

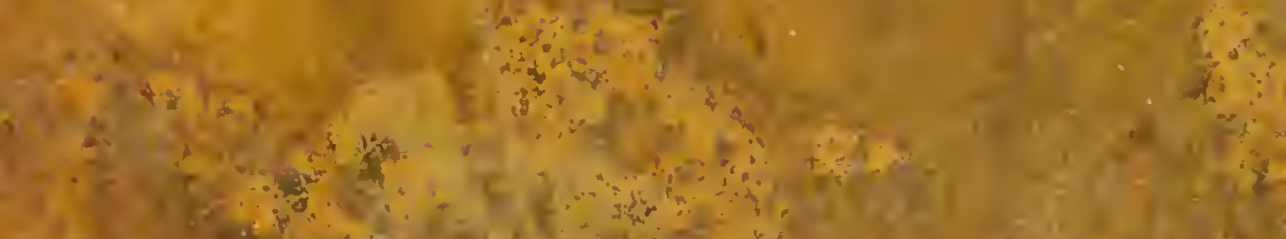

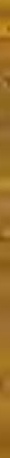

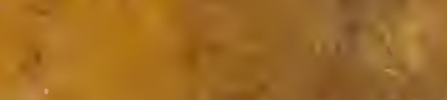

s.

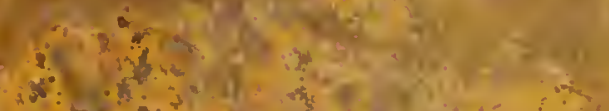

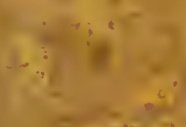

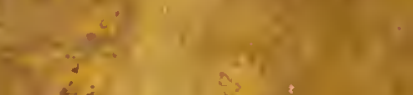

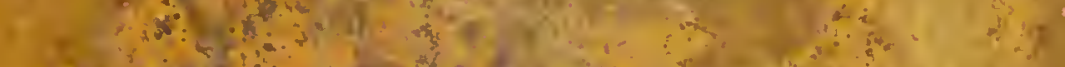

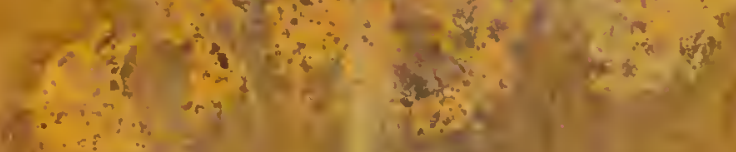 $4:$ tose tin

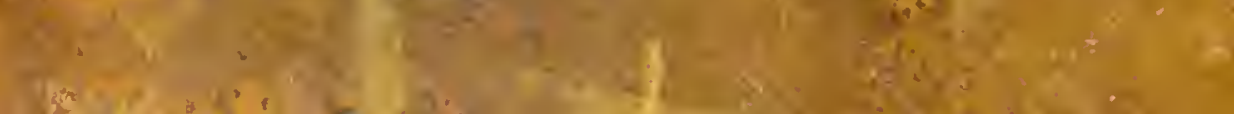

